\title{
On productivity, resource capture, and yield stability of cover crop species mixtures
}

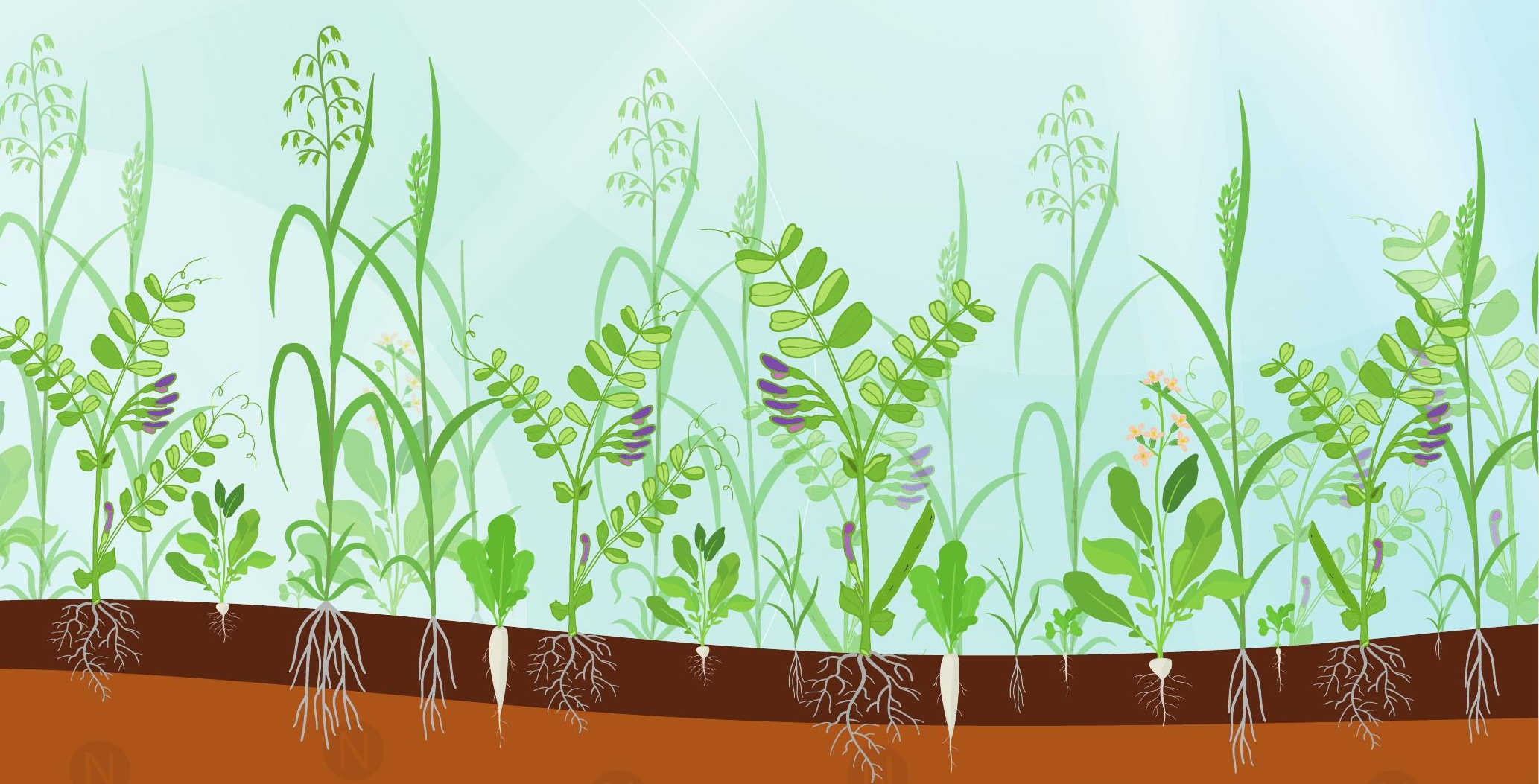




\section{Propositions}

1. Species identity rather than species richness determines yield in cover cropping. (this thesis)

2. $\mathrm{N}$ fertilization of winter cover crops is counter-productive. (this thesis)

3. Epidemiology should not be boxed into separate sciences for human, animal and plant diseases.

4. Plant communication offers scope for yield increase.

5. Living with a good chef must be combined with self-control.

6. The insecurities of academic life are a serious disincentive for young people to pursue a scientific career.

Propositions belonging to the thesis entitled:

On productivity, resource capture, and yield stability of cover crop species mixtures

Ali Elhakeem

Wageningen, 8 April 2021 
On productivity, resource capture, and yield stability

of cover crop species mixtures

Ali Elhakeem 


\section{Thesis committee}

\section{Promotor}

Dr W. van der Werf

Associate professor, Centre for Crop Systems Analysis

Wageningen University \& Research

\section{Co-promotor}

Dr L. Bastiaans

Associate professor, Centre for Crop Systems Analysis

Wageningen University \& Research

\section{Other members}

Prof. Dr K.E. Giller, Wageningen University \& Research

Prof. Dr E. Lammerts van Bueren, Wageningen University \& Research

Prof. Dr L. Mommer, Wageningen University \& Research

Dr L.A. Buchi, Natural Resources Institute, University of Greenwich, United Kingdom

This research was conducted under the auspices of the C.T. de Wit Graduate School for Production Ecology and Resource Conservation 


\section{On productivity, resource capture, and yield stability of cover crop species mixtures}

\section{Ali Elhakeem}

\section{Thesis}

submitted in fulfilment of the requirements for the degree of doctor at Wageningen University by the authority of the Rector Magnificus

Prof. Dr A.P.J. Mol, in the presence of the

Thesis Committee appointed by the Academic Board to be defended in public on Thursday 8 April 2021 at 11 a.m. in the Aula. 
Ali Elhakeem

On productivity, resource capture, and yield stability of cover crop species mixtures, 182 pages.

$\mathrm{PhD}$ thesis, Wageningen University, Wageningen, NL (2021)

With references, with summary in English

ISBN: 978-94-6395-694-9

DOI: https://doi.org/10.18174/540613 


\section{Abstract}

Winter cover crops are grown in temperate regions to capture nitrogen, build organic matter in soil, and suppress weeds during autumn and winter. This thesis aimed to identify whether growing species mixtures instead of pure stands strengthens the ecosystem services provided by cover crops. Emphasis was given to productivity, resource capture and yield stability. From 2015 to 2019, I conducted fourteen field experiments across three locations in the Netherlands and one location in Germany. Twenty-five cover crop species were characterized as to their productivity to produce a shortlist of promising species for further studies. I found large differences in productivity between species. Species with early ground cover, such as crucifers and black oats, had the highest productivity and they showed the greatest suppression of weeds. An analysis was made of complementarity and dominance effects in mixtures. Complementarity occurred more often when the mixed species were equally productive, e.g. when combining oilseed radish and black oats, while mixing species with different productivity resulted more often in dominance of the highly productive species in the mixture. Mixing cover crop species within the row or in alternate rows had a small and variable effect on the competitive relationship between mixed species. Across all experiments, mixtures produced 25 to $42 \%$ more biomass and captured 11 to $34 \%$ more nitrogen than pure stands. This large difference was reduced when the comparison was restricted to the most productive pure stands and species mixtures. In this case, mixtures and pure stands produced similar biomass in most experiments, though, on average, mixtures captured $9 \%$ more nitrogen from soil than the best pure stands. In an analysis of data collected in multiple treatments at multiple sites and years, I analysed how the variability of yield differed between mixtures and pure stands. The contributions to yield variability were estimated as variance components using Bayesian mixed models. Yield variability was related to the variation in growing conditions as related to variation in soils and weather between sites and years. At this level there was no difference between mixtures and pure stands. Therefore, I conclude that mixtures do not provide insurance against variability in growing conditions. Within each combination of site and year (site-year), mixing species, however, significantly reduced the yield variability between treatments. This difference was mainly due to the low yield of some species when grown in pure stands, illustrating the importance of species choice. Moreover, mixtures had smaller within-field variation than pure stands. I investigated how biomass formation of cover crops can be separated in the processes of radiation interception and radiation use efficiency. Of the high yielding species, some intercepted large amounts of radiation (crucifers) and some had high radiation use efficiency (oats). Combining species with high radiation interception and high radiation use efficiency did, however, not provide transgressive overyielding. I determined the effect of nitrogen fertilizer on nitrogen capture and productivity of oilseed radish, black oats, common vetch and a mixture of the three species. Addition of nitrogen fertilizer did not boost the growth of cover crops. Subsequently, the net nitrogen loss increased with $\mathrm{N}$ fertilizer. No nitrogen losses were found in plots with the species mixture. Based 
on the results, I conclude that application of nitrogen fertilizer to cover crops does not increase net nitrogen capture. Overall, I showed that mixtures were mostly dominated by the highly productive species. Productivity of cover crops was more strongly governed by the environmental conditions and the identity of dominant species than by mixing of species. Spatial configuration, species richness and starter $\mathrm{N}$ application had a negligible influence on mixture performance.

Keywords: winter cover crops, mixtures, pure stands, productivity, yield variability, radiation capture, radiation use efficiency, net $\mathrm{N}$ capture, spatial configuration. 


\section{Contents}

Chapter 1 General introduction 1

Chapter 2 Productivity, nitrogen capture and weed suppression of 25 cover crop species; an exploratory comparison and species characterization

Chapter 3 Cover crop mixtures result in a positive net biodiversity effect irrespective of seeding configuration

Chapter 4 Do cover crop mixtures give higher and more stable yields than pure stands?

Chapter 5 Radiation interception and radiation use efficiency in mixtures

of winter cover crops

Chapter 6 Can nitrogen fertilization of winter cover crops promote nitrogen uptake and reduce nitrogen-leaching?

Chapter 7 General discussion

References

Appendix A

Appendix B

Appendix C

Appendix D

Summary

Acknowledgments

List of publications

PE\&RC Training and Education Statement

About the author 



\section{CHAPTER 1}

General Introduction 


\subsection{Agricultural intensification and cover crops}

The world population is increasing and is estimated to reach 9.7 billion by 2050 (UN, 2019). Intensification of agricultural production methods has helped to keep up with the growing demand for agricultural products from the growing world population, but at the cost of environmental pollution, particularly due to spill-over of nutrients and pesticides. Moreover, increased land use for agriculture has greatly contributed to habitat loss and losses in biodiversity (Paul et al., 1996; Singh, 2000; Green et al., 2005; Mozumdera and Berrens, 2007; Godfray et al., 2010; Tilman et al., 2011; Bologna and Aquino, 2020). Additionally, intensification of agriculture has resulted in decreases in soil organic matter, which affects the productivity of the land (Singh, 2000). Decay of soil organic matter through mineralization is important to provide mineral nutrients to plants, but at the same time it is necessary to conserve the soil organic matter stock. This contrast leads us to what is known as the soil carbon dilemma (Janzen, 2006). Soil organic matter is recognized as a key element in soil quality as it provides and enhances the physical, chemical and biological properties of the soil (Reeves, 1997). For instance, soil organic matter maintains soil aggregates, increases water holding capacity, supplies nutrients to crops, and increases diversity of soil organisms (Craswell and Lefroy, 2001; Johnston et al., 2009). Therefore, there is an urgent need for agricultural systems that support natural processes that maintain soil organic matter and replace anthropogenic inputs by ecosystem services from natural processes (Bommarco et al., 2013). Cover crops are plants that do not directly contribute to the production of food, feed, fuel or fibre, but do provide a wide range of ecosystem services (Hartwig and Ammon, 2002; Blanco-Canqui et al., 2015). Including cover crops in crop rotations increases on-farm biodiversity, which is the key for a more sustainable ecosystem (Mohler and Johnson, 2009; Bommarco et al., 2013). A vigorously growing cover crop can capture residual nitrogen from the soil (Walmsley et al., 2018). In this way, nitrogen losses from leaching may be reduced. In temperate regions, winter cover crops are grown throughout autumn to accumulate biomass that eventually is incorporated into the soil as fresh organic material and contributes in building up the organic matter stock (Sharma et al., 2018). Growing winter cover crops was also shown to improve soil physical properties (Steele et al., 2012). Simultaneously, cover crop residues mineralize and release nutrients that have positive consequences for the yield of the subsequent cash crop (Chu et al., 2017). Therefore, by growing winter cover crops, we can conserve organic matter while profiting from its decay. 


\subsection{Greening measures and advantages of species diversity}

Within the European Union, the Common Agriculture Policy (CAP reform) incorporated "greening measures" in the financial support system provided to European farmers. In order to obtain a subsidy, the greening measures obliged the European farmers to assign at least $5 \%$ of their land as an ecological focus area (EFA). One means to meet this criterion is by growing cover crops (European Commission, 2019). In some EU countries, like the Netherlands, it is required to mix at least two species of cover crops to receive the EFA-subsidy (Dijksma, 2014). By mixing species, diversity increases and this is expected to result in environmental advantages (Kramberger et al., 2012). For this reason, growing mixtures of cover crops has received increasing attention during recent years. It is still however a relatively new territory for research. So far, much more research has gone into mixture effects in food crops or natural vegetation.

Agrobiodiversity resulting from mixing plant species was shown to promote ecosystem services and thereby reduce the dependency on agrochemicals (Tamburini et al., 2020). Despite the potential advantages of mixing species that was shown in food crop studies, cover crops are mostly grown as pure stands around the world. Therefore, it is worthwhile questioning whether the advantages shown for mixed food crops would also hold for winter cover crops. Recent studies were carried out, mostly in the United States and Europe, to investigate whether growing species mixtures can augment ecosystem services provided by winter cover crops (Wortman et al., 2012; Finney et al., 2016; Wendling et al., 2017; Couedel et al., 2018a; Couedel et al., 2018b). It was suggested that mixing species of cover crops that have complementary traits can increase multifunctionality and agroecosystem sustainability (Finney and Kaye, 2017; Blesh, 2018). For instance, mixtures composed of a legume and non-legume species combined high nitrogen retention and high nitrogen supply (Tribouillois et al., 2016; Couedel et al., 2018c), suppressed weeds well (Hayden et al., 2012; Baraibar et al., 2018; Couedel et al., 2018b), and enhanced the yield of the subsequent cash crop (Chu et al., 2017).

It is well stablished that ecosystem services provided by cover crops are strongly related to their productivity (Blanco-Canqui et al., 2015; Buchanan et al., 2016; Finney et al., 2016; Gfeller et al., 2018; Mesbah et al., 2019). It was shown in earlier studies that cover crop mixtures exhibit overyielding; higher yield per unit area than the expected yield based on the average of pure stands (Smith et al., 2014; Tribouillois et al., 2016; Couedel et al., 2018a; Couedel et al., 2018c). For cover crops, it is more relevant to compare the yield of a mixture with that of the 
highest yielding pure stand, given the goal is to maximize absolute yield. In this case, overyielding is known as transgressive overyielding (Schmid et al., 2008), which is rarely shown in cover crop studies (Wendling et al., 2017). In ecological studies, yield advantage from species mixtures is known as the net biodiversity effect, which expresses mixture yield benefit in absolute terms (Loreau and Hector, 2001; Bruno et al., 2005; Roscher et al., 2005). Loreau and Hector (2001) presented two components of the net biodiversity effect, termed the complementarity effect and the selection effect. The complementarity effect represents whether, on average, the species in mixture benefit from mixing, while the selection effect expresses to which extent a species with a higher yield in pure stands obtains a greater yield gain in the mixture. Breaking down the net biodiversity effect into a complementarity and selection effect may improve our understanding of the competitive relationship between mixed species of cover crops. To my knowledge, these aspects were not investigated in earlier studies on winter cover crops.

\subsection{Mechanisms underlying overyielding}

Overyielding takes place when there is niche complementarity between the mixed species (Vandermeer, 1992). Overyielding can also occur through facilitation, which means that one species improves the growth conditions of another species through modifying the environment (Callaway, 1995; Callaway and Walker, 1997). This positive interaction can take place belowground, for instance by mixing species that have different rooting patterns to explore the soil more completely and thus capture more mineral nutrients than the pure stand system (Zhang et al., 2017). Complementarity can also take place aboveground, through combining species with different shoot architecture which can result in a higher radiation capture than in a pure stand (Zhang et al., 2008). Next to resource capture, conversion of the captured resources into biomass influences productivity (Sinclair and Muchow, 1999). It was shown that well managed food crop mixtures achieved an increase in land use efficiency, water use efficiency, fertilizer use efficiency and radiation use efficiency (Raza et al., 2019; Ren et al., 2019; Li et al., 2020b; Tan et al., 2020). Studies on resource capture and resource use efficiency in cover crops are lacking. Therefore, there is a need for such studies to understand how overyielding of cover crop mixtures is related to resource capture and resource use efficiency. 


\section{$1.4 \quad$ Yield stability of cover crops}

In temperate regions, sowing date of cover crops is dependent on the harvesting date of cash crops, which varies from July to October. During the fallow period, when cover crops are gown, temperature and radiation levels are both rather low, resulting in suboptimal conditions for plant growth and development (Vos and van der Putten, 1997; van Delden et al., 2001) (Fig. 1.1). In the Netherlands, the photosynthetic rate of a crop was estimated to gradually decrease from 290 $\mathrm{kg} \mathrm{CH}_{2} \mathrm{O} \mathrm{ha}^{-1}$ in early summer to $50 \mathrm{~kg} \mathrm{CH}_{2} \mathrm{O} \mathrm{ha}^{-1}$ in early winter (De Wit, 1959). Decisions on which species to grow as a winter cover crop should be based on a sound understanding of the growth performance of the selected species. A good cover crop should establish quickly and cover the soil to suppress weeds, capture mineral nutrients from soil, intercept as much solar radiation as possible before winter and accumulate biomass. A mismatch between the selected species and prevailing weather conditions or soil type may result in crop failure and subsequently loss of ecosystem services. Species mixtures are expected to have a higher yield stability than pure stands as shown for food crops and grasslands (Isbell et al., 2015; Raseduzzaman and Jensen, 2017). Only a few studies have recently tested whether mixing species of cover crops reduces the chance of crop failure and increases yield stability (Wortman et al., 2012; Smith et al., 2014; Florence et al., 2019; Wendling et al., 2019). The hypothesis that mixing species reduces the risk of crop failure is based on the assumption that if one species

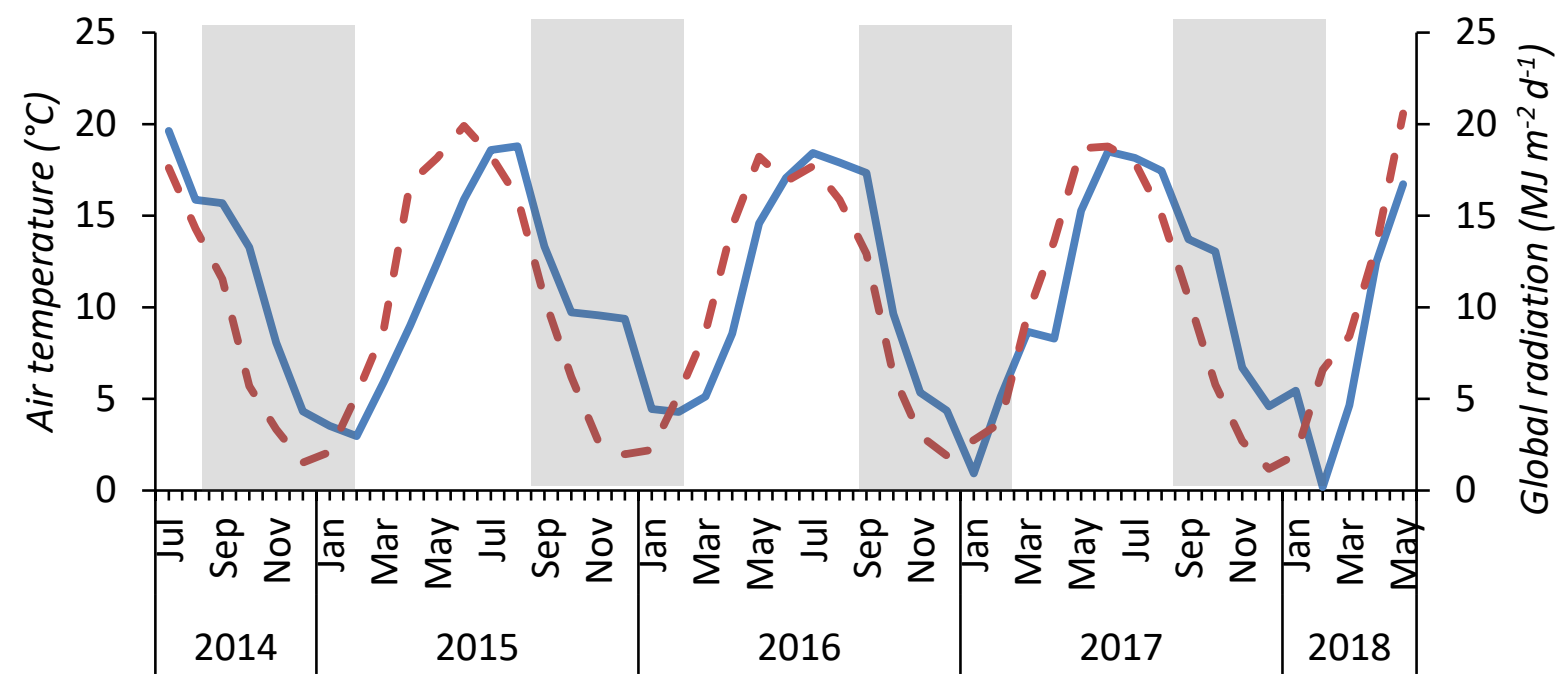

Figure 1.1. Monthly mean air temperature (blue solid line; ${ }^{\circ} \mathrm{C}$ ) and monthly average daily global radiation (orange dashed line, $\mathrm{MJ} \mathrm{m}^{-2} \mathrm{~d}^{-1}$ ) in the Netherlands. Grey highlight represents the time window when cover crops are commonly grown in North-western Europe. The length of the growing period of cover crops may differ every year, depending on sowing and harvesting dates of cash crops. Meteorological data were obtained from the Royal Meteorological Institute in the Netherlands (KNMI). 
fails to grow, the companion species may compensate by filling in the gaps. Results produced from the published studies are contrasting and subsequently it is difficult to draw a conclusion based on the existing information. Therefore, further work is needed to evaluate productivity and yield stability of cover crop mixtures.

\subsection{Nitrogen dilemma}

Some farmers apply nitrogen in a mineral or organic form as a starter application to boost the growth of cover crops. Within the EU, the amount of starter fertilizer varies according to cover crop species, farmer, country, and other factors (Smit et al., 2019). In the Netherlands, farmers are advised to apply $\mathrm{N}$ to crucifers and grasses (van Leeuwen-Haagsma et al., 2019). However, the advice on $\mathrm{N}$ application to winter cover crops is not based on scientific evidence. There is a lack of knowledge on the nitrogen capture by winter cover crops and the mitigating effect on $\mathrm{N}$ loss through leaching. Abdalla et al. (2019) reviewed 106 studies, mostly in temperate regions, and concluded that cover crops are effective in reducing nitrogen leaching especially when $\mathrm{N}$ input to the preceding cash crop is high. However, this review does not clarify whether a starter $\mathrm{N}$ application contributes to the function of cover crop species to reduce $\mathrm{N}$ losses by leaching. Therefore, further investigation is needed to understand whether and how $\mathrm{N}$ application to winter cover crops influences net nitrogen capture and nitrogen losses.

\subsection{Thesis objectives}

In this thesis, I investigated whether cover crop mixtures outperform pure stands. I tried to identify the relevance of the mechanisms involved in mixture performance by studying complementarity and compensation for growth between the component species. Furthermore, I aimed to understand the factors that influence productivity and resource capture of species mixtures and pure stands under different environmental circumstances characterized by radiation, temperature, and soil conditions. In this thesis, particular attention is given to the effects of spatial configuration of component species in a mixture and the functional diversity of mixed species. I also investigated the effect of a starter nitrogen application on nitrogen capture of cover crops. Finally, I investigated how these insights can be used to guide species choice and spatial design of cover crop mixtures to ensure a sufficient and stable influx of organic matter. 


\subsection{Thesis outline}

In chapter 2, I characterize the establishment and productivity of 25 species that can be used as cover crops in the Netherlands. Dutch farmers can choose to mix at least two of these species to be eligible for subsidies (Dijksma, 2014). In a field experiment, I compared the differences among species in the speed of ground cover, biomass accumulation, $\mathrm{N}$ capture and weed suppression. Based on the results of this explorative chapter, species were selected for the studies described in the following chapters.

In chapter 3, I determine how spatial configuration influences biomass accumulation, $\mathrm{N}$ capture and early competition between the component species within a mixture. In a three-year field experiment in the Netherlands, species of cover crops were sown in either pure stand or twospecies mixtures. Two spatial configurations were used: species mixed within-row and species mixed in alternate rows. Species mixed in a within-row design are closer to each other and therefore both competition and complementarity are expected to be more pronounced. The alternate row configuration reduces the proximity between the mixed species. Particularly, in a situation where one species has a considerably faster early growth than the other species, this might prevent dominance of the fastest growing species. But it could also reduce the potential for complementarity by gap filling. Yield advantage of growing mixtures was quantified by calculating the net biodiversity effect, which is the difference between the observed and the expected yields of the component species. The net biodiversity effect has two components, the complementarity effect (CE) and the selection effect (SE). CE characterizes true complementarity between mixed species, while SE represents competitive dominance of the high yielding species over the other species.

In chapter 4, I study the difference in productivity and yield stability between cover crop mixtures and pure stands. A wide range of mixtures and pure stands was grown at four sites in two years to create variation in growing conditions. The four sites were located in the Netherlands and Germany. I tested the hypothesis that, as compared to pure stands, mixtures with complimentary species produce higher biomass and capture more $\mathrm{N}$ from soil. I also tested the hypothesis that yield stability of mixtures is higher than that of pure stands. Yield stability of mixture and pure stands was expressed by calculating yield variability at three levels: between sites-years, between treatments, and between plots. Using linear mixed effect models, variance components were extracted separately for mixtures and pure stands. In this way, I 
tested the hypothesis that 1) mixtures are more productive than pure stands and 2) at the three levels of variability, yield of mixtures is less variable than that of pure stands.

Chapter 5 is based on the experiments described in chapter 4 . In chapter 5, I investigate how mixing cover crop species affects radiation capture and radiation use efficiency. First, I determined and compared the differences in radiation capture and radiation use efficiency of individual cover crop species. Then, I tried to relate radiation capture and radiation use efficiency of mixtures to that of the pure stands of the species they are composed of. To determine light interception, I used data on daily global radiation and regular observations on fraction of ground cover of each treatment in each site-year.

In chapter 6 , I focus on the effect of a starter nitrogen application on the net nitrogen capture by cover crops. I tested the hypothesis that addition of a small amount of nitrogen as a starter application boosts the growth of cover crops and enhances the net nitrogen capture from soil. At high nitrogen applications, I expected higher losses of nitrogen from the soil. To test these hypotheses, two years of field experiments were conducted. I installed a gradient of nitrogen application rates from $0 \mathrm{~kg} \mathrm{~N}^{-1}$ to $90 \mathrm{~kg} \mathrm{~N} \mathrm{ha}^{-1}$. Net nitrogen capture was calculated as nitrogen in plant tissue minus nitrogen application. Results of net nitrogen capture, nitrogen losses, and biomass were compared for three cover crops species: oilseed radish, black oats and common vetch, and a mixture of the three species.

In chapter 7, I synthesize the results of the previous chapters and discuss the conclusions drawn from my studies in relation to the published literature. In this chapter, I discuss the implications of my findings for growing mixtures of cover crops in North-western Europe. I provide suggestions to improve practices and policies related to mixed cover cropping in this region for optimizing the ecological benefits of this practice. 
CHAPTER 2

Productivity, nitrogen capture and weed suppression of 25 cover crop species; an exploratory comparison and species characterization

\begin{abstract}
Ali Elhakeem, Lammert Bastiaans, Wopke van der Werf
Centre for Crop Systems Analysis, Wageningen University and Research, Wageningen, the Netherlands.
\end{abstract}




\begin{abstract}
Cover crops are grown after a main crop to capture nitrogen and cover the soil with biomass that smothers weeds and will be incorporated into the soil to build soil organic matter. Many candidate cover crop species are available. Here, I compare the accumulated biomass and N capture of 25 cover crop species to select candidate species for further studies on cover crop mixtures. A field experiment was done in Wageningen in 2016. Species were sown in late August and harvested after eleven weeks. For each species, I monitored emergence and ground cover over time. At harvest, biomass and $\mathrm{N}$ yield were quantified, while weed biomass was determined at four weeks after sowing. Establishment and productivity varied significantly among species. Early ground cover was positively correlated with cover crop biomass and negatively correlated with weed biomass. Crucifers, black oat, sorghum, corn spurrey and phacelia realized early ground cover with a high final biomass and good weed suppression. Legumes gave late and incomplete ground cover, resulting in a low final biomass and poor weed suppression. Sorghum, French marigold and Mexican marigold wilted when the minimum air temperature dropped below $5{ }^{\circ} \mathrm{C}$, showing these species to be less suited for cool conditions. This study showed that early ground cover is an important characteristic of a cover crop species. Based on this first exploration, a shortlist of promising species for further study was compiled.
\end{abstract}

Keywords: cover crops, biomass, $\mathrm{N}$ yield, weed suppression, species characterization 


\subsection{Introduction}

Cover crops are grown during the fallow period between two cash crops to capture nitrogen from the profile and form biomass that will be incorporated into the soil to build soil organic matter which supports soil fertility (Kaspar and Singer, 2011; Sharma et al., 2018). Furthermore, cover crops suppress weeds (Kruidhof et al., 2009; Brust et al., 2011; Brennan and Smith, 2018). Some cover crop species suppress plant-parasitic nematodes (Kruger et al., 2013) and soil pathogens (Patkowska et al., 2015). Leguminous cover crop species fix $\mathrm{N}$ from the atmosphere, through biological $\mathrm{N}$ fixation (Moller and Reents, 2009). Cover crops also prevent erosion by covering the ground (De Baets et al., 2011). The wide range of natural services provided by cover crops makes them an important tool for ecological intensification, which aims to reduce the dependency of agriculture on agrochemicals by strengthening ecological processes in crop systems (Bommarco et al., 2013; Blanco-Canqui et al., 2015).

Temperature and solar radiation level decrease during autumn, resulting in progressively poorer growing conditions for cover crops. A good cover crop species is therefore characterized by early establishment and quick ground cover so it can take maximum advantage of the short window of suitable weather before winter sets in. Moreover, cover crops should be highly competitive against weeds to prevent these from germination, establishment, and production of seeds. High productivity is an important characteristic of a good cover crop as it relates to the amount of $\mathrm{C}$ and $\mathrm{N}$ that will be incorporated into the soil (Blanco-Canqui et al., 2015; Finney et al., 2016) and the suppression of weeds (Buchanan et al., 2016; Mesbah et al., 2019).

Various species of cover crops are used in temperate regions, such as crucifers, grasses and legumes. These species differ in traits and productivity. In general, a good biomass production ensures the provision of ecosystem services intended to be provided by a cover crop (BlancoCanqui et al., 2015; Finney et al., 2016). Therefore, the objective of this study was to characterize the establishment and productivity of a wide range of species that can be used as a cover crop in the Netherlands. Specifically, we wanted to know how biomass, nitrogen capture and weed suppression differed among species of cover crops. Furthermore, observations on emergence and ground cover were made to explain differences in biomass, nitrogen capture and weed suppression. 


\subsection{Material and methods}

\subsubsection{Experimental design}

In Autumn 2016, a field experiment was conducted at Droevendaal farm, $51^{\circ} 59^{\prime} 39^{\prime \prime} \mathrm{N}, 5^{\circ} 39^{\prime}$ 28.3" E, Wageningen, The Netherlands, on sandy soil with $2.7 \%$ of soil organic matter. Twentyfive species were grown in four replicates in a randomized complete block design. The experiment thus consisted of 100 plots $(3 \mathrm{~m} \times 5 \mathrm{~m}$ each). Details of the experiment are summarised in Table 2.1.

The 25 selected species belong to seven plant families (Table 2.2): Brassicaceae (oilseed radish, white mustard, brown mustard, forage rape and salad rocket), Poaceae (black oat, sorghum, Westerwold ryegrass, Italian ryegrass, perennial ryegrass and tall fescue) and Fabaceae (field beans, blue lupin, common vetch, berseem clover, white clover, red clover, lucerne, birdsfoot trefoil and common sainfoin) as the main families, comprising 20 of the 25 selected species. The other five species belong to the Asteraceae (Mexican marigold and French marigold), Solanaceae (sticky nightshade), Boraginaceae (phacelia), Caryophyllaceae (corn spurrey).

Before sowing, a seedbed was prepared to a depth of $8 \mathrm{~cm}$ with a power harrow. Seeds were sown at a row distance of $12.5 \mathrm{~cm}$ and 24 rows per plot using a $3 \mathrm{~m}$ wide seed planter (Turbo drill, Rape GmbH, Germany). Cover crops were sown on August $23^{\text {rd }}$, 2016. Seeding rate was according to the recommendation of the seed supplier. Seeding rate and thousand seed weight are presented in Table 2.2. To promote cover crop establishment, $30 \mathrm{~kg} \mathrm{~N} \mathrm{ha}^{-1}$ was applied immediately after sowing in the form of slow release fertilizer (calcium ammonium nitrate, $27 \% \mathrm{~N})$.

\subsubsection{Seed germination, plant emergence and ground cover}

Before sowing, germination percentage of the seeds of all cover crop species was determined in the laboratory. Seeds were placed on wetted filter paper in Petri dishes and watered daily. The number of germinated seeds was counted daily till all seeds had germinated or no further germination was observed for seven consecutive days. For the small-seeded species, three Petri dishes with 100 seeds each were used, while for the large-seeded species (i.e. field beans and blue lupins), six Petri dishes with 50 seeds each were used.

Field emergence was measured on two one-meter long row sections in each plot. The sections were marked, and emerged plants were counted daily until no further emergence was observed for ten consecutive days. 


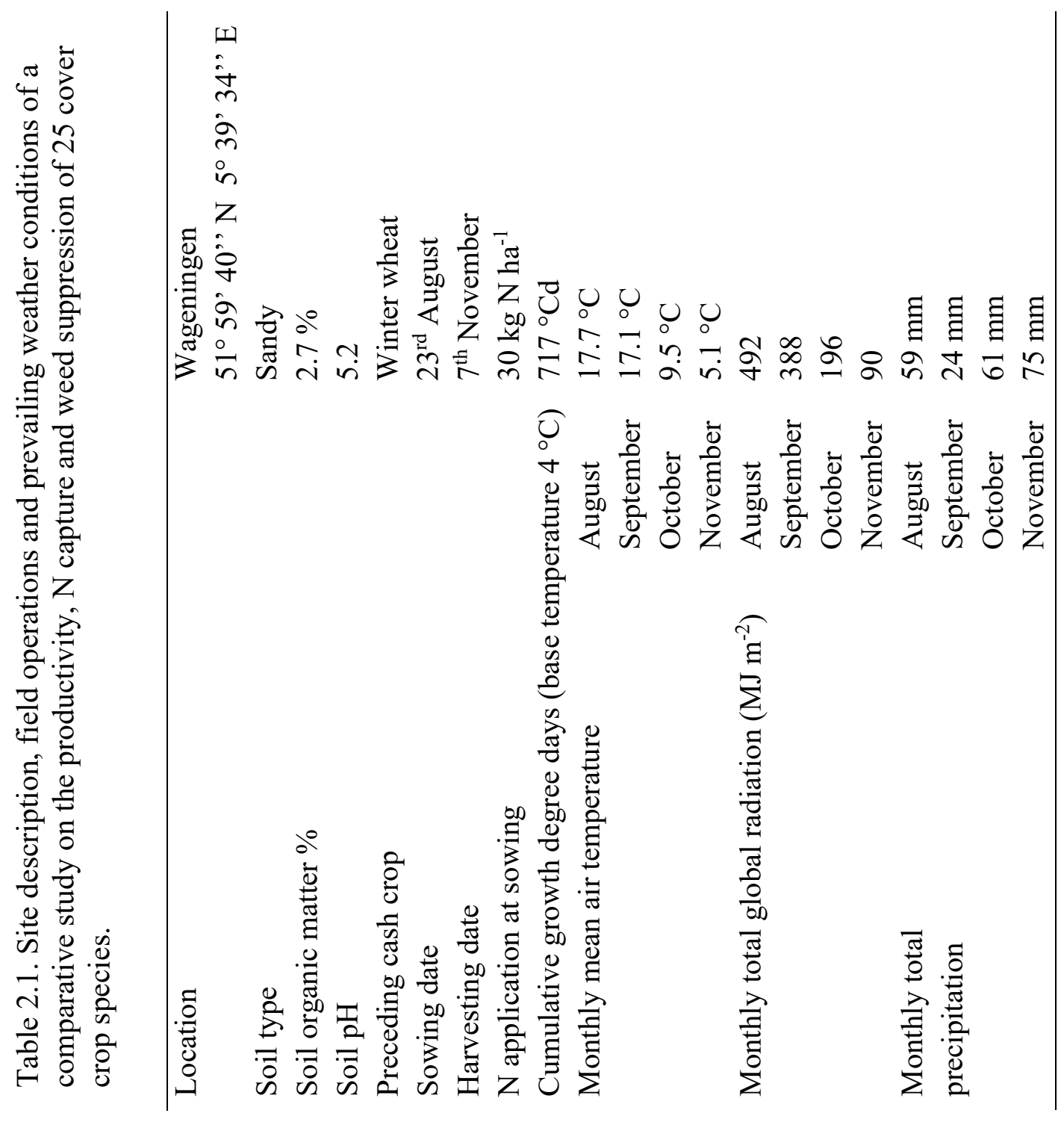




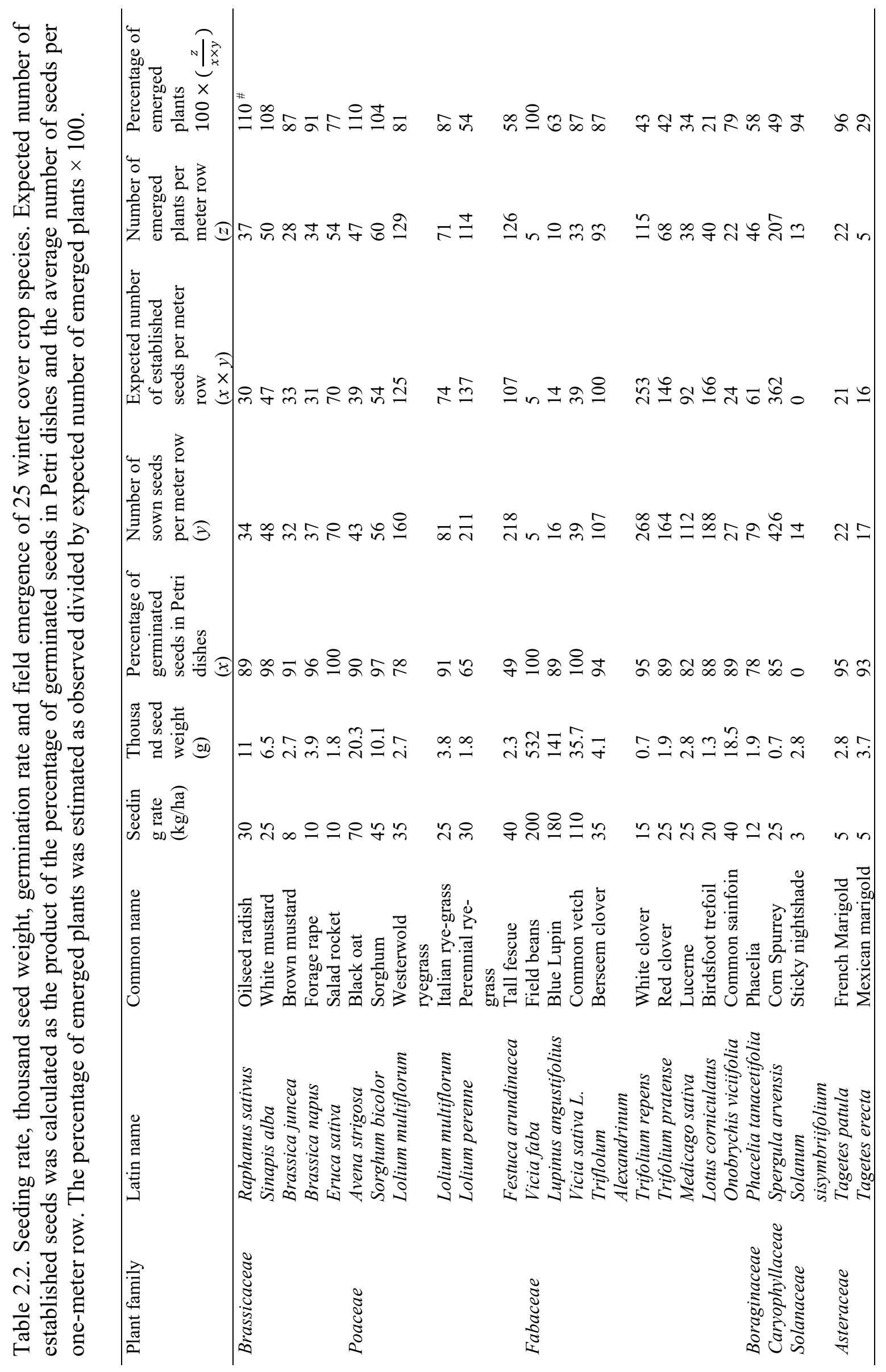


Photos of ground cover were taken in the centre of each plot from one week after sowing until harvest. A metal frame $(1 \mathrm{~m} \times 0.75 \mathrm{~m})$ was fixed just above the canopy, with a camera mounted $1 \mathrm{~m}$ above the frame to standardize the distance from the camera to the top of the canopy. Photos were analysed using DIPimage toolbox for image analysis in MATLAB (MathWorks, 2013). Fraction of ground cover was determined for each replicate. A logistic model was fit to the average ground cover over time:

$$
G C(t)=\frac{G C_{\max }}{1+\mathrm{e}^{-s\left(t-t_{50}\right)}},
$$

where $G C(t)$ is the fraction of ground cover at day $t$ (days after sowing; DAS), $G C_{\max }$ is the maximum ground cover fraction, $t_{50}$ (DAS) is the time at which $50 \%$ maximum ground cover was reached, while $s\left(\mathrm{~d}^{-1}\right)$ is the relative rate of ground cover increase. Early establishment is characterized by a small value of $t_{50}$.

\subsubsection{Biomass sampling}

Aboveground biomass was determined on 7 November 2016, eleven weeks after sowing, on an area of $1 \mathrm{~m} \times 3 \mathrm{~m}$ in each plot using an electric mower that cut the plants at approximately 1-2 $\mathrm{cm}$ above the soil. Plots of French marigold, Mexican marigold and sorghum were harvested three weeks earlier, at $8 \mathrm{WAS}$, because these three species were turning brown and starting to wilt as a response to the cold weather (minimum daily air temperature $<5{ }^{\circ} \mathrm{C}$; Fig. 2.1). Because of the bad condition of the foliage, nutrient concentration in plant tissue of French marigold and Mexican marigold was not analysed. From each plot of the other species, the total sampled fresh weight was weighed, and representative subsamples were taken and oven-dried for 48 hours at $70{ }^{\circ} \mathrm{C}$ to determine the dry matter fraction. From the dried plant samples, $\mathrm{C}$ and $\mathrm{N}$ content were determined using dynamic flash combustion in a CN elemental analyser (EA 1108: Fisons Instrument). $\mathrm{N}$ yield of each species was then calculated as the product of plant dry weight and $\mathrm{N}$ content.

\subsubsection{Weed sampling}

Weeds were sampled at 4 WAS. From $1 \mathrm{~m}^{2}$ in each plot, weeds (predominantly Chenopodium album) were pulled by hand. Both the shoot and the main root of weeds were harvested. Weed samples were oven-dried for 48 hours at $70^{\circ} \mathrm{C}$ to establish weed dry weight.

\subsubsection{Data analysis}

Logistic curves were fitted using the function drm (package drc; (Ritz et al., 2015) in R version 3.5.1 (R Core Team, 2018). Model parameters were extracted for each species using the function ddply of the package plyr (Wickham, 2011). 


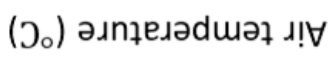

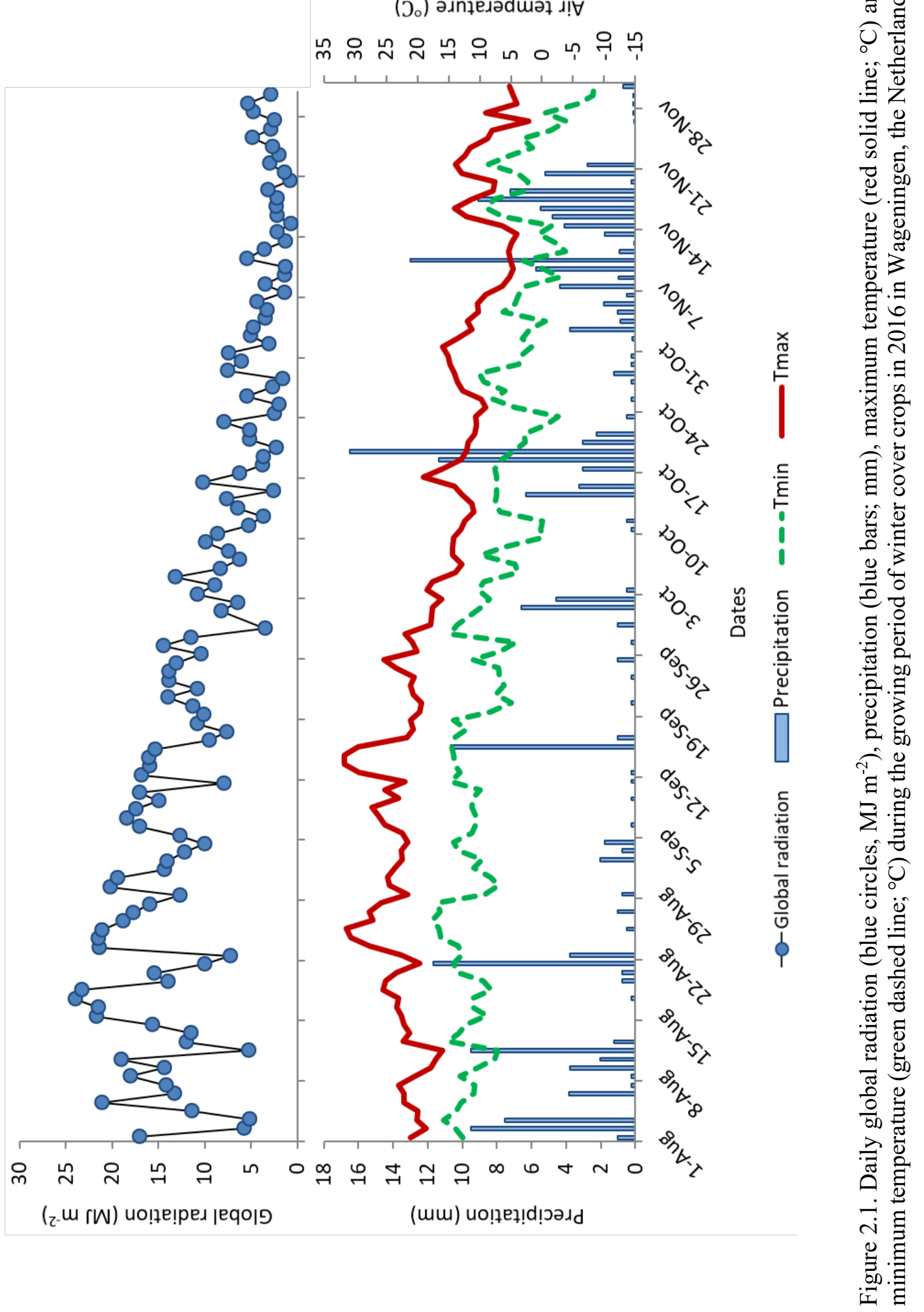


Analysis of variance (ANOVA) was carried out in R version 3.5.1 (R Core Team, 2018) to analyse differences between species in biomass, $\mathrm{N}$ yield, weed biomass and the parameters of the logistic function for ground cover $\left(G C_{\max }, t_{50}\right.$ and $\left.s\right)$. Block was set as a random effect. The assumptions of normality and homogeneity of variances were checked graphically (Zuur et al., 2009). When ANOVA showed a significant difference between treatments, pairwise comparisons were conducted using Fisher's Least Significant Difference (LSD) test. Simple linear regressions were carried out to test the correlations between $t 50$, biomass of cover crop and weed biomass. These correlations were conducted to investigate how earliness of crop establishment relates to crop biomass and weed suppression.

\section{$2.3 \quad$ Results}

\subsubsection{Seed germination and plant emergence}

Most species had more than $90 \%$ germination in the laboratory (Table 2.2). Oilseed radish, blue lupin, red clover, lucerne, birdsfoot trefoil, common sainfoin and corn spurrey had a germination rate between $80 \%$ and $90 \%$. Westerwold ryegrass, perennial ryegrass, tall fescue and phacelia had germination rates below $80 \%$, whereas seeds of sticky nightshade did not germinate at all.

There was a clear difference between species in field emergence. On average, the percentage of emerged plants was $94 \%$ for crucifers, $83 \%$ for grasses and $62 \%$ for legumes. White clover, Red clover, lucerne, birdfoot trefoil, corn spurrey, and Mexican marigold had a field emergence below 50\%. Sticky nightshade had a high percentage of emerged plants of $94 \%$, but these plants emerged later than the other species at two WAS.

\subsubsection{Ground cover}

The logistic function provided an accurate description of the development in ground cover of the cover crops with $\mathrm{R}^{2}$ values ranging from 0.87 to 1.00 (Fig. 2.2). The rate of progress in ground cover differed considerably among species and not all species reached full ground cover. Crucifers had an early establishment with $t_{50}$ ranging from 15 to 17 days after sowing (DAS; Table 2.3). Ground cover curves of crucifers had steep slopes with $s$ values ranging from 0.35 to $0.47 \mathrm{~d}^{-1}$. Except for salad rocket, all crucifer species reached full ground cover at around 4 WAS. At that time salad rocket had reached its maximum ground cover of only $94 \%$. Amongst the grasses, black oat and sorghum had the fastest ground cover. Their $t_{50}$ values were 18 and 16 DAS, respectively, with an $s$ value of $0.32 \mathrm{~d}^{-1}$ for black oat and $0.38 \mathrm{~d}^{-1}$ for sorghum. Black 


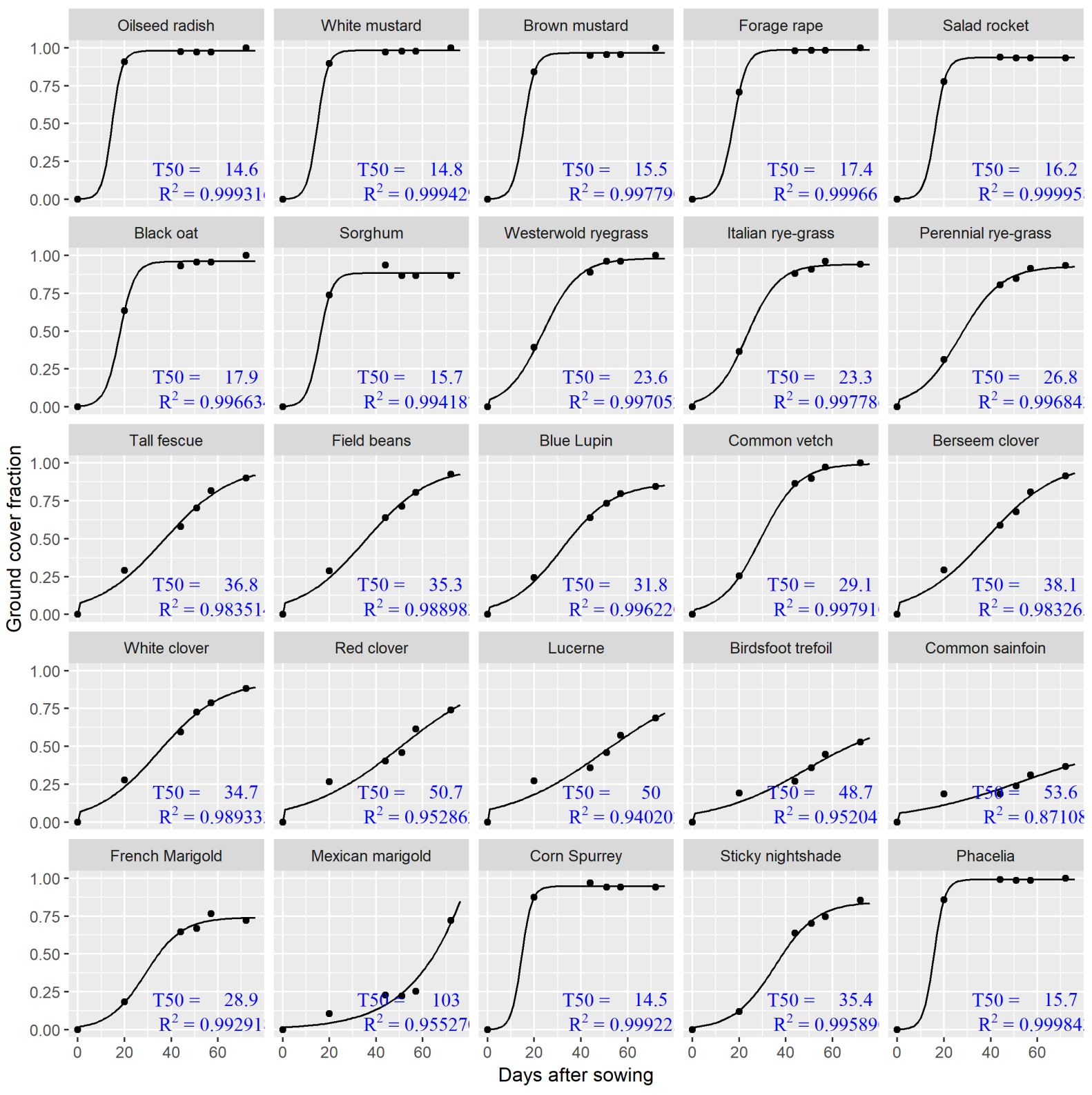

Figure 2.2. Fraction ground cover over time of 25 winter cover crop species. All species were sown on the $23^{\text {rd }}$ of August and harvested on the $7^{\text {th }}$ of November. $t_{50}$ represents time to reach $50 \%$ of the maximum soil cover. Lines are the fitted logistic functions (Equation 2.1).

oat reached full ground cover at 5 WAS, but the growth of sorghum was affected by low temperatures at the beginning of October (minimum daily air temperature $<5{ }^{\circ} \mathrm{C}$ ) and it just covered $88 \%$ of the ground at around 5 WAS without further increase. The three ryegrass species had an identical development. Their $t_{50}$ ranged between 23 and 27 DAS and their relative rate of ground cover increase ranged between 0.11 and $0.15 \mathrm{~d}^{-1}$. Westerwold ryegrass reached full ground cover at $10 \mathrm{WAS}$, while the maximum ground cover of Italian ryegrass and perennial rye grass was $94 \%$ and $93 \%$, respectively. Of the grass species, tall fescue was the slowest to cover the ground. It had an $s$ value of $0.07 \mathrm{~d}^{-1}$ and its $t 50$ was 37 DAS. At harvest, tall 


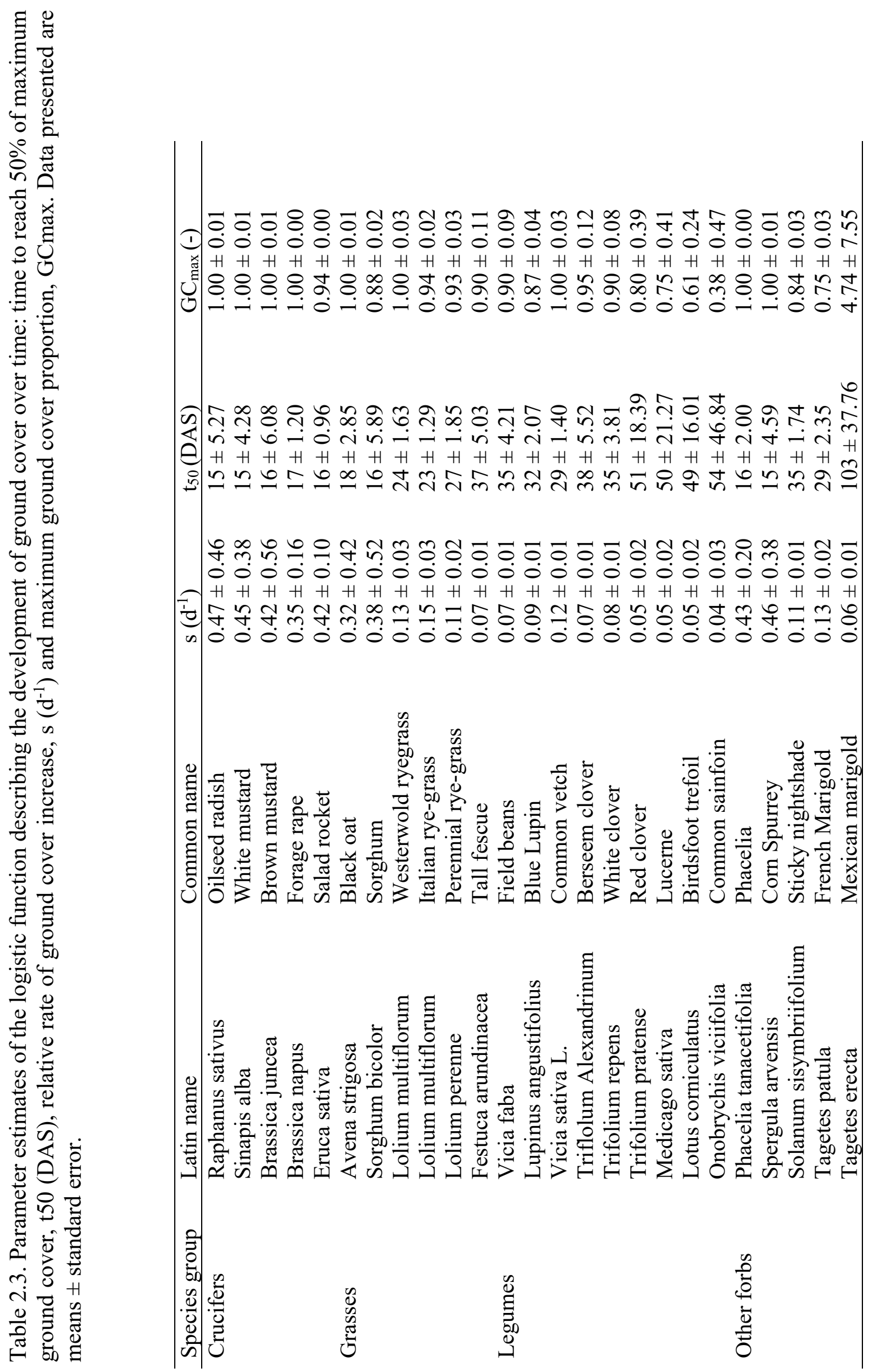


fescue just covered $90 \%$ of the ground.

Legumes covered the ground more slowly than crucifers and grasses. Of the legume species, common vetch was the fastest to cover the ground ( $t_{50}=29$ DAS, $\left.s=0.12 \mathrm{~d}^{-1}\right)$ and it reached full ground cover at 9 WAS. Blue lupin, field beans, berseem clover and white clover all had a similar speed of ground cover increase with $t_{50}$ ranging between 32 and 38 DAS, $s$ ranging between 0.07 and $0.09 \mathrm{~d}^{-1}$, and maximum ground cover ranging between $87 \%$ and $95 \%$. Red clover, lucerne, birdsfoot trefoil and common sainfoin had the slowest ground cover development, with $t_{50}$ ranging between 49 and 54 DAS and $s$ ranging between 0.04 and $0.05 \mathrm{~d}^{-}$ ${ }^{1}$. By the time of harvest, these four species covered $38 \%$ to $75 \%$ of the ground.

Corn spurrey and phacelia had an early establishment and fast ground coverage ( $t_{50}$ between 15 and 16 DAS; $s$ between 0.43 and $0.46 \mathrm{~d}^{-1}$ ). Full ground cover was reached at around 4 WAS, similar to crucifers. French marigold and sticky nightshade had a slower development with $t_{50}$ values of 29 and 35 DAS and $s$ values of 0.13 and $0.11 \mathrm{~d}^{-1}$, respectively. At final harvest, they did not fully cover the ground. Mexican marigold developed very slowly: t50 was 103 DAS, it had a slope $(s)$ of $0.06 \mathrm{~d}^{-1}$ and full ground cover was not obtained.

\subsubsection{Biomass accumulation}

The total amount of accumulated biomass differed significantly between species (Fig. 2.3; $F_{24,72}$ $=16.4 ; p<0.001)$. Crucifers, except for salad rocket, were among the species with the highest amount of biomass (between 4.9 and $4.3 \mathrm{t} \mathrm{ha}^{-1}$ for oilseed radish, white mustard, forage rape and brown mustard). Salad rocket accumulated almost half of this amount $\left(2.1 \mathrm{t} \mathrm{ha}^{-1}\right)$. Amongst grasses, black oat produced the highest amount of biomass $\left(4.8 \mathrm{t} \mathrm{ha}^{-1}\right)$ and this amount was comparable to the biomass of the crucifers. Sorghum and the two annual ryegrass species accumulated moderate amounts of biomass, ranging from 2.9 to $3.4 \mathrm{t} \mathrm{ha}^{-1}$. Perennial ryegrass and tall fescue had low biomass $\left(\leq 2.0 \mathrm{t} \mathrm{ha}^{-1}\right)$. Among the legumes, biomass accumulation differed substantially $\left(0.4-3.3 \mathrm{tha}^{-1}\right)$. Field beans $\left(3.3 \mathrm{tha}^{-1}\right)$ and blue lupin $\left(3.3 \mathrm{tha}^{-1}\right)$ had the largest biomass, whereas berseem clover and common vetch had intermediate amounts of biomass (2.4 $\mathrm{tha}^{-1}$ and $1.8 \mathrm{t} \mathrm{h}^{-1}$, respectively). Biomass production of the other legume species (white clover, lucerne, red clover, birdsfoot trefoil, common sainfoin) was lower than $1.5 \mathrm{t} \mathrm{ha}^{-}$ ${ }^{1}$. From the other forbs, phacelia $\left(4.6 \mathrm{tha}^{-1}\right)$ and corn spurrey $\left(4.1 \mathrm{t} \mathrm{ha}^{-1}\right)$ accumulated amounts comparable to that of crucifers. Sticky nightshade $\left(2.0 \mathrm{t} \mathrm{ha}^{-1}\right)$ and French marigold $\left(1.5 \mathrm{tha}^{-1}\right)$ accumulated less and Mexican marigold accumulated only $0.2 \mathrm{tha}^{-1}$. 


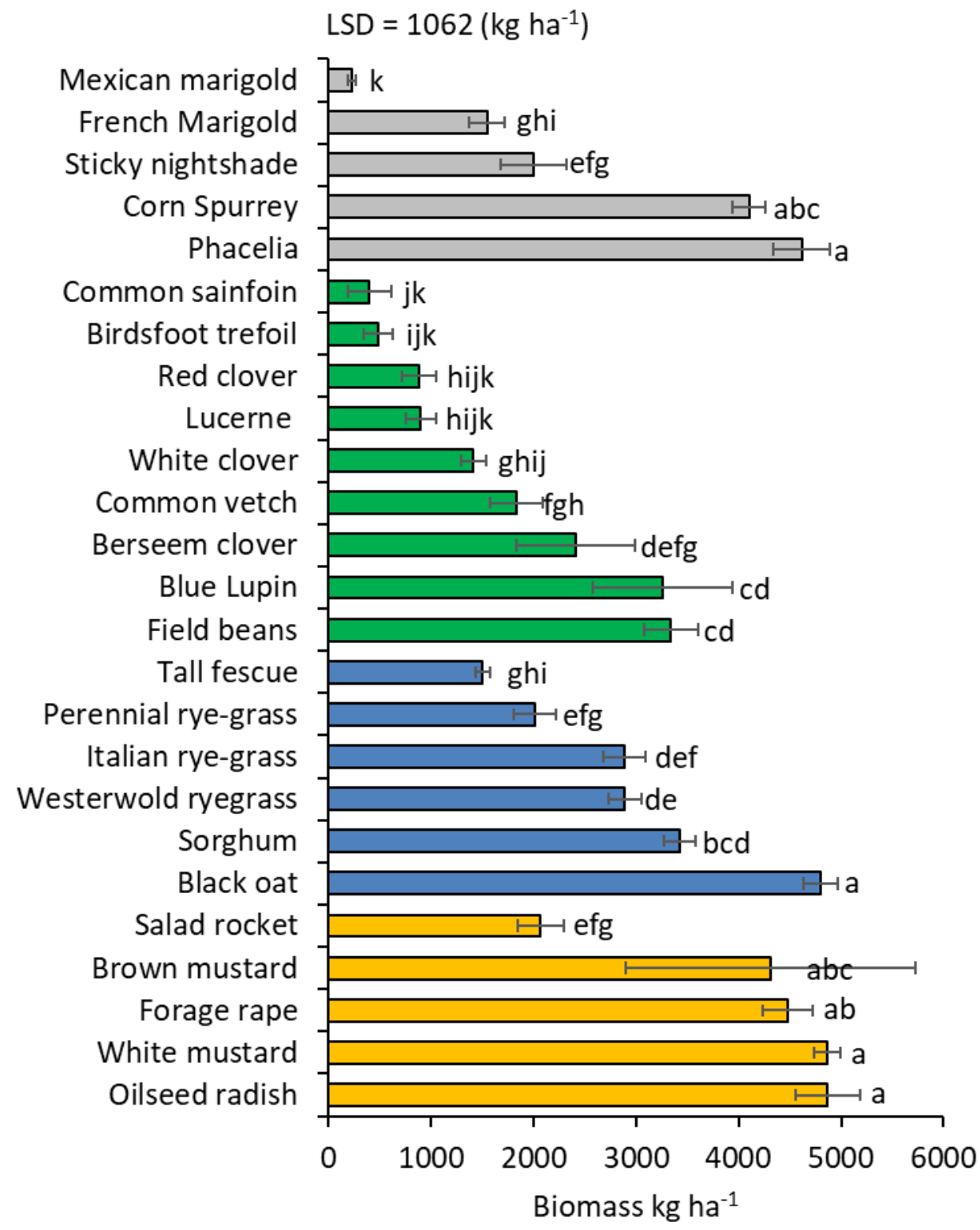

Figure 2.3. Biomass $\left(\mathrm{kg} \mathrm{ha}^{-1}\right)$ of 25 winter cover crop species at final harvest at 11 WAS. Colour of bars refers to different species groups: orange $=$ crucifers, blue $=$ grasses, green $=$ legumes, grey $=$ other forb species. Error bars represent \pm one standard error. Different letters denote significant differences between species at $p<0.05 . \mathrm{LSD}=$ least significant difference.

\subsection{4 $N$ content, $N$ yield and $C: N$ ratio}

$\mathrm{N}$ content differed between species (Fig. 2.4a; $F_{22,66}=23.3 ; p<0.001$ ). Species that accumulated the highest biomass had the lowest $\mathrm{N}$ content (g N/g biomass) and vice versa. Sticky nightshade as well as legumes, except for field beans, blue lupin and berseem clover, had the highest $\mathrm{N}$ content, ranging between $4.2 \%$ and $2.9 \%$. The lowest $\mathrm{N}$ content was observed for black oat, crucifers (except for salad rocket), phacelia and corn spurrey, with $\mathrm{N}$ contents ranging between $1.5 \%$ and $1.1 \%$. Sorghum and species with final biomass below $3 \mathrm{t} \mathrm{ha}^{-1}$, had a $\mathrm{N}$ content ranging between $2.4 \%$ and $1.6 \%$. N yield differed significantly between species (Fig. 
$\left.2.4 \mathrm{~b} ; F_{22,66}=4.6 ; p<0.001\right)$. The highest $\mathrm{N}$ yield was realized by common vetch $(81.0 \mathrm{~kg} \mathrm{~N}$ $\mathrm{ha}^{-1}$ ), but this amount was not different from that of blue lupin, corn spurrey, white mustard, oilseed radish, forage rape, phacelia and field beans (in a range of 59.1 to $74.1 \mathrm{~kg} \mathrm{~N} \mathrm{ha}^{-1}$ ). Intermediate $\mathrm{N}$ yield was accumulated by all grass species (except for tall fescue), white clover, berseem clover, sticky nightshade and brown mustard (in the range of 42.5 to $56.8 \mathrm{~kg} \mathrm{~N} \mathrm{ha}^{-1}$ ). The lowest $\mathrm{N}$ yield was observed for common sainfoin $\left(13.5 \mathrm{~kg} \mathrm{~N} \mathrm{ha}^{-1}\right)$ but this $\mathrm{N}$ yield was not statistically different from the $\mathrm{N}$ yield found for birdsfoot trefoil, red clover, lucerne, salad rocket and tall fescue (in a range of 15.5 to $35.4 \mathrm{~kg} \mathrm{~N} \mathrm{ha}^{-1}$ ).

In general, species that accumulated a high amount of biomass had a high $\mathrm{C}: \mathrm{N}$ ratio, and vice versa (Fig. 2.4c; $\left.F_{22,66}=27.9 ; p<0.001\right)$. Black oat had a higher $\mathrm{C}: \mathrm{N}$ ratio $(\mathrm{C}: \mathrm{N}=31.3)$ than the other grass species ( $\mathrm{C}: \mathrm{N}$ ranging from 15.0 to 23.1). The high $\mathrm{C}: \mathrm{N}$ ratio of black oat was not significantly different from that of brown mustard $(\mathrm{C}: \mathrm{N}=32.1)$ and white mustard $(\mathrm{C}: \mathrm{N}=$ 29.9). Oilseed radish, forage rape, corn spurrey and phacelia had $\mathrm{C}: \mathrm{N}$ ratios ranging from 24.9 to 26.9. A lower $\mathrm{C}: \mathrm{N}$ ratio was realized by salad rocket $(\mathrm{C}: \mathrm{N}=20.2)$. Amongst legumes, field beans, blue lupin and berseem clover had a relatively high $\mathrm{C}: \mathrm{N}$ ratio (ranging from 20.0 to 16.2), while $\mathrm{C}: \mathrm{N}$ ratios of the other legume species ranged from 9.8 to 12.6 . The lowest $\mathrm{C}: \mathrm{N}$ ratio in legumes was found in common vetch (9.8). The $\mathrm{C}: \mathrm{N}$ ratio of sticky nightshade was as low as that of common vetch $(\mathrm{C}: \mathrm{N}=11.5)$.

\subsubsection{Weed biomass}

Weed biomass was sampled at 4 WAS. It varied greatly, from $6.5 \mathrm{~kg} \mathrm{ha}^{-1}$ in plots with white mustard to $709 \mathrm{~kg} \mathrm{ha}^{-1}$ in plots with perennial ryegrass $\left(F_{24,74}=2.7 ; p<0.001\right.$; Fig. 2.5$)$. On average, weed biomass was $74 \pm 77 \mathrm{~kg} \mathrm{ha}^{-1}$ in plots with crucifers, $349 \pm 204 \mathrm{~kg} \mathrm{ha}^{-1}$ in plots with grass, $406 \pm 142 \mathrm{~kg} \mathrm{ha}^{-1}$ in plots with legumes and $237 \pm 70 \mathrm{~kg} \mathrm{ha}^{-1}$ in plots with other forb species. The weed biomass in plots with perennial ryegrass $\left(709 \mathrm{~kg} \mathrm{ha}^{-1}\right)$ was not significantly different from the weed biomass observed in plots with red clover, lucerne, white clover, birdsfoot trefoil and tall fescue (ranging from 397 to $627 \mathrm{~kg} \mathrm{ha}^{-1}$ ). Compared to perennial ryegrass, significantly lower weed biomass was observed in plots with field beans, Italian ryegrass, common vetch, blue lupin (ranging from 359 to $392 \mathrm{~kg} \mathrm{ha}^{-1}$ ). Plots with white mustard had the lowest weed biomass $\left(6.5 \mathrm{~kg} \mathrm{ha}^{-1}\right)$, but this weed biomass was not significantly different from the weed biomass in plots with the other crucifer species, other forb species, black oat, sorghum, Westerwold ryegrass, berseem clover and common sainfoin (ranging from 13 to 314 $\mathrm{kg} \mathrm{ha}^{-1}$ ). 


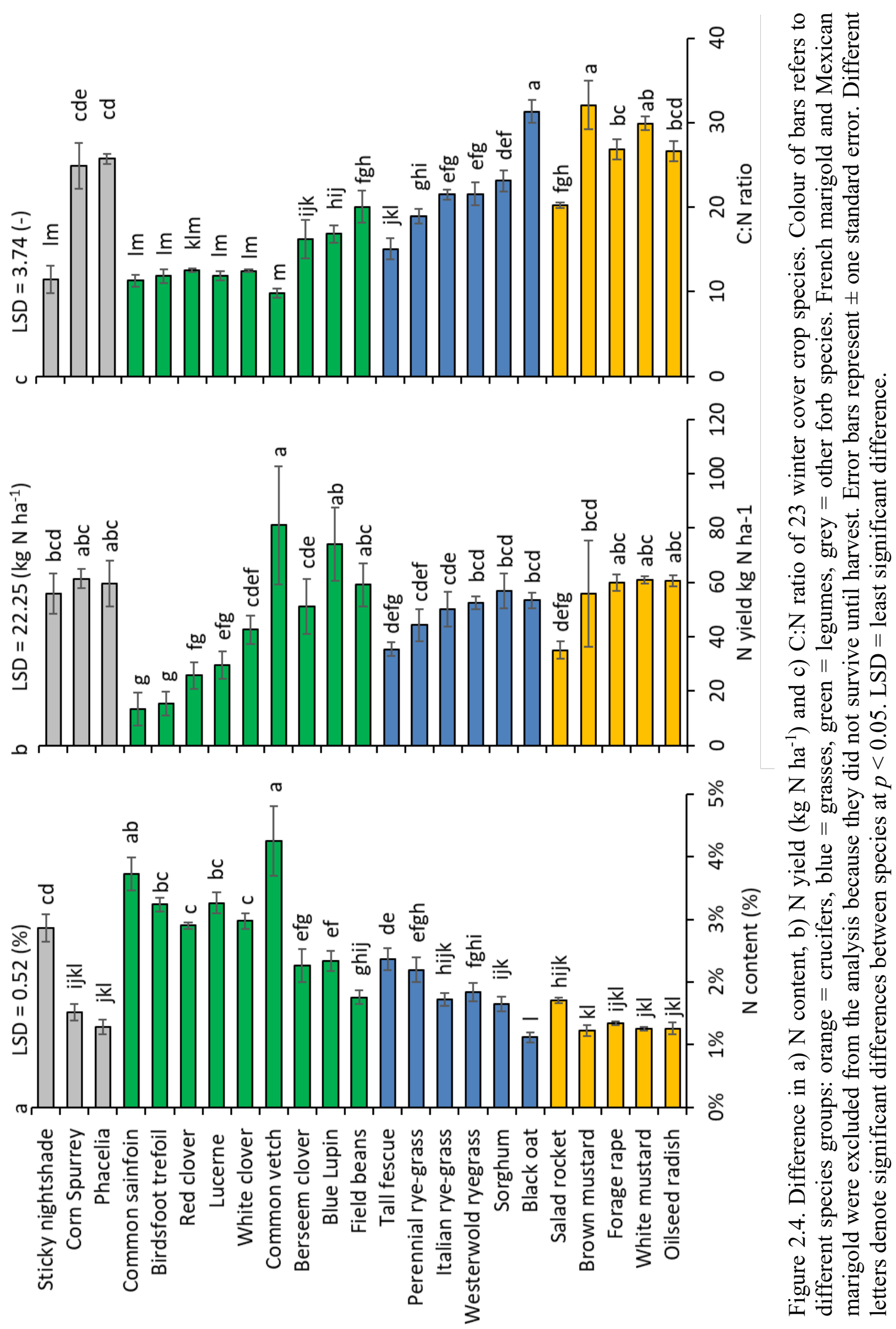




\subsubsection{Correlations between ground cover, cover crop biomass and weed biomass}

The three parameters characterizing the ground cover curves ( $t_{50}, s$ and $G C_{\max }$ ) were highly correlated. $t_{50}$ was negatively correlated with $s$ and $G C_{\max }(\mathrm{p}<0.01$; Supplementary Fig. 2.1). Cover crop biomass decreased significantly with greater values of $t_{50}\left(\mathrm{p}<0.001 ; \mathrm{R}^{2}=0.72 ;\right.$ Fig. 2.6a). In contrast, weed biomass was positively correlated with $t 50\left(\mathrm{p}<0.001 ; \mathrm{R}^{2}=0.43\right.$; Fig. 2.6b). Thus, species with earlier establishment and higher biomass were better at suppressing weeds ( $\mathrm{p}<0.001 ; \mathrm{R}^{2}=0.49 ;$ Fig. 2.6c).

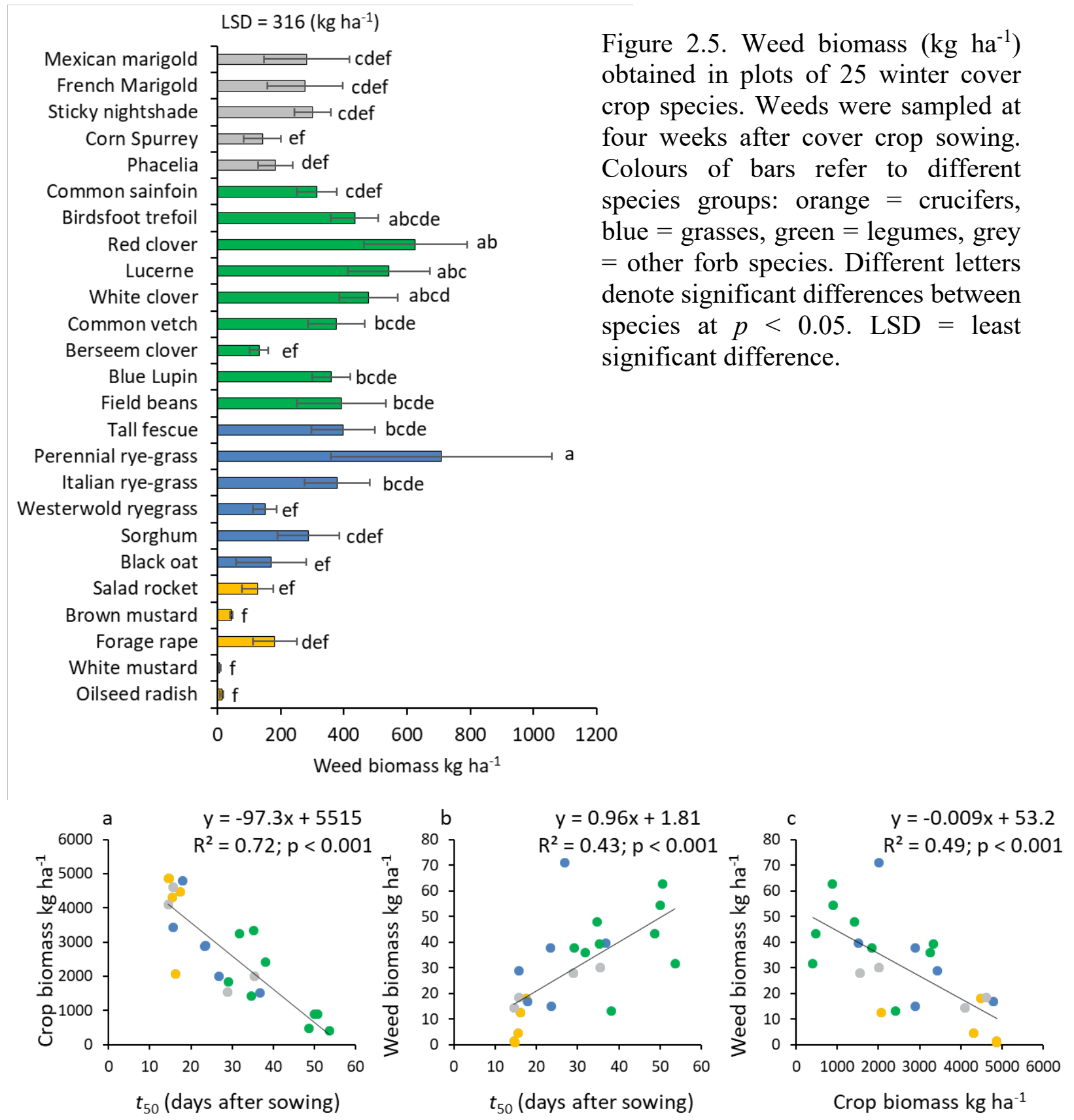

Figure 2.6. Linear regression analysis for a) crop biomass vs $t_{50}, \mathrm{~b}$ ) weed biomass vs $t_{50}$, and c) weed biomass vs crop biomass. Colours of symbols refers to plant families: orange $=$ crucifers, blue $=$ grasses, green $=$ legumes, grey $=$ other forb species. 


\subsection{Discussion and conclusion}

Here we characterized 25 cover crop species for productivity, nitrogen yield, ground cover development, and weed suppression. All these traits differed substantially between species, confirming results of earlier studies (Tribouillois et al., 2015; Toom et al., 2019).

Tribouillois et al. (2018) found that a high rate of plant emergence is crucial for cover crop performance. This finding was in line with our results. Most species with an emergence rate exceeding $90 \%$ accumulated more than $3 \mathrm{t}_{\text {biomass }} \mathrm{ha}^{-1}$.

The earliness of a crop to cover $50 \%$ of the ground (small $t_{50}$; DAS) was negatively correlated with the rate of ground cover increase $\left(s ; \mathrm{d}^{-1}\right)$ and the maximum fraction of ground cover $\left(G C_{\max }\right)$. These three parameters were significantly correlated with cover crop productivity (Supplementary Fig. 2.1). The observations show that $t_{50}$ and $s$ are good predictors for biomass accumulation and $\mathrm{N}$ yield (Fig. 2.6a). This finding confirms an earlier study that found that ground cover, $t_{50}$ in particular, is a good predictor of the biomass of cover crops (Buechi et al., 2016). Therefore, to obtain high biomass and $\mathrm{N}$ yield one should select for species with early establishment and quick ground cover.

Ecosystem services provided by cover crops are related to the amount of biomass produced (Blanco-Canqui et al., 2015). However, quality of the accumulated biomass is also important. Cover crop residues with high C:N ratio result in low $\mathrm{N}$ mineralization (Trinsoutrot et al., 2000; Li et al., 2013). Incorporation of large amounts of cover crop residues with a high $\mathrm{C}: \mathrm{N}$ ratio into the soil may negatively affect the subsequent main crop due to the competition for mineral $\mathrm{N}$ required for decomposition (Alonso-Ayuso et al., 2018). In our study, black oat, white mustard and brown mustard combined a high biomass with a $\mathrm{C}: \mathrm{N}$ ratio above 30 . Such species could be combined in a mixture with species with a lower $\mathrm{C}: \mathrm{N}$ ratio to improve the quality of the incorporated biomass. A number of species, such as, oilseed radish, forage rape, phacelia and corn spurrey, accumulated large amounts of biomass with relatively low C:N ratio $(<30)$. These species are expected to contribute to the build-up of soil organic matter without negative effects on the subsequent main crop. Species that developed slowly in this study, such as common sainfoin, birdsfoot trefoil, red clover, white clover, lucerne, common vetch, berseem clover, and tall fescue, were characterized by a low yield and a low C:N ratio. Earlier, Tribouillois et al. (2016) reported that these species, compared to the high yielding species, have a lower base temperature and lower optimum temperature for growth. They thus can be a 
suitable option when the prevailing temperatures are low.

Weed suppression is an important ecosystem service of cover crops (Kruidhof et al., 2009). We showed that cover crop species differ in weed suppression. Weed suppression was positively correlated with the earliness of crop establishment (small t50 and large $s$ values) and crop biomass accumulation (Fig. 2.6; Supplementary Fig. 2.1). The strong relationship between crop biomass and weed suppression was also observed in other studies (Osipitan et al., 2019). Gfeller et al. (2018) suggested that at least $3 \mathrm{t} \mathrm{ha}^{-1}$ of biomass is required for adequate weed suppression by cover crops. Out of the 25 species, only ten species exceeded this threshold of $3 \mathrm{t} \mathrm{ha}^{-1}$ : oilseed radish, white mustard, brown mustard, forage rape, black oat, sorghum, field beans, blue lupin, phacelia and corn spurrey. Except for field beans and blue lupin, all of these species suppressed weeds reasonably well. Irrespective of the amount of accumulated biomass, legumes are usually not as competitive against weeds as species in other plant families (Baraibar et al., 2018). We also observed that weeds grown in legume plots had the highest individual weed biomass. This indicates that growing pure stands of legumes as cover crop increases the growth of weedy plants instead of suppressing them, even if they had relatively good biomass, such as blue lupin and faba bean.

In conclusion, establishment and productivity of cover crops varied widely among species. Crucifers were in general a good choice if the purpose was to accumulate a high amount of biomass, capture high quantities of soil mineral $\mathrm{N}$ and suppress weeds. Amongst grasses, black oat was a suitable cover crop species due to its early establishment and high productivity. From the other forb species, corn spurrey and phacelia showed potential to produce high biomass and suppress weeds. Except for field beans and blue lupin, legumes in pure stands had low productivity and most of them did not suppress weeds well. Sorghum, French marigold and Mexican marigold showed to be less suitable species for use as a cover crop due to their sensitivity to air temperatures below $5{ }^{\circ} \mathrm{C}$. We showed that early establishment and quick ground cover are important characteristics for a successful cover crop.

The limitation of this one-year field study is of course that it was conducted on one site in one year, and the results cannot be used to draw general conclusions on the relative ranking of species as to their productivity, as this ranking would undoubtedly be affected by pedoclimatic variation between trials. However, the current dataset did provide useful background information for making a shortlist of species to study in further trials. Furthermore, it illustrated the strong relationships that exist between ground cover and biomass production and between 
biomass and weed suppression. Furthermore, it illustrated marked species differences in C:N ratio.

\section{Acknowledgements}

This study is a part of the Clever Cover Cropping project which is a collaboration between the Centre for Crop Systems Analysis (Wageningen University \& Research), the Soil Biology Group, the center for soil ecology (CSE) and the Netherlands Institute of Ecology (NIOOKNAW). This study was supported by a grant from the Netherlands Organization for Scientific Research (NWO green, grant number 870.15.072) with co-financing from seed producers (Agrifirm, Vandinter Semo, P.H. Petersen Saatzucht, and Joordens Zaden). 

CHAPTER 3

Cover crop mixtures result in a positive net biodiversity effect irrespective of seeding configuration

Ali Elhakeem, Wopke van der Werf, James Ajal, Danila Lucà, Sébastien Claus, Rodrigo

Alonso Vico, Lammert Bastiaans

Centre for Crop Systems Analysis, Wageningen University and Research, Wageningen, the Netherlands. 


\begin{abstract}
Mixtures of plant species are often higher yielding due to species complementarities. Such effects may be beneficial to agriculture but are under-used in practice. It is therefore important to demonstrate beneficial effects of mixtures that are easy to implement for farmers. Here, I study yield in mixtures of agricultural cover crops. I hypothesized that the degree to which species express complementarity might be affected by the spatial configuration of the mixture. To test this hypothesis, I seeded mixtures using two configurations: (1) seed mixtures in each row (intimate mixing), and (2) different species in separate (alternate) rows (less intimate mixing). Three years field experiments were conducted to compare growth and $\mathrm{N}$ uptake by sole stands and the two pairwise mixture configurations of three cover crop species: vetch (Vicia sativa L.), bristle oat (Avena strigosa) and oilseed radish (Raphanus sativus L.). Shoot biomass production and $\mathrm{N}$ uptake were determined. Results were analysed using additive partitioning to determine the net biodiversity effect and its components. Mixtures, overall, accumulated significantly more shoot biomass and shoot $\mathrm{N}$ than the corresponding pure stands did on average; hence, the net biodiversity effect was positive. The yield benefit of mixtures (observed minus expected) was $0.66 \mathrm{t}_{\text {biomass }} \mathrm{ha}^{-1}$ and $10.7 \mathrm{~kg} \mathrm{~N} \mathrm{ha}^{-1}$ compared to an average sole cover crop of $2.58 \mathrm{t}$ biomass ha ${ }^{-1}$ and $53.1 \mathrm{~kg} \mathrm{~N} \mathrm{ha}^{-1}$. Contribution to the net biodiversity effect for biomass was, on average, equally divided between the complementarity effect and the selection effect. For $\mathrm{N}$ uptake, the net biodiversity effect was mostly realized through complementarity. Experimental year and species combination had a significant effect on biomass and $\mathrm{N}$ yield of mixtures. Mixtures containing vetch had the greatest gain in biomass compared to expectation. Whether within or between row mixing gave the highest yield and $\mathrm{N}$ uptake depended on species combination and year, but in most cases, the effect of configuration was not significant. Thus, overall, using cover crop mixtures resulted in a positive net biodiversity effect irrespective of seeding configuration.
\end{abstract}

Keywords: cover crops, mixtures, spatial configuration, within-row, alternate rows, net biodiversity effect. 


\subsection{Introduction}

Cover crops are grown to provide agronomical and ecological services. They can be intercropped with food crops, for instance, to suppress weeds (Brust et al., 2011), manage soil water (Sastre et al., 2018) and/or amend nitrogen to the main crop (Mendonça et al., 2017). Cover crops can also be sown solely during the fallow period. In northwest Europe, such cover crops that fill up the fallow period are known as "winter cover crops". They are sown at the end of summer or early autumn after harvest of the main crop. They grow for a period of approximately two to three months, after which their residuals are incorporated into the soil to enhance soil organic matter and soil physical properties (Chu et al., 2017; Steele et al., 2012). Winter cover crops can also capture nitrogen that has not been taken up by the main crop and might otherwise leak to surface water or ground water (Couëdel et al., 2018; Tosti et al., 2014). Furthermore, cover crops may be used to manage nematodes by stimulating egg hatch without allowing reproduction (Ngala et al., 2015).

Since 2013, the Common Agriculture Policy (CAP reform) introduced a new set of measures to make the financial support system to the European farmers more eco-friendly. These measures are called greening measures. They include an obligation to farmers with arable land exceeding 15 ha to manage at least 5\% of this area as ecological focus area (EFA), in order to obtain a subsidy. EFA are land areas in which agriculture practices favour the environment, e.g. growing cover crops (European Commission, 2019). In some EU countries, e.g. the Netherlands, it is required to mix at least two species of cover crop species to receive EFAsubsidies (Dijksma, 2014). This is why growing mixtures of cover crop species has received increasing attention. There is, however, a lack of solid data on the performance of mixtures and on the influence of seeding configuration on mixture performance.

Studies in natural grasslands have shown advantages of mixing plant species, including improved utilization of mineral $\mathrm{N}$, higher biomass production, build-up of soil $\mathrm{C}$ and $\mathrm{N}$ stocks, higher ecosystem stability, and reduced crop losses by fungal diseases (Bybee-Finley et al., 2016; Cong et al., 2014; Fornara and Tilman, 2008; Tilman et al., 2006; Knops et al, 1999; Tilman et al., 1996). Similar advantages were also shown for food crops, including higher water use efficiency, greater and more stable grain yield, build-up of soil $\mathrm{C}$ and $\mathrm{N}$ stocks (MartinGuay et al., 2018; Raseduzzaman and Jensen, 2017; Cong et al., 2015; Yu et al., 2015; Mao et al., 2012; Dapaah et al., 2003). Typically, these advantages are related to complementary traits of the species. Species with different architecture may occupy niches that do not fully overlap. 
For instance, different rooting patterns in soil may result in partitioning of the uptake of water and nutrient resources in the soil, with competition only occurring in as much as the root systems occupy the same soil volume. Such niche differentiation results in enhanced resource capture and may partially lift competitive restraints on growth (Vandermeer, 1992).

Most cover crop species that are commonly used in practice in Europe belong to one of three families: the Fabaceae (legumes; bean family), the Brassicaceae (cabbage family) and the Poaceae (grasses). The latter two families grow fast and they capture nutrients during their growth (Tribouillois et al., 2015). In addition, many species of the Brassicaceae family have an allelopathic effect on weeds (Turk and Tawaha, 2003) and some members of this family can trap plant-pathogenic nematodes and prevent their multiplication (Monfort et al., 2007; Stirling and Stirling, 2003). Species of the Fabaceae, such as vetch, can fix atmospheric nitrogen and influence the availability of phosphorus in the rhizosphere by altering the soil pH (MaltaisLandry, 2015; Zahran, 1999). Combining species with different functional traits is thought to improve the overall performance of a cover crop mixture because trait divergence would result in a divergence of foraging strategies. This would result in competition avoidance and better growth on average (Holmes et al., 2017; Wendling et al., 2015; Kramberger et al., 2012).

Competition avoidance through trait divergence results in resource partitioning or niche differentiation (Tilman et al., 1997). If niche differentiation is present, we expect that cover crop species will benefit most if they are fully mixed, i.e. with minimal spatial separation between the species. In this way, the mixing of species is most intense, such that the intensive intraspecific competition within species may be replaced by the weaker interspecific competition. The more favourable ratio between intraspecific and interspecific competition allows for a better expression of the advantages of niche differentiation. In agronomic terms, this implies that species should be seeded in a mixed-within-row configuration. A potential disadvantage of this configuration is expected if one of the species grows faster than the other. Then, the slower starting species might be overgrown and outcompeted, resulting in a situation where the mixture closely resembles a pure stand of the most dominant crop species. In this case, benefits provided by true mixtures will not come to expression. We expect that crowding of one species by the other can be mitigated if the cover crops are seeded in an alternate-row configuration, giving a somewhat greater spatial separation between individuals of the two species. This would allow the less-competitive species to establish better, resulting in a more balanced mixture, in which mixture advantages will be better expressed. 
In intercropping studies, yield advantages obtained by mixed species are usually expressed by land equivalent ratio (LER; Mead and Willey; 1980) or relative yield total (RYT; De Wit and van den Bergh; 1965). Both metrics reflect a relative yield gain, where the expected yields in mixture, as derived from the productivity of the species in sole stands, are used as a benchmark. A value of one indicates that mixtures perform as expected, whereas a value exceeding one points at a yield gain in mixture. Loreau and Hector (2001) introduced an alternative measure of yield gain, called the net biodiversity effect $(N E)$, which expresses mixture benefit in absolute terms (e.g. $\mathrm{g} \mathrm{m}^{-2}$ ). Such an absolute measure seems more in line with the objectives of a cover crop because cover crops aim at production of total biomass, rather than production of biomass of a particular species. Also in this case, the mixture yield expected based on the productivity of the species in sole stands is used as benchmark. In this study, we use $N E$ as a metric for yield gain, and $N E_{\mathrm{N}}$ as a metric for the net effect of cover crop mixtures on shoot $\mathrm{N}$ accumulation. The net biodiversity effect has two components, termed the complementarity effect $(C E)$ and the selection effect $(S E)$ by Loreau and Hector (2001). The first $(C E)$ represents the overall yield gain by both species, and is proportional to the product of the average relative yield gain (relative yield minus relative density) and the average yield in pure stands. The second (SE) represents the relationship between the relative yield gains of the species and their yields in pure stand. The net biodiversity effect $N E$ is the sum of $C E$ and $S E$. $C E$ characterizes true complementarity between the species, while $S E$ represents competitive dominance of one species over the other.

Here we investigate the influence of spatial configuration on the performance of cover crop mixtures using additive partitioning. We compared pure stands of vetch, oats and oilseed radish with the corresponding two-species mixtures, which were sown in either a within-row mixture configuration or an alternate row configuration. We hypothesized that: 1) species mixtures will produce more biomass and accumulate more nitrogen than expected on the basis of the biomass and nitrogen accumulation in pure stands, 2) a within-row configuration will produce the highest yield advantage (high $N E$ and $C E$, and low $S E$ ) if the two mixed species are competitively balanced, e.g. with similar initial growth rates. However if the species composing the mixture differ considerably in early growth rate, we hypothesize that 3 ) a within row design would be expected to have a lower $C E$ but greater $S E$, while an alternate row design will prevent dominance of one species and show greater $N E$ and $C E$, and lower $S E$, thereby outperforming the within-row mixture. 


\subsection{Materials and methods}

\subsubsection{Site description}

Field experiments were conducted in three consecutive years (2015 - 2017) at the experimental facility "Unifarm" of Wageningen University in Wageningen, The Netherlands. In each year, cover crops were sown in August and harvested in November. Measurements were made of soil cover and biomass accumulation over time. Nutrient content was determined at final harvest. The details of the three fields, field operations and weather conditions are summarized in Table 3.1. Soil type in all three sites was a sandy soil with soil organic matter content ranging from $2.4-2.7 \%$.

\subsubsection{Experimental design}

We selected representative species from the three botanical families that are most commonly used as cover crops: Fabaceae, Brassicaceae, and Poaceae. The selected species were common vetch (Vicia sativa L.), fodder radish (Raphanus sativus L.), and bristle oat (Avena strigosa). The experiments were conducted using a randomized complete block design with nine treatments and three replicates in 2015 and four replicates in 2016 and 2017. Each block consisted of nine plots $(1.25 \mathrm{~m} \times 7.75 \mathrm{~m}$ per plot in 2015 and $1.25 \mathrm{~m} \times 9.00 \mathrm{~m}$ per plot in 2016 and 2017). Each experiment comprised pure stands of the three selected species as well as the three binary combinations (vetch $\times$ radish, VR; vetch $\times$ oats, VO; oats $\times$ radish, OR) grown in two spatial configurations: mixed-within-row (WITHIN) and alternate-row (ALT) (Fig. 3.1). Cover crops were sown at a row distance of $12.5 \mathrm{~cm}$ resulting in 10 rows per plot. Seeding rates were $110 \mathrm{~kg} \mathrm{ha}^{-1}$ (common vetch), $90 \mathrm{~kg} \mathrm{ha}^{-1}$ (bristle oat) and $30 \mathrm{~kg} \mathrm{ha}^{-1}$ (oilseed radish) according to farmer practice. The thousand seed weights of common vetch, bristle oat and oilseed radish were $51.7 \mathrm{~g}, 19.2 \mathrm{~g}$ and $10.0 \mathrm{~g}$, respectively. Species were mixed according to a replacement design, using, for each of the companion species, $50 \%$ of the seed rate in pure stand. Seeds were sown using a Hege 80 belt cone planter. Plots with pure stands and the within row configuration were drilled in one go, while plots with the alternate row configuration were drilled in two passes, one for each species, with half of the coulters active. The experimental field area measured approximately $500 \mathrm{~m}^{2}$ in 2015 and $800 \mathrm{~m}^{2}$ in the other two years.

\subsubsection{Non-destructive measurements}

Emergence of plants was monitored and recorded every second day on two one-meter sections of a crop row from three days after sowing until no further emergence was observed. 
Z

节

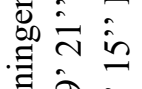

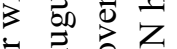

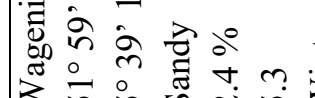

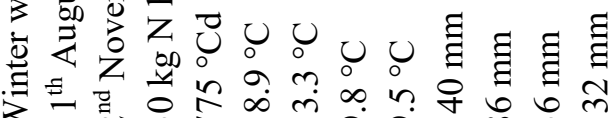

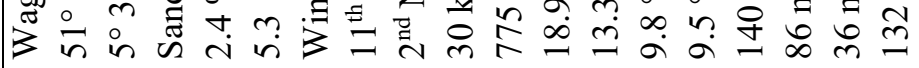



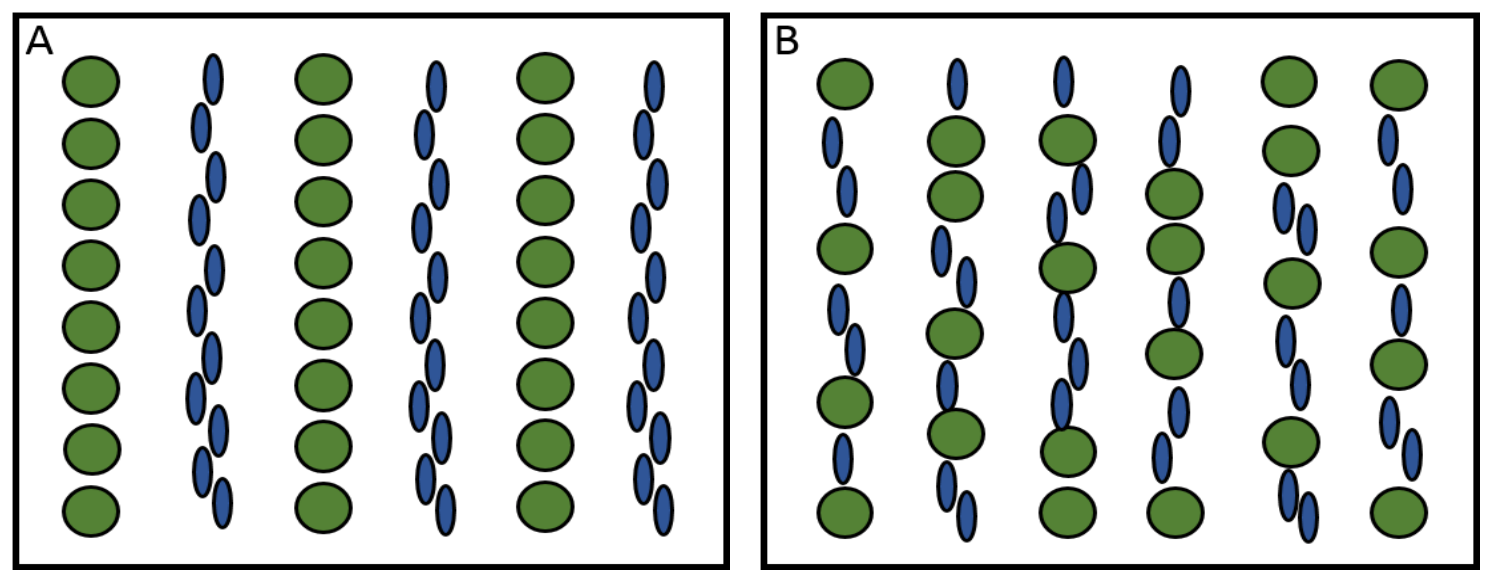

Figure 3.1. Schematic illustrations of the two spatial configurations used in the experiments: (A) Alternate-row configuration and (B) Within-row configuration.

Starting from the second week after sowing, photos of ground cover were taken weekly in all plots to determine the percentage of ground cover. The photos were standardized by using a metal frame $(1 \mathrm{~m} \times 0.75 \mathrm{~m})$ that was held near the top of the canopy, with a camera mounted on top of the frame pointing vertically downward, to guarantee a fixed position, angle and distance between canopy and camera in all the photos. The area used for making photos was harvested at 12 weeks after sowing (WAS). To establish the percentage of green cover, photos were analysed using DIPimage toolbox for image analysis in MATLAB (MathWorks, 2013).

\subsubsection{Destructive samples}

Aboveground plant mass was harvested at 3, 6, 9, and 12 WAS. The sampling areas consisted of six rows with a length of $1 \mathrm{~m}(1 \mathrm{~m} \times 0.75 \mathrm{~m})$. Harvested samples were oven-dried for 48 hours at $70^{\circ} \mathrm{C}$ to measure total shoot dry weight. From a subsample of the dried plant material, shoot $\mathrm{C}$ and $\mathrm{N}$ content were determined using combustion in a $\mathrm{CN}$ elemental analyser.

\subsubsection{The net biodiversity effect and its components}

The net biodiversity effect (NE, $\mathrm{g} \mathrm{m}^{-2}$ ), following Loreau and Hector (2011), was calculated as the summation of the differences between observed and expected yields of the component species in the mixture.

$$
N E=\sum\left(Y_{i}-p_{i} M_{i}\right)
$$

Where $Y_{i}=$ yield of species $i$ in mixture $\left(\mathrm{g} \mathrm{m}^{-2}\right) ; M_{i}=$ yield of species $i$ in pure stand $(\mathrm{g}$ $\left.\mathrm{m}^{-2}\right) ; p_{\mathrm{i}}$ is the relative density of species $i$ in the mixture, calculated as density of species $i$ in mixture, divided by density of the same species in pure stand ( 0.5 in the experiments). If yield in the mixture exceeds the yield expectation based on sole stands, the value of $N E>0$ and a 
yield gain is realized. The net biodiversity effect can be broken down into a complementarity effect $(C E)$ and a selection effect $(S E)$ :

$$
N E=C E+S E
$$

$C E$ expresses whether, on average, the two species benefit from mixing. This part of NE can be calculated based on the average relative yield gain $(\overline{\Delta R Y})$ and the average yield of the pure stands $\left(\bar{M} ; \mathrm{g} \mathrm{m}^{-2}\right)$ :

$$
C E=N \cdot \overline{\Delta R Y} \cdot \bar{M}
$$

where $N$ is the number of species in the mixture (i.e. two). The relative yield gain $(\Delta R Y)$ is the difference between observed and expected relative yield:

$$
\Delta R Y_{i}=R Y_{i}-p_{i}=\frac{Y_{i}}{M_{i}}-p_{i}
$$

$\overline{\Delta R Y}$ is average of the two species-specific values of $\Delta R Y_{i}$. Over-yielding resulting from niche differentiation will thus be reflected in a positive $C E$.

The $S E$ is calculated from the covariance of the relative yield gains and the yields of the pure stands:

$$
S E=N \cdot \operatorname{cov}\left(\Delta R Y_{i}, M_{i}\right)
$$

$S E$ expresses how relative yield gain co-varies with yield in pure stand, i.e. it expresses to which extent a species with a higher yield in pure stands obtains a greater relative yield gain in the mixture. $S E$ will be positive if the largest $R Y$ is associated with the highest yielding species in sole stand. Similarly, $S E$ will be negative if the largest $R Y$ is found with the species with the lowest yield in sole stand. An $S E$ that is significantly different from zero is thus an indicator for interactions between species that are either positive or negative for the most productive of the two. The value of $S E$ might be modified by increasing the space between the species, i.e. by modifying the configuration of the mixture.

$N E, C E$, and $S E$ for $\mathrm{N}$ uptake $\left(N E_{\mathrm{N}}, C E_{\mathrm{N}}\right.$, and $\left.S E_{\mathrm{N}}\right)$ were calculated in the same way as described for biomass, with $\mathrm{N}$ uptake $\left(\mathrm{g} \mathrm{m}^{-2}\right)$ substituted for biomass $\left(\mathrm{g} \mathrm{m}^{-2}\right)$.

\subsubsection{Statistical analysis}

Analysis of variance (ANOVA) was used to compare the differences in biomass production of 
the three pure stands at each sampling and to compare $\mathrm{N}$ accumulation between pure stands at final sampling. The assumptions of normality and homogeneity of variance were checked.

Effect of mixing species and spatial configuration on biomass yield and $\mathrm{N}$ accumulation were investigated using linear mixed effect models in R (version 3.4.3) (R Core Team, 2018), package nlme (Pinheiro et al., 2019). The nine treatments were grouped either into two clusters that represent cropping system (pure stands and mixtures) or into three clusters, consisting of three treatments each, representing spatial configuration (pure stands, alternate-rows mixtures and within-row mixtures). Experimental year, cropping system or spatial configuration and their interactions were used as fixed factors, while block (nested in year) was used as a random factor. Post-Hoc analyses were conducted using Fisher's least significance differences (LSD) at $P \leq 0.05$. Differences for which $P>0.05$, but $P \leq 0.10$ were referred to as marginally significant.

Based on biomass and $\mathrm{N}$ accumulation, we calculated $N E, N E_{\mathrm{N}}, C E, C E_{\mathrm{N}}, S E$, and $S E_{\mathrm{N}}$. The new data set (six treatments; 3 mixtures $\times 2$ configurations) was analysed with linear mixed effect models, in which the response variables were $N E, N E_{\mathrm{N}}, C E, C E_{\mathrm{N}}, S E$, and $S E_{\mathrm{N}}$. Experimental year, species combination, spatial configuration and their interactions were used as fixed factors, while block (nested in year) was used as random factor. Data were analysed per species combination.

T-tests per species combination and year were used to inspect whether $N E, N E_{\mathrm{N}}, C E, C E_{\mathrm{N}}, S E$ and $S E_{\mathrm{N}}$, of the two spatial configurations were different from one another and whether the same metrics, for each of the two spatial configurations, differed from zero.

\subsection{Results}

\subsubsection{Establishment}

Establishment of the three species varied amongst the experimental years. In sole stands, in the three years $(2015,2016$ and 2017), the number of established plants per meter row was 21, 26 and 19 for vetch; 39, 47 and 19 for oats and 23, 26 and 28 for radish. The average within-row distance of pure stands and mixtures (ranging from 2.1 to $5.3 \mathrm{~cm}$ ) was in all instances considerably smaller than the between-row distance $(12.5 \mathrm{~cm})$, indicating substantially closer interaction between plants within then between rows. Establishment in mixtures was not significantly different from that in sole crops. 


\subsubsection{Ground cover}

In 2016 and 2017, radish was the fastest species to cover the soil (Fig. 3.2). In these two years, radish had a rapid early growth reaching $>90 \%$ soil cover in four weeks. Oats had a slow start, but, with a delay of one to two weeks, it displayed as fast an increase in canopy cover as radish. In both years, vetch was very slow by comparison to cover the soil, reaching full cover only at 12 WAS. The year 2015 was characterized by an excessive amount of rainfall $(140 \mathrm{~mm})$ in August (Table 3.1). This delayed soil cover development of oats and radish from 6 WAS on, and they covered only $60 \%$ of the soil at 12 WAS. Vetch was the least affected of the three species and reached $>90 \%$ soil cover at nine WAS.

In all three years, mixtures tended to have the same or a nearly similar pattern of soil cover as the fastest pure stand of the species in the mixture (Fig. 3.3). Except for oats-radish in 2015 (a combination of two species that both suffered from the wet August month), all mixtures eventually reached full soil cover. In most cases, there was no significant difference in soil cover between the two spatial configurations.

\subsubsection{Aboveground biomass and yield gain}

Amongst the pure stands, radish had always the highest biomass at 3 WAS (Fig. 3.4). It maintained a high growth rate until 6 WAS and, from then on, only produced a marginal amount of biomass. Its production was markedly lower in 2015 than in the other years. Oats had a slow but steady increase in biomass accumulation. It reached a similar amount of biomass as radish,
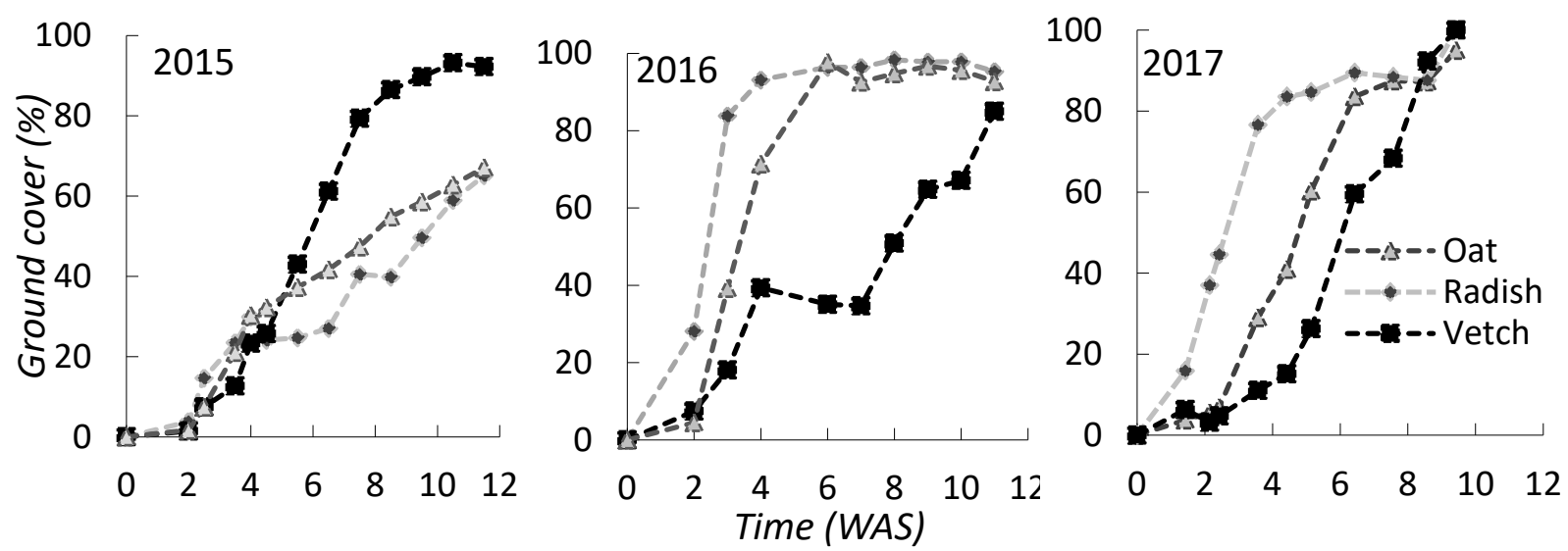

Figure 3.2. Ground cover over time for three cover crop species in pure stand: oil seed radish (Raphanus sativus L.), common vetch (Vicia sativa L.), and bristle oat (Avena strigosa), grown between August and November in three years (2015-2017). WAS = weeks after sowing. 
except in 2015, when it produced a greater amount than radish. Vetch accumulated a similar amount of biomass as oats and a higher amount than radish in 2015. In 2016 and 2017, oats and radish accumulated a higher amount of shoot biomass than vetch. The highest biomass production was observed in 2016.
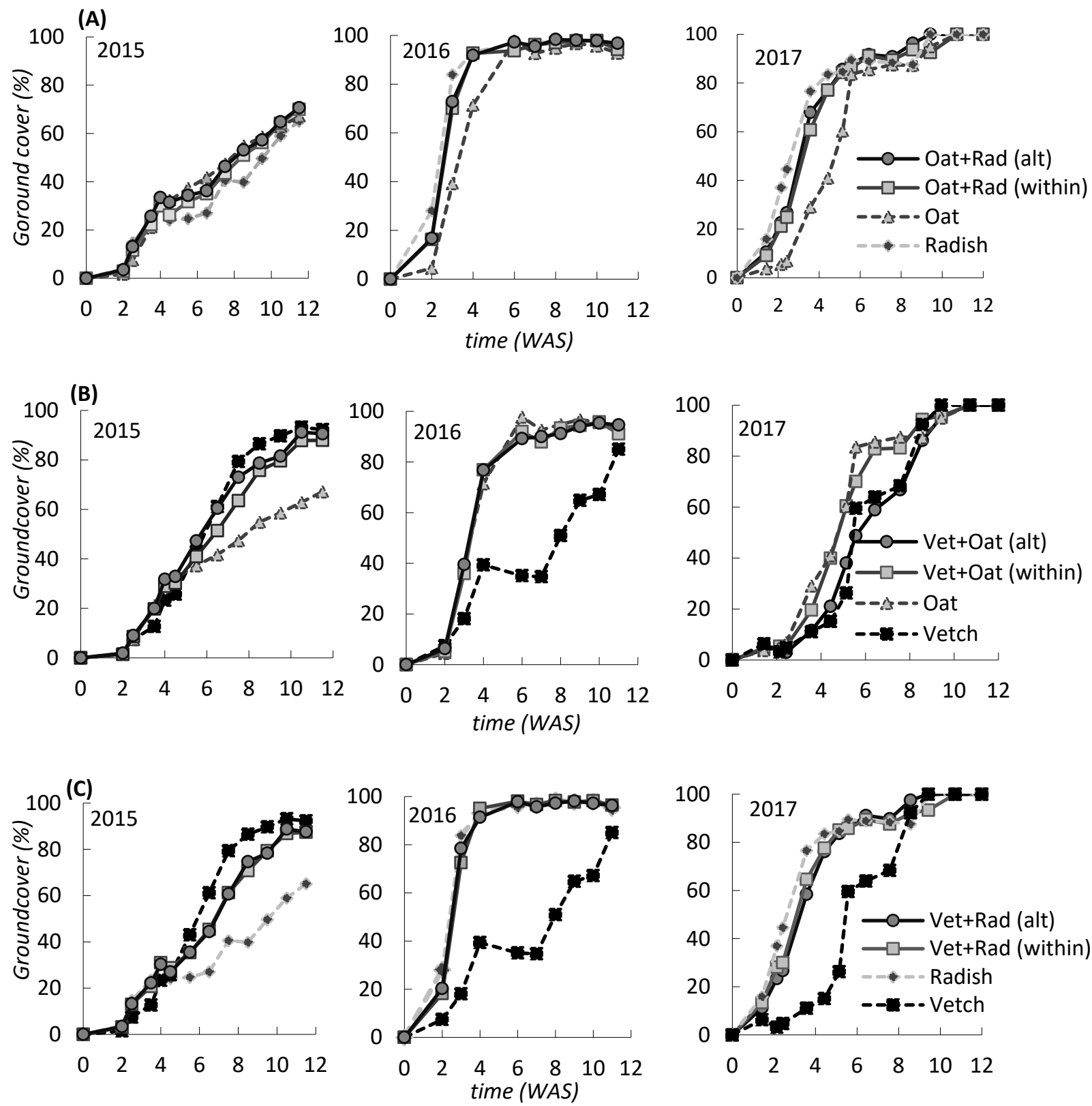

Figure 3.3. Ground cover over time for three cover crop mixtures: (A) bristle oat mixed with oil seed radish $(\mathrm{Oat} \times \mathrm{Rad})$; (B) common vetch mixed with bristle oat (Vet $\times$ Oat); (C) common vetch mixed with oil seed radish (Vet $\times$ Rad). All mixtures were grown between August and November in three years (2015-2017). WAS = weeks after sowing. Dotted curves represent ground cover of pure stands and solid line represents mixtures at two spatial configurations; mixed withinrow (within) and mixed in alternate rows (alt). 

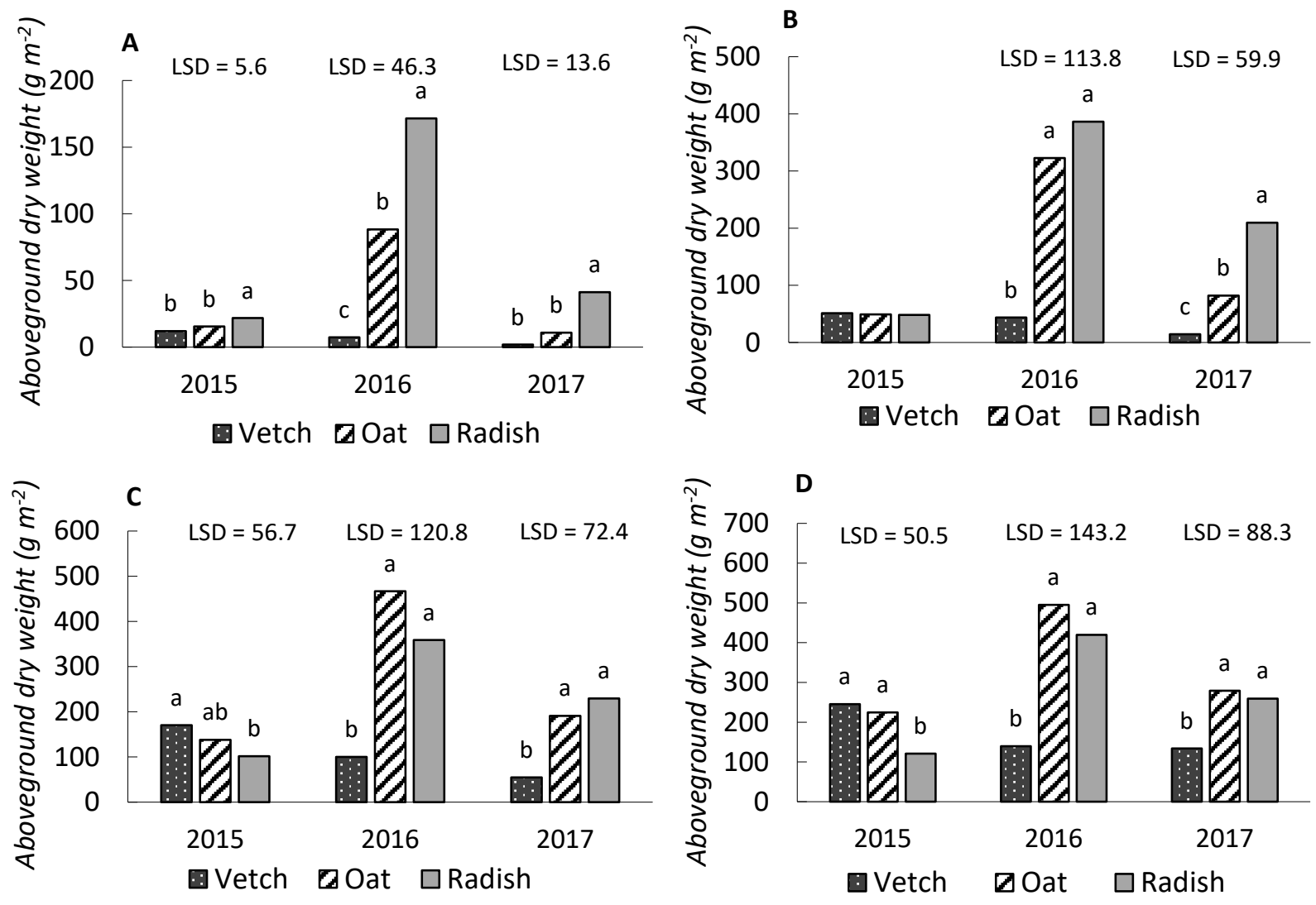

Figure 3.4. Aboveground biomass yield of three cover crop species in pure stand: oil seed radish (Raphanus sativus L.), common vetch (Vicia sativa L.), and bristle oat (Avena strigosa), in three years (2015-2017) at (A) 3 weeks after sowing (WAS), (B) 6 WAS, (C) 9 WAS, and (D) 12 WAS. Different letters denote significant differences between species within each year at $P \leq$ $0.05 . \mathrm{LSD}=$ least significant difference.

Across the three years, the average biomass of mixtures $\left(3.3 \mathrm{t} \mathrm{ha}^{-1}\right)$ was substantially higher than the average of the pure stands $\left(2.6 \mathrm{t} \mathrm{ha}^{-1} ; P=0.002\right)$. Results however differed per year and a significant interaction between experimental year and species combination was found for biomass production $(P<0.001)$. Compared to pure stands, mixtures produced similar biomass in $2015(P=0.830), 1.3 \mathrm{t} \mathrm{ha}^{-1}$ higher biomass in $2016(P=0.007)$, and $0.5 \mathrm{t} \mathrm{ha}^{-1}$ higher biomass in $2017(P=0.056)$. Alternate-row mixtures produced higher biomass than pure stands in 2016 $(P=0.014)$, whereas within-row mixtures produced a marginally significantly higher biomass than pure stands in 2017 ( $P=0.100$; Fig. 3.5A).

In two out of three years, the biomass production of Oats-Radish in alternate-row configuration (ORALT) resulted in a yield gain (positive $N E$ ). Results of this mixture in the within-row configuration (OR within) were variable (Fig. 3.6; Table 3.2). In 2016, the year with the highest biomass production of the two species in pure stand, a significant difference in yield gain between the two configurations was found. This difference was due to a positive 


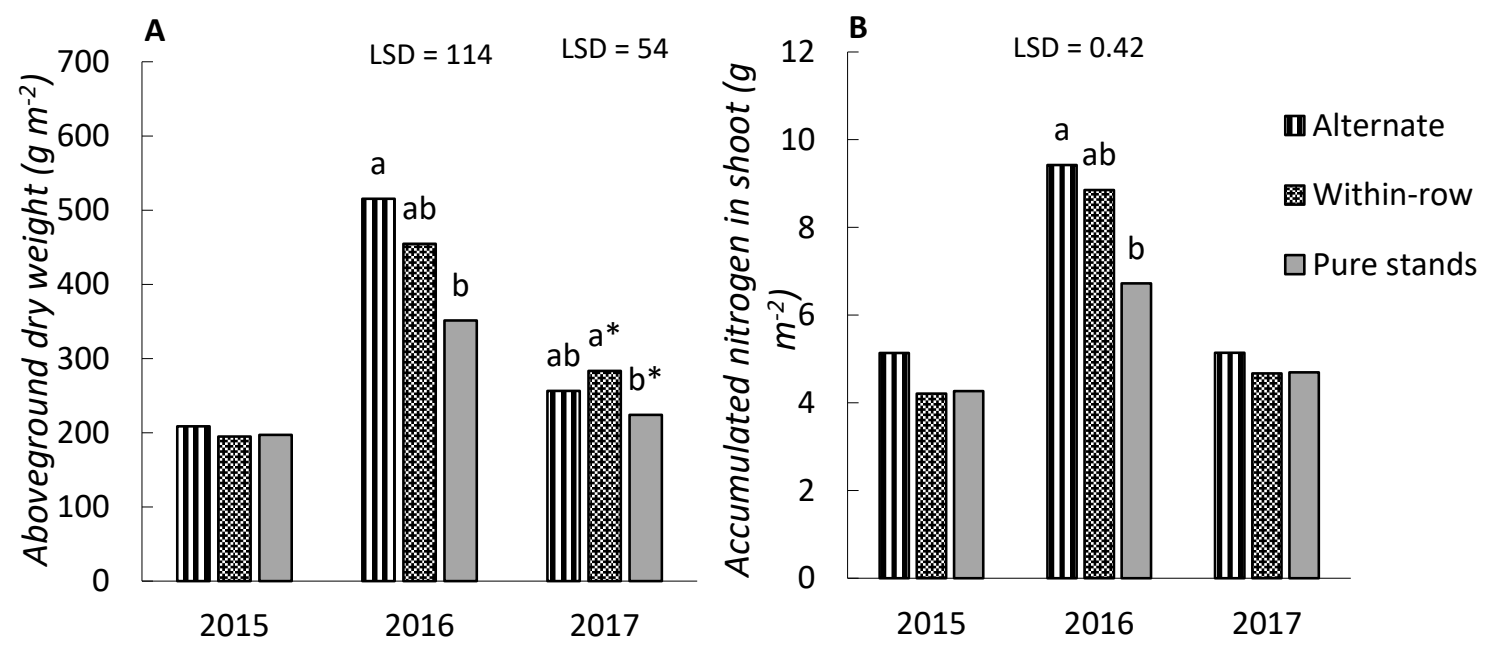

Figure 3.5. Average aboveground biomass $\left(\mathrm{g} \mathrm{m}^{-2}\right)$ (A) and average amount of accumulated shoot nitrogen $\left(\mathrm{g} \mathrm{m}^{-2}\right)(\mathrm{B})$ of three cover crop species in pure stand and mixtures in two species configurations (alternate rows and within-row) in three years (2015-2017). Different letters denote significant differences between treatments within each year at $P \leq 0.05$. Different letters with asterisk represent marginal difference at $P \leq 0.1$. LSD $=$ least significant difference.

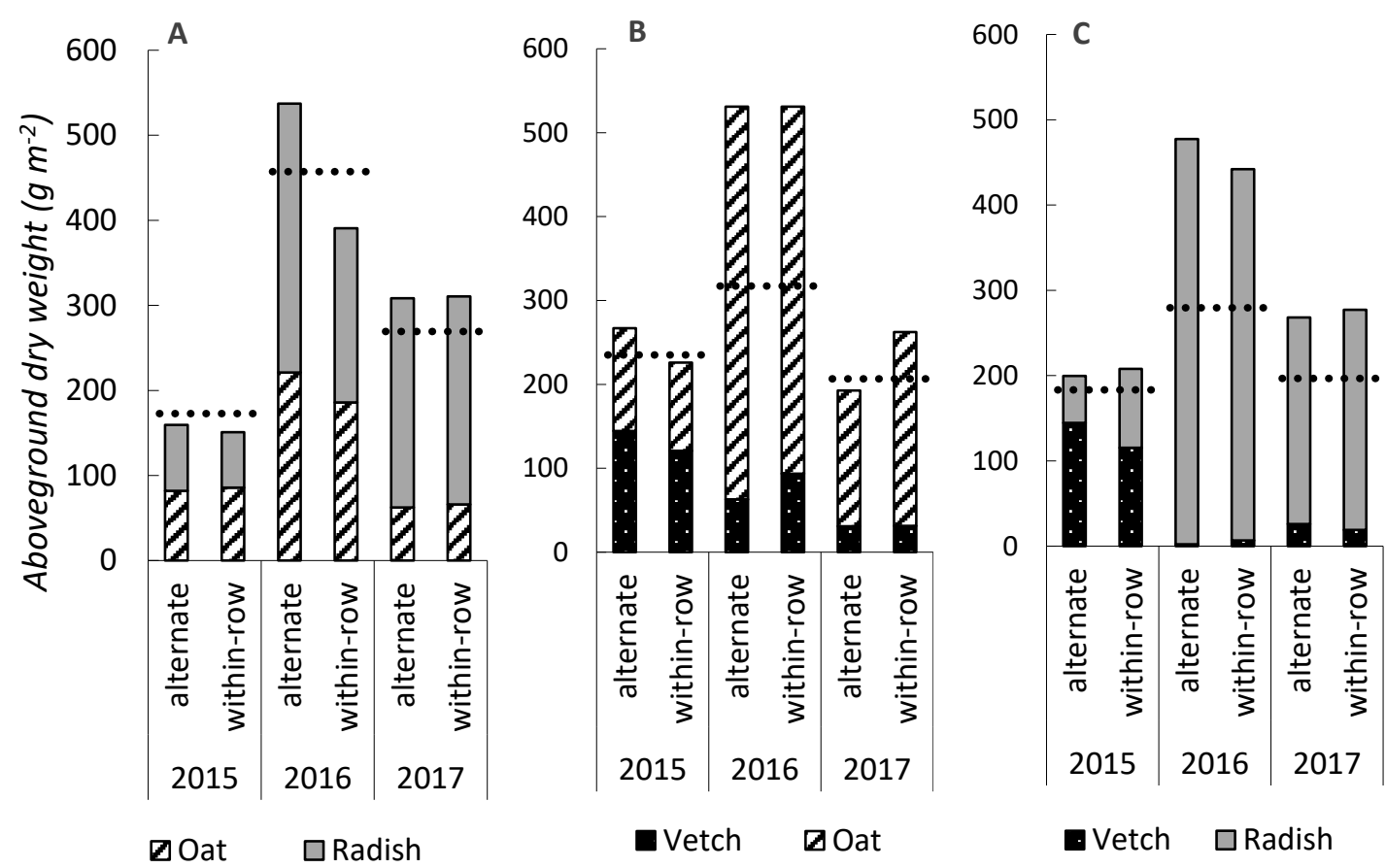

Figure 3.6. Aboveground biomass yield of three cover crop mixtures; Oat $\times$ Radish (A), Vetch $\times$ Oat (B), and Vetch $\times$ Radish (C) in three consecutive years (2015-2017). Horizontal dotted lines represent the expected biomass calculated as the average of the yields in pure stand of the cover crop species in the mixture.

complementarity effect $(C E)$ which was positive for OR $\mathrm{RLT}_{\mathrm{ALT}}$ and a negative complementarity effect for ORWITHIN. In all three years, irrespective of configuration, RY of radish exceeded the RY of oats. This was particularly evident in 2017, with an average RY of 0.95 for radish and 
of 0.23 for oats. Since radish, next to a larger RY, also had the lower pure stand production of the two species, a negative selection effect resulted. This selection effect ranged from -4.3 to $14.4 \mathrm{~g} \mathrm{~m}^{-2}$.

Throughout the three years, the performance of vetch-oats (VO) mixtures was highly variable. Most striking was the substantial yield gain of $214 \mathrm{~g} \mathrm{~m}^{-2}(67 \%)$ in 2016 in both alternate-row $(P=0.055)$ and within-row $(P=0.010)$ configuration, mainly due to complementarity (Table 3.2). In 2015 , only the alternate-row configuration resulted in a yield gain $\left(31.9 \mathrm{~g} \mathrm{~m}^{-2} ; 14 \% ; P\right.$ $=0.020)$, whereas in 2017 only the within-row configuration produced a yield gain $\left(55.7 \mathrm{~g} \mathrm{~m}^{-}\right.$ $2 ; 27 \% ; P=0.035)$. A significant difference in yield gain between the two spatial configurations was observed in $2015(P=0.037)$. This difference was associated with a higher complementarity between vetch and oats in the alternate-row configuration. In 2016 and 2017, for both configurations, the RY of oats was considerably higher than that of vetch. Since also the pure stand production of oats was higher, this resulted in a positive selection effect, ranging from 25.3 to $87.7 \mathrm{~g} \mathrm{~m}^{-2}$.

In 2016 and 2017, Vetch-Radish (VR) mixtures, irrespective of configuration, resulted in a yield gain (180 and $76 \mathrm{~g} \mathrm{~m}^{-2}$, respectively). In these two years, the yield gain mainly resulted from a strong selection effect, with a strong dominance of radish $(\mathrm{RY}=0.93$ to 1.13$)$ and vetch nearly being outcompeted ( $R Y=0.02$ to 0.19 ). In 2016 , the selection effect in the within-row configuration was significantly higher than in the alternate-row configuration. In 2015, the net biodiversity effect was not different from zero. In this year, the relative contribution of radish and vetch to the mixtures was more balanced, reflected in RY of radish ranging from 0.46 to 0.76 and RY of vetch ranging from 0.47 to 0.59 . This more equal contribution was most likely caused by the excessive precipitation in August, which hindered the growth of radish but not that of vetch. The separation of species in alternate rows (VRALT) allowed for better biomass accumulation by vetch as compared to the other spatial configuration (VRwithin, $P=0.027$ ). The opposite was true for radish, as it produced more biomass in VRWITHIN than in $\operatorname{VR}_{\text {ALT }}(P=$ 0.023). This resulted in significant differences in $C E$ and $S E$ between configurations, with a higher $C E$ for the within-row configuration and a higher $S E$ for the alternate-row configuration. These contrasting responses of the components underlying the net biodiversity effect resulted in the absence of a significant difference in $N E$. 


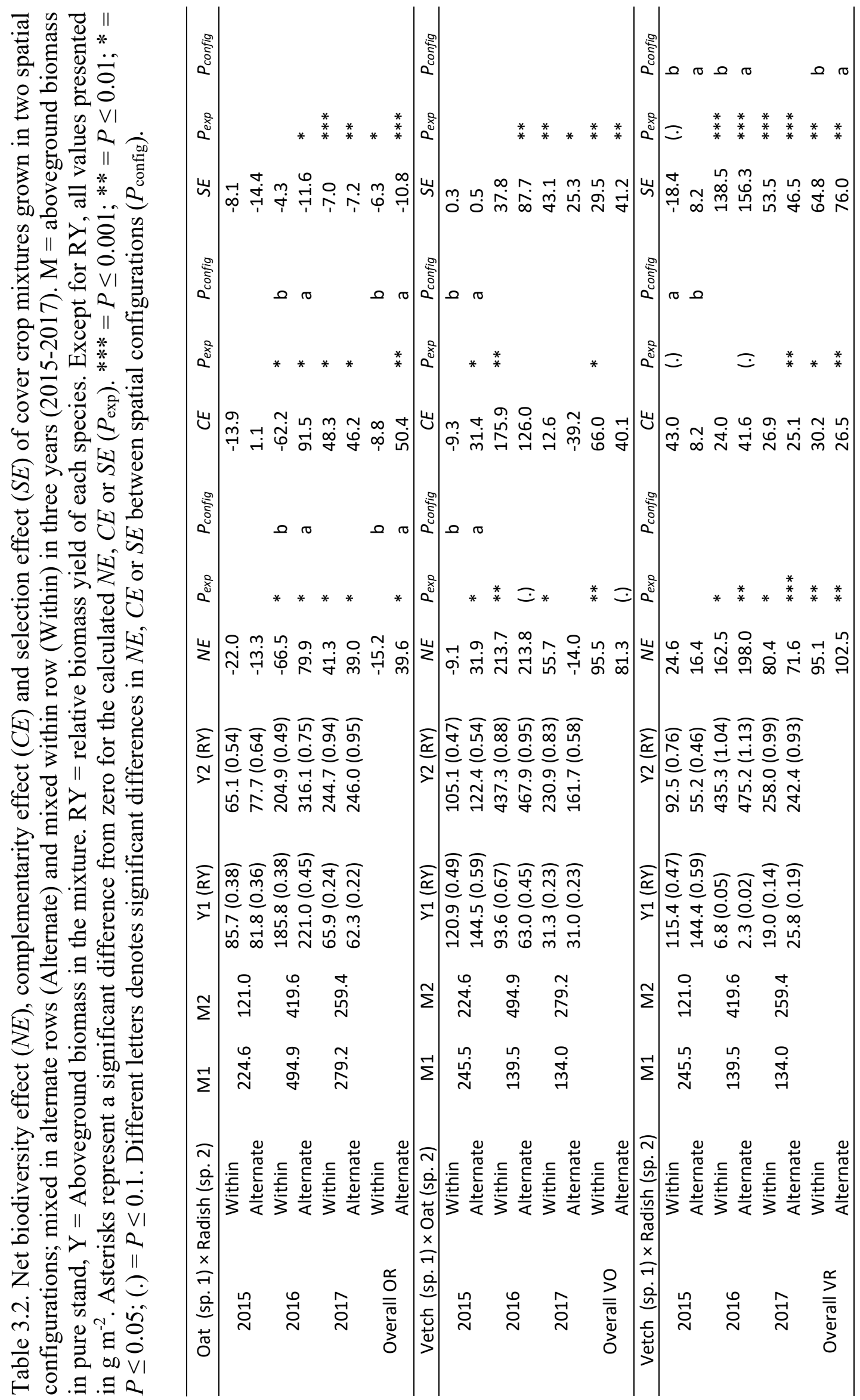




\subsubsection{Accumulation of shoot nitrogen}

Shoot nitrogen content varied among species. Vetch had the highest percentage of shoot N: $3.55 \%$ in $2015,3.96 \%$ in 2016 and $4.80 \%$ in 2017 . The $\mathrm{N}$-content of radish was lower: $1.60 \%$ in $2015,2.08 \%$ in 2016 and $1.49 \%$ in 2017 , whereas oats had the lowest percentage of $\mathrm{N}$ in the shoot: $0.99 \%$ in $2015,1.25 \%$ in 2016 and $1.36 \%$ in 2017. Both in 2015 and 2017, vetch had a higher $\mathrm{N}$ yield (total above ground $\mathrm{N}$ ) than radish and oats (Fig. 3.7). In 2016, the year with the high biomass production of radish and oats, radish had a higher $\mathrm{N}$ yield than oats and vetch. While the $\mathrm{N}$ yield of oats was variable (2.2 to $6.1 \mathrm{~g} \mathrm{~N} \mathrm{~m}^{-2}$ ), it was always among the species with the lowest $\mathrm{N}$ yield. The $\mathrm{N}$ yield of radish was even more variable (1.9 to $8.7 \mathrm{~g} \mathrm{~N} \mathrm{~m}^{-2}$ ), whereas that of vetch was more stable varying from 5.4 to $8.7 \mathrm{~g} \mathrm{~N} \mathrm{~m}^{-2}$.

Averaged over the three years, species mixtures accumulated a higher amount of $\mathrm{N}$ in the shoot $\left(6.4 \mathrm{~g} \mathrm{~N} \mathrm{~m}^{-2}\right)$ than pure stands $\left(5.3 \mathrm{~g} \mathrm{~N} \mathrm{~m}^{-2} ; P=0.029\right)$. Nitrogen accumulation in the shoot of the mixtures showed similar patterns as shoot biomass (Fig. 3.5B). Vetch had much higher $\mathrm{N}$ content than the other two species but it made up only a small proportion of the biomass of the mixtures. Averaged over three years, the N-content of vetch was lower in mixture $(3.11 \%)$ than in pure stand $(4.10 \%)$. For oats and radish in mixture with vetch, the opposite was found. Here, the average $\mathrm{N}$-content increased from $1.20 \%$ in pure stands to $1.70 \%$ in mixtures (oats) and from $1.72 \%$ in pure stands to $1.96 \%$ in mixtures (radish). For oats and radish, the net biodiversity $\left(N E_{\mathrm{N}}\right)$ and complementarity $\left(C E_{\mathrm{N}}\right)$ effect were on average positive and significantly higher in alternate row mixtures than in within-row mixtures (Fig. 3.8; Table 3.3). No significant difference between the two configurations was observed for $S E_{\mathrm{N}}$, though this component tended to be positive for $\operatorname{OR}_{\text {ALT }}\left(0.18 \mathrm{~g} \mathrm{~N} \mathrm{~m}^{-2} ; P=0.053\right)$.

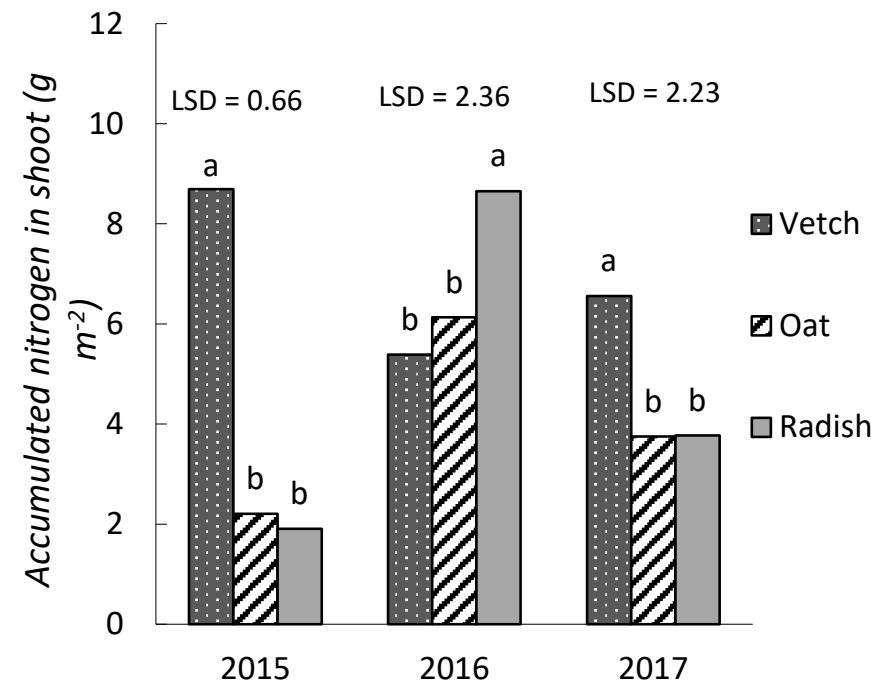

Figure 3.7. Accumulated amount of shoot nitrogen $\left(\mathrm{g} \mathrm{m}^{-2}\right)$ at 12 weeks after sowing for three cover crop species in pure stand: oil seed radish (Raphanus sativus L.), common vetch (Vicia sativa L.), and bristle oat (Avena strigosa), in three years (2015-2017). Different letters denote significant differences between species within each year at $P \leq 0.05$ level. $\mathrm{LSD}=$ least significant difference. 


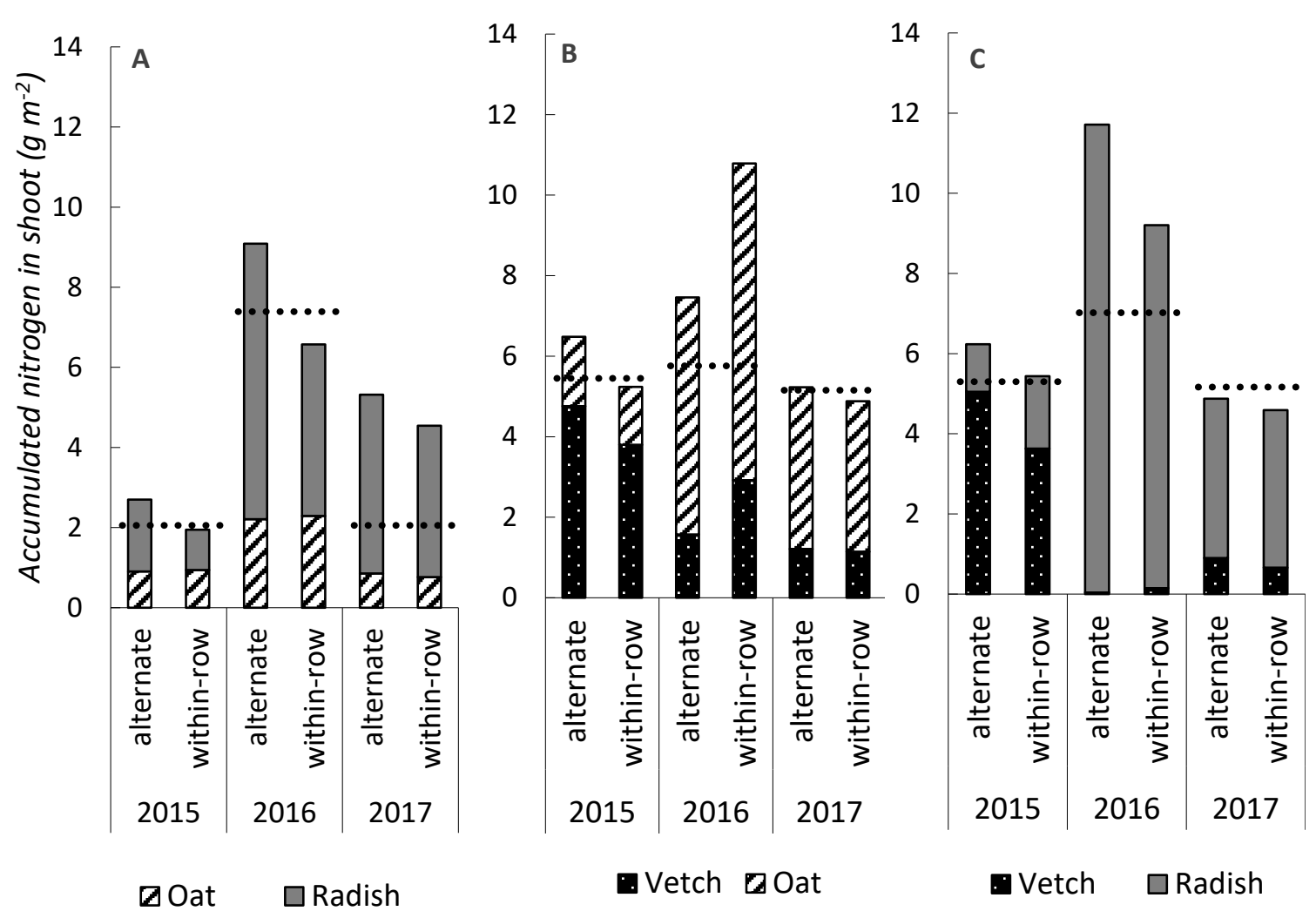

Figure 3.8. Accumulated amount of shoot nitrogen $\left(\mathrm{g} \mathrm{m}^{-2}\right)$ in three cover crop mixtures; Oat $\times$ Radish (A), Vetch $\times$ Oat (B), and Vetch $\times$ Radish (C) in three consecutive years (20152017). Horizontal dotted lines represent the expected biomass calculated as the average of the pure stands yield of the cover crop species involved.

Over the three years, $N E_{\mathrm{N}}$ of both vetch-oats mixtures was marginally-significantly higher than zero $(P<0.1)$. In both configurations, this resulted from a positive $C E_{\mathrm{N}}$ combined with a negative $S E_{\mathrm{N}}$. In all vetch-oats mixtures, RYN of oats was considerably higher than 0.5 (on average 0.96 ), whereas RYN of vetch was in most instances below 0.5 (on average 0.36 ).

For the combination of vetch with radish, the 3-year-average of $N E_{\mathrm{N}}$ tended to be positive in alternate row mixtures $\left(1.9 \mathrm{~g} \mathrm{~N} \mathrm{~m}^{-2}, P=0.057\right)$ but not different from zero in within-row mixtures. At the same time, $C E_{\mathrm{N}}$ was positive for both the alternate row mixtures $\left(1.6 \mathrm{~g} \mathrm{~m}^{-2}, P\right.$ $=0.030)$ and the within-row mixtures $\left(1.0 \mathrm{~g} \mathrm{~m}^{-2}, P=0.029\right) . S E_{\mathrm{N}}$ was significantly greater in alternate row mixtures than in within-row mixtures $(P=0.032)$, though both values were not significantly different from zero. The relative $\mathrm{N}$ yield of radish (on average 1.01) was always considerably higher than that of vetch (on average 0.21 ). 


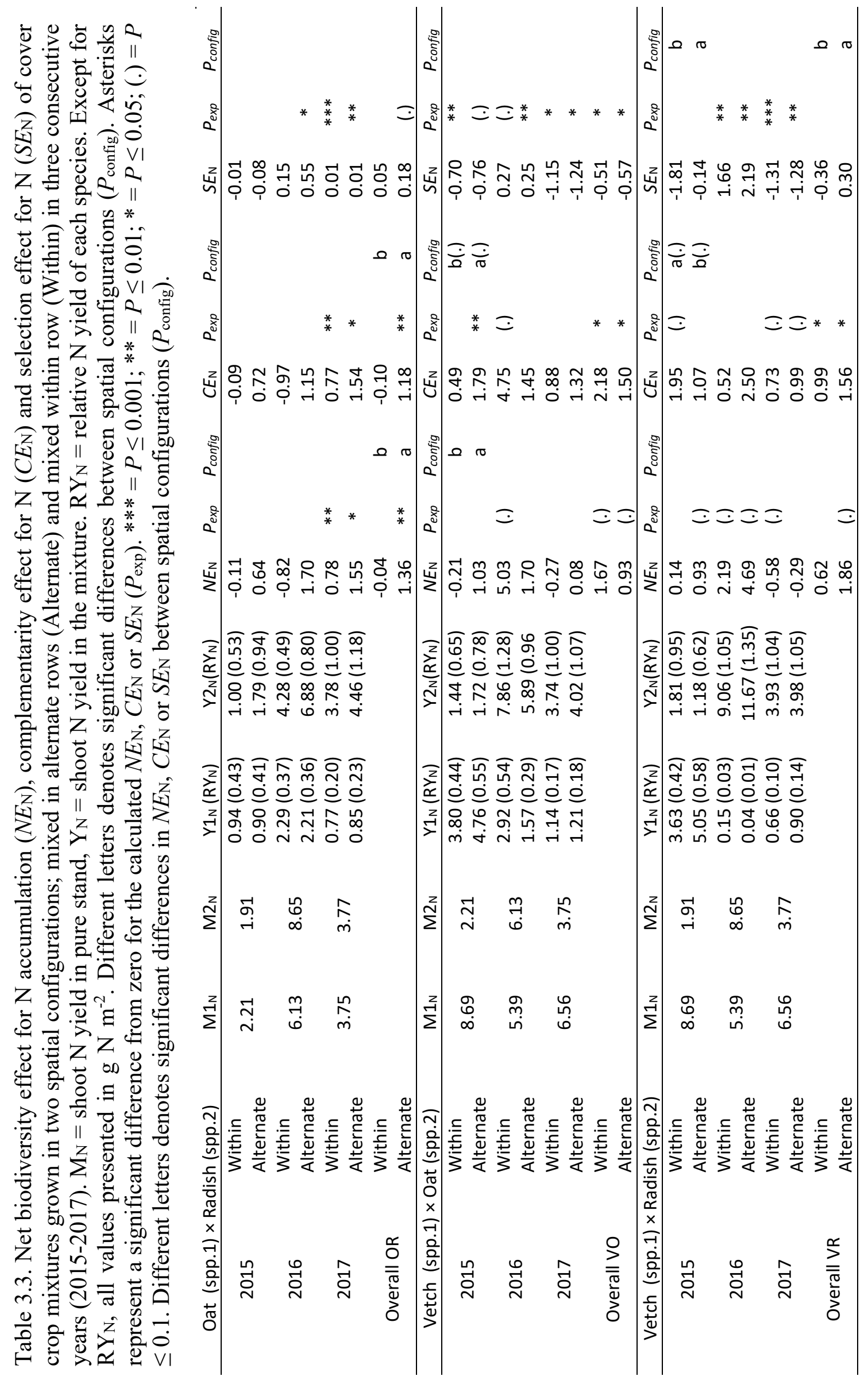




\subsection{Discussion}

In this study, we investigated whether spatial configuration influences mixture performance in terms of biomass and $\mathrm{N}$-accumulation. We hypothesised that 1) mixtures, on average, would over-yield pure stands, 2) that over-yielding is higher when species are mixed within-the-row, provided that the composing species have comparable growth rates, and that 3) if one of the species has a much faster early growth rate, the alternate row design would prevail, as it prevents the system to be dominated by a single species.

Our results demonstrated that, on average, both for biomass and $\mathrm{N}$-yield, mixtures were more productive than expected based on pure stands. By comparing the biomass yield of the 18 experimental mixtures ( 3 species combinations $\times 2$ configurations $\times 3$ years) with that of the pure stands, we found that 13 of the 18 tested mixtures had a relative yield total (RYT) above one. The average of the 18 RYT values is 1.16 and it was significantly higher than one $(P=$ $0.008, d f=17, t=3.03)$. The majority of these mixtures were the ones with a significant positive $N E$. The average of the $18 \mathrm{NE}$ values is $61 \mathrm{~g} \mathrm{~m}^{-2}$ which is significantly higher than zero $(P=$ $0.007, d f=17, t=3.09)$. This observation thus illustrates that mixing cover crop species results in yield advantage. Our results confirm the findings of Wendling et al. (2017), testing a wide range of cover crops mixtures, and Hayden et al. (2014), who studied productivity of a ryevetch mixture. In both studies, yield advantages (LER > 1) from mixing species of cover crops were reported. For N-yield even more positive results were obtained, with 16 out of 18 mixtures having a RYT $\mathrm{N}$ above one, with an average value of 1.27 that is significantly higher than one $(P<0.001, d f=17, t=5.35)$ and 12 out of 18 mixtures having a positive $N E_{\mathrm{N}}$ with a positive average value of $1.2 \mathrm{~g} \mathrm{~N} \mathrm{~m}^{-2}(P=0.02, d f=17, t=2.60)$. Similar results were also reported by Couëdel et al. (2018) who presented yield advantage for $\mathrm{N}$ uptake from mixing a wide range of crucifers with legumes in bispecific mixtures.

In comparing the absolute biomass yields in mixture with that of the pure stands, we found 10 mixtures with a yield exceeding that of the highest producing pure stand. For N-yield, we found a similar result: half of the mixtures accumulated more $\mathrm{N}$ than the pure stand of the species with the highest $\mathrm{N}$-accumulation. These results suggest that mixtures not only have higher average biomass and $\mathrm{N}$ yields than pure stands, but also frequently exceed that of the highest productive species in pure stand. Based on the data on biomass production and $\mathrm{N}$-accumulation, we conclude that our results confirm the first hypothesis that mixtures, on average, are more productive than pure stands. 
We found substantial year effects on the performance of species and mixtures. The year 2016 was highly productive for radish and oats. The high yields of pure stands were associated with excellent mixture performance, since five out of six mixtures accumulated more biomass and $\mathrm{N}$ yield than their respective best performing pure stand. Additionally, for all mixtures, except ORWITHIN, the highest $N E$ and $N E_{\mathrm{N}}$ values were obtained in 2016. Apparently, benefits resulting from mixing complimentary species are positively correlated to their growth performance under specific conditions. This makes sense, since under optimal growth conditions plants will grow taller and capture more resources. Consequently, total resource capture will be higher and it is under these circumstances that any advantage following from niche differentiation may be more profoundly expressed. However, when the two best performing species (oats and radish) in the best year (2016) were combined within row, the mixture performance was less good than when they were combined in alternate rows, providing evidence that interspecific complementarity may have an optimum interaction distance; not too close and not too far.

The experiments show clearly that the use of mixtures can mitigate risks. For instance, if one species fails to accumulate biomass rapidly due to unfavourable weather for its growth, the companion species can take over. Such a compensation mechanism is absent in single-speciescrops, which therefore will be more prone to crop failure. We witnessed an example of crop failure in 2015, when growth of radish was hampered due to the excessive precipitation at around one month after sowing. In this year, radish produced approximately half of the biomass produced by vetch and oats. Consequently, biomass yield of vetch-radish mixtures $\left(200 \mathrm{~g} \mathrm{~m}^{-2}\right.$ in alternate-rows and $208 \mathrm{~g} \mathrm{~m}^{-2}$ in within-row configuration) and oats-radish mixtures $(151 \mathrm{~g}$ $\mathrm{m}^{-2}$ in alternate-rows and $160 \mathrm{~g} \mathrm{~m}^{-2}$ in within-row configuration) were higher than the biomass yield of radish in pure stand $\left(121 \mathrm{~g} \mathrm{~m}^{-2}\right)$. Similar results were observed for $\mathrm{N}$ yield.

Averaged over years, positive $N E$ and $N E_{\mathrm{N}}$ were observed with yield advantages of $0.66 \mathrm{t}$ biomass $\mathrm{ha}^{-1}$ and $10.7 \mathrm{~kg} \mathrm{~N} \mathrm{ha}^{-1}$. A positive net biodiversity effect implies that the actual yield of the mixture exceeds the expected yield based on the pure stand performance of the component species. For biomass, yield advantage was, averaged over the species combinations, equally realised through $\mathrm{CE}$ and $\mathrm{SE}$, whereas for $\mathrm{N}$ uptake yield advantage was mostly realized through CE. The metric CE characterizes the contribution of complementarity between species on the performance of the mixture. CE is positive if both species have greater yield than expected from their density, or if the relative yield gain of the species that wins is larger than the relative yield loss of the species that loses. The metric SE characterizes the association 
between the pure stand performance of species and their relative yield gain in the mixture. A positive SE results if the higher yielding species encroaches on the growth space of the lower yielding species, reducing the yield of the latter, or if both species gain in the mixture, but the higher yielding species gains more in a relative sense than the lower yielding species. In mixing species in agriculture, the aim is to exploit mechanisms for complementarity. If the selection effect is the only mechanism for yield increase in a mixture, one might consider to grow a pure stand of the most productive species. At the same time, high yield of the dominant species lowers the risk connected to the use of mixtures: in cases without complementarity we found that the productivity of the mixture was close to that of the highly productive species. Here, we found that in many instances, the intercropping benefit was related to CE. Hence, our results support the benefit of mixing, but the contribution of CE was more prominent for nitrogen capture than for biomass production.

The highest yield benefit from species mixtures was expected to come to expression when species are mixed at closest proximity, provided balanced growth patterns (Lowry and Brainard, 2016; Musa et al., 2010). In our study, the closest proximity between species was obtained in the within-row configuration, whereas the two species were further apart in the alternate row design. Our results show that spatial configuration hardly had an effect on biomass production and $\mathrm{N}$ yield. In fact, only in two of the nine comparisons, significant differences in yield gain between the two configurations were observed (vetch-oats in 2015 and oats-radish in 2016). In both instances, the net effect was higher in the alternate row configuration than in the within-row configuration. Likewise, with vetch-oats in 2015, the net effect for $\mathrm{N}$ accumulation was higher in the alternate row configuration than in the within-row configuration.

The aforementioned observations led us to reject our second hypothesis, but only in these particular cases. Analysis of the components of $N E$ and $N E_{\mathrm{N}}$ shows that differences between the two configurations were caused by the higher complementarity ( $C E$ and $\left.C E_{\mathrm{N}}\right)$ between species in the alternate-row configuration as compared to the within-row configuration. A better mixture performance in alternate rows was anticipated if one of the component species would have a much faster early development, resulting in one species dominating the other. For the two abovementioned mixtures, differences in early growth rate of the component species in pure stand were either absent (2015) or relatively small (2016). Moreover, for these mixtures, the contribution of the component species to biomass yield in the within-row configuration was 
balanced. Therefore, none of the component species was dominating the mixtures (fig. 3.6). These results thus show that we also have to reject our third hypothesis.

Apart from mixture advantage, it is interesting and possible to verify whether the alternate row design was able to prevent species dominance. Both in 2016 and 2017, pure stands of radish had significantly greater early growth rate and early soil cover than pure stands of vetch (fig. 3.2 and 3.4A). Typically, in this situation one would expect a stronger dominance of radish over vetch in the within-row configuration than in the alternate-row configuration. The biomass data do however not confirm this hypothesis. In both years, radish strongly dominated vetch (fig. 3.6), irrespective of configuration. Obviously, sowing the mixture in alternate-row configuration was not able to prevent dominance. In fact, in 2016, the $S E$ in vetch-radish in alternate rows was significantly higher than in the within-row configuration. Our results are in contrast with those of Campiglia et al. (2014). They showed that the performance of subterranean clover mixed in an alternate row design with durum wheat suffered less at a row distance of $17 \mathrm{~cm}$, compared to both a smaller row distance $(10 \mathrm{~cm})$ as well as a within-row design. This example suggests that for an alternate row design to be successful in preventing species dominance, the row distance is crucial. The relatively small row distance $(12.5 \mathrm{~cm})$ in our experiment, combined with the strong dominance of radish over vetch, might well explain the absence of a difference between the two configurations. This suggests that distorted competitive relations between two species following from their difference in early development cannot be prevented by mixing the species in an alternate row configuration if the rows are close together.

Another factor that might have influenced the failure of the alternate row design to level the competitive relationship between two species is the availability of mineral N. It is well established, that there is a negative correlation between the availability of $\mathrm{N}$ and the performance of a legume in a mixture with non-legumes (e.g. Blesh, 2018). N-fertilization generally increases the competitiveness of non-legumes (Wendling et al., 2017). In all experimental years, we applied $30 \mathrm{~kg} \mathrm{~N} \mathrm{ha}^{-1}$ as a starter fertilizer, in accordance to common farmers' practice. This application might have contributed to the weak performance of vetch when mixed with oats and radish. With such a strong inequality in competitiveness, it might be nearly impossible for any spatial configuration to create more evenness.

In our experiments, an effect of spatial configuration on biomass production and $\mathrm{N}$ accumulation was rarely present. At the same time, the effects of year and species combination 
as well as their interaction were evident. Similar results were reported in earlier studies with either a major effect of year (Tosti et al., 2014; Brennan et al., 2009) or a minor effect of spatial configuration on biomass yield of cover crop mixtures (Lowry and Brainard, 2016). We thus conclude that in cover cropping, specifically with small row distances, spatial configuration is not of major significance.

\section{Acknowledgments}

This research is part of the clever cover cropping project which is a collaboration between the Soil Quality Group of Wageningen University, the Centre for Crop Systems Analysis of Wageningen University, and the Centre for Soil Ecology and the Netherlands Institute of Ecology. The project is funded by the Netherlands Science Foundation NWO (grant number 870.15.072) with co-financing from the private sector (Agrifirm, Vandinter Semo, P.H. Petersen Saatzucht, and Joordens Zaden).

\section{Appendix A}

Table A1 Analysis of variance for biomass and nitrogen uptake grouped by years and harvesting dates.

Table A2 Analysis of variance for biomass and nitrogen uptake grouped by cropping system.

Table A3 Analysis of variance of net biodiversity effect $(N E)$ and its components for biomass.

Table A4 Analysis of variance of net biodiversity effect $(N E)$ and its components for $\mathrm{N}$ uptake. 


\section{CHAPTER 4}

\section{Do cover crop mixtures give higher and more stable yields than pure}

stands?

Ali Elhakeem ${ }^{1}$, Lammert Bastiaans ${ }^{1}$, Saskia Houben ${ }^{1}$, Twan Couwenberg ${ }^{1}$, David Makowski², Wopke van der Werf ${ }^{1}$

${ }^{1}$ Centre for Crop Systems Analysis, Wageningen University and Research, Wageningen, the Netherlands.

${ }^{2}$ University Paris-Saclay, AgroParisTech, INRAE, Unit Applied Mathematics and computer science, Paris, France. 


\begin{abstract}
Planting cover crops after harvest of the main crop has become a key practice in temperate agriculture to reduce $\mathrm{N}$ leaching and increase soil organic matter. However, the growth of cover crops can be affected by adverse weather. Growing mixtures is thought to increase yield and reduce variation in productivity, but quantitative information on this subject is limited and uncertainty remains on the optimal choice of species and mixture composition for cover cropping to obtain high cover crop yields and resilient performance under a wide range of conditions. Here we tested a broad selection of pure stands and mixtures of cover crop species in two years (2017-2018) at four sites: three sites in the Netherlands (Wageningen, Neer and Scheemda) and one site in Germany (Grundhof). All pure stands and mixtures were grown for a period of 11-13 weeks between August and November in each year. Aboveground biomass was harvested and $\mathrm{N}$ yield was determined. Yields in treatments were regressed on mean yield in site-years to estimate responsiveness in different treatments. Mixed effects models were used to estimate and compare yield variability in pure stands and mixtures at three levels: 1) between site-years, 2) between treatments and 3) between plots. This analysis was performed for biomass and $\mathrm{N}$-yield. Across all pure stands and mixtures tested, average biomass was greater in mixtures than in pure stands, but average biomass was similar when this comparison was made between the five highest yielding pure stands and the five highest yielding mixtures across all site-years. Thus, the lower mean productivity in pure stands was mostly due to some low yielding species. The five best mixtures had $9 \%$ higher $\mathrm{N}$ yield than the five best pure stands. The response to average productivity in site-years was similar for mixtures and pure stands. Variation in cover crop yield over site-years was large in both pure stands and mixtures. On the other hand, mixing species significantly reduced the variability in biomass between treatments and between plots. But, when pure stands with low productivity were excluded, this difference in yield variability disappeared. This implies that the risk of choosing a sub-optimal cover crop is lower when a species mixture is used instead of a pure stand, unless the best pure stands are known. The results indicate that the positive effects of diversity on productivity and yield variability in cover cropping are restricted to the field level and do not provide insurance against adverse conditions related to variability in growing conditions amongst sites and years.
\end{abstract}

Keywords: cover crops, mixtures, species diversity, biomass, $\mathrm{N}$ yield, variability 


\subsection{Introduction}

In temperate regions, winter cover crops are sown after harvest of a cash crop to capture mineral nitrogen and reduce leaching or volatilisation of $\mathrm{N}$ in autumn (Abdalla et al., 2019; Norberg and Aronsson, 2019). In conventional systems in north-western Europe, cover crops are ploughed under before the next cash crop is sown. The incorporated residues help build soil organic matter (Steele et al., 2012) while cover crop residues on the soil surface or incorporated into the top soil can reduce weed establishment (Kruidhof et al., 2009). Cover crops improve soil water infiltrability (Dabney et al., 2001), and some species were shown to improve the yield of the subsequent cash crop due to mineralization of $\mathrm{N}$ from the decomposing biomass during summer (Chu et al., 2017).

Cover crop species from different plant families have different traits altering the provisioning of different services. For instance, legumes fix atmospheric nitrogen but, under north-west European conditions, they are not as productive as grasses or crucifers. Crucifers are productive, and some species can elicit hatching of nematodes without being a suitable host for nematode reproduction such that they can suppress nematode populations (Stirling and Stirling, 2003; Monfort et al., 2007). However, crucifers are sensitive to soil compaction and water logging (Chapter 3). Grasses are productive and efficient in converting resources into biomass but they produce residues with high C:N ratio and lignin that can immobilize soil $\mathrm{N}$ (Li et al., 2020c), thereby affecting the growth of a subsequent cash crop (Alonso-Ayuso et al., 2018). Positive effects of cover crop residues on the subsequent cash crop yield were observed when a legume, characterized by low $\mathrm{C}: \mathrm{N}$ ratio, and cereal cover crop species were grown as a mixture (Abdalla et al., 2019). In this case, the high biomass accumulated by the cover crop mixture was associated with good litter quality. Thus, mixtures may help to combine strengths of different cover crop species and mitigate individual species' drawbacks.

Implementation of EU regulation 641/2014 resulted in payments to farmers for growing winter cover crops as mixtures in several European countries (European Commission, 2019). The promotion of mixtures is based on the assumption that species diverse cover crops provide greater ecological services than single species cover crops, for instance due to greater biomass accumulation (Blanco-Canqui et al., 2015). Differences in species responses to weather or soil conditions may result in compensatory growth responses in species mixtures where one species makes up for underperformance of a companion species (Li et al., 2001). Mixing species with different responses to the variable weather and soil conditions in autumn could therefore result 
in a reduction of risk of the cover crop failing to accumulate enough biomass and provide ecosystem services (Gfeller et al., 2018; Wendling et al., 2019). Furthermore, it is expected that complementary traits, e.g. different architecture or growing patterns, will improve the capture of resources in mixtures as compared to pure stands (Vandermeer, 1992). Earlier studies have shown these postulated advantages of species mixtures of cover crops (Finney et al., 2016; Raseduzzaman and Jensen, 2017; Wendling et al., 2017; Blesh, 2018; Couedel et al., 2018a; Couedel et al., 2018b; Florence et al., 2019), natural grasslands (Tilman et al., 1996; Knops et al., 1999; Tilman et al., 2006; Fornara and Tilman, 2008; Cong et al., 2014) and food crops (Cong et al., 2015; Yu et al., 2015; Xu et al., 2020).

The benefits of mixing species of cover crops have been assessed in several studies, but yield stability was evaluated in only four studies (Wortman et al., 2012; Smith et al., 2014; Florence et al., 2019; Wendling et al., 2019). The term yield stability usually refers to the variability in crop yield over years and environmental conditions, that is: stability is the absence or limited presence of variability. There are several ways to estimate variability (Lin et al., 1986). Variance and coefficient of variation (standard deviation divided by the mean) are two standard indicators for characterizing variability in ecology and agronomy (Francis and Kannenberg, 1978; Rao and Willey, 1980; Knapp and van der Heijden, 2018). In previous studies on yield variability in cover crops, authors used the coefficient of variation of yield across replicates (spatial stability) and/or across years (temporal stability) (Wortman et al., 2012; Smith et al., 2014; Florence et al., 2019; Wendling et al., 2019). The interpretation of the coefficient of variation can be challenging because it varies not only with the standard deviation, but also with the mean (Doring and Reckling, 2018). Therefore, in this study, we decided to focus on variance.

Some authors have addressed the issue of yield variability by plotting individual crop yield (Finlay and Wilkinson, 1963; Faris et al., 1983) or deviations from average crop yield (Wendling et al., 2019) against the average yield level at different sites. This method may be used to characterize differences in responsiveness between different species or mixtures to site conditions. We used this approach as a first exploration of the yield variability present in our data set. We then took on a more quantitative approach, where we compared the variability of pure stands and species mixtures at three levels: across site-years, across treatments, referring to the variance between species for pure stands and between species combinations for the mixtures, and across plots within a field. The novel approach that was introduced for this 
purpose allows to simultaneously quantify these three different types of variance and thus reveals at which level the variability among mixtures deviates from the variability among pure stands.

For a given cover crop species or mixture composition, there will be variation in yield between site-years, due to differences in soil and weather conditions, and management, including sowing and harvesting date. This "between site-years" variance is very important for practice. Farmers prefer a cover crop that combines a high yield with low variability "between site-years", i.e. it will do well regardless of environmental circumstances and management.

The second type of variance to compare between pure stands and mixtures is that between individual entries of each group; that is the variation between different species within the group of pure stands and between different mixture compositions within the group of species mixtures. If mixtures reduce variability in performance as a result of "regression to the mean", we expect this "between treatments" variance component to be smaller for the group of mixtures than for the group of pure stands. Moreover, if variability within pure stands is higher than variability in mixtures, it means that the risk of choosing a sub-optimal pure stand species is greater than the risk of choosing a sub-optimal mixture.

The third relevant type of variance is the variation in yield between different spots in the same field. This variation is supposedly reduced in mixtures due to different responses of species to fine-grain differences in growing conditions within a field, e.g. soil humidity, organic matter content, or available nitrogen. Variance between plots in a given pure stand or mixture in a given site-year relates to the ability of the pure stand or mixture to accommodate to microvariation in growing conditions within the field. A low variance indicates that the species shows consistent performance across the field. In mixtures, this could mean that the species are compensating for a poor performance of the companion species. However, this was not observed in earlier studies (Wortman et al., 2012; Smith et al., 2014; Florence et al., 2019).

Species that are known to be highly productive, such as oil-seed radish and black oats are often present in mixtures, while pure stands also comprise species that provide ancillary services such as nematode control (Tagetes spp.) but are not necessarily high yielding. To eliminate the potential bias of low yielding sole crops in the dataset, we compared productivity and yield variability of the highest yielding pure stands with productivity and yield variability of the highest yielding mixtures. 
Thus, we made a quantitative comparison between pure stands and mixtures of cover crops in terms of biomass, $\mathrm{N}$ capture, and the variability in these traits, using data from four sites and two years. Variability among site-years was first examined by investigating yield response to site productivity. Thereafter mixed effects models were used, to quantify for both pure stands and mixtures the average productivity and the variability at three levels: 1) between site-years, 2) between treatments, and 3) between plots. We tested two hypotheses: 1) average biomass and $\mathrm{N}$ uptake is higher in cover crop mixtures than in pure stands, 2) at all three levels (between site-years, between treatments and between plots) the variability in biomass and $\mathrm{N}$ uptake is smaller in mixtures than in pure stands. Finally, the same hypotheses were tested using the five most productive pure stands and the five most productive mixtures to eliminate the effect of low yielding species in the group of pure stands.

\subsection{Materials and methods}

\subsubsection{Site description}

Field experiments were conducted in two consecutive years (2017-2018) at four locations, three in the Netherlands (Neer, Wageningen and Scheemda) and one in northern Germany (Grundhof). Different fields were used in the two years to avoid cumulative effects of growing the same mixture at the same site in subsequent years. Soil type was sandy in Neer and Wageningen, clay in Scheemda and sandy clay in Grundhof. Soil organic matter content ranged from $2.1 \%$ in Grundhof in 2017 to $8.0 \%$ in Scheemda in 2017. The distance between the two furthest sites (Neer and Grundhof) was approximately $450 \mathrm{~km}$. In all cases, the seedbed was prepared to a depth of $8 \mathrm{~cm}$ with a power harrow. Cover crops were sown at the end of summer and harvested 11-13 weeks later. Immediately after sowing, $30 \mathrm{~kg} \mathrm{~N} \mathrm{ha}^{-1}$ was applied as slow release fertilizer (calcium ammonium nitrate, $27 \% \mathrm{~N}$ ) to promote cover crop establishment. Sowing and harvesting dates of winter cover crops varied across site-years due to variation in harvest date of the preceding cash crop and rainfall at the site. The difference between the earliest (Neer) and the latest (Wageningen) sowing date of cover crops was approximately three weeks. Details of all sites, including field operations and weather conditions, are summarized in Table 1.

\subsubsection{Experimental design}

At all sites, we used a randomized complete block design. The number of replicates was four in Wageningen and three at the other locations. In 2017, each experiment comprised 10 pure stands and 10 mixtures, while in 2018, each experiment comprised 12 pure stands and 11 


\begin{tabular}{|c|c|c|c|c|c|c|c|c|c|c|c|c|c|c|c|}
\hline & 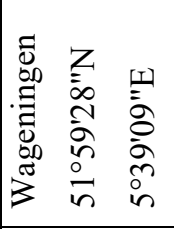 & 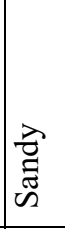 & $\vec{m}$ & $\stackrel{\infty}{.}$ & กี & & 离 & 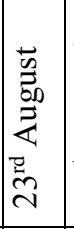 & 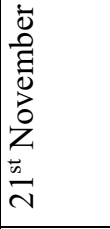 & 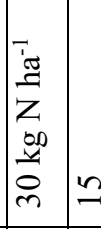 & $\begin{array}{ll}0 \\
\text { y }\end{array}$ & I & $\frac{7}{n}$ & & $\stackrel{尺}{\Sigma}$ \\
\hline & 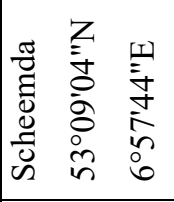 & $\frac{\vec{\pi}}{0}$ & oे & $m$ & $\stackrel{?}{\sim}$ & 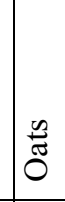 & & 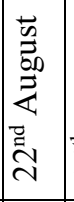 & 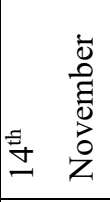 & 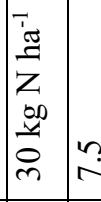 & is & $\tilde{I}$ & $\hat{\imath}$ & & શे \\
\hline & 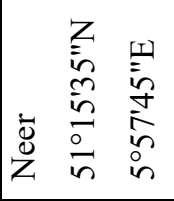 & 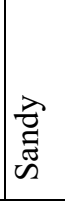 & in & $\cong$ & in & U. & & 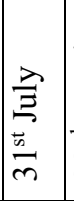 & 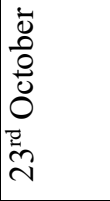 & 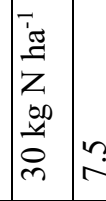 & r & 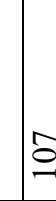 & 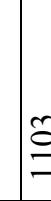 & & $\stackrel{\hat{O}}{\underline{\underline{O}}}$ \\
\hline 产 & 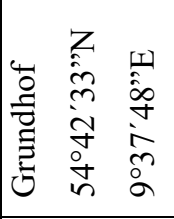 & 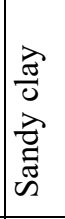 & $\stackrel{\vec{r}}{\vec{r}}$ & ส & ชู & 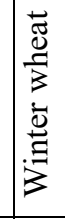 & & 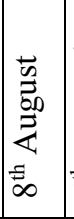 & 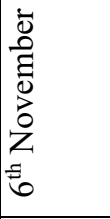 & 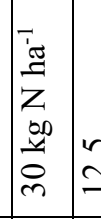 & 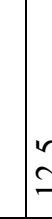 & $\exists$ & $\bar{\infty}$ & & $\check{\alpha}^{\circ}$ \\
\hline & 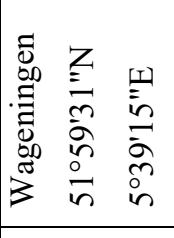 & 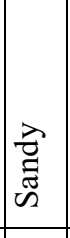 & $\ddot{r}$ & i & in & 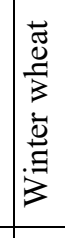 & & 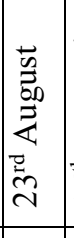 & 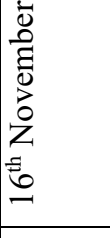 & 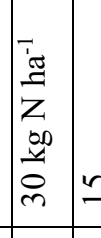 & s & $\hat{m}$ & $\hat{\imath}$ & & 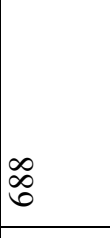 \\
\hline & 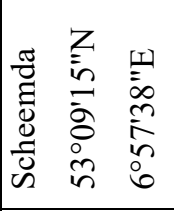 & $\begin{array}{l}x \\
\vec{z} \\
\vec{w} \\
\text { wh }\end{array}$ & $\dot{\infty}_{\infty}$ & $F$ & $\ddot{i n}$ & 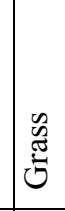 & & 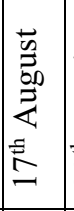 & 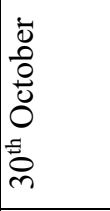 & 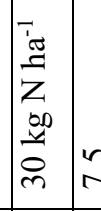 & is & $\overline{\tilde{\tau}}$ & $\hat{\imath}$ & & $\bar{\imath}$ \\
\hline & 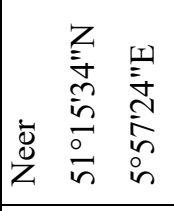 & $\begin{array}{l}\vec{x} \\
\text { 离 } \\
\text { की }\end{array}$ & in & f & in & שي & & 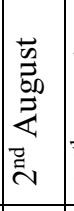 & 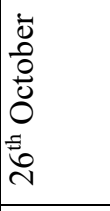 & 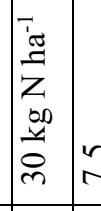 & 5 & $\Phi$ & $\tilde{\sigma}$ & & ָ̃ \\
\hline$\stackrel{\bar{े}}{ }$ & 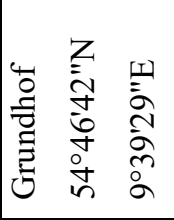 & 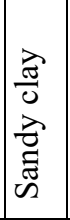 & $\vec{i}$ & $\approx$ & : & 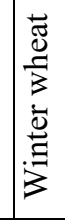 & & 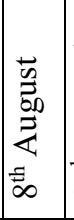 & 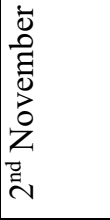 & 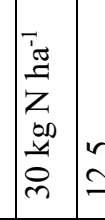 & & $\bar{f}$ & $?$ & & ఏ్ \\
\hline 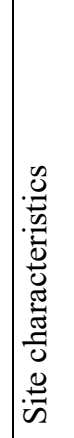 & & 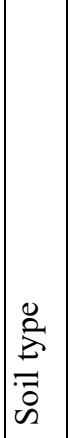 & 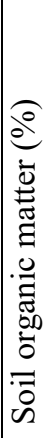 & 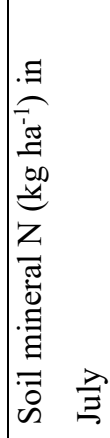 & $\begin{array}{l} \\
\frac{T}{2} \\
\frac{1}{0} \\
0 \\
\text { n. }\end{array}$ & 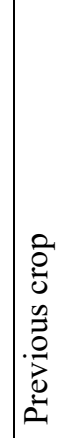 & & 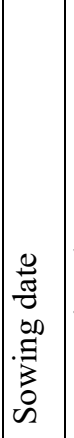 & 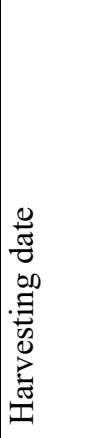 & 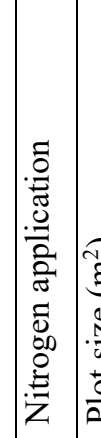 & & 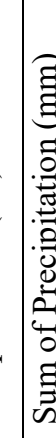 & & & 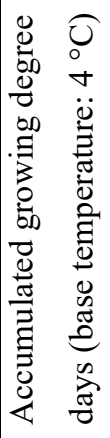 \\
\hline
\end{tabular}


mixtures. Pure stands comprised the most common species used as cover crops across the experimental regions. From a pilot experiment with 25 pure stand species of cover crops, we selected the most productive species from different botanical groups (data not shown). The selected species in the current study belonged to six different plant families: Brassicaceae, Poaceae, Fabaceae, Boraginaceae, Asteraceae, and Linaceae. Based on these species, 2-, 3- and 4-species mixtures were composed in collaboration with stakeholders (seed companies). To maximize the potential advantages of mixtures, species were mixed that differ in architecture and belong to different plant families (Table 4.2). Some species such as oilseed radish were present in more mixtures than other species, representing the interest of stakeholders to test particular mixture compositions with expected complementarities. Cover crops were sown in rows with $12.5 \mathrm{~cm}$ between rows using a $3 \mathrm{~m}$ wide seed planter in Wageningen (Rabe Turbo drill, Germany) and a $1.5 \mathrm{~m}$ wide seed planter in the other sites (Hege, belt cone planter, Germany). For each species, we used the seeding rate recommended by the seed supplier (Table 4.2). In plots with mixtures, seeds were mixed within the row following a replacement design. To create 2-, 3- and 4-species mixtures, we used $50 \%, 33 \%$ and $25 \%$ of the full seeding rate of each component species, respectively.

\subsubsection{Soil sampling}

Soil samples were collected from each plot at sowing of cover crops, using a $20 \mathrm{~cm}$ soil probe. Soil samples from the same block were mixed to create three or four (Wageningen) replicate samples. Total mineral $\mathrm{N}$ in the samples was determined using calcium chloride extraction (Table 4.1).

\subsubsection{Biomass harvest}

Aboveground plant mass was harvested at approximately 12 weeks after sowing using a $1.5 \mathrm{~m}$ wide harvesting machine (Haldrup F-55). Plants were cut at 1-2 $\mathrm{cm}$ aboveground. Weeds were separated from the sampled material. The harvested area differed between site-years and ranged between 4.5 and $15 \mathrm{~m}^{2}$ (Table 4.1). Total plot fresh weight was recorded by the harvesting machine while a randomly selected and shredded sub-sample was also obtained from the harvesting machine. Sub-samples were oven dried at $70{ }^{\circ} \mathrm{C}$ for 48 hours. Subsequently, the dry weight of all species was calculated. Use of machinery was not possible in Grundhof in 2017, due to extremely wet conditions. In this case, an area of one $\mathrm{m}^{2}$ per plot was harvested by hand and dry weight was measured for the total harvested biomass. From the dried samples in all site-years, $\mathrm{C}$ and $\mathrm{N}$ concentration was determined, using a dynamic flash combustion in a $\mathrm{C}: \mathrm{N}$ 


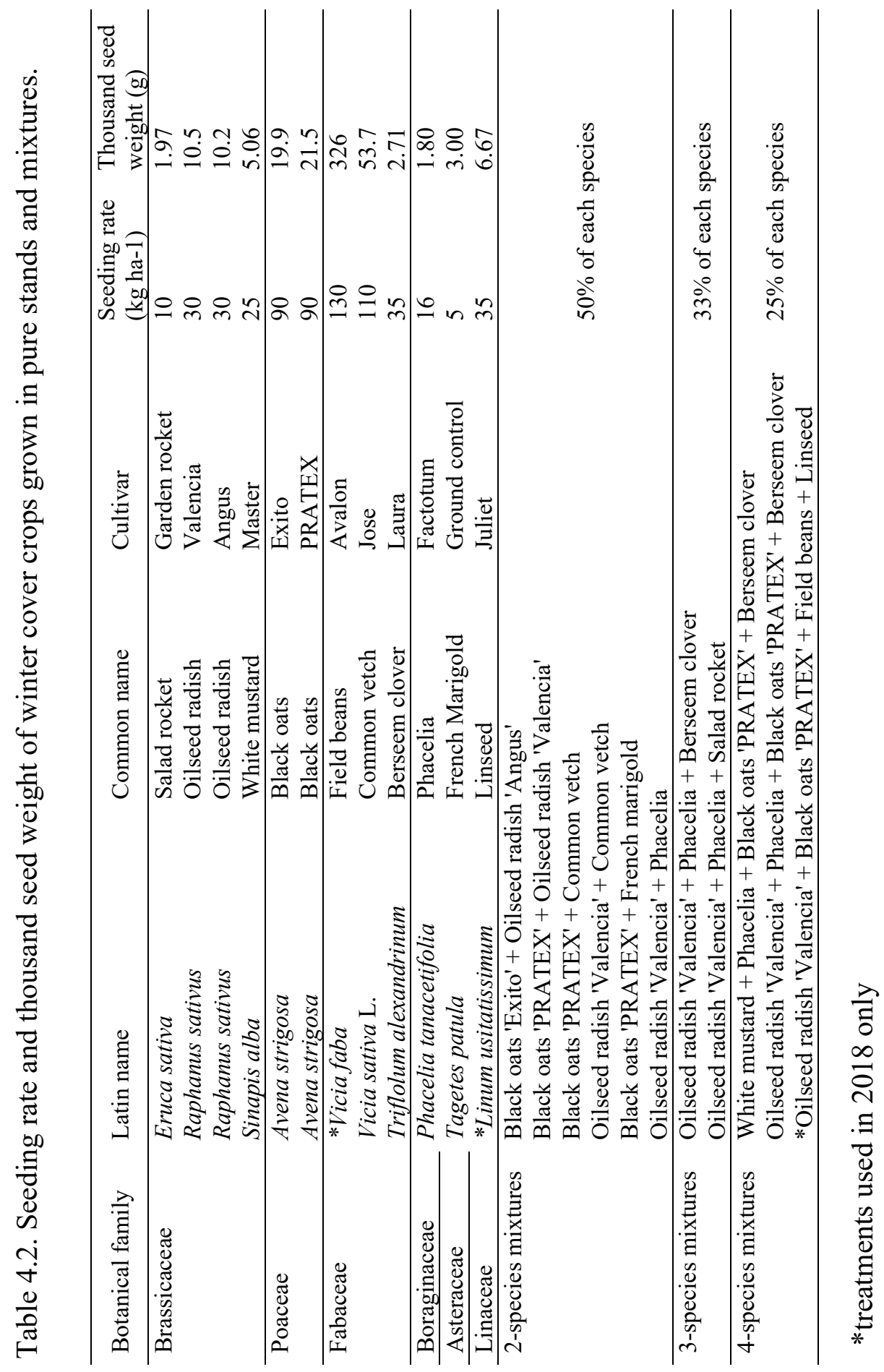


elemental analyser (EA 1108: Fisons Instrument). $\mathrm{N}$ yield was then calculated as the product of biomass and $\mathrm{N}$ concentration.

\subsubsection{Data analysis}

Analysis of biomass and $N$ yield

Linear mixed effect models were used to analyse biomass and $\mathrm{N}$ yield in different cover crop species, to compare biomass and $\mathrm{N}$ yield in pure stands and mixtures, and to compare the different plant families. Species (pure stands and mixture compositions) were defined as fixed effects. In all models, we included block and site-year as nested random factors. Models were fitted using the function lmer of the package lme4 (Bates et al., 2014) in R version 3.4.3 (R Core Team, 2018). Biomass and N yield were analysed separately. Significance of fixed effects was determined with analysis of variance (ANOVA). Pairwise comparisons were made using Tukey HSD test. The assumptions of normality and homogeneity of variances were checked graphically (Zuur et al., 2009). To investigate the changes in biomass and $\mathrm{N}$ yield in response to the number of component species, we used a linear mixed effect model with the number of species as a fixed effect.

Variation in yield of cover crop treatments across site-years

A linear regression was fitted between biomass (or $\mathrm{N}$ yield) and the mean biomass per site-year (or mean site-year $\mathrm{N}$ yield) to investigate the response to site productivity in different mixtures and pure stands. A separate linear regression was fitted for each pure stand and mixture. Mean site-year biomass or mean site-year $\mathrm{N}$ yield were calculated as the average biomass or $\mathrm{N}$ yield of all pure stands and mixtures in a site-year for eight site-years. Treatments that were only included in 2018 were omitted from this analysis.

Analysis of yield variances between site-years, treatments and plots

A mixed model with three variance components was developed to quantify differences in variability of yield and $\mathrm{N}$ capture between pure stands and mixtures. Variance components were estimated separately for the pure stands and the mixtures. The first variance component, $\sigma_{\text {site year, }}^{2}$, characterizes the variance between site years. It describes how the average yield in a site year varies amongst site years. Superimposed on the random site year effect is a random effect for treatment $\sigma_{\text {treatment }}^{2}$ where treatment denotes species identity among the pure stands or mixture composition amongst the mixtures. This variance characterizes the variation in biomass or $\mathrm{N}$-yield between different species among the pure stands and between different species combinations among the mixtures, across the site years. The third variance component 
describes the variation between plots in the same treatment and site-year. All variances were estimated simultaneously using a Bayesian linear mixed model, defined as:

$Y_{s t i}=\beta_{0}+\beta_{1} x+\mathrm{a}_{s}+\mathrm{b}_{t}+\varepsilon_{s t i}$

where $Y_{s t i}$ is the biomass or $\mathrm{N}$ yield measured in the $s^{\text {th }}$ site-year, $t^{\text {th }}$ pure stand or species mixture, and $i^{\text {th }}$ replicate, $\beta_{0}$ is the overall mean biomass or $\mathrm{N}$ yield in a pure stand, and $\beta_{1}$ is the difference in biomass or $\mathrm{N}$ yield between pure stands and mixtures. The variable $x$ is an indicator variable which is 0 for pure stands and 1 for mixtures. $\mathrm{a}_{s}$ is a random site-year effect which is normally distributed with mean zero and variance $\sigma_{\text {site year }}^{2}, \mathrm{~b}_{t}$ is a random pure stand or mixture effect which is normally distributed with variance $\sigma_{\text {treatment }}^{2}$, and $\varepsilon_{s t i}$ is a random residual term describing the between-plots variability, including the measurement error. The variance of $\varepsilon_{s t i}$ is $\sigma_{\text {plot }}^{2}$. All random variables were assumed normally and independently distributed with zero mean. Models were fitted using the package MCMCglmm (Hadfield, 2010 ) in R version 3.4.3 (R Core Team, 2018). Markov Chain Monte Carlo (MCMC) chains were run with 50,000 iterations (3,000 iterations for burn-in) and a thinning interval of 10 . The MCMC outputs were used to approximate the posterior distributions of the ratio of the variance in mixture to the variance in pure stands at all three levels of variability (between site-years, between treatments, between plots), for biomass and $\mathrm{N}$ yield, separately. Results were used to compute the posterior mean and median of the variance ratio, its $95 \%$ credible interval, and the probability of a variance ratio smaller than one, i.e. the probability that mixtures are more stable in yield than pure stands. At any level of variability, if the variance ratio was significantly smaller than one, we would have concluded a higher stability in mixtures yield as compared to pure stands and vice versa.

\section{Analysis of productivity and yield variability of the most productive treatments}

Highly productive species, such as crucifers and black oats are often present in mixtures, while pure stands also comprise species that are less productive such as legumes and flowering forbs. This may result in a biased comparison of yields in pure stands and mixtures. To prevent such bias, we made a comparison of yield and yield variability of the five most productive pure stands and mixtures across the eight site-years, thus effectively excluding the influence of low yielding treatments (Table 4.3). Biomass and $\mathrm{N}$ yield were compared for the five most productive mixtures and the five most productive pure stands, using linear mixed effect models including biomass and $\mathrm{N}$ yield as fixed effects and block nested within site-years as random effects. Differences in yield variability between the most productive mixtures and pure stands were analysed using the Bayesian linear mixed model (Equation 4.1). 


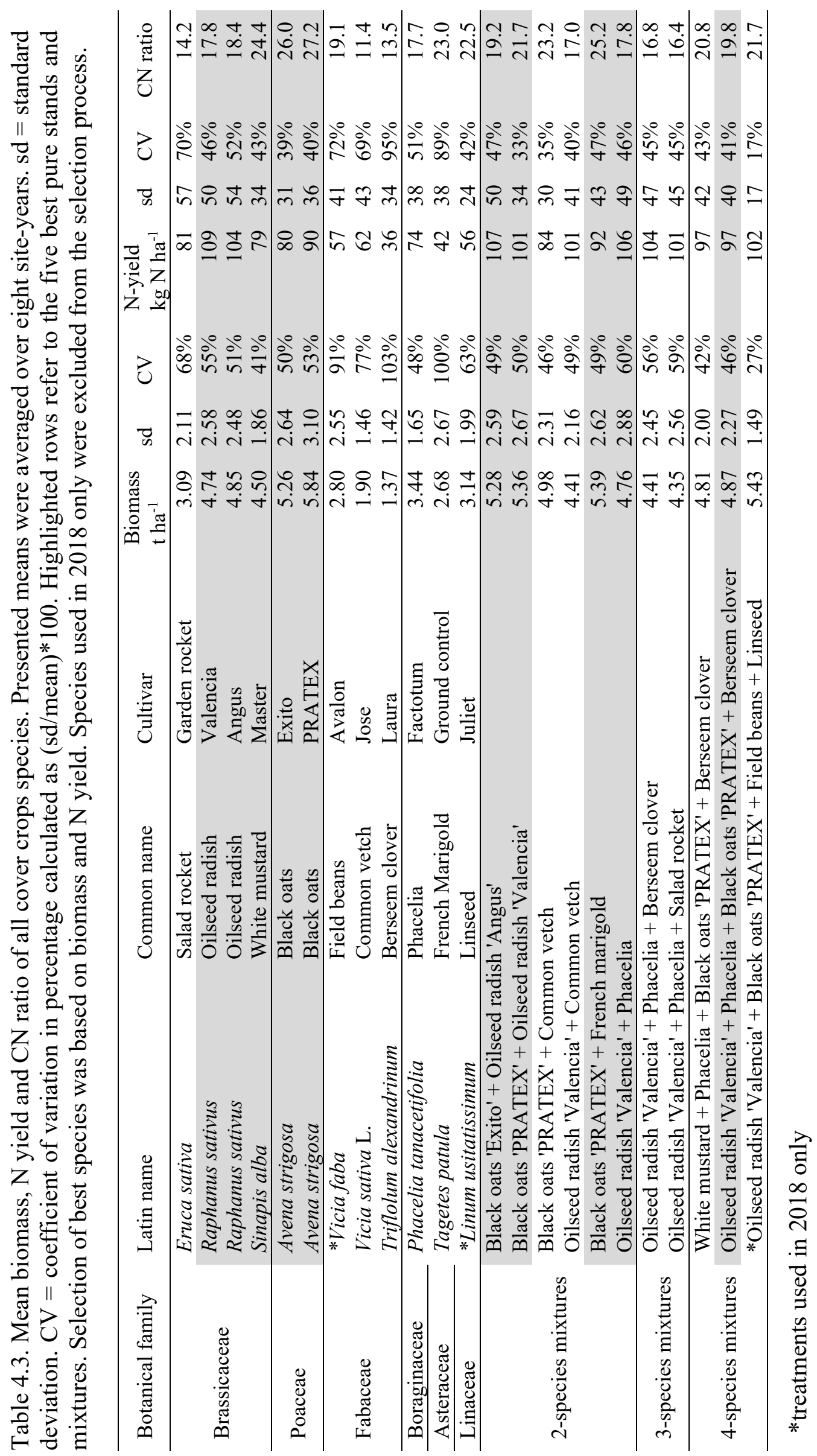




\subsection{Results}

Site-year had a significant effect on cover crop biomass yield $(p<0.001), \mathrm{N}$ concentration $(p<$ $0.001)$ and $\mathrm{N}$ yield $(p<0.001)$. This effect was particularly due to the difference in biomass yield between Neer (on average $8.2 \mathrm{t} \mathrm{ha}^{-1}$ in 2017 and $7.3 \mathrm{t} \mathrm{ha}^{-1}$ in 2018) and the other sites (with averages ranging from 2.0 to $4.1 \mathrm{t} \mathrm{ha}^{-1}$; Fig. 4.1). The higher productivity in Neer was associated with an earlier sowing date than at the other sites. As a result, there was a big difference in the accumulated growing degree days between Neer (1022 to $1077{ }^{\circ} \mathrm{Cd}$ from emergence to harvest) and the other three sites (ranging from 688 to $905^{\circ} \mathrm{Cd}$; Table 4.1 ). In addition, cumulative global radiation over the growth period of cover crops was higher in Neer (from 925 to $1103 \mathrm{MJ} \mathrm{m}^{-2}$ from emergence to harvest) than in the other sites (from 679 to 801 $\mathrm{MJ} \mathrm{m}^{-2}$ ). Mixtures tended to have a higher average yield than pure stands in each site-year.

In six of the eight site-years, the highest biomass was produced by black oats, whereas oil-seed radish and white mustard each realized the highest production in one of the other two site-years (Supplementary Fig. B1 and B2). Black oats had the lowest N concentration (on average 1.65\% $\pm 0.54 \%$ ) and the highest $\mathrm{C}: \mathrm{N}$ ratio among all species (on average 26.6 \pm 8.6 ; Table 4.3). Thus, while black oats produced a large amount of biomass, it accumulated a comparatively low amount of $\mathrm{N}$ from the soil (Supplementary Fig. B3 and B4). Crucifers produced large amounts of biomass with high nitrogen concentration ( $\mathrm{N}$ concentration $=2.26 \% \pm 0.74 \%$ ) and therefore had a significantly lower $\mathrm{C}: \mathrm{N}$ ratio than found in black oats (on average $18.7 \pm 7.3 ; p<0.001$ ). Crucifers accumulated on average the highest amount of nitrogen (averaged over site-years 90.5
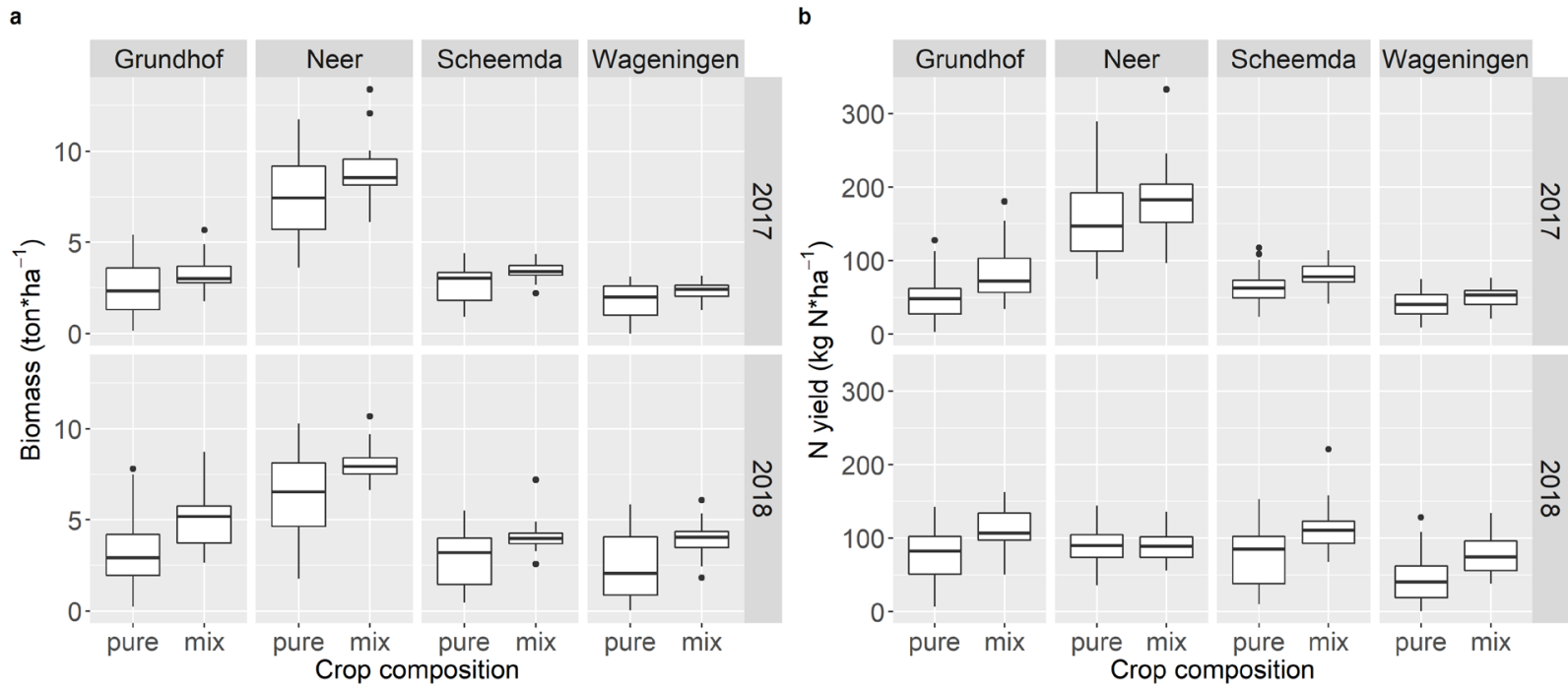

Figure 4.1. Average biomass (a) and $\mathrm{N}$ yield (b) of winter cover crops grown as pure stands (pure) or mixtures (mix) in 2017 and 2018 at four sites; Grundhof (Germany), Neer, Scheemda and Wageningen (all three in the Netherlands). 
$\mathrm{kg} \mathrm{N} \mathrm{ha}^{-1}$ ). In six of the site-years, oil-seed radish accumulated most nitrogen (ranging from 73.0 to $159.2 \mathrm{~kg} \mathrm{~N} \mathrm{ha}^{-1}$ ), whereas in the other two site-years, white mustard accumulated most nitrogen (ranging from 103.2 to $117.2 \mathrm{~kg} \mathrm{~N} \mathrm{ha}^{-1}$; Supplementary Fig. B3 and B4). Amongst the crucifers, salad rocket produced the lowest biomass (on average $3.1 \mathrm{t} \mathrm{ha}^{-1}$ ) but it captured relatively large amounts of $\mathrm{N}$ (on average $81 \mathrm{~kg} \mathrm{~N} \mathrm{ha}^{-1}$ ), resulting in a low $\mathrm{C}: \mathrm{N}$ ratio (on average 14.2).

Legumes combined low biomass with a high $\mathrm{N}$ concentration $(2.86 \% \pm 0.67 \%)$ and they had the lowest $\mathrm{C}: \mathrm{N}$ ratio of all plant families (on average 14.2). Phacelia, French marigold and linseed, three forb species included in the experiments, produced, on average, $3.09 \mathrm{tha}^{-1}$ biomass which was below that of black oats and crucifers but higher than that of the legumes. These three forb species captured moderate amounts of $\mathrm{N}$ (on average $57.6 \mathrm{~kg} \mathrm{~N} \mathrm{ha}^{-1}$ ).

Averaged over site-years, species mixtures produced a $1.27 \mathrm{t} \mathrm{ha}^{-1}$ higher amount of biomass ( $p$ $<0.001)$ and accumulated $27 \mathrm{~kg} \mathrm{~N} \mathrm{ha}^{-1}$ more nitrogen than pure stands $(p=0.014)$. Two-species mixtures had $1.30 \mathrm{t} \mathrm{ha}^{-1}$ greater biomass than pure stands, but three-species mixtures produced $0.63 \mathrm{t} \mathrm{ha}^{-1}$ less biomass than 2-species mixtures while production of 4-species mixtures was intermediate between 2- and 3-species mixtures. There was thus no consistent increase of productivity with the number of species in mixtures (Fig. 4.2). Mixtures accumulated more nitrogen than pure stands, irrespective of the number of component species. There were no significant differences in $\mathrm{N}$ yield between mixtures with 2, 3 or 4 species.

a

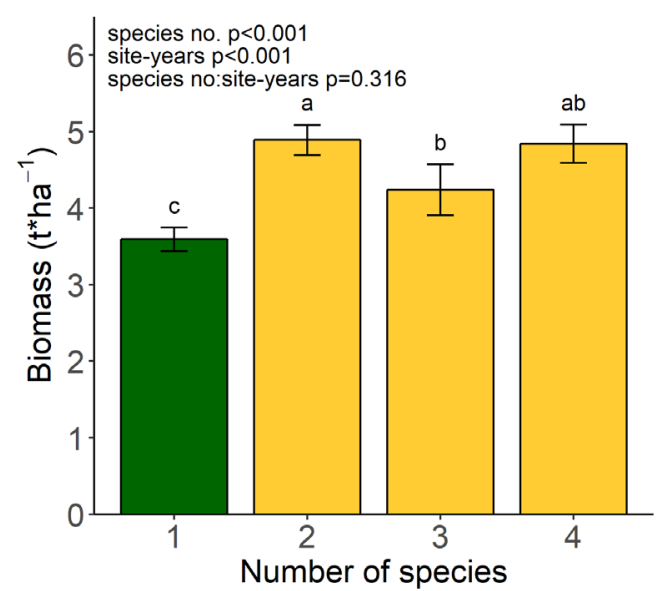

b

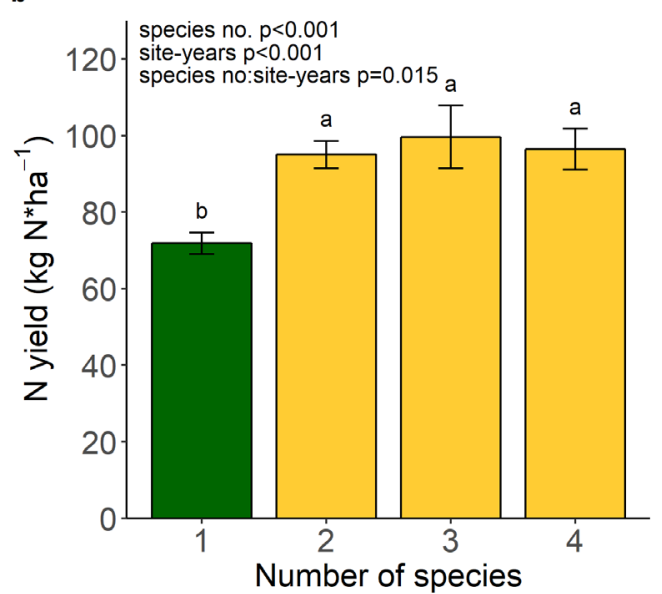

Figure 4.2. Response of biomass (a) and $\mathrm{N}$ yield (b) of winter cover crops to the number of component species within mixtures in 2017 and 2018 at four sites: Grundhof (Germany), and Neer, Scheemda and Wageningen (all three in the Netherlands). Results of a linear mixed effects model with number of species as a categorical covariate. Green bars represent pure stands $(n=12)$, yellow bars represent 2 -species mixtures $(n=6), 3$-species mixtures $(n=2)$ and 4-species mixtures $(n=3)$. Error bars represent $\pm 1 \times$ standard error. Different letters denote significant differences at $\mathrm{P} \leq 0.05$; Tukev HSD test. 
For each species and species mixture, a linear regression was fitted between crop productivity (biomass or $\mathrm{N}$ yield) and the mean site productivity (Fig 4.3). Pure stands varied more in the rate of response to site productivity than mixtures. Among the pure stands, biomass of black oats showed the greatest response (measured as ton $\operatorname{ton}^{-1}$ ) to site mean biomass with slopes ranging from 1.14 to 1.36 . Crucifers had lower slopes than black oats, ranging from 0.76 to 1.20. The smallest slope was observed for legumes ranging between 0.56 and 0.60 . Mixtures had a similar response as crucifers with slopes ranging between 0.84 and 1.29.

$\mathrm{N}$ yield of pure stands varied more than that of mixtures in their response to site productivity, expressed in terms of $\mathrm{N}$-yield. Crucifers showed the steepest increase in $\mathrm{N}$ yield, with slopes (measured in $\mathrm{kg} \mathrm{N} \mathrm{kg}^{-1} \mathrm{~N}$ ) ranging between 1.28 and 1.48, but a very low slope (0.54) was observed for white mustard, the species with the lower slope also for biomass. Slopes of legumes, black oats and forbs (French marigold and phacelia) were mostly smaller than those of crucifers, ranging from 0.72 to 0.98 . Slopes of mixtures were similar to those of crucifers and black oats and ranged between 0.71 and 1.25 .

As shown in the previous analysis, site-year had a great effect on the yield of all treatments. This finding is confirmed by the results of the mixed model with the three variance components:
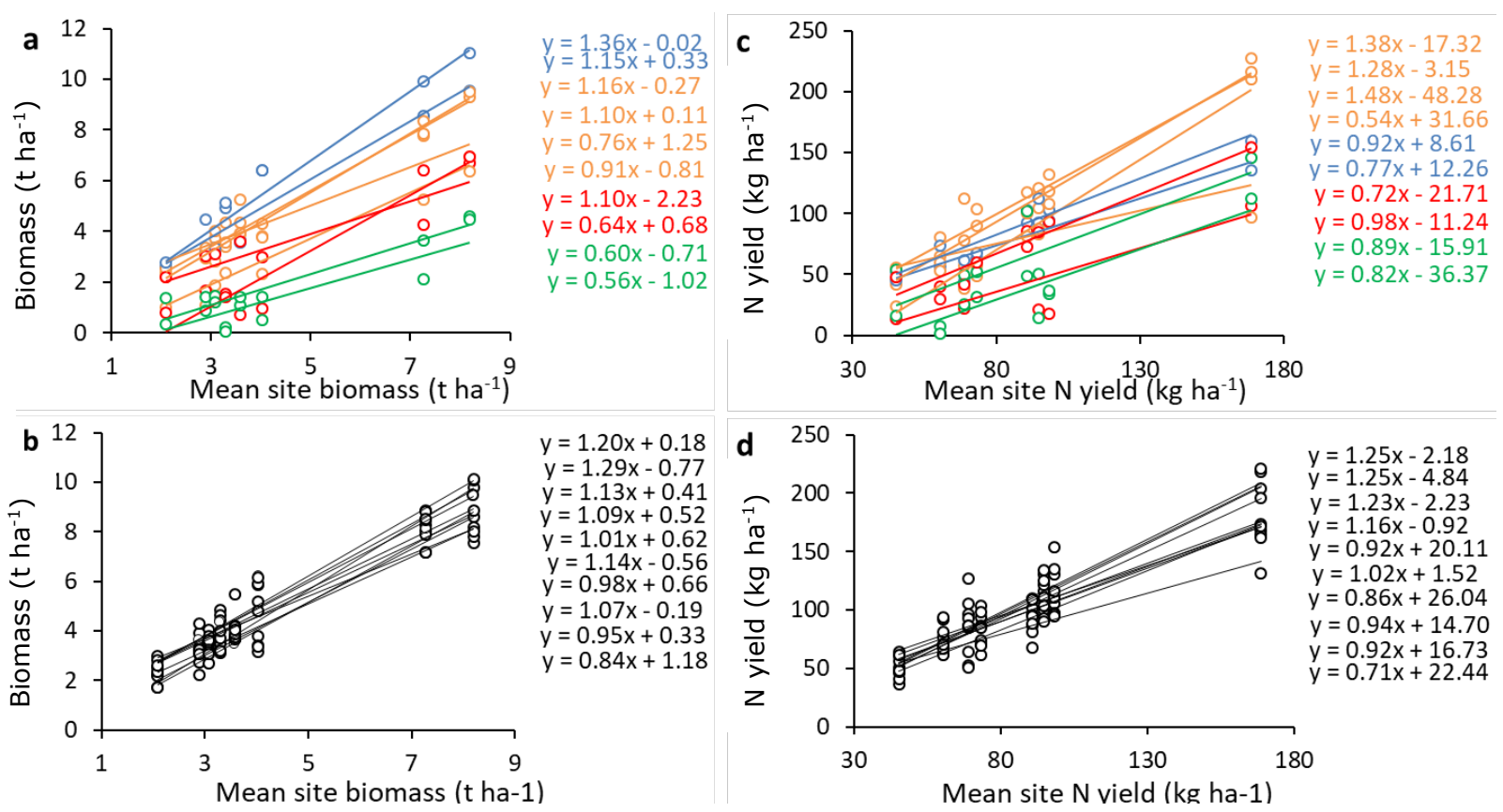

Figure 4.3. Response of biomass ( $a$ and $b$ ) and $N$ yield ( $c$ and $d$ ) of winter cover crops to the site productivity calculated as the average biomass or $\mathrm{N}$ yield of all pure stands (a and $\mathrm{c}$ ) and mixtures ( $b$ and $d$ ) at each site-year. Blue lines represent black oats, orange lines represent crucifers, green lines represent legumes, and red lines represent other forbs. Black lines represent mixtures. 
mixing species did not substantially reduce the variability of biomass and $\mathrm{N}$ yield across siteyears (Fig. 4.4). The ratio of the between-site-year variance for mixtures and for pure stands was not statistically different from one. The ratio of the between-site-year variances of mixtures and pure stands had a wide credible interval, indicating large uncertainty. These results also held when Neer, the site with the higher biomass production, was removed from the analysis.

For both biomass and $\mathrm{N}$ yield, the ratio of the between-treatments variance of mixtures and pure stands was significantly smaller than one. The $95 \%$ credible interval of the variance ratio of the between-species variance for biomass yield was [0.01, 0.23]. Similarly, for N yield, mixtures
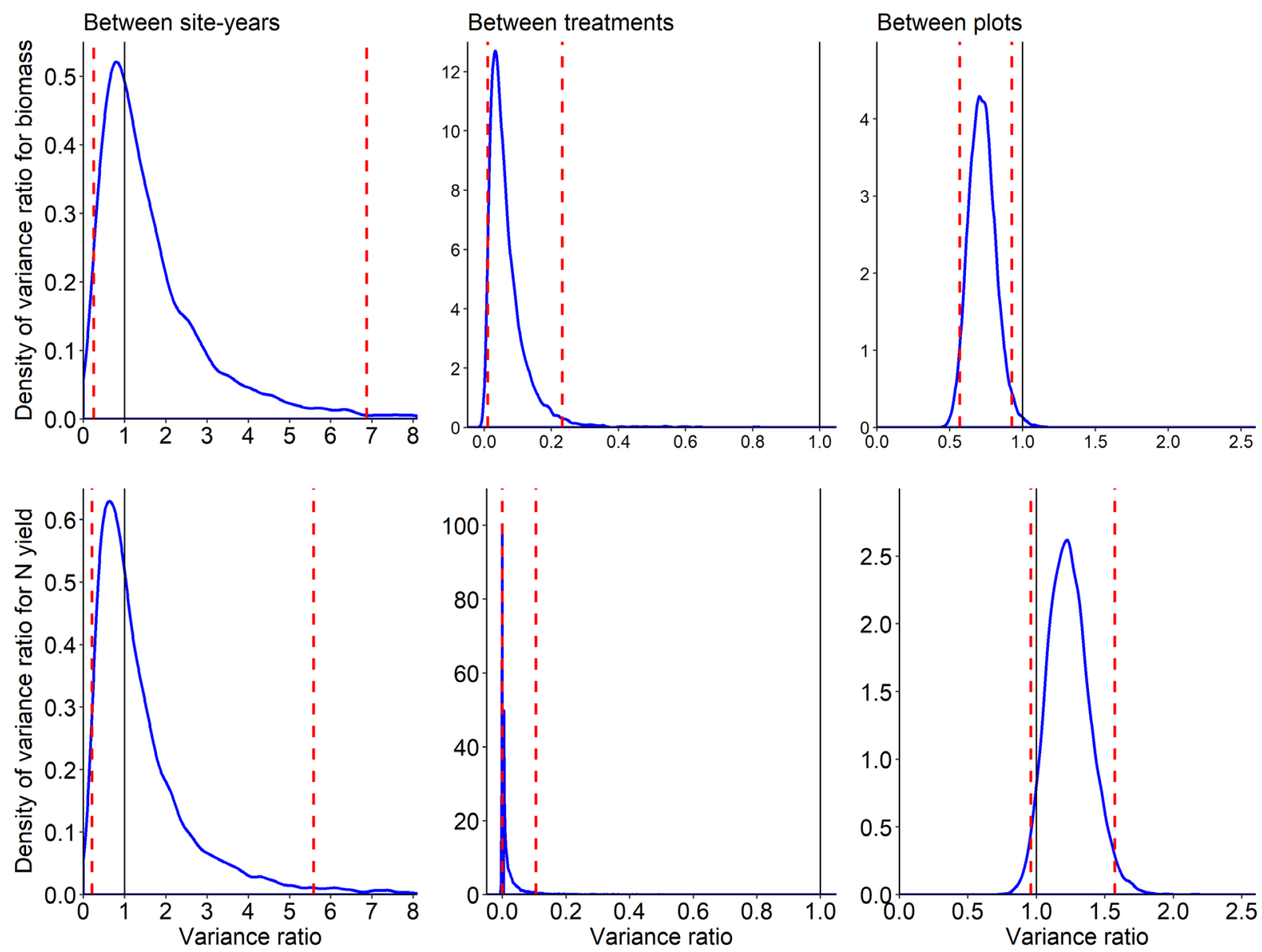

Figure 4.4. Variance ratios of cover crop mixtures over pure stands, calculated for biomass (top three panels) and $\mathrm{N}$ yield (lower panels). The calculated variance ratios reflect three different sources of variability; between-site-years (left panels), between species or mixture compositions within site years (middle panels), and between plots within species or mixture compositions within site-years (right panels). Each panel shows the estimated posterior probability density (blue curve) of the variance ratio, based on a Bayesian estimation of parameters in a generalized linear mixed effects model using Markov Chain Monte Carlo estimation. The vertical black line refers to the null hypothesis variance ratio of one. The two dotted red lines represent the $2.5 \%$ and $97.5 \%$ credible limits of the estimated variance ratio. Variance ratio $<1$ means that variance of mixtures is smaller than variance of pure stands, and vice versa. 
had a significantly smaller between-treatments variance as compared to pure stands, resulting in a variance ratio with a credible interval $[<0.01,0.1]$. These results show that the variability of biomass and $\mathrm{N}$ yield between different mixtures was smaller than the variability between different pure stands.

Mixing species of cover crops also reduced between-plots (within field) variability of biomass production. The credible interval of the ratio of between-plots variance in mixtures and pure stands was $[0.56,0.91]$ for biomass yield. Such a reduced between plots variability was not observed for $\mathrm{N}$ yield with a credible interval of $[0.96,1.57]$ for the variance ratio for between plots variance in $\mathrm{N}$ yield of mixtures and pure stands.

In a final analysis, we compared the average biomass and $\mathrm{N}$ yield of the five best performing pure stands with that of the five best performing mixtures, thus excluding an effect of the less well performing pure stands (Fig. 4.5). In this analysis, there was no difference in biomass of the five best performing species in pure stand and the best mixtures in any of the eight siteyears of the study. However, mixtures had a higher $\mathrm{N}$ yield than pure stands in 4 out of 8 siteyears. Averaged over site years, the best mixtures accumulated $8.5 \mathrm{~kg} \mathrm{~N}^{-1}(9 \%)$ more nitrogen than the best performing pure stands $(p=0.028)$.

a
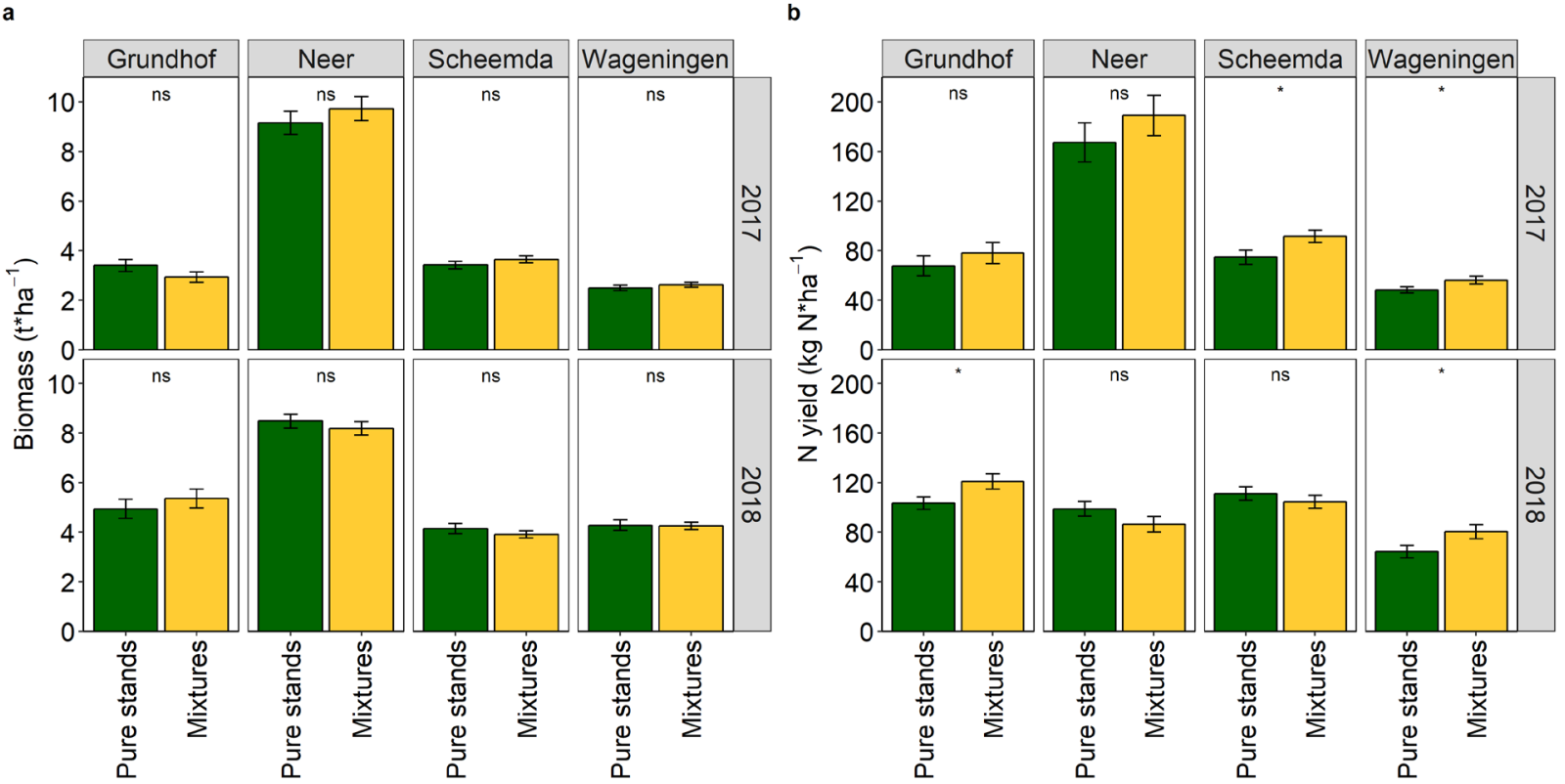

Figure 4.5. Average biomass (a) and $\mathrm{N}$ yield (b) of the five best pure stand treatments of cover crops (green bars) compared to the five best mixture treatments (yellow bars) in eight siteyears, estimated with mixed effect models. Error bars represent $\pm 1 \times$ standard error. ${ }^{*}=\mathrm{P} \leq$ $0.05 ; \mathrm{ns}=\mathrm{P}>0.05$. 
When only the five best performing species for mixtures and pure stands were considered, differences in yield variability disappeared. Results revealed that the between site-year variances were similar in pure stands and mixtures, for both biomass and $\mathrm{N}$ yield. We thus further considered that the five most productive pure stands and mixtures had the same variances.

\subsection{Discussion}

Results of this study give a nuanced perspective on the effect of species mixtures on biomass and $\mathrm{N}$ yield in cover cropping. The overall average biomass and $\mathrm{N}$ capture were greater in mixtures than in pure stands. However, when low yielding pure stands were excluded and the analysis was restricted to the highest yielding pure stands and species mixtures, no difference in biomass production between the mixtures and the pure stands was found. This implies that farmers obtain comparable levels of production whether they choose to grow the best species alone or in a mixture. There was, however, a higher $\mathrm{N}$ yield in mixtures in four of the eight siteyears of the study, with an average increase of $8.02 \mathrm{~kg} \mathrm{~N} \mathrm{ha}^{-1}(9 \%)$.

Several recent studies found higher average biomass production in cover crop mixtures than in pure stands (Finney et al., 2016; Murrell et al., 2017; Blesh, 2018; Florence et al., 2019). In these studies, as in our study, yield of mixtures was equivalent to that of the best performing pure stands, indicating that the lower average yield of pure stands was related to inclusion of species with low productivity. Including less productive species in mixtures is of less importance, as their low performance is compensated through gap filling by better performing species. For instance, in a previous study, we found that gaps in the canopy created by poorly growing winter vetch were compensated by more productive companion species such as black oats and oil-seed radish (Chapter 3).

The average $\mathrm{C}: \mathrm{N}$ ratio of the five best mixtures $(\mathrm{C}: \mathrm{N}=20.6)$ was lower than that of the five best pure stands $(\mathrm{C}: \mathrm{N}=22.7 ; p<0.001)$, which may result in a better mineralization from residues of mixtures than from residues of pure stands. Thus, while biomass of the best mixtures and best pure stands was similar, a better mineralization from residues of mixtures is to be expected due to higher $\mathrm{N}$ concentration (Trinsoutrot et al., 2000; Li et al., 2013). The better capture of nutrients by cover crop mixtures, as compared to pure stands, was also reported by Couedel et al. (2018a) and Couedel et al. (2018b).

Differences in responsiveness to diverse growth conditions were smaller between mixture 
treatments than between pure stands. Legumes were less responsive to the improvement in growth conditions than black oats and crucifers. These findings are in agreement with those reported by Wendling et al. (2019). Moreover, in an earlier food crop study, cereal yield was more responsive to differences in site productivity than legume yield, whereas intercrops of cereals and legumes had the same responsiveness to site productivity as cereals (Faris et al., 1983). Thus, high yielding species benefit more from better growing conditions than low yielding species, resulting in a large variation in responsiveness between pure stands. Mixtures showed similar responsiveness as high yielding pure stands.

Using species mixtures did not reduce variation in biomass and $\mathrm{N}$ capture between sites and years, contradicting the initial hypothesis that mixing species would contribute to stabilization of yield under uncertain and variable environmental conditions. There was a high variability in biomass and $\mathrm{N}$ yield of cover crops between site-years, regardless whether the crop was mixed or sown in pure stand. This finding was also reported by Wendling et al. (2019). The site-year effect has many possible causes, such as differences in soil type, precipitation, temperature, radiation and sowing/harvesting dates. In this study, there was approximately a three weeks difference between the earliest and latest sowing date. Consequently, global radiation and growing degree days were dramatically different across sites, particularly between Neer and the other three sites (Table 4.1). The similarity of the variance between site-years of mixtures and pure stands indicates that using mixtures will not overcome adverse growing conditions related to late sowing and adverse weather. When growing conditions are less favourable in autumn, e.g. due to low temperatures, low radiation levels, or excessive rain and water logging of the soil, mixtures suffer as much as pure stands. In our experiments this was the case in the siteyear Grundhof-2017. On the other hand, favourable growth conditions as in site Neer (in 2017 and 2018) resulted in enhanced growth in both pure stands and mixtures.

In other field studies, contrary to our findings, mixtures of cash crop species (i.e. intercrops) were found to produce less variable yield across site-years as compared to sole crops. From 51 field experiments, despite the large difference in yield levels across site-years, yield variability of pigeonpea-sorghum intercrop was found to be $11 \%$ lower than that of sole pigeonpea and 20\% lower than sole sorghum (Rao and Willey, 1980). Moreover, a global meta-analysis showed that yield variability of cereal-grain legumes intercrop was $25 \%$ lower than that of sole cereals and 37\% lower than that of sole grain-legumes (Raseduzzaman and Jensen, 2017). These different findings on yield stability between the studies on cash crops and cover crops 
may be related to the fact that cash crops are usually grown under more favourable conditions than cover crops. Cash crops are sown when growing conditions are favourable whereas sowing of cover crops is dependent on the harvesting date of the preceding cash crop. Depending on this harvesting date, cover crops can grow under colder or warmer conditions. Further work is needed to elucidate why mixing food crops would stabilize productivity whereas mixing cover crops would not.

The between-treatment variation in biomass and $\mathrm{N}$ yield was lower for mixtures than for pure stands, which was in agreement with the second hypothesis. It indicates that in mixtures there is some degree of "regression towards the mean". The between-treatments variation in productivity is relevant for growers when they make their decision on what to sow. The high variability within the group of pure stands (Fig. 4.4) means that some candidate species are poor performers when it comes to accumulation of biomass or $\mathrm{N}$, while other species or varieties perform much better. Our results indicate that certain species, e.g. berseem clover, common vetch, salad rocket and French marigold, are consistently low yielding (Supplementary Fig. B1 and B2). Such species may be useful for specific purposes, e.g. nematode control or provision of flower resources to beneficial insects, but if the aim is to improve the soil by incorporation of biomass and organic nitrogen, such species may be avoided as pure stands. On the other hand, black oats and crucifers are good candidates if the purpose is to accumulate high biomass and capture high amounts of N. The high yield and low variability of yield in mixtures were probably due to the fact that all mixtures comprised at least one productive species (black oats and/or a crucifer). These high yielding species contributed the most to the biomass produced by mixtures, which is known as the selection effect (Loreau and Hector, 2001). When the low yielding treatments were eliminated from the analysis, the high between-treatment variation within the group of pure stands became significantly smaller and equivalent to that of mixtures. This result is in line with our conclusion that the inclusion of low yielding pure stands was the reason for the initial high between-treatments variability among pure stands.

Spatial variability in biomass production, estimated as between plots variation within a given field and year was reduced in species mixtures as compared to pure stands. Conversely, previous studies on biomass variability of cover crops across plots showed no decrease in yield variability from growing mixtures (Wortman et al., 2012; Smith et al., 2014; Florence et al., 2019). The significant effect of mixing on between-plots variability in our study may be related to larger harvested plot size in our study compared to previous studies. We used harvested plot 
sizes of several $\mathrm{m}^{2}$ in each experiment while previous studies used smaller sample sizes of 0.18 to $1.5 \mathrm{~m}^{-2}$. Using a larger plot size reduces measurement error and would in general tend to increase the power to reject the null hypothesis, which we did in this case. Unlike for biomass, mixtures did not reduce the between-plot variance for $\mathrm{N}$ yield. In most mixtures, we found a positive correlation between biomass yield and $\mathrm{N}$ concentration; plots with higher biomass had slightly higher $\mathrm{N}$ concentration. Moreover, component species within a mixture have different $\mathrm{N}$ concentrations, and therefore the compensation mechanism observed for biomass production does not necessarily result in a reduced variability for $\mathrm{N}$ yield. Consequently, between-plots variance for $\mathrm{N}$ yield did not differ between pure stands and mixtures.

In conclusion, we found that cover crop mixtures that contain productive species have the same biomass and higher nitrogen uptake than the most productive pure stands. We did not find a relationship between the number of component species within a mixture and productivity. Responsiveness to site productivity was more variable between pure stands than between mixtures. Using estimation of variance components with mixed effects models, we compared yield variability between cover crop mixtures and pure stands at three levels: between siteyears, between treatments, and between plots within site-years. The site-year effect on biomass was similar for pure stands and mixtures, implying that mixtures do not even out the variation that is due to variation in growing conditions. However, within each site year, mixtures of cover crops had considerably lower variation across treatments and slightly lower variation across plots than pure stands. These differences in variation between mixtures and pure stands disappeared when only the most productive treatments were used in the analysis. Overall, these results highlight that some complementarity between species did occur, but agronomic consequences in terms of yield increase and yield variability, were less prominent than expected.

The implication for practical farming is that mixtures are good, and at least not inferior to pure stands, as long as they contain high yielding species. Clear evidence was obtained that $\mathrm{N}$ capture is improved in mixtures. Whether mixtures can consistently reduce yield variability in cover cropping would require longer data series than we had in these trials. Long term experiments are needed to assess yield and yield variability in different species and species compositions. Modelling could also help to assist in the evaluation of mixture effects of yield variability.

\section{Acknowledgements}

This study is a part of the Clever Cover Cropping project which is a collaboration between the 
Centre for Crop Systems Analysis (Wageningen University \& Research), the Soil Biology Group, the center for soil ecology (CSE) and the Netherlands Institute of Ecology (NIOOKNAW). This study was supported by a grant from the Netherlands Organization for Scientific Research (NWO green, grant number 870.15.072) with co-financing from seed producers (Agrifirm, Vandinter Semo, P.H. Petersen Saatzucht, and Joordens Zaden).

\section{Appendix B}

Table B1 mean estimates for biomass and variance of mixtures and pure stands.

Table B2 mean estimates for $\mathrm{N}$ yield and variance of mixtures and pure stands.

Figure B1 Average biomass per treatment in 2017 at four sites.

Figure B2 Average biomass per treatment in 2018 at four sites.

Figure B3 Average N yield per treatment in 2017 at four sites.

Figure B4 Average N yield per treatment in 2018 at four sites.

Figure B5 Average N content (\%) per treatment in 2017 at four sites.

Figure B6 Average N content (\%) per treatment in 2018 at four sites. 


\section{CHAPTER 5}

\section{Radiation interception and radiation use efficiency in mixtures of winter}

cover crops

Ali Elhakeem, Wopke van der Werf, Lammert Bastiaans

Centre for Crop Systems Analysis, Wageningen University and Research, Wageningen, the Netherlands. 


\begin{abstract}
Cover crops are sown in autumn after harvest of a main crop to capture residual nitrogen and to build biomass that will contribute to soil organic matter after being ploughed under. Mixtures are purportedly more productive than pure stands of single species. Dry matter accumulation in field crops can be separated in the processes of resource capture and resource conversion. Here we apply this conceptual approach to analyse whether and how pure stands of single species and stands of species mixtures differ in radiation interception and radiation use efficiency. Cover crops were sown as pure stands (12 treatments) or mixtures (11 treatments) at two years in four sites, three in the Netherlands and one in northern Germany. Ground cover was measured throughout a growing period of up to twelve weeks to quantify radiation interception while final biomass was determined at harvest. The ratio of biomass and cumulative radiation interception was used to calculate radiation use efficiency. Oats and crucifers were the most productive species. Crucifers covered the soil quickly and their radiation interception was consequently high $\left(517 \mathrm{MJ} \mathrm{m}^{-2}\right)$ but their radiation use efficiency was low $\left(0.80 \mathrm{~g} \mathrm{MJ}^{-1}\right)$. Oats intercepted less radiation (459 $\mathrm{MJ} \mathrm{m}^{-2}$ ) than crucifers but had a higher radiation use efficiency $\left(1.15 \mathrm{~g} \mathrm{MJ}^{-1}\right)$. Legumes had low radiation interception $\left(332 \mathrm{MJ} \mathrm{m}^{-2}\right)$ combined with low radiation use efficiency $(0.64$ $\mathrm{MJ} \mathrm{m}^{-2}$ ) while the group of forb species belonging to other plant families (e.g. Linaceae, Boraginaceae and Asteraceae) had intermediate radiation interception $\left(371 \mathrm{MJ} \mathrm{m}^{-2}\right)$ and radiation use efficiency $(0.84$ $\left.\mathrm{g} \mathrm{MJ}^{-1}\right)$. The radiation interception and radiation use efficiency of mixtures was similar to that of the dominant species in the mixtures, in all cases a crucifer or oats. The analysis of radiation interception and radiation use efficiency in this study indicates that mixture performance was governed by species dominance within the mixture, with the species capturing most of the light determining to a large extent the radiation use efficiency of the mixture as a whole. Results show the importance of including one or more productive species in a species mixture used for cover cropping, i.e. oats or a crucifer. If species with slow initial growth or low radiation use efficiency are included in a mixture to provide particular services, such as flower resources, atmospheric nitrogen fixation or antibiosis against pests, these species should be included in a large enough proportion to enable their establishment in the mixture.
\end{abstract}

Keywords: winter cover crops, mixture, RI, RUE, ground cover, biomass. 


\subsection{Introduction}

Cover crops are grown to provide a wide range of ecosystem services. They are widely used to prevent leaching of nitrogen after harvest of a main crop, to enhance soil quality, control weeds and suppress pests and diseases (Dabney et al., 2001; Sainju et al., 2002; Kruidhof et al., 2009; Steele et al., 2012; Abdalla et al., 2019; Norberg and Aronsson, 2019). Ultimately, growing cover crops is meant to increase the yield of the subsequent cash crop (Chu et al., 2017), and the practice is considered an important component of ecological intensification, a strategy that aims for high system productivity with less agrochemical inputs (Bommarco et al., 2013). The magnitude of the services provided by a cover crop depends on the amount of biomass produced (Blanco-Canqui et al., 2015; Finney et al., 2016). Thus, to assure effective cover cropping, there is a preference for using species that are highly productive.

In late summer and early autumn, the period when winter cover crops are usually cultivated, temperature and solar radiation are steadily decreasing, with serious implications for crop production. This is clearly reflected in the potential crop photosynthetic rate of a closed canopy in the Netherlands, which was estimated to gradually decrease from $290 \mathrm{~kg} \mathrm{CH} 2 \mathrm{O} \mathrm{ha}^{-1}$ in June to $50 \mathrm{~kg} \mathrm{CH} 2 \mathrm{O} \mathrm{ha}{ }^{-1}$ in December (De Wit, 1959). Therefore, a successful cover crop needs quick soil cover development to allow it to intercept as much as possible of the relatively high amounts of solar radiation during the first weeks after its establishment. Next to radiation interception (RI), the efficiency of converting intercepted radiation into biomass, known as radiation use efficiency (RUE), is an important trait to realize a high crop productivity (Monteith, 1977).

In 2014, the EU implemented regulation 641/2014 that has led to payments to farmers as an incentive to introduce mixtures of cover crops (European Commission, 2019). This regulation is based on the idea that cover crops composed of more than one species are more productive and provide greater ecological services than a crop composed of a single species. Comparison between the productivity of pure stands and species-mixtures of cover crops was carried out in previous studies e.g. (Finney et al., 2016; Murrell et al., 2017; Wendling et al., 2017; Blesh, 2018; Florence et al., 2019). In most studies, mixtures of cover crop species were found to produce greater yields than the weighted average of the yields of their component species in pure stand. Frequently, the mixtures produced the same yield as the best performing pure stand species and, in one study, they were even found to produce a greater amount of biomass than the best performing pure stand (Wendling et al., 2017). 
It has frequently been suggested that overyielding by species mixtures is due to niche complementarity between the component species (e.g. Vandermeer, 1992). For instance, mixing species with different rooting patterns and/or shoot architecture allows for greater resource capture than pure stand crops (Zhang et al., 2014). Mixing wheat and maize in strips, for instance, increased the amount of intercepted radiation and yield (Wang et al., 2015). The greater amount of intercepted radiation in the strip system was suggested to result from the greater amounts of radiation intercepted by wheat and maize plants in the border rows. A greater radiation use efficiency can be another explanation for overyielding of species mixtures. In this particular example, it was shown that RUE of the two species was indeed changed. Radiation use efficiency of wheat was significantly increased compared to its pure stand, but this increase was offset by a reduction in RUE of maize (Gou et al., 2017). Mixing species can alter both radiation interception and radiation use efficiency of the component species (van Oort et al., 2020).

Information on radiation interception and radiation use efficiency of individual cover crop species is scarce. It is also unknown how mixing cover crop species affects radiation capture and radiation use efficiency. Therefore, the objective of this study was to investigate how radiation interception (RI) and radiation use efficiency (RUE) vary among cover crop species and how RI and RUE of mixtures of cover crop species relate to that of the pure stands of the species they are composed of. In this study, these aspects were studied for a selection of species that are commonly used as cover crops in Northwestern Europe. We hypothesised that 1) RI and RUE differ among species of cover crops, 2) species with quick ground cover intercept the highest amounts of radiation and 3) mixtures intercept higher amounts of radiation and have higher RUE than that of their component species in pure stands.

\subsection{Materials and methods}

\subsubsection{Site description and experimental design}

This study was conducted at four sites in two consecutive years (2017-2018). One site was in the north of the Netherlands (Scheemda), one in the middle of the Netherlands (Wageningen), and a third in the south of the country (Neer), while a fourth site was situated in northernGermany (Grundhof). Grundhof is about $370 \mathrm{~km}$ further north than Neer, the most southern location. Fields in Grundhof were characterized as sandy-clay soils with $2.1 \%$ and $3.4 \%$ of organic matter in 2017 and 2018, respectively. Soil mineral nitrogen in the top $20 \mathrm{~cm}$ was 25 and $22 \mathrm{~kg} \mathrm{ha}^{-1}$ in 2017 and 2018, respectively. In Neer, soil texture was sandy with $2.5 \%$ of 
organic matter in both years. Mineral nitrogen in topsoil was 46 and $13 \mathrm{~kg} \mathrm{ha}^{-1}$ in 2017 and 2018, respectively. In Scheemda, soil texture was sandy soil with $8.0 \%$ organic matter and 71 $\mathrm{kg} \mathrm{ha}^{-1}$ of mineral nitrogen in 2017 , and clay soil with $6.9 \%$ organic matter and $33 \mathrm{~kg} \mathrm{ha}^{-1}$ mineral nitrogen in 2018. In Wageningen, soil texture was sandy in both years with $3.4 \%$ of organic matter and $20 \mathrm{~kg} \mathrm{ha}^{-1}$ of mineral nitrogen in 2017, and $3.1 \%$ organic matter and $18 \mathrm{~kg}$ $\mathrm{ha}^{-1}$ of mineral nitrogen in 2018 . The details of all sites, including field operations and weather conditions, are summarized in Table 5.1.

In Northwestern Europe, cover crops are used for a range of purposes, like increasing soil organic matter content, nitrogen retention, nitrogen fixation and management of soil-born pests and diseases. Cover crop species used in this study were selected among the species commonly used and officially registered for this purpose (Table 5.2). The species belong to six botanical families: Brassicaceae, Poaceae, Fabaceae, Boraginaceae, Asteraceae and Linaceae. The selected species were divided into four groups: crucifers (comprising two cultivars of oilseedradish, white mustard and salad rocket), oats (comprising two cultivars of black oats), legumes (comprising field beans, common vetch and berseem clover) and a clustering of the species belonging to the last three families, and referred to as 'other forbs' (consisting of phacelia, French marigold and linseed). These groups are characterized by different functional traits and architecture. Crucifers are dicotyledons producing large quantities of biomass and capturing considerable amounts of nutrients. Oats produces large quantities of biomass and captures nutrients well, like crucifers, but belongs to the monocotyledons, providing alternative options for crop rotation. Grasses are represented by just two cultivars of black oats, as this species has been adopted widely by farmers during the last decade. Legumes fix atmospheric nitrogen and thus are beneficial to N-poor soils. Species in the 'other forbs' group have in common that they are usually selected to improve soil health, as they contribute to the regulation of plant-parasitic nematodes, like French marigold to manage Meloidogyne spp. (Hooks et al., 2010) and soilborne diseases, like linseed and phacelia to help manage Fusarium oxysporum (Patkowska et al., 2015).

Based on these four groups, 2-, 3- and 4-species mixtures were composed. Each mixture contained at least one representative from the more productive groups of crucifers and oats. Presence of these two groups was also used to categorize the mixtures in three classes: 1) mixtures with a cruciferous species (Mix cruc ; 2) mixtures with oats (Mix oats) and 3) mixtures with a cruciferous and oats (Mix cruc-oats; Table 5.2). All mixtures followed a replacement design, 


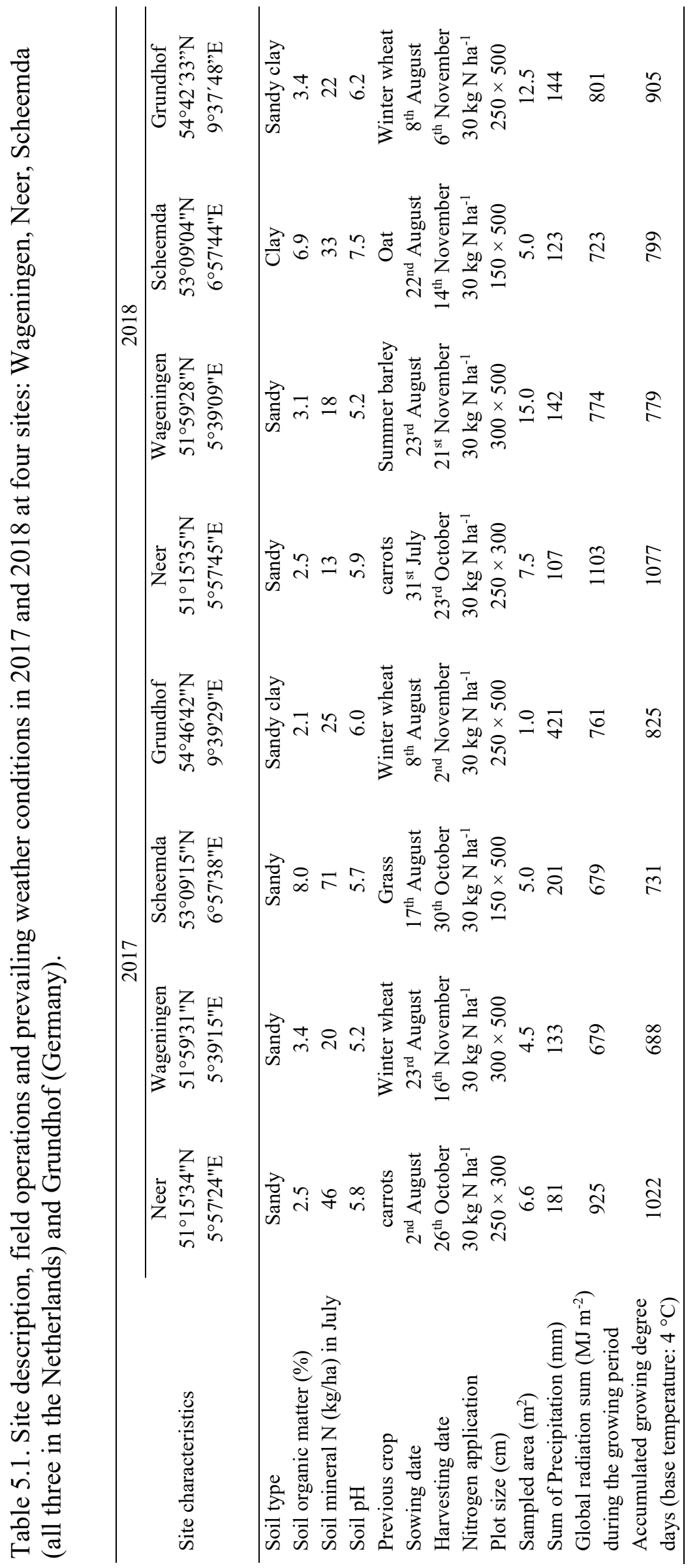




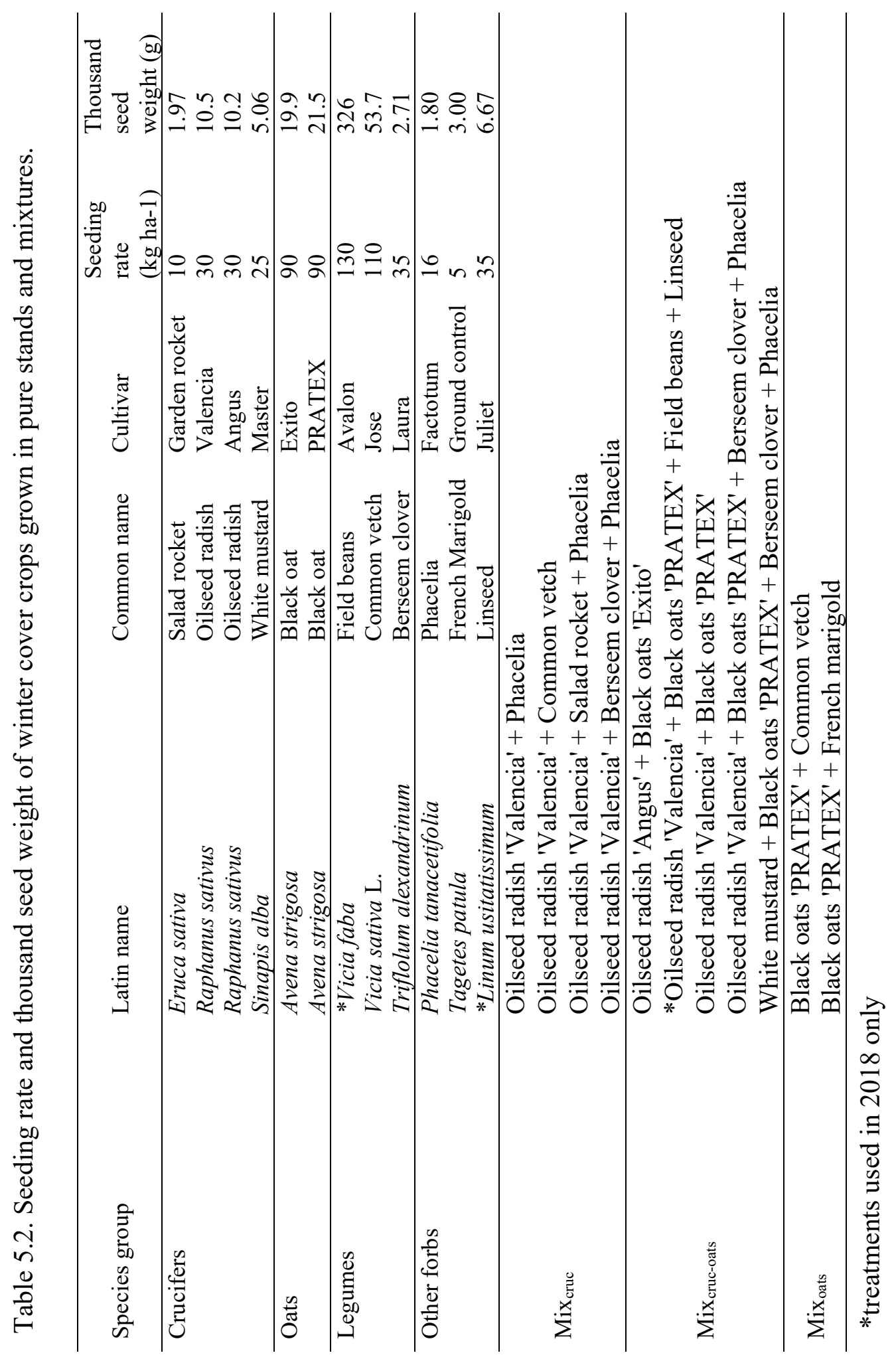


with seeds mixed within the row. To create 2-, 3- and 4-species mixtures, we used 50\%, 33\% and $25 \%$ of the seeding rate of each component species, respectively.

The pure stands and mixtures were grown between August and November in a randomized complete block design with either three or four (Wageningen) blocks. In 2017, each block consisted of 10 pure stands and 10 mixture plots. In 2018, two additional pure stands and one additional mixture were included. Plot area was $15.0 \mathrm{~m}^{2}(3.0 \mathrm{~m} \times 5.0 \mathrm{~m})$ in Wageningen, 12.5 $\mathrm{m}^{2}(2.5 \mathrm{~m} \times 5.0 \mathrm{~m})$ in Grundhof and $7.5 \mathrm{~m}^{2}$ in both Neer $(2.5 \mathrm{~m} \times 3.0 \mathrm{~m})$ and Scheemda $(1.5 \mathrm{~m}$ $\times 5.0 \mathrm{~m}$ ). All species were sown in rows with $12.5 \mathrm{~cm}$ between rows using a $3 \mathrm{~m}$ wide seed planter (Turbo drill, Rape GmbH, Germany) in Wageningen and a $1.5 \mathrm{~m}$ wide planter (belt cone planter, Hege $\mathrm{GmbH}$, Germany) in the other sites. Seeding rate followed the recommendation by the seed supplier (Table 5.1). In both years, the difference between the site with the earliest (Neer) and the latest (Wageningen) sowing date was approximately three weeks.

\subsubsection{Biomass harvesting}

Aboveground biomass was harvested at approximately 12 weeks after sowing. In each plot, plants were harvested using a $1.5 \mathrm{~m}$ wide harvesting machine (Haldrup F-55, Haldrup GmbH, Germany). The harvested area differed between site-years and varied from 4.5 to $15 \mathrm{~m}^{2}$ if harvesting was done with machinery (Table 5.1). In Grundhof in 2017, harvesting was done manually because the wet conditions prevented machine harvesting. In this case, an area of one $\mathrm{m}^{2}$ was harvested from each plot. Total plot fresh weight was recorded by the harvesting machine. From each plot, a randomly selected and shredded sub-sample was provided by the harvesting machine. Sub-samples were oven dried at $70{ }^{\circ} \mathrm{C}$ for 48 hours to determine dry matter content. Subsequently, dry weight of each plot was calculated as the product of plot fresh weight and dry matter content. Additionally, from the mixture plots, an area of $0.5 \mathrm{~m}^{2}$ was handharvested just prior to machine harvest. From this sample, species were separated and oven dried $\left(70{ }^{\circ} \mathrm{C}\right.$ for 48 hours) to determine the relative dry matter contribution of each species in the mixture. In Grundhof in 2017, dry matter contribution of each species was determined from the total harvested area.

\subsubsection{Ground cover}

Photos of ground cover were taken to determine the time course of the fraction of soil covered by plants. In Wageningen, such photos were taken eight times during the season while at the other sites, they were taken five times, at 2, 3, 4, 5 and 8 weeks after sowing. A metal frame $(1 \mathrm{~m} \times 0.75 \mathrm{~m})$ was fixed to a pole and lowered to the top of the canopy to standardize the 
pictures. The camera was mounted on the metal frame at a fixed position, $1 \mathrm{~m}$ above canopy, and pointed vertically downwards. To analyse the fraction ground cover, photos were analysed using DIPimage toolbox for image analysis in MATLAB (MathWorks, 2013). For pure stands and mixtures, fraction of ground cover of a specific site-year was averaged over replicates. Based on these averaged values a logistic model was fit to the observed ground cover data:

$$
G C_{T}=\frac{G C_{\max }}{1+\mathrm{e}^{-s\left(T-T_{50}\right)}}
$$

where $G C_{T}$ is the fraction ground cover at time $T$ (days after sowing), $G C_{\max }$ is the maximum fraction ground cover, $T_{50}$ (DAS) is the time when $50 \%$ of the maximum ground cover was reached, while $s\left(\mathrm{DAS}^{-1}\right)$ is a rate parameter connected to how steep the function rises as it passes through $T_{50}$. Based on this function and the estimated parameter values, fraction ground cover for each day was estimated for all pure stands and mixtures. Based on these daily values, the cumulative fraction ground cover was calculated as the integration of $G C_{T}$ over time.

\subsubsection{Radiation interception (RI) and Radiation use efficiency (RUE)}

Daily radiation interception (RI) was estimated as the product of the fraction ground cover $G C_{T}$ and the global radiation on a specific day. Global radiation data for Wageningen, Neer and Scheemda, were obtained from the Royal Netherlands Meteorological Institute (KNMI; De Bilt, the Netherlands). For Grundhof this information was retrieved from "DWD, Aachen-Orsbach, Germany". For all pure stands and mixtures, in each site-year, RI was accumulated over the growing period to arrive at the cumulative radiation interception (CRI; $\mathrm{MJ} \mathrm{m}^{-2}$ ). Radiation use efficiency (RUE; $\mathrm{g} \mathrm{MJ}^{-1}$ ) of pure stands and mixtures was then estimated as the observed biomass at harvest divided by CRI.

\subsubsection{Data analysis}

In each site-year, logistic curves for ground cover were fitted in R version 3.4.3 (R Core Team, 2018), using the function drm of the package drc (Ritz et al., 2015). Model parameters were then extracted for all pure stands and mixtures using function ddply of the package plyr (Wickham, 2011).

Linear mixed effect models were used to analyse differences in the estimated parameters of the logistic function for ground cover $\left(T_{50}, G C_{\max }\right.$ and $\left.s\right)$ as well as biomass, CRI and RUE. The fixed factor was species or species group. In all models, random factors were set as block nested within site nested within year. Model fitting was conducted using the function lme of the package nlme (Pinheiro et al., 2019). Significance was determined with analysis of variance 
(ANOVA) in R. The assumption of normality and homogeneity of variances was checked. Following the analysis, pairwise comparisons were conducted using Tukey HSD test.

\subsection{Results}

\subsubsection{Ground cover}

The logistic function provided an accurate description of the progress in ground cover of the different pure stands and species mixtures ( $\mathrm{R}^{2}$ ranging from 0.78 to 1.00$)$. In all site-years, all pure stands and mixtures reached full ground cover at some point during the growing period (Fig. 5.1; Supplementary Fig. C1). The time required to cover $50 \%$ of the ground $\left(T_{50}\right)$ and the rate parameter $s$ differed amongst species groups $\left(\mathrm{F}_{6,156}=53.7 ; \mathrm{p}<0.001\right.$ and $\mathrm{F}_{6,156}=20.8 ; \mathrm{p}<$ 0.001 , respectively). Species with the shortest time to reach $T_{50}$ had the largest value for $s$ (the fastest increase in ground cover), and vice versa. Averaged over site-years, crucifers, Mix $x_{\text {cruc }}$

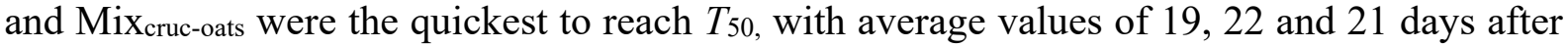
sowing, respectively (Table 5.3). Oats and Mix oats $_{\text {reached }} T_{50}$ at 24 and 26 DAS, respectively. Next in rank was the group of other forbs that reached $T_{50}$ at $34 \mathrm{DAS}$, followed by the legumes that reached $T_{50}$ at 41 DAS. Groups with a short time to reach $T_{50}$ were also the first to reach full ground cover (Fig. 5.1). Among pure stands, crucifers (oilseed radish, mustard and salad rocket) were the quickest to reach full ground cover. They reached full ground cover at around
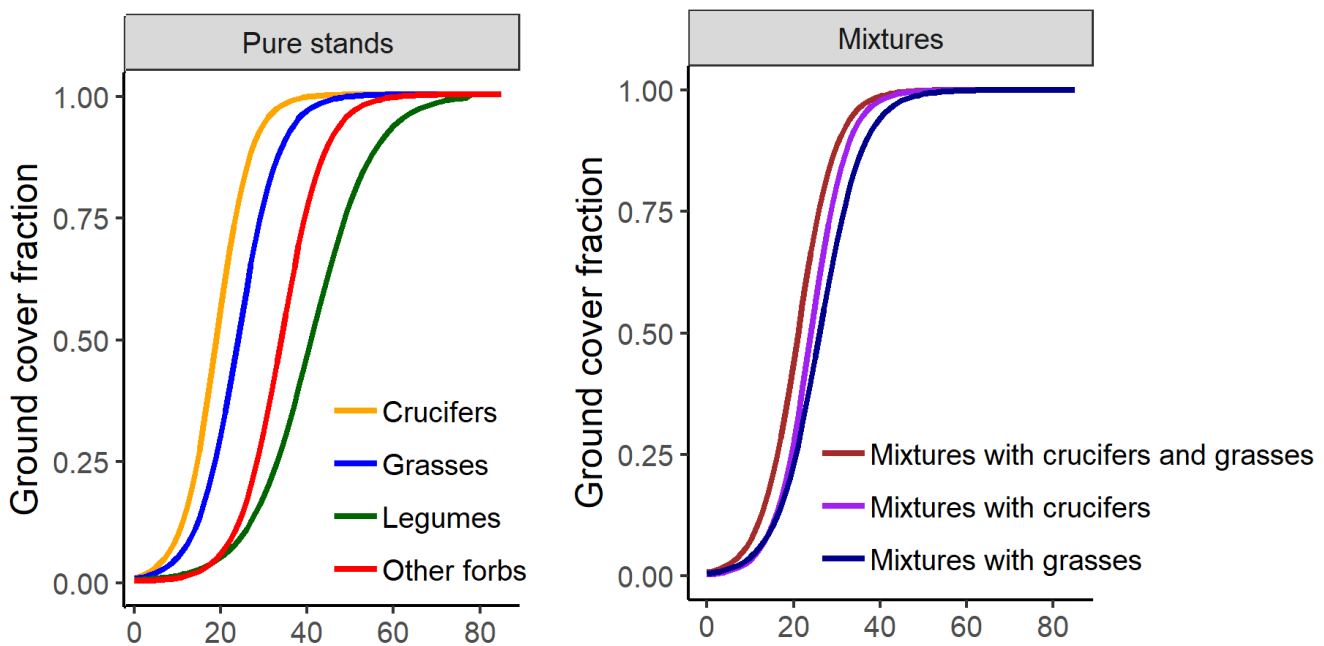

Days after sowing

Figure 5.1. Time course of fraction ground cover of four species groups of cover crops growing in pure stand (crucifers, grasses 'oats', legumes and other forbs) and three species groups of mixtures with either one dominant component species (crucifer or oats) or with two dominant species (crucifers and oats). Logistic functions are based on individual fits of observed ground cover data in eight site-years. All crops were grown between August and November over eight site-years. 


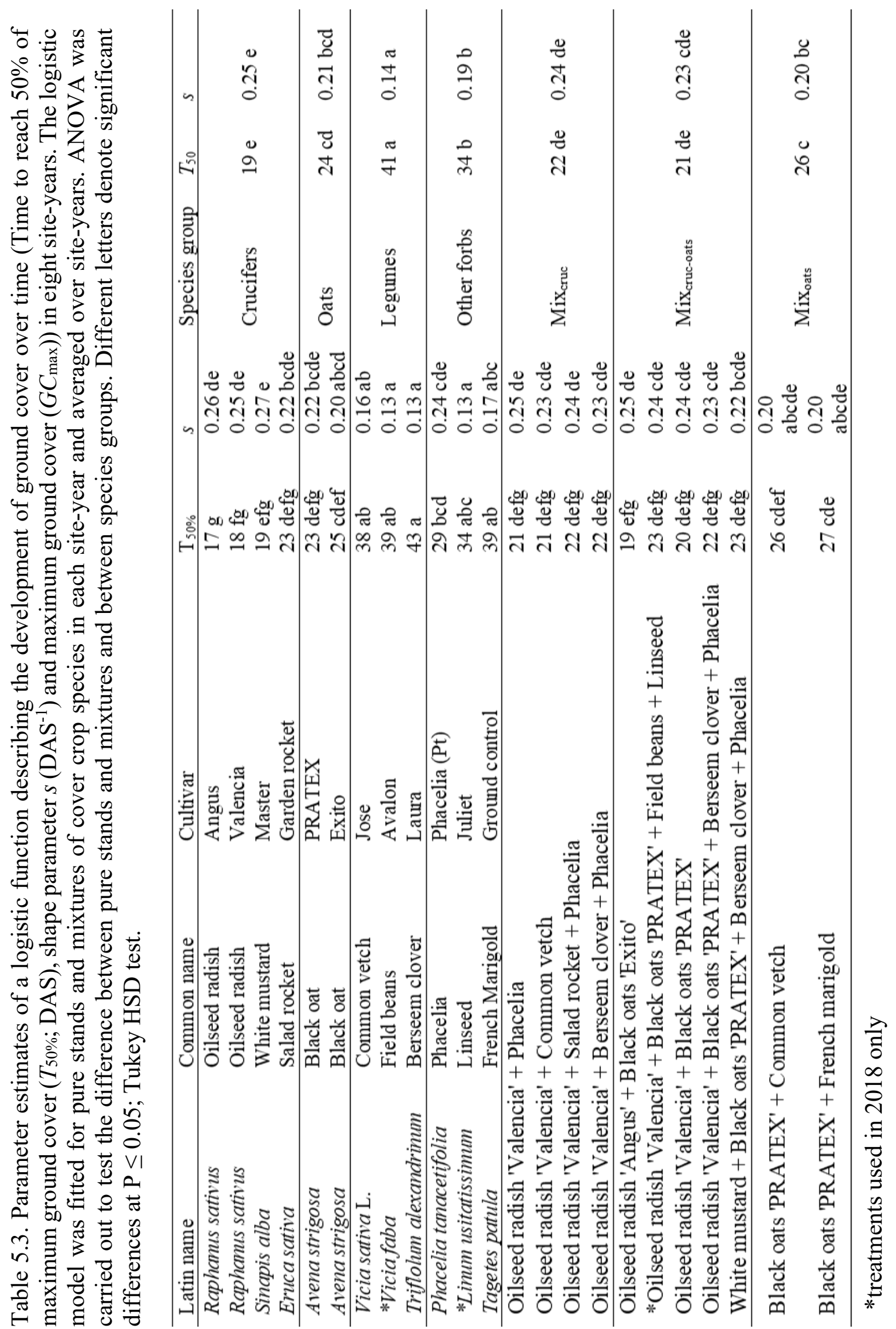


five weeks after sowing. Following crucifers, oats reached full ground cover at around seven WAS, whereas the group of other forbs (phacelia, French marigold and linseed) reached full ground cover at around eight WAS. Legumes (berseem clover, field beans and common vetch) reached full ground cover only at around nine WAS. Soil cover of mixtures was similar or close to that of the pure stand of the fastest covering component species (oil-seed radish and/or black oats). Mixtures with crucifers (Mix $x_{\text {cruc}}$ ) and those with crucifers and oats (Mix full ground cover at around six WAS while mixtures with oats (Mixoats) reached full ground cover at around seven WAS.

\subsubsection{Cumulative radiation interception (CRI)}

Due to the differences in sowing date and global daily radiation pattern during the growing season, there was considerable variation in CRI between site-years. For instance, in Neer the sum of global radiation during the growing period was $925 \mathrm{MJ} \mathrm{m}^{-2}$ in 2017 and $1103 \mathrm{MJ} \mathrm{m}^{-2}$ in 2018. For the other site-years, this value ranged between $679 \mathrm{MJ} \mathrm{m}^{-2}$ in Wageningen-2017 and Scheemda-2017 and $801 \mathrm{MJ} \mathrm{m}^{-2}$ in Grundhof-2018 (Table 5.1). Averaged over site-years, amongst pure stands, the largest amount of global radiation was intercepted by crucifers (517 $\mathrm{MJ} \mathrm{m}^{-2} ; \mathrm{F}_{6,156}=57.0 ; \mathrm{p}<0.001$; Fig. 5.2), followed by oats $\left(459 \mathrm{MJ} \mathrm{m}^{-2}\right)$, whereas the lowest amount of global radiation was intercepted by the other forbs $\left(371 \mathrm{MJ} \mathrm{m}^{-2}\right)$ and legumes $(332$

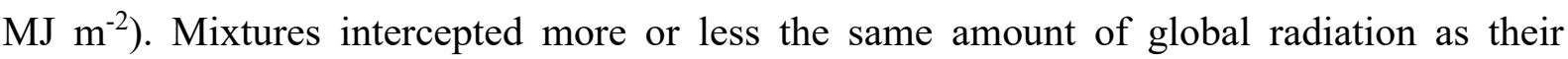
dominant species. The amount of CRI of Mixcruc-oats and Mix cruc was 501 and $495 \mathrm{MJ} \mathrm{m}^{-2}$, respectively, whereas, CRI of Mix oats was $445 \mathrm{MJ} \mathrm{m}^{-2}$.

\subsubsection{Aboveground biomass}

The accumulated amount of biomass was strongly affected by site-year. The average biomass yield in Neer was $820 \mathrm{~g} \mathrm{~m}^{-2}$ in 2017 and $733 \mathrm{~g} \mathrm{~m}^{-2}$ in 2018. Yields were much lower in the other site-years, with the average biomass yield ranging from $268 \mathrm{~g} \mathrm{~m}^{-2}$ (Wageningen-2017) to $370 \mathrm{~g}$ $\mathrm{m}^{-2}$ (Grundhof-2018). Ranking of biomass production of pure stands was site dependent. In Wageningen, Neer and Grundhof, in both 2017 and 2018, the greatest aboveground biomass was produced by black oats. These sites were characterised by a relatively low soil organic matter content (ranging from $2.1 \%$ to $3.4 \%$ ). In Scheemda, the site with a relatively high organic matter content (2017: 8.0\% and 2018: 6.9\%), the greatest aboveground biomass was produced by oil-seed radish (2017) and white mustard (2018). Averaged over site-years, amongst pure stands, oats accumulated the greatest amounts of biomass $\left(556 \mathrm{~g} \mathrm{~m}^{-2}\right)$, followed by crucifers $\left(433 \mathrm{gm}^{-2}\right)$, the other forbs $\left(332 \mathrm{gm}^{-2}\right)$ and legumes $\left(228 \mathrm{~g} \mathrm{~m}^{-2}\right.$; Fig. 5.3; F6,156 $\left.=41.3 ; \mathrm{p}<0.001\right)$. 


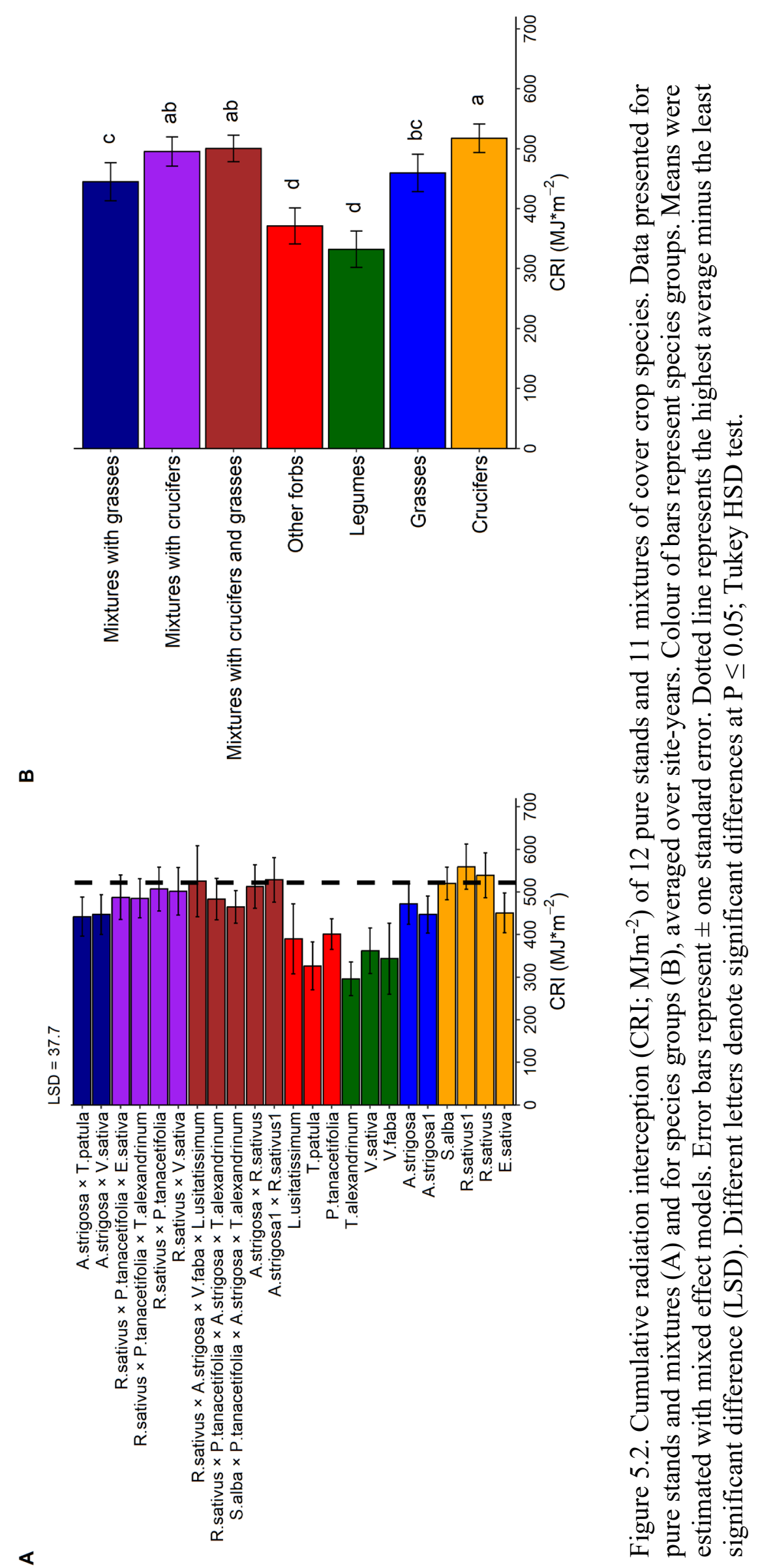




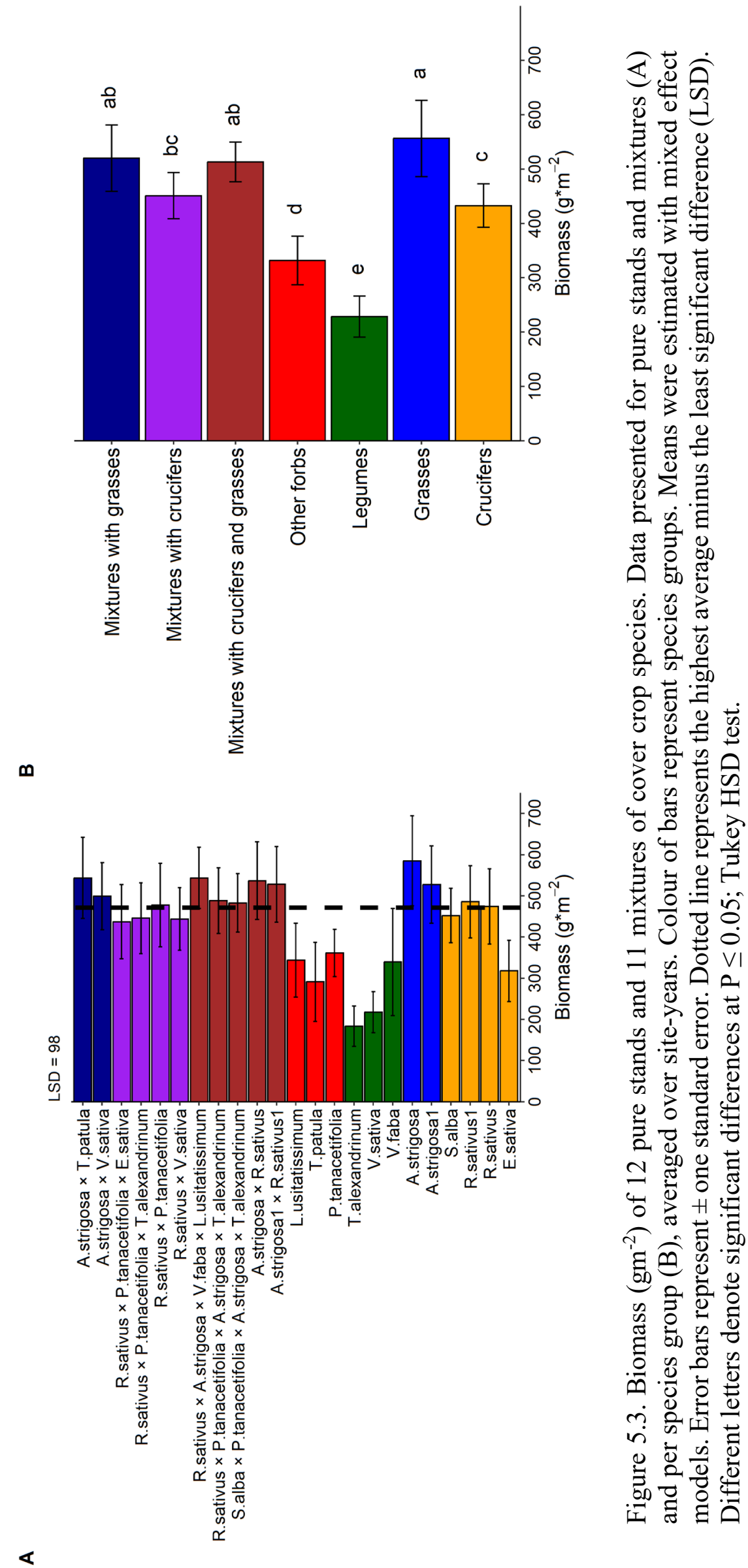


Among crucifer species, salad rocket produced relatively low amounts of biomass. The average production of $318 \mathrm{~g} \mathrm{~m}^{-2}$ was considerably lower than that of the other crucifer species (average $\left.471 \mathrm{~g} \mathrm{~m}^{-2}\right)$.

Biomass of mixtures was largely similar to that of their component species with the greatest biomass in pure stand. Biomass of Mix $x_{\text {oats }}$ and Mix $x_{\text {cruc-oats }}$ was $520 \mathrm{~g} \mathrm{~m}^{-2}$ and $513 \mathrm{~g} \mathrm{~m}^{-2}$, respectively, whereas, biomass of Mix $x_{\text {cruc }}$ was $451 \mathrm{~g} \mathrm{~m}^{-2}$. The highly productive species (crucifers and oats) dominated the mixtures and had the largest share in mixtures biomass (Table 5.4). In Mix ${ }_{\text {oats, }}$ the contribution of black oats to the total biomass ranged from $92 \%$ to 97\%. Similar, in Mix cruc, the contribution of the crucifers was extremely large and ranged from $90 \%$ to $94 \%$. In three of the total of five mixtures that contained a representative of both oats and crucifers (Mix cruc-oats) there were species from the other two groups included. But also in these mixtures their contribution was marginal and most of the biomass (91-94\%) belonged to two most productive groups. In all Mix cruc-oats, the share of the crucifers (58\%-73\%) was larger than that of the oats $(27 \%-38 \%)$. In these mixtures, the contribution of legumes and other forbs was thus small and ranged from $1 \%$ to $8 \%$ for legumes and from $3 \%$ to $9 \%$ for the other forbs.

\subsubsection{Radiation use efficiency (RUE)}

For each species, in each site-year, radiation use efficiency (RUE) was calculated as harvested biomass divided by CRI (Table 5.5). Averaged over site-years, oats was the most efficient species-group in converting intercepted global radiation into biomass with an RUE of $1.15 \mathrm{~g}$ $\mathrm{MJ}^{-1}\left(\mathrm{~F}_{6,156}=36.3 ; \mathrm{p}<0.001\right)$. The RUE of oats was followed by that of other forbs (RUE = $\left.0.84 \mathrm{~g} \mathrm{MJ}^{-1}\right)$ and crucifers $\left(\mathrm{RUE}=0.80 \mathrm{~g} \mathrm{MJ}^{-1}\right)$. The RUE of legumes $\left(0.64 \mathrm{~g} \mathrm{MJ}^{-1}\right)$ was lower than that of all other groups of pure stands. RUE of mixtures with either oats or crucifers was similar to that of the pure stand of these species: Mix ${ }_{\text {oats }}$ had an RUE of $1.13 \mathrm{~g} \mathrm{MJ}^{-1}$, whereas Mix cruc had an RUE of $0.86 \mathrm{~g} \mathrm{MJ}^{-1}$. Mixtures that contained both oats and crucifers had an intermediate RUE of $1.00 \mathrm{~g} \mathrm{MJ}^{-1}$. 


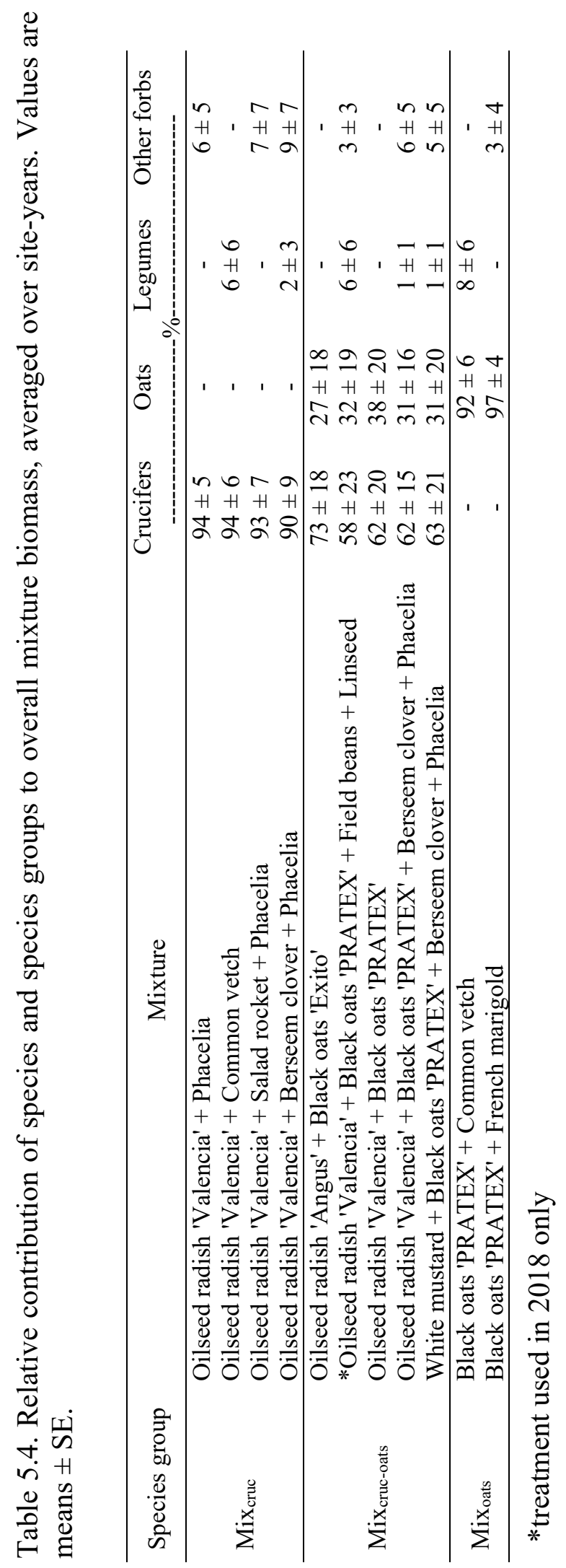




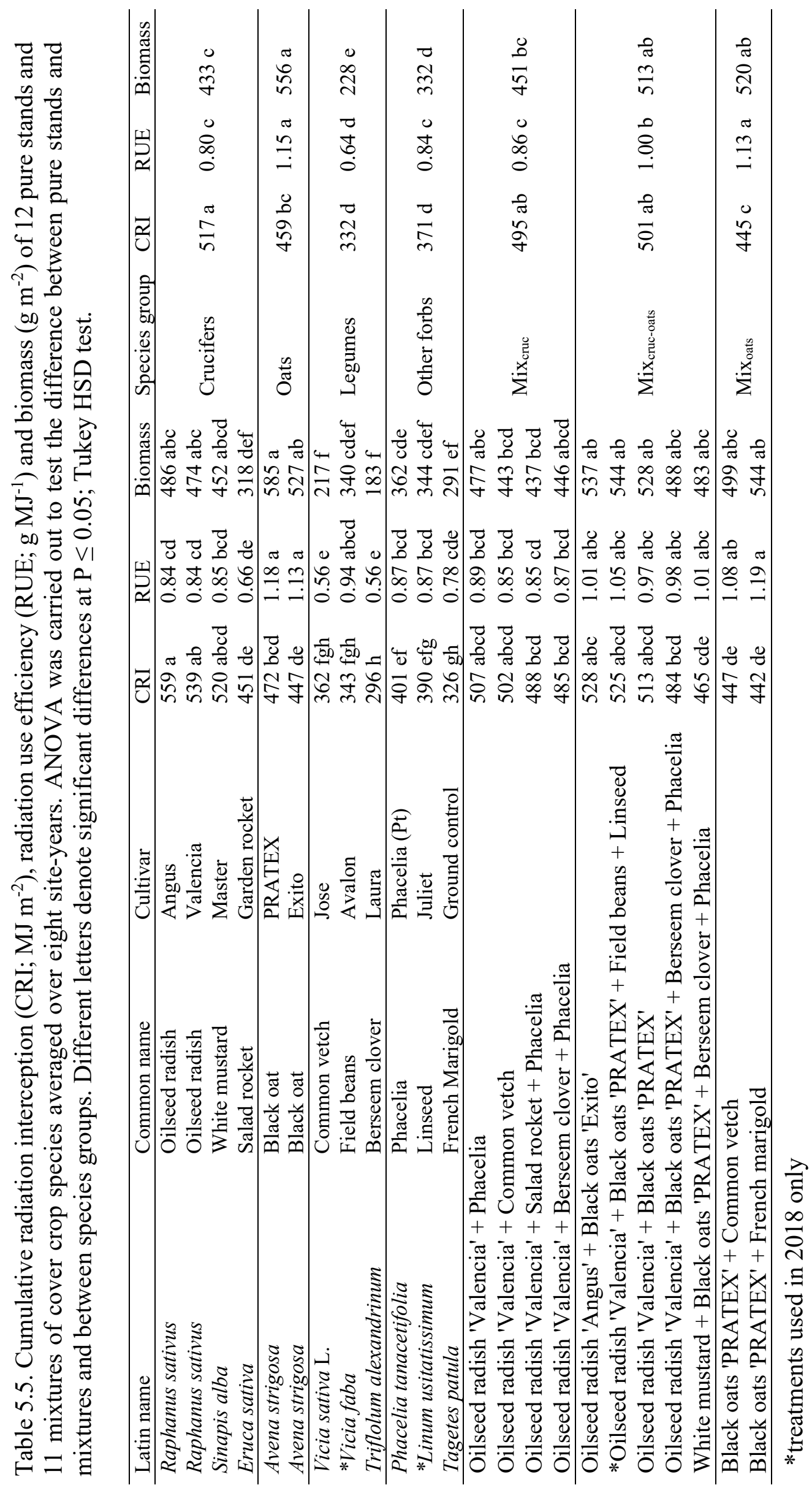




\subsection{Discussion}

\subsubsection{Cover crop species in pure stand}

We observed large differences in radiation interception (RI) and radiation use efficiency (RUE) between the four groups of species when grown as pure stands, which confirm our first hypothesis. Crucifers had the greatest RI but a low RUE, whereas oats had the greatest RUE but intermediate RI. Oats produced a significantly greater amount of biomass than the crucifers. RI of the other forbs and the legumes was low. The other forbs combined this with a weak RUE, comparable to that of the crucifers, but for the legumes, the RUE was very low. Similar to our finding, Li et al. (2020d) found that RUE of common vetch was approximately half that of oats. Consequently, the biomass production of the other forbs was greater than that of the legumes. These observations confirm that if the purpose of a cover crop is to produce a high amount of biomass, oats or crucifers are to be preferred (Chapter 3 ).

The differences between the two most productive groups of cover crops are likely to be related to their leaf orientation. Oats, A. strigosa, is a typical monocot species with an erect leaf orientation. This results in suboptimal light interception, particularly during the first five weeks after sowing when LAI is still relatively low. On the other hand, crucifers, with a horizontal leaf orientation, have the ability to cover the soil very rapidly. This allows them to intercept a high fraction of incoming radiation during the early stages when LAI is still relatively small. This argument is supported by the fact that crucifers $\left(T_{50}=19, s=0.25\right)$ had a quicker development and covered $50 \%$ of the ground faster than oats $\left(T_{50}=24, s=0.21\right)$. These results confirm our second hypothesis that species with early development intercept the highest amounts of radiation.

The differences in leaf orientation not only affect RI, but also have implications for RUE. The more vertical leaf orientation results in a better distribution of radiation within the canopy. Hatfield and Dold (2019) reviewed the literature and found that the photosynthetic rate is affected by leaf position and arrangement. Canopies consisting of plants with upright leaf angles allow for penetration of radiation to the lower canopy layers, resulting in a more homogeneous light distribution over canopy layers and therefore higher canopy photosynthesis (Marchiori et al., 2010; Sarlikioti et al., 2011). This better distribution of radiation within the canopy is usually associated with low light extinction coefficient and high biomass (Zhu et al., 2020). For crucifers, the horizontal leaf orientation leads to a high capture of radiation in the top layers of the canopy, resulting in light saturation and comparatively inefficient conversion of light into 
assimilates. At the same time, this also leads to more shading of the lower layers of the canopy, and a poor contribution of the lower layers to overall canopy photosynthesis. The higher light extinction coefficient and better radiation interception is thus associated with a relatively low RUE (Zhu et al., 2020).

In this study only black oats ( $A$. strigose) was used as a representative of the grasses. The reason is that black oats is known for its high biomass production and it is widely used as a cover crop. This quality of black oats was also demonstrated in Chapter 2, in which we studied the growth characteristics of a wide range of cover crops species. Based on the results of Chapter 2, black oats was the only suitable grass species to be used as winter cover crop that can cover the soil quickly and accumulate large amounts of biomass.

Compared to the other crucifer species, salad rocket was an exception as its ground cover development was slower at the initial growth stage, resulting in lower radiation capture. At the same time, the RUE of salad rocket was relatively low, though not significantly different from that of the other crucifer species. If salad rocket was left out of the comparison between black oats and the other crucifer species (oilseed radish and white mustard) there was no difference in biomass production, despite the lower RUE of the crucifers. In this case, the lower RUE of crucifers was compensated by their greater radiation capture.

Legumes and the 'other forbs', i.e. phacelia, linseed and French marigold had the lowest biomass. Both groups had a much slower soil cover development than crucifers and oats and this resulted in a significantly lower RI. Additionally, legumes and the 'other forbs' had a lower RUE than oats, and lower than both oats and crucifers in the case of legumes. This combination of weak development and low RUE resulted in a lower biomass production than both oats and crucifers. When the purpose of cover cropping is high biomass accumulation, nutrient retention or weed suppression, these species should not be considered as the first choice. These species, however, are useful if the purpose is to fix the atmospheric nitrogen in the soil, as known for legumes (Long, 1989). The other forb species can be used to manage root-lesion nematodes (Pratylenchus penetrans) and root-knot nematodes (Meloidogyne spp.), as shown in studies on marigold (Pudasaini et al., 2006; Hooks et al., 2010; Adekunle, 2011; Ogundele et al., 2016). Phacelia can stimulate the growth of antagonistic microorganisms, like Penicillium spp., that have antagonistic effect against plant pathogens, like Fusarium oxysporum (Patkowska et al., 2015). 


\subsubsection{Mixtures of cover crops}

The species mixtures in this study were categorized according to the presence of representatives of the two most productive species groups. In hindsight, this was a justifiable choice, as the biomass of the mixtures was mostly composed of biomass from these species groups. On average, the crucifer species made up $93 \%$ of Mix cruc, whereas black oats made up 94\% of Mixoats. In mixtures with a representative of either crucifers or oats, the biomass production matched that of the group to which the productive species belonged. Apart from biomass production, this also held for the two components on which biomass production was based: RI and RUE. Mix $x_{\text {oats }}$ thus had a biomass production that did not differ from that of the group of oats and combined moderate RI with good RUE. Biomass production of Mix cruc was not different from that of the group of crucifers and combined good RI with weak RUE. The performance of these mixtures was thus strongly dependent on the identity of the dominant species. That was also shown in earlier studies on winter cover crops (Wendling et al., 2017; Chapter 3) where highly productive species contributed the most to mixture biomass. Hence, we reject the third hypothesis stating that mixtures intercept higher amounts of radiation and have higher radiation use efficiency than their component species.

Including a high yielding species in a mixture may reduce the risk of obtaining a low yield (Wendling et al., 2019), but these dominant species should not be included in a mixture if the purpose of a cover crop is to provide a specific ecosystem service like pest or disease control and this service is provided by a less competitive species in the mixture. In this case, the targeted species that provides this specific service needs to be protected from being overgrown by its companion species, e.g. by a low seeding rate of the more competitive species in the mixture.

Since the production of the two most productive species groups (oats and crucifers) are based on different traits in terms of RI and RUE, introducing representatives of both species in a mixture could potentially result in the greatest biomass production. This would require that RI would evolve to the level of the crucifers, whereas RUE would reach that of the oats. Our analysis shows that in Mix cruc-oats, RI was indeed taken to the level of the crucifers. However, the RUE stayed behind that of the oats and ended up intermediate between that of oats and crucifers. When reasoning about this in a more mechanistic way, this outcome suggests that 'too much' light was intercepted by the high capturing, but poorly converting crucifers. This high RI by the crucifers was at the cost of RI of the oats, which deprived them of the opportunity to raise the RUE of the mixture to the highest level. This reasoning is supported by the relatively 


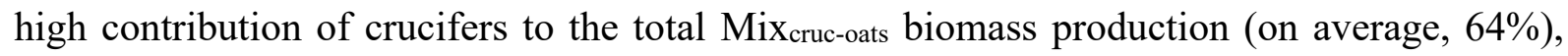
while that of black oats was only half of that (32\%). Additionally, the allelopathic potential of crucifiers can negatively affect the surrounding species (Haramoto and Gallandt, 2005) and might also have contributed to the underperformance of oats in the Mix cruc-oats. Despite the lower contribution of oats, the accumulated biomass of Mix cruc-oats was equal to that of oats or Mix oats (groups with the greatest RUE) and greater than that of crucifers (the group with the greatest CRI). These observations suggest that an optimal production of a mixture of oats and crucifers will only be realized if crucifers are dominant during the first stages of crop development, to guarantee a fast soil cover with maximum RI. However, after these initial stages, when the LAI becomes greater than 1-2, productivity could be enhanced if the oats with its more vertical leaf orientation would overtop the crucifers. A dominance of oats during this later stage might result in a more even light distribution and it could prevent light saturation in the top leaves, thus contributing to a greater RUE at crop level. Only such a combination has the potential to combine a high RI with a high RUE and might thus be able to create transgressive overyielding of the mixture.

The results of this study clearly demonstrate that the selection of the most appropriate cover crop species or species mixture is strongly dependent on the purpose of the cover crop. The specific purposes of the group of other forbs (pest and disease suppression) and legumes (Nfixation) seem hard to realize if those species are combined with a high yielding species. The results show that, due to their relatively low RI and RUE, the species are simply outcompeted, making it hard to deliver the ecosystem-services they are intended to provide. Growing them in pure stand seems a better option. If the purpose is to grow a high amount of biomass to contribute as much as possible to the build-up of soil organic matter, the use of mixtures does not comprise such a detriment. Productivity of cover crop species mixtures showed to be comparable to that of the best producing species it contained, but not any better. The inherent trade-off between RI and RUE makes it difficult to realize a species mixture in which both RI and RUE are maximized. Thus, in mixtures that mainly aim to contribute to the build-up of soil organic matter, rather than in quantity, the advantage might be contained in the quality of the produced biomass. This qualitative advantage might evolve from a more diverse composition (Hwang et al., 2015). Risk aversion is also a potential benefit of these mixtures (Wendling et $a l ., 2019)$, as under extremely adverse conditions certain species might fail. In that situation, a mixture acts as insurance against complete failure, as the less affected species will compensate for the poor performance of the sensitive species. Such conditions were not encountered in the 
eight-site years of the current study, but extreme wet conditions severely hampered the growth of Raphanus sativus L. in Chapter 3 in 2015. Typically, in mixtures with A. strigosa and $V$. sativa L., complete crop failure was prevented, as these species (partly) compensated the poor performance of oilseed radish under wet and water-logged conditions.

\subsubsection{Conclusion}

We presented here that RI and RUE of winter cover crops are species dependent and differ widely. Oats and crucifers are the two most productive species groups, but their high productivity is based on a different combination of RI and RUE. Oats combine a high RUE with moderate RI, whereas crucifers combine high RI with a lower RUE. Both patterns eventually resulted in much greater biomass production than that of the other forbs and the legumes. Performance of a mixture was highly dependent on the identity of its dominant species. The combination of oats and crucifers did not exceed the productivity of the oats, the species group with the greatest productivity. In the mixture with both oats, a crucifer and other species, the crucifer took a dominant position, due to its superior radiation capture, which in part explains its high early vigour. As a result, the RI of the mixture was as high as that of crucifers, but RUE was only intermediate between that of crucifers and oats. It is argued that to compose a mixture that makes optimum use of the qualities of both oats and crucifers, one should select for a fast developing, but low growing crucifer species that is later overtopped by oats with vertical leaf orientation.

\section{Acknowledgements}

This study is a part of the Clever Cover Cropping project which is a collaboration between the Centre for Crop Systems Analysis (Wageningen University \& Research), the Soil Biology Group, the center for soil ecology (CSE) and the Netherlands Institute of Ecology (NIOOKNAW). This study was supported by a grant from the Netherlands Organization for Scientific Research (NWO green, grant number 870.15.072) with co-financing from seed producers (Agrifirm, Vandinter Semo, P.H. Petersen Saatzucht, and Joordens Zaden).

\section{Appendix C}

Figure C1 Fraction of ground cover over time of pure stands and mixtures of cover crops.

Figure C2 Scatter plot showing radiation capture and radiation use efficiency of cover crops. 


\section{CHAPTER 6}

\section{Can nitrogen fertilization of winter cover crops promote nitrogen uptake}

\section{and reduce nitrogen-leaching from soil?}

Ali Elhakeem ${ }^{1 \uparrow}$, Rima J. Porre ${ }^{2 \uparrow}$, Ellis Hoffland ${ }^{2}$, Wopke van der Werf ${ }^{1}$, Gerlinde B. De Deyn $^{2}$, Jos van Dam ${ }^{3}$, Lammert Bastiaans ${ }^{1}$

${ }^{1}$ Centre for Crop System Analysis, ${ }^{2}$ Soil Biology Group, ${ }^{3}$ Soil Physics and Land Management Group, Wageningen University and Research, Wageningen, the Netherlands.

"These authors contributed equally to this work. 


\begin{abstract}
Winter cover crops are often grown after a main crop to capture residual nutrients and accumulate biomass that is later incorporated into the soil to increase soil organic matter and to provide nutrients to the following main crop. The growing season of winter cover crops is short; therefore, a starting nitrogen application could kick-start their initial growth which could potentially increase their productivity and reduce nitrogen leaching. We hypothesised that 1) for non-leguminous cover crop species, application of nitrogen improves biomass and nitrogen uptake, and lowers nitrogen leaching, 2) these effects are absent with leguminous species, and 3) mixing species improves biomass and nitrogen uptake and reduces leaching due to complementary nitrogen uptake. In a 2-year field study, 2018 and 2019, we grew oilseed radish (Raphanus sativus L.), black oat (Avena strigosa) and common vetch (Vicia sativa L.), as pure stands and as a 3-species mixture. Five levels of nitrogen fertilizer were applied ranging from 0 to $90 \mathrm{~kg} \mathrm{~N} \mathrm{ha}^{-1}$. All crops were sown in August and harvested 12 weeks later. Shoot and root biomass as well as nitrogen uptake were determined. Mineral nitrogen concentration in the soil pore water below the rooting zone was measured once a month if sufficient rainfall allowed using porous suction cups. We modelled leaching of mineral nitrogen based on the estimated volume of water leached and its mineral nitrogen concentration. Among pure stands, the effect of a starting nitrogen application on biomass was minor and it was only significant for oilseed radish in 2018. However, the recovered amounts of nitrogen were less than the applied amounts. Oilseed radish and black oat were the most productive species. Averaged over nitrogen application levels, their biomass ranged from 5.2 to $5.3 \mathrm{tha}^{-}$ ${ }^{1}$ for oilseed radish and from 4.3 to $5.3 \mathrm{t} \mathrm{ha}^{-1}$ for black oat. The biomass of vetch ranged from 1.5 to 2.9 $\mathrm{tha}^{-1}$. Vetch had higher leaching than other species in 2019. Nitrogen yield of vetch did not respond to nitrogen application, indicating leaching risk with increasing $\mathrm{N}$ input to vetch. Biomass of the 3 -species mixture was at least as high as that of the best performing species. For mixtures, in both years, there was a linear increase in nitrogen yield in response to nitrogen input. We conclude that application of nitrogen fertilizer to winter cover crops growing in sandy soils does not contribute to avoiding nitrogen losses.
\end{abstract}

Keywords: Fertilization, cover crops, $\mathrm{N}$ leaching, biomass, $\mathrm{N}$ uptake 


\subsection{Introduction}

Agricultural intensification has helped to match the increasing global demand for food products, but at the cost of nitrogen $(\mathrm{N})$ losses. During the last decades, increased food production was accompanied by the doubling in global application of agrochemicals $(\mathrm{N}$, phosphorus and pesticides) to our terrestrial ecosystems (Tilman et al., 2001). Ecological intensification was proposed to minimize the use of agrochemicals and replace it by natural mechanisms that provide nutrients, and control pests, diseases and weeds (Bommarco et al., 2013). These services can be obtained from growing cover crops, and therefore cover crops are an important component of ecological intensification (Wittwer et al., 2017; Wittwer and van der Heijden, 2020).

Cover crops are planted during the fallow period between two cash crops. They are not aimed to produce food, feed, fuel or fibre but to provide a range of ecosystem services (Blanco-Canqui et al., 2015). Cover crops capture nutrients and accumulate biomass that is later incorporated into the soil to increase soil organic matter. The incorporated biomass releases nutrients that may increase yields of the main crop (Chu et al., 2017; Sharma et al., 2018). Additionally, cover crops can prevent weed growth (Kruidhof et al., 2009; Brust et al., 2011; Brennan and Smith, 2018), suppress pests e.g., plant parasitic nematodes (Kruger et al., 2013), prevent erosion (De Baets et al., 2011) and they have been shown to enhance soil physical properties (Steele et al., 2012).

Cover crops also play a role in the $\mathrm{N}$ cycle and the $\mathrm{N}$ use efficiency of the agroecosystem. During growth, they scavenge surplus soil nutrients and incorporate them into their biomass (Thorup-Kristensen et al., 2003; Kaspar and Singer, 2011). As a result of N capture, cover crops can decrease denitrification and leaching of mineral $\mathrm{N}\left(\mathrm{NO}_{3}{ }^{-}\right.$and $\left.\mathrm{NH}_{4}{ }^{+}\right)$in autumn $($Behnke and Villamil, 2019). Because cover crops also take up water, not only the concentration of nutrients but also the total volume of water leached is lower (Kaspar and Singer, 2011; Blanco-Canqui, 2018). In the study of Kasper and Singer (2011) all cover crops managed to reduce leaching, but a major difference was observed between the legume in this study (reduction 6\%) and all other crops (average reduction 94\%). A meta-analysis by Thapa et al. (2018) showed that nonlegume cover crops reduced leaching on average by $56 \%$ while leguminous cover crops did not significantly reduce leaching losses compared to fallow soil.

The magnitude of ecosystem services provided by cover crops depends largely on the amount 
of biomass they produce (Blanco-Canqui et al., 2015). Vigorous growth early onwards, given the short growing season in late summer/early autumn, is an important feature of a successful cover crop. A starting application of $\mathrm{N}$ could kick-start the initial growth of the cover crop and this could potentially reduce $\mathrm{N}$ leaching from soil throughout the growth period. High biomass producing species, that take up more water and nutrients, are generally most efficient in preventing N leaching (Blanco-Canqui, 2018; Thapa et al., 2018) and could possibly benefit from an initial $\mathrm{N}$ application. Fertilizing leguminous cover crops, which fix $\mathrm{N}$ from the atmosphere, would probably lead to even more $\mathrm{N}$ leaching.

In temperate regions, cover crops usually receive a starting $\mathrm{N}$ application to ensure quick establishment and to boost growth in autumn. The amount of $\mathrm{N}$ applied differs among countries, regions and even farmers (Smit et al., 2019). For instance, in the Netherlands, the recommended amount of $\mathrm{N}$ fertilization on a sandy soil is $0 \mathrm{~kg} \mathrm{~N} \mathrm{ha}^{-1}$ for vetch and $50 \mathrm{~kg} \mathrm{~N} \mathrm{ha}^{-1}$ for oilseed radish and black oat (van Leeuwen-Haagsma et al., 2019). In a case study by the European commission, farmers from Spain, France, the Netherlands and Romania were asked about cover crop practices. From these countries, between $1 \%$ and $38 \%$ of farmers apply nitrogenous fertilizers to cover crops with the amount of $\mathrm{N}$ added ranging between 2 and $43 \mathrm{~kg} \mathrm{~N} \mathrm{ha}^{-1}$ (Smit et al., 2019). Either way, the application of a starter $\mathrm{N}$ will only be useful if the extra $\mathrm{N}$-captured by cover crops exceeds the amount of $\mathrm{N}$ applied. There are no clear guidelines on how and when to fertilize cover crops. We are not aware of any scientific studies on this topic. The currently available information is limited to general manuals for farmers (van LeeuwenHaagsma et al., 2019).

It is known from natural and agroecosystems that increased species biodiversity can increase resource exploitation, which leads to an increased plant biomass and thus $\mathrm{C}$ and $\mathrm{N}$ accumulation in the soil (Tilman et al., 1996; Fornara and Tilman, 2008; De Deyn et al., 2009; Cong et al., 2014). Rooting depth varies widely among species (Bukovsky-Reyes et al., 2019) and could lead to spatial complementarity in $\mathrm{N}$ uptake, i.e. exploitation of a larger soil volume, uptake of more nutrients and more reduction in $\mathrm{N}$ leaching compared to sole crops (Hauggaard-Nielsen and Jensen, 2005; Miyazawa et al., 2010; Brooker et al., 2015; Heuermann et al., 2019). In a study by Burr-Hersey et al. (2017), they showed, by x-ray tomography, that Vicia sativa L. has more shallow roots, Raphanus sativus L. has a thick taproot and that Avena strigosa has fibrous roots that reach deeper into the soil. Moreover, leguminous species can fix $\mathrm{N}$ from the atmosphere, through biological N fixation (Blesh, 2018; Blesh et al., 2019; Bukovsky-Reyes et 
al., 2019). In a mixture with leguminous species, the growth of neighbouring plants can be increased because of the higher $\mathrm{N}$ availability in the soil. Because of this complementary resource use, cover crops grown in mixtures could thus have a higher residue quality (low $\mathrm{C}: \mathrm{N}$ ) as well as a higher biomass than expected from pure stands. This yield advantage, subsequently, can reduce the amounts of $\mathrm{N}$ that will be leached and return more nutrients to the soil in spring.

In this study we investigate the effect of different levels of mineral $\mathrm{N}$ fertilization on the performance of cover crops and mineral $\mathrm{N}$ leaching during cover crop growth. We compared pure stands of vetch, black oat and oilseed radish and its corresponding 3-species mixture, which were given a starter application of $0,15,30,60$ and $90 \mathrm{~kg} \mathrm{~N} / \mathrm{ha}$. We hypothesized that: 1) for both oilseed radish and black oat, a moderate $\mathrm{N}$ application improves net $\mathrm{N}$ capture and biomass, and lowers $\mathrm{N}$ leaching, 2) $\mathrm{N}$ application for vetch does not affect net $\mathrm{N}$ capture and biomass and increases $\mathrm{N}$ leaching, and 3) mixture of cover crops is more efficient than pure stands in taking up $\mathrm{N}$ and reducing leaching due to complementary $\mathrm{N}$ uptake.

\subsection{Materials and methods}

\subsubsection{Site description}

The field experiments were conducted in the autumn of 2018 and 2019 at the experimental facility of Wageningen University, Wageningen, The Netherlands. Each year, cover crops were sown in August and harvested at maximum standing biomass, in November. Non-destructive measurements were made of soil cover and leachates over time. Cover crop biomass, nutrient content and mineral $\mathrm{N}$ in the soil were determined in November at the harvest. Both experimental fields are located on a sandy soil with a low $(<3 \%)$ soil organic matter content. Residual soil mineral N (in August) in 2018 and 2019 was 19 and $36 \mathrm{~kg} \mathrm{~N} \mathrm{ha}{ }^{-1}$, respectively. The details of the two fields are summarized in Table 6.1.

\subsubsection{Experimental design}

The field experiment consisted of four cover crop treatments: Raphanus sativus L. c.v. Valencia (oilseed radish), Vicia sativa L. c.v. Amelia (vetch), Avena strigosa c.v. Pratex (black oat), and their mixture (oilseed radish + vetch + black oat) and five $\mathrm{N}$ application rates: 0, 15, 30, 60 and $90 \mathrm{~kg} \mathrm{~N} / \mathrm{ha}$ as calcium ammonium nitrate $(27 \% \mathrm{~N}-6 \% \mathrm{CaO}-4 \% \mathrm{MgO})$. The experimental design was full factorial with three replicates ( 4 cover crop x 5 fertilization $\times 3$ replicates $=60$ plots) and was planted in a completely randomized block design. Each plot was $3 \times 5 \mathrm{~m}$. Cover crops were sown at a row distance of $12.5 \mathrm{~cm}$ resulting in 24 rows per plot. Seeding rates were 
Table 6.1. Site description and conducted field operations in 2018-2019. Soil properties were analysed in the topsoil $(0-25 \mathrm{~cm})$.

\begin{tabular}{|c|c|c|}
\hline Site characteristics & Born 4 (2018) & Hoge Hoef 4 (2019) \\
\hline Location & $\begin{array}{l}\text { Wageningen, } \\
51^{\circ} 59^{\prime} 34.724 " \mathrm{~N} \\
5^{\circ} 39^{\prime} 6.803^{\prime \prime} \mathrm{E}\end{array}$ & $\begin{array}{l}\text { Wageningen } \\
51^{\circ} 59^{\prime} 14.976 " \mathrm{~N} \\
5^{\circ} 39^{\prime} 25.593 " \mathrm{E}\end{array}$ \\
\hline Texture & Sand $83 \%$, Silt $12 \%$, Clay $2 \%$ & Sand $78 \%$, Silt $16 \%$, Clay $3 \%$ \\
\hline Soil organic matter $\%$ & 1.7 & 2.7 \\
\hline $\mathrm{C}: \mathrm{N}$ & 13 & 14 \\
\hline Soil $\mathrm{pH}$ & 5.3 & 5.8 \\
\hline Bulk density $\mathrm{g} \mathrm{cm}^{-3}$ & 1.3 & 1.5 \\
\hline Mineral $\mathrm{N}$ in August ( $\mathrm{kg} \mathrm{N} / \mathrm{ha}$ ) & 19.2 & 35.6 \\
\hline Total N (kg N / ha) & 4460 & 3500 \\
\hline Total P (kg P / ha) & 770 & 905 \\
\hline Total K (kg K/ ha) & 335 & 255 \\
\hline Preceding cash crop & Winter barley & Fallow \\
\hline Sowing date & $24^{\text {th }}$ August & $23^{\text {rd }}$ August \\
\hline Harvesting date & $21^{\text {st }}$ November & $25^{\text {th }}$ November \\
\hline $\begin{array}{l}\text { Accumulated growth degree days } \\
\text { (base temperature: } 4^{\circ} \mathrm{C} \text { ) }\end{array}$ & 725 & 750 \\
\hline
\end{tabular}

$30 \mathrm{~kg} \mathrm{ha}^{-1}$ (oilseed radish), $110 \mathrm{~kg} \mathrm{ha}^{-1}$ (vetch) and $90 \mathrm{~kg} \mathrm{ha}^{-1}$ (black oat) according to farmer practice. The thousand seed weights of oilseed radish, vetch and black oat were $10.0 \mathrm{~g}, 51.7 \mathrm{~g}$ and $19.2 \mathrm{~g}$, respectively. Species were mixed according to a replacement design, using, for each of the species, $33 \%$ of the seed rate in the pure stand. Seeds were sown using a Hege 80 belt cone planter. The plots were fertilized shortly after sowing.

\subsubsection{Pore water collection below the rooting zone}

Three ceramic cup samplers (rhizosphere research products, Wageningen) were placed in each plot on an angle of $45^{\circ}$ at a depth of $70 \mathrm{~cm}$ below the soil surface. Pore water samples were stored in the freezer and subsequently analysed for $\mathrm{NO}_{3}{ }^{-}$and $\mathrm{NH}_{4}{ }^{+}$using Segmented Flow Analysis (Houba et al., 2000). The frequency of collecting leachates was once per month, when sufficient rainfall (>5 mm) was predicted (Fig. 6.1). Due to a drought in 2018, there was a large water deficit in the soil and pore water collection was not possible in October even if sufficient rainfall was predicted.

\subsubsection{Cover crop soil cover}

Every week, starting two weeks after sowing, photos were taken in each plot to determine the percentage of soil cover. Photos were taken at a fixed position $(1 \mathrm{~m}$ between canopy and camera) with a camera pointed vertically downwards, mounted on a metal frame. The frame (1 


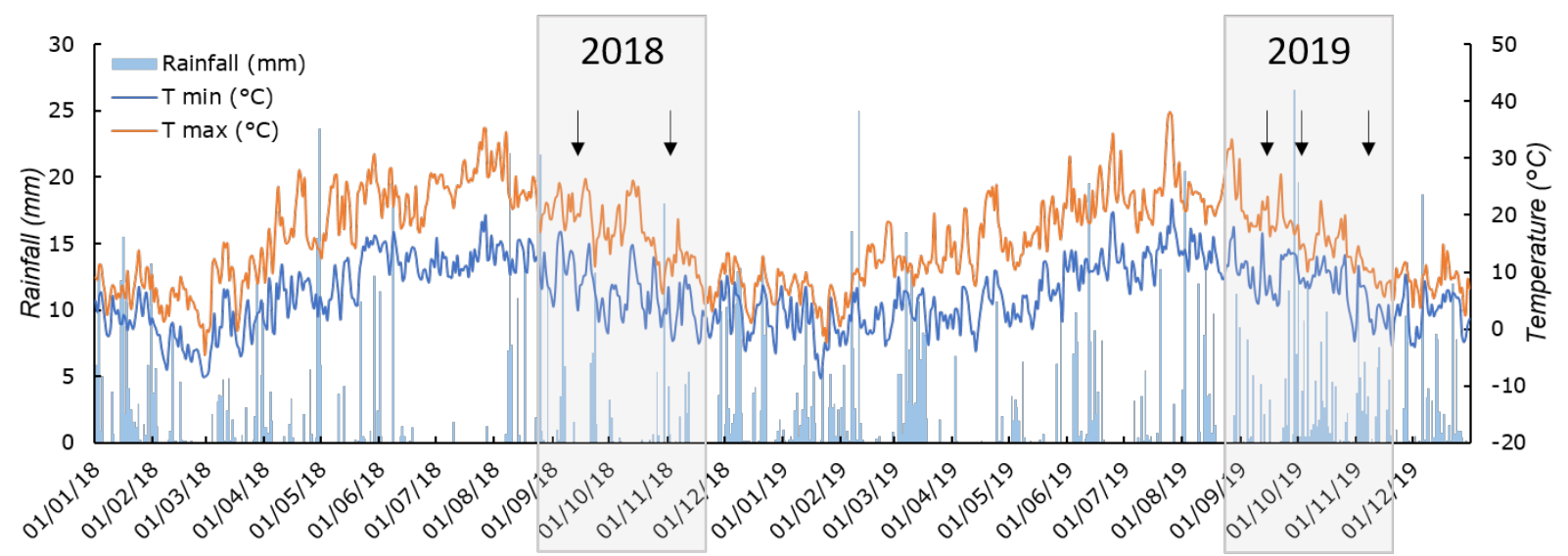

Figure 6.1. Weather data collected from weather station the Veenkampen (Wageningen University). The grey squares indicate the period when the field experiments were conducted. Black arrows indicate collection times of pore water. Due to a water deficit in the soil, pore water collection in October 2018 did not result in sufficient pore water for nutrient analysis $(<1 \mathrm{ml})$.

$\times 0.75 \mathrm{~m}^{2}$ ) was positioned near the top of the cover crop canopy to standardize the area of the picture. This same area used for making the photos was harvested at 12 WAS. Green cover percentage was established by analyzing the photos using the DIPimage toolbox for image analysis in MATLAB (MathWorks, 2013). A logistic model was fit to the observed ground cover data. Fraction ground cover for each day was estimated as:

$$
G C_{T}=\frac{G C_{\max }}{1+\exp ^{-s\left(T-T_{50 \%}\right)}},
$$

where $G C_{T}$ is a fraction of ground cover at day $T, G C_{\max }$ is the maximum ground cover fraction, $T_{50 \%}$ is the time when $50 \%$ of maximum predicted soil cover was reached, while $s$ is a parameter that affects how steeply the function rises as it passes through $T_{50 \%}$.

\subsubsection{Cover crop biomass}

Above- and belowground cover crop biomass was harvested in November of each year, at 12 WAS. Aboveground biomass was cut at ground level in an area consisting of eight rows with a length of $1 \mathrm{~m}\left(1 \times 1 \mathrm{~m}^{2}\right)$ at the center of each plot. In the mixture, cover crop species were separated and analysed separately. Per plot four root cores with an $8 \mathrm{~cm}$ diameter and $30 \mathrm{~cm}$ depth, were extracted. Two cores were sampled in the row and two cores between the rows. Each core was divided into four depth layers, 0-5 cm, 5-10 cm, 10-20 cm and 20-30 cm. Samples from each plot were pooled together per depth layer. Harvested samples were washed to remove adhering sand and organic matter particles, oven-dried for $48 \mathrm{~h}$ at $70{ }^{\circ} \mathrm{C}$ to measure total dry weight. The dried plant materials were ground and analysed for the concentration of $\mathrm{C}$ and $\mathrm{N}$ in shoot and root separately using a $\mathrm{CN}$ elemental analyser. The amount of $\mathrm{N}$ in shoot 
and root was calculated as the product of the multiplication of biomass and $\mathrm{N}$ concentration.

\subsubsection{Net N-capture and N-recovery}

Net $\mathrm{N}$ - capture was calculated to understand the effect of different levels of $\mathrm{N}$ application on $\mathrm{N}$ capture service provided by the cover crops. Net $\mathrm{N}$-capture $\left(\mathrm{kg} \mathrm{N} \mathrm{ha}^{-1}\right)$ was calculated as: $\mathrm{N}_{\text {yield }}-\mathrm{N}_{\text {app }}$; where $\mathrm{N}_{\text {yield }}$ is the total $\mathrm{N}$ in plants, in shoot and $\operatorname{root}\left(\mathrm{kg} \mathrm{N} \mathrm{ha}^{-1}\right)$ and $\mathrm{N}_{\text {app }}$ is $\mathrm{N}$ applied as a fertilizer $\left(\mathrm{kg} \mathrm{N} \mathrm{ha}^{-1}\right)$. Any $\mathrm{N}$ application is advantageous if the net $\mathrm{N}$-capture exceeds that at no $\mathrm{N}$ application. In this case, as compared to no application, plants have taken up more mineral $\mathrm{N}$ from the soil in addition to the amount added as a fertilizer. The optimum $\mathrm{N}$ application rate is, subsequently, the application rate that corresponds to the highest net $\mathrm{N}$ capture value. N-recovery in percent was based on the regression between net $\mathrm{N}$-capture and $\mathrm{N}$ application. If the slope of the regression is positive, then N-recovery will exceed the amount of applied $\mathrm{N}$ and extra amount of $\mathrm{N}$ is recovered by plants from the soil.

\subsubsection{Soil mineral N}

Soil samples were collected each year at two-time points namely at cover crop sowing and at cover crop harvest (12 WAS). Soil samples were collected from each plot to a depth of $20 \mathrm{~cm}$ from five random locations within each plot. We pooled the five samples of each plot together. Soil samples were dried at $40^{\circ} \mathrm{C}$ for 48 hours and sieved over a $2 \mathrm{~mm}$ mesh sieve. The soil mineral $\mathrm{N}$ was determined by extracting dry soil in a 1:10 (w/v) suspension with $0.01 \mathrm{M} \mathrm{CaCl}_{2}$ (Houba et al., 2000). The extracts were analysed with a segmented flow analyser for $\mathrm{NO}_{3}{ }^{-}+$ $\mathrm{NO}_{2}{ }^{-}$and $\mathrm{NH}_{4}{ }^{+}$(SFA; Skalar 6 channel SFA analyser, Skalar, Netherlands, 2003).

\subsubsection{Leachate estimates}

We used the Soil Water Atmosphere Plant (SWAP) model to estimate leaching losses at the plot scale (van Dam et al., 2008; Kroes et al., 2009; Kroes et al., 2017). SWAP simulates the water movement and root water extraction in the soil, which we used to estimate the total volume of water percolation to the subsoil for the entire cover crop growing season, and thus the total amount of $\mathrm{N}$ leached by accounting for the concentrations of mineral $\mathrm{N}$ in the leachates. Rainfall data were obtained from a weather station located on the Wageningen University experimental farm (the Veenkampen); reference evapotranspiration data were obtained from the KNMI (Royal Dutch Meteorological Institute). Crop input data were soil cover and rooting depth (measured in the experiment). We obtained the data of the soil hydraulic properties, according to the soil type, from the handbook of SWAP (van Dam et al., 2008; Kroes et al., 
2009; Kroes et al., 2017). Simulation of water infiltration, redistribution, and percolation in the soil is based on the Richards equation. Root water extraction is based on the potential transpiration, root density distribution and the drought reduction function of Feddes et al. (1978). We assumed a uniform root density distribution. Groundwater levels were estimated based on data from a groundwater well in the vicinity (51 $\left.599^{\prime} 54.6^{\prime \prime} \mathrm{N} 5^{\circ} 39^{\prime} 47.7^{\prime \prime} \mathrm{E}\right)$. The model was initialized with a soil water status assumed at field capacity in January of the modelled year. The amount of $\mathrm{N}$ leached in each plot at each date was calculated by multiplying the mineral $\mathrm{N}$ concentration in the pore water and the simulated volume of water leached on that day (24 hours).

\subsubsection{Data analysis}

All statistics were carried out in $\mathrm{R}$ version 3.5.1 ( $\mathrm{R}$ Core Team). Figures were made using the packages ggplot2 (Wickham, 2016) and cowplot (Wilke, 2019). We tested the effect of cover crop type (factor, 4 levels) and fertilization (factor, 5 levels) on soil mineral $\mathrm{N}$, cover crop biomass, cover crop $\mathrm{N}$ uptake and the amount of mineral $\mathrm{N}$ leached using linear mixed effects models with the function lme from the package nlme (Pinheiro et al. 2016) with 'block' as a random factor. Significance was determined with analysis of variance (ANOVA), anova (base) in R. Type III sum of squares was used when significant interaction between cover crop and fertilization was present. Normality and homogeneity of model residual variances were assessed by plotting model residuals. Data on N leached in September 2018 and November 2019 was not normally distributed and log transformed. Heterogeneous residual variances were addressed using a variance structure in the model with the function varIdent (nlme) (Pinheiro et al., 2019). The model with the variance structure was retained when it was a significantly better fit than the model without, determined by comparing Akaike's information criterion (AIC) using the function anova in R. To determine significant differences between levels of a factor (i.e. between cover crop residues), a Tukey's honestly significant difference posthoc test (HSD) was used, with the function emmeans (Lenth et al., 2019) and CLD from package multcomp (Hothorn et al., 2008). Regression analysis was conducted to test the response of net $\mathrm{N}$ capture to $\mathrm{N}$ application, linear and second degree polynomial functions were tested. After testing the linearity assumption, the linear function was selected. 


\subsection{Results}

\subsubsection{Soil cover by cover crop}

Soil cover by cover crops was not affected by $\mathrm{N}$ application, except for oilseed radish in 2018 . Oilseed radish with no $\mathrm{N}$ applied covered $80 \%$ of the soil, whereas in the treatments with $\mathrm{N}$ applied full soil cover was reached. Except for radish with no $\mathrm{N}$ applied in 2018, all species and the mixture completely covered the soil by the end of their growing period (Table 6.2). Vetch was the slowest species to cover the soil. Averaged over the two years and $\mathrm{N}$ applications, vetch covered $50 \%$ of the soil after the fifth week from the sowing time whereas, black oat, oilseed radish and the mixture covered $50 \%$ of soil around the third week after sowing.

\subsubsection{Cover crop biomass}

Cover crop total biomass varied from 1.5-6.0 $\mathrm{t} \mathrm{ha}^{-1}$ and varied significantly between the cover crop species $\left(2018: \mathrm{F}_{3,38}=91.3 ; p<0.001 ; 2019: \mathrm{F}_{3,38}=66.0 ; p<0.001\right)$. In both years vetch had the lowest biomass; vetch produced 1.5 and $2.9 \mathrm{t} \mathrm{ha}^{-1}$ of biomass in 2018 and 2019, respectively (Fig. 6.2). Among the pure stands, the highest biomass was produced by black oat $\left(5.3 \mathrm{tha}^{-1}\right)$ and oilseed radish $\left(5.2 \mathrm{t} \mathrm{ha}^{-1}\right)$ in 2018 and by oilseed radish $\left(5.3 \mathrm{tha}^{-1}\right)$ in 2019. Compared to the most productive species, the 3-species mixture produced a similar amount of biomass in 2018 and $0.66 \mathrm{t} \mathrm{ha}^{-1}$ higher biomass in 2019. We did not observe any effect of fertilization on biomass except for oilseed radish in $2018\left(\mathrm{~F}_{4,38}=4.50 ; p=0.005\right)$. In this year, oilseed radish biomass was $2.1 \mathrm{t} \mathrm{ha}^{-1}$ higher at $15 \mathrm{~kg} \mathrm{~N}^{-1}$ than at no $\mathrm{N}$ application.

Table 6.2. percentage of soil covered by cover crop species; black oat, oilseed radish, vetch and mixture of the 3 -species at 2,3,4,6 and 8 weeks after sowing. $T_{50 \%}$ represents the time when $50 \%$ of maximum predicted soil cover was reached, represented in days after sowing.

\begin{tabular}{|c|c|c|c|c|c|c|c|}
\hline \multirow{2}{*}{ Year } & \multirow{2}{*}{ Species } & \multicolumn{4}{|c|}{ Percentage of soil covered by cover crops } & \multicolumn{2}{|r|}{$T_{50 \%}$} \\
\hline & & 2 WAS & $3 \mathrm{WAS}$ & $4 \mathrm{WAS}$ & $6 \mathrm{WAS}$ & 8 WAS & DAS \\
\hline \multirow{4}{*}{2018} & Black oat & $8 \%$ & $39 \%$ & $81 \%$ & $98 \%$ & $98 \%$ & 23 \\
\hline & Oilseed radish & $11 \%$ & $42 \%$ & $78 \%$ & $92 \%$ & $93 \%$ & 22 \\
\hline & Vetch & $4 \%$ & $8 \%$ & $16 \%$ & $48 \%$ & $82 \%$ & 43 \\
\hline & Mixture & $9 \%$ & $33 \%$ & $69 \%$ & $96 \%$ & $98 \%$ & 24 \\
\hline \multirow{4}{*}{2019} & Black oat & $12 \%$ & $56 \%$ & $92 \%$ & $100 \%$ & $100 \%$ & 20 \\
\hline & Oilseed radish & $39 \%$ & $87 \%$ & $98 \%$ & $100 \%$ & $100 \%$ & 15 \\
\hline & Vetch & $5 \%$ & $15 \%$ & $34 \%$ & $83 \%$ & $98 \%$ & 32 \\
\hline & Mixture & $19 \%$ & $62 \%$ & $92 \%$ & $100 \%$ & $100 \%$ & 19 \\
\hline
\end{tabular}



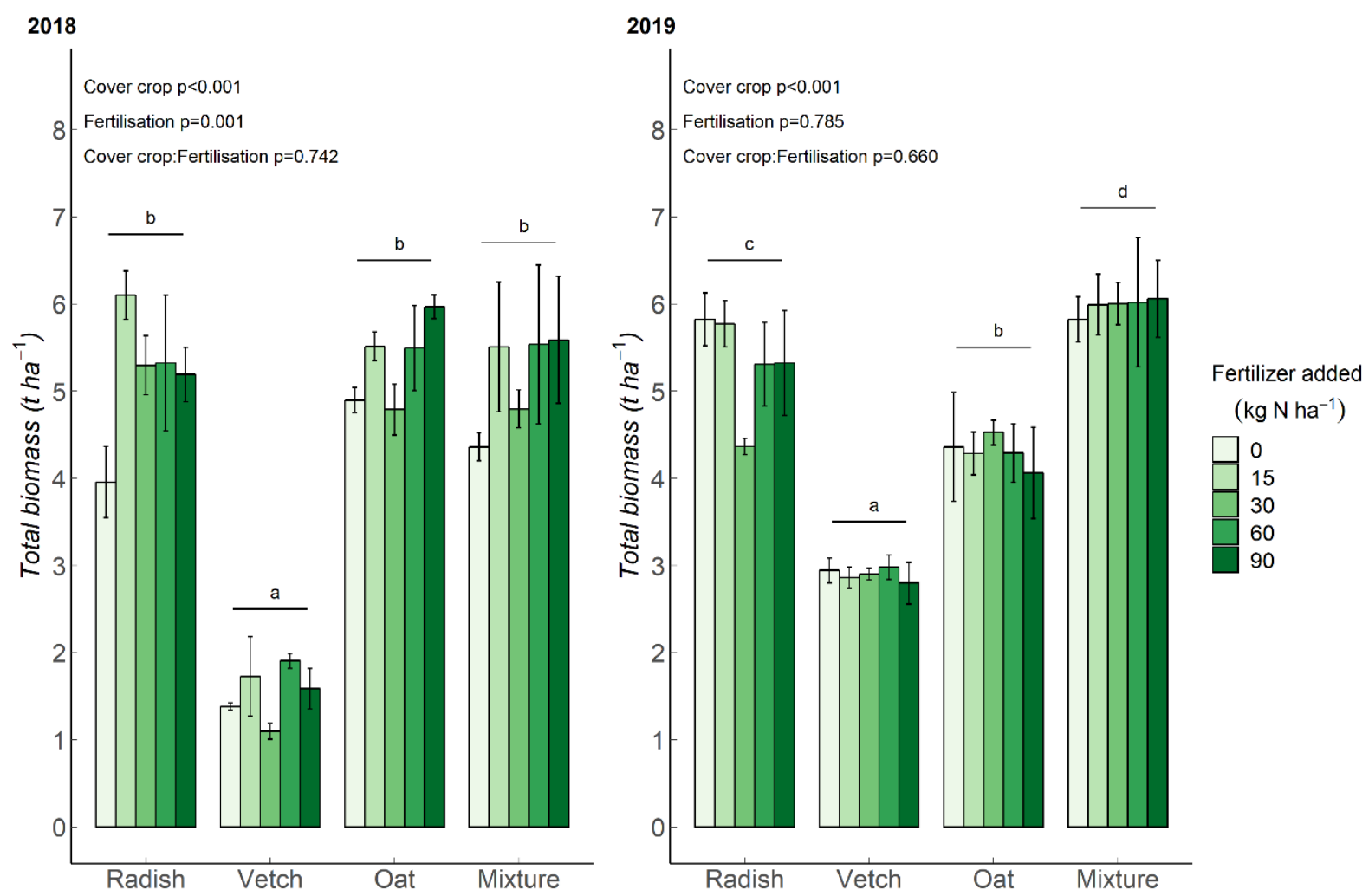

Figure 6.2. Total (aboveground and belowground) dry weight of three species of cover crops: oilseed radish, vetch and black oat and their mixture in 2018 and 2019. Error bars denote the standard error $(n=3)$, different letters indicate significant differences between the cover crops in total biomass $(\mathrm{p}<0.05)$.

\subsubsection{Cover crop $N$ yield}

The concentration of $\mathrm{N}$ in plant tissues varied among species $\left(2018\right.$ : $\mathrm{F}_{3,38}=70.3 ; p<0.001$; 2019: $\left.\mathrm{F}_{3,38}=50.9 ; p<0.001\right)$. Averaged over the 2 years, vetch had the highest $\mathrm{N}$ concentration with an average of $3.6 \%$, followed by oilseed radish $2.3 \%$, black oat $2.0 \%$ and the 3 -species mixture 2.1\% (Supplementary Fig. D1). Following from the biomass and N concentration, N yield was significantly different among the cover crop species $\left(2018: \mathrm{F}_{3,38}=10.1 ; p<0.001\right.$; 2019: $\left.\mathrm{F}_{3,38}=21.9 ; p<0.001\right)$. All species captured more $\mathrm{N}$ from the soil in 2019 than in 2018 (Fig. 6.3). Vetch, though having the highest $\mathrm{N}$ concentration, produced the lowest $\mathrm{N}$ yields as compared to the other species (56 and $105 \mathrm{~kg} \mathrm{~N} \mathrm{ha}^{-1}$ in 2018 and 2019, respectively). In both years, oilseed radish and the mixture captured the highest amounts of $\mathrm{N}$ (oilseed radish $=102$ and $140 \mathrm{~kg} \mathrm{~N} \mathrm{ha}^{-1}$; mixture $=91$ and $151 \mathrm{~kg} \mathrm{~N} \mathrm{ha}^{-1}$ in 2018 and 2019, respectively). Black oat captured a similar amount of $\mathrm{N}$ as oilseed radish and the mixture in 2018 and a similar amount as vetch in 2019 (87 and $102 \mathrm{~kg} \mathrm{~N} \mathrm{ha}^{-1}$ in 2018 and 2019, respectively). The effect of $\mathrm{N}$ application on $\mathrm{N}$ yield was significant in both years. In 2018, except for vetch, there was a linear increase in $\mathrm{N}$ yield as a response to $\mathrm{N}$ application in oilseed radish, black oat and the mixture 

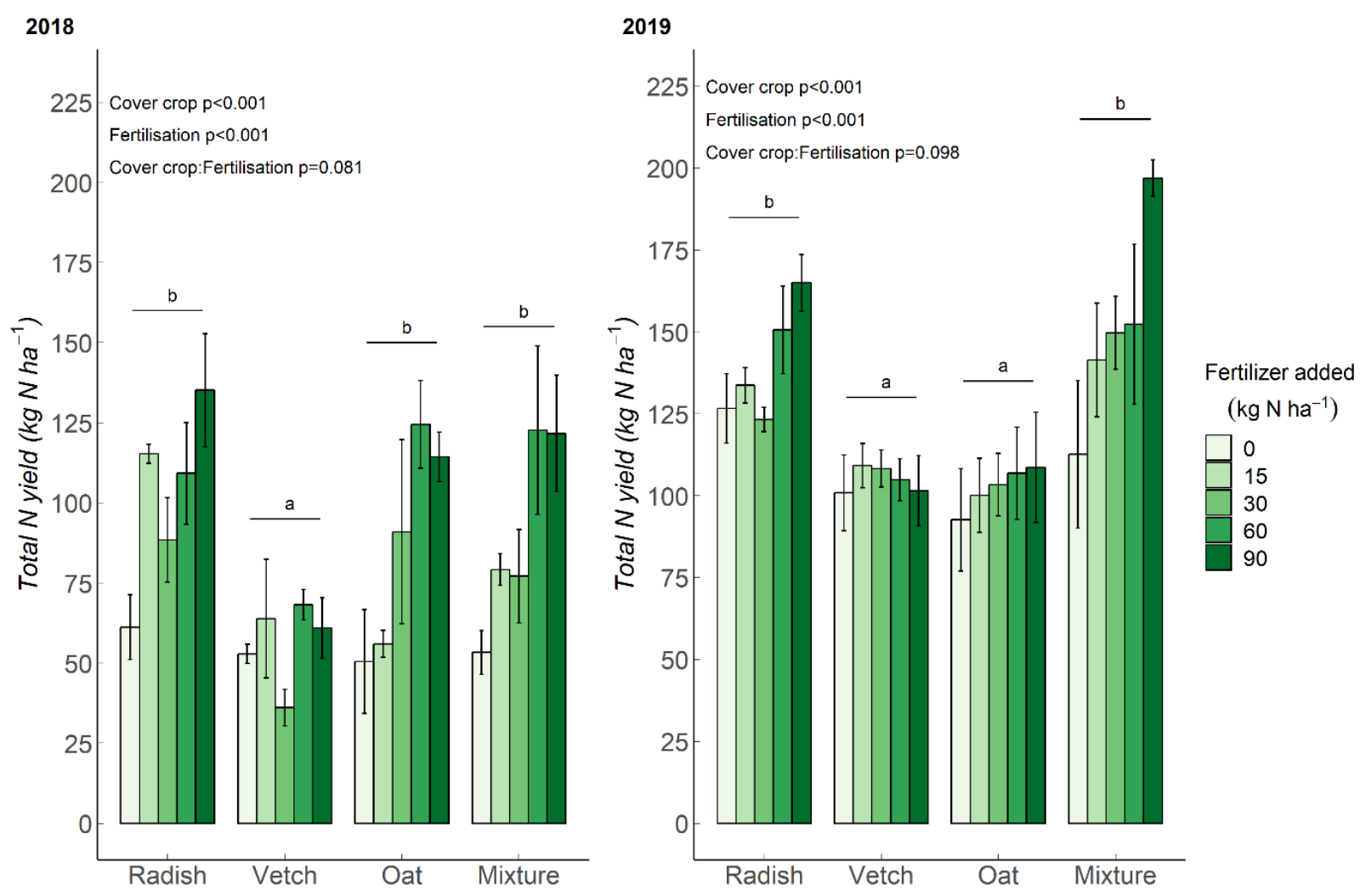

Figure 6.3. Total (aboveground and belowground) $\mathrm{N}$ yield of three species of cover crops: oilseed radish, vetch and black oat and their mixture in 2018 and 2019. Error bars denote the standard error $(\mathrm{n}=3)$, different letters indicate significant differences between the cover crops in total $\mathrm{N}$ yield $(\mathrm{p}<0.05)$.

$\left(\mathrm{F}_{4,38}=11.1 ; p<0.001\right)$. In 2019 , this linear response was only visible in the mixture $\left(\mathrm{F}_{4.38}=\right.$ $4.8 ; p=0.003)$.

\subsubsection{Net $\mathbf{N}$ capture}

Net $\mathrm{N}$ capture either decreased or was not affected by $\mathrm{N}$ application (Fig. 6.4). In 2018, only the net $\mathrm{N}$ capture of vetch showed a negative response to $\mathrm{N}$ application $\left(\mathrm{R}^{2}=0.88 ; p=0.019\right)$, the other crop treatments were not affected. The slope of the regression suggests that, approximately, only $12 \%$ of the applied $\mathrm{N}$ to vetch was recovered in 2018 . In 2019 , when the soil organic matter and soil mineral $\mathrm{N}$ content was higher, net $\mathrm{N}$ capture of all pure stands was negatively affected by $\mathrm{N}$ application. N-recovery differed among species. From the applied amounts of $\mathrm{N}$, oilseed radish recovered $44 \%\left(\mathrm{R}^{2}=0.89 ; p=0.017\right)$, black oat recovered $16 \%$ $\left(\mathrm{R}^{2}=0.99 ; p<0.001\right)$ and vetch recovered $0 \%\left(\mathrm{R}^{2}=0.99 ; p<0.001\right)$. In both years, net $\mathrm{N}$ capture of the mixture was not affected by $\mathrm{N}$ application. 

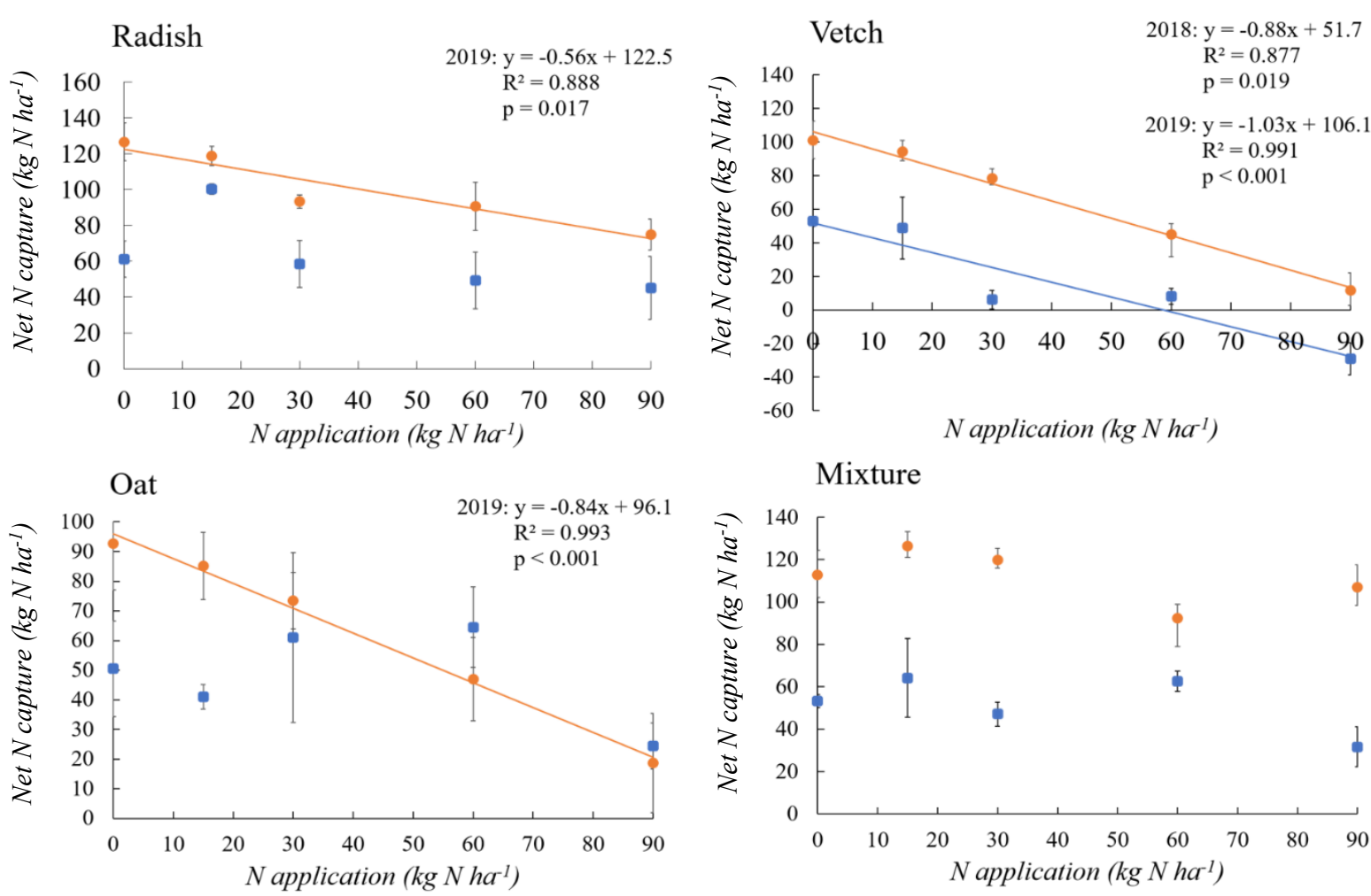

Figure 6.4. Average net $\mathrm{N}$-capture as a response to five levels of $\mathrm{N}$ applications $(0,15,30,60$ and $90 \mathrm{~kg} \mathrm{~N} \mathrm{ha}^{-1}$ ) of three crop species (winter vetch, black oat and oilseed radish) and a mixture of the three species. Blue closed squares represent data from 2018 and orange closed circles represents data from 2019. Net $\mathrm{N}$-capture was calculated as $\mathrm{N}$ yield $-\mathrm{N}$ application in $\mathrm{kg} \mathrm{N} \mathrm{ha-1}$.

\subsubsection{Mineral N leaching}

Pore water collection, and thus analysis of the concentration of mineral $\mathrm{N}$ in the pore water, was done on five different dates (Supplementary Fig D2 and D3). The modelled downward flow of water per cover crop and fertilization treatment (in $\mathrm{m}^{3} \mathrm{ha}^{-1}$ day $^{-1}$ ) differed over time (Supplementary Table D1). In early November 2018, no downward water flow occurred due to a dry spell. Overall, the modelled groundwater flow did not differ much among treatments. Only on October $1^{\text {st }}, 2019$, there was a difference of approximately $2 \mathrm{~m}^{3} \mathrm{ha}^{-1}$ day $^{-1}(=0.2 \mathrm{~mm}$ day $\left.^{-1}\right)$ per treatment. This difference occurred because the soil cover at this time was different between the vetch crop and the other crop treatments (Table 6.2). N leaching could be calculated for the 4 sampling days when downward water flow occurred. The estimated amount of mineral $\mathrm{N}$ leached (in $\mathrm{kg} \mathrm{N} \mathrm{ha}^{-1} \mathrm{day}^{-1}$ ) was, for all cover crops, highest on the $12^{\text {th }}$ of September 2018 (between 0.13 and $0.48 \mathrm{~kg} \mathrm{~N}^{-1}$, Fig. 6.5). On this day $\mathrm{N}$ leaching on average increased with fertilizer rate $\left(\mathrm{F}_{4,36}=3.92, p=0.003\right)$. Mineral $\mathrm{N}$ leached below radish was $\sim 0.3 \mathrm{~kg} \mathrm{~N}^{-1}$ day $^{-}$

${ }^{1}$ higher when $90 \mathrm{~kg} \mathrm{~N} \mathrm{ha}^{-1}$ was applied compared to no $\mathrm{N}$ fertilization. In 2019 there was no 

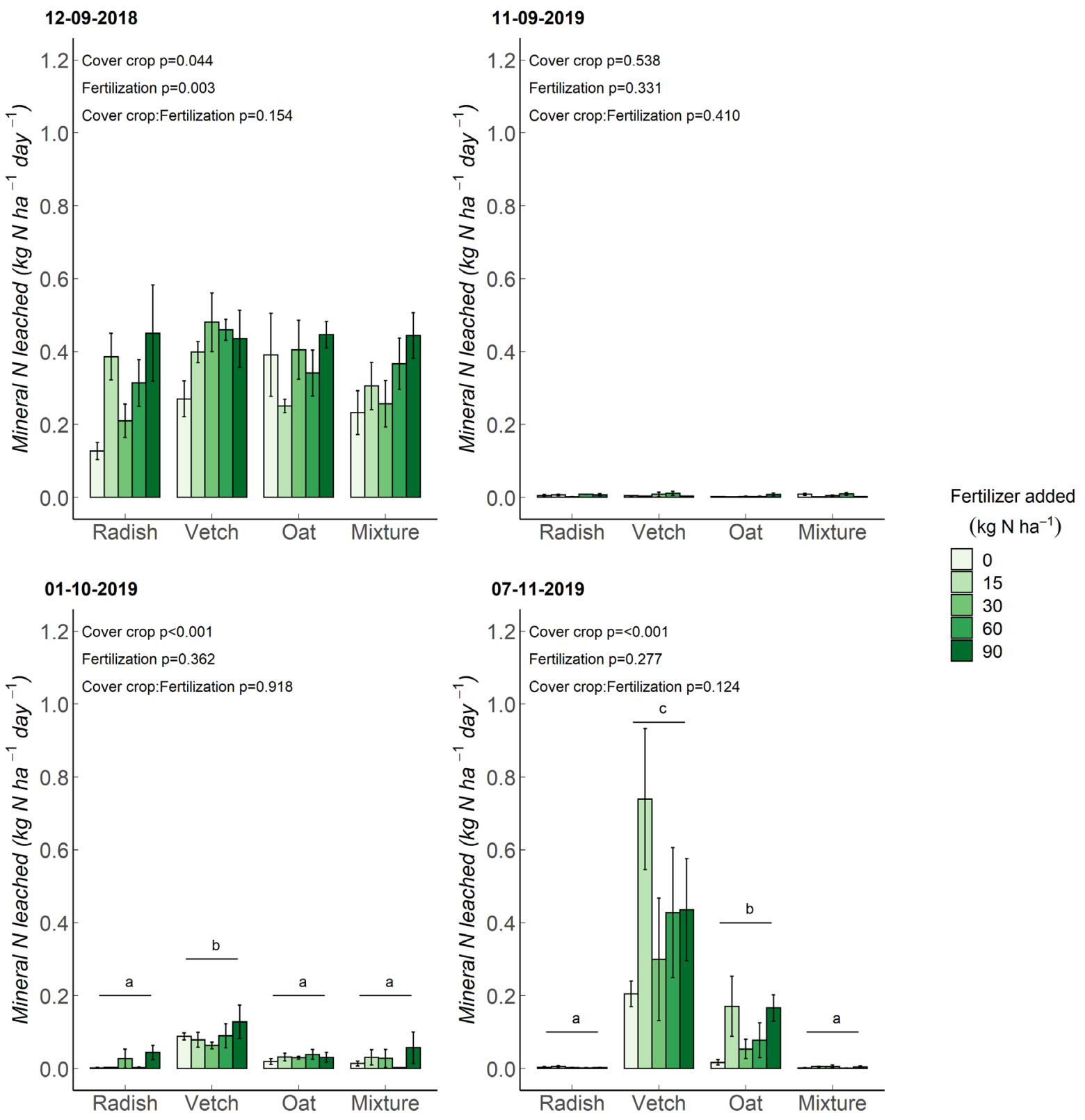

Figure 6.5. Amount of $N$ leached calculated for the $12^{\text {th }}$ of September 2018, the $11^{\text {th }}$ of September 2019, the $1^{\text {st }}$ of October 2019 and the $7^{\text {th }}$ of November 2019. Error bars denote the standard error $(\mathrm{n}=3)$, different letters indicate significant differences between the cover crops $(\mathrm{p}<0.05)$.

effect of fertilization on any of the measured dates. The amount of $\mathrm{N}$ leached was significantly higher below vetch compared to all other cover crop treatments on sampling days in October and November in 2019 (Oct: $\mathrm{F}_{3,33}=39.29, p<0.001$, Nov: $\mathrm{F}_{3,38}=18.84, p<0.001$ ).

\subsubsection{Soil mineral N}

$\mathrm{N}$ fertilization significantly increased soil mineral $\mathrm{N}$ in November of $2018\left(\mathrm{~F}_{4,38}=1.89, p<\right.$ 0.001, Fig. 6.6). In November of 2019 soil mineral $\mathrm{N}$ was significantly higher when vetch or 

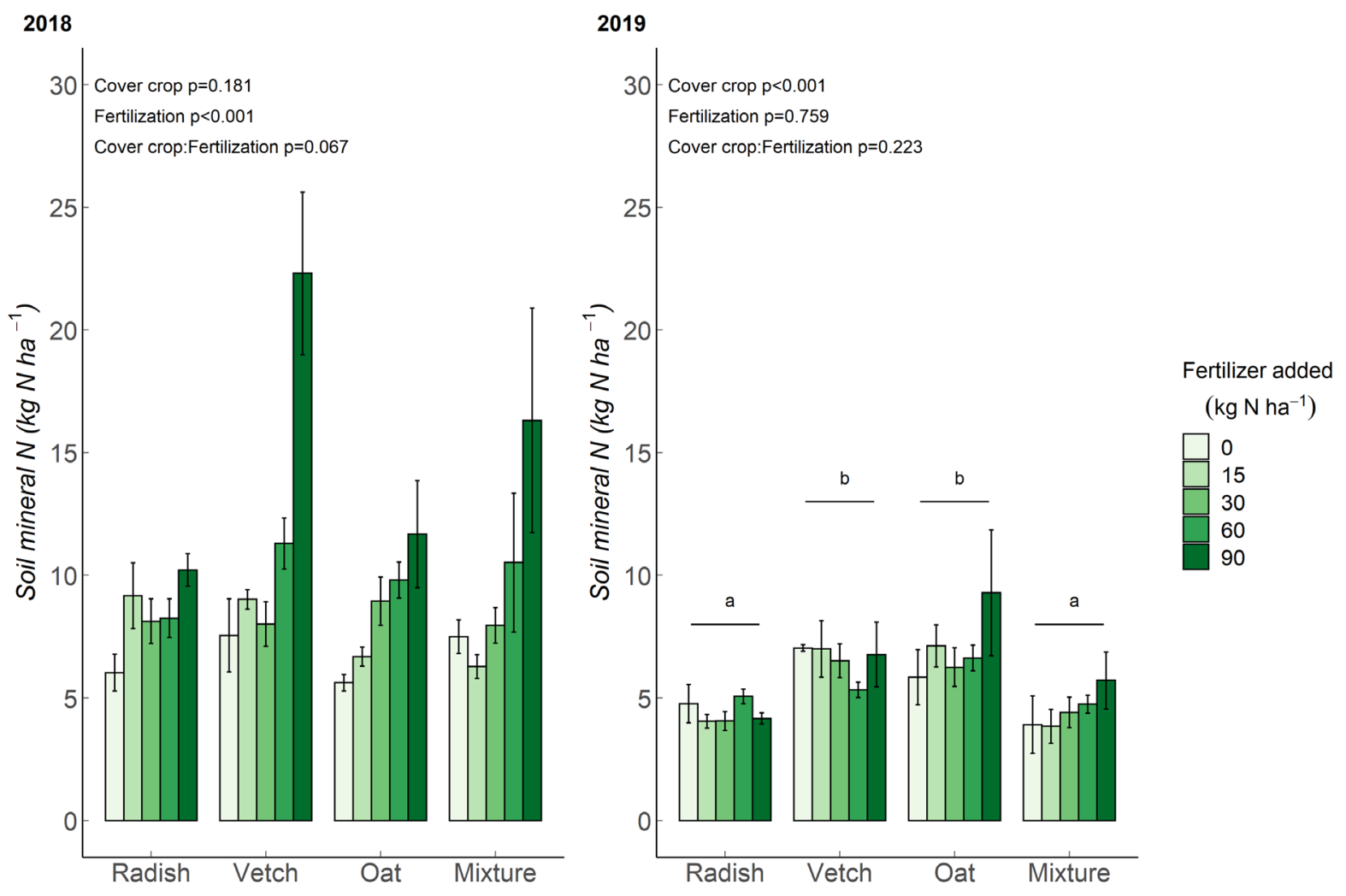

Figure 6.6. Soil mineral N measured at the time of harvest in 2018 and 2019. Error bars denote the standard error $(n=3)$, different letters indicate significant differences between the cover crops $(\mathrm{p}<0.05)$.

black oat was grown compared to oilseed radish and the mixture in $2019\left(\mathrm{~F}_{3,38}=15.32, p<\right.$ 0.001, Fig. 6.5). In 2018 there were no significant differences between cover crops.

\subsection{Discussion}

Our results demonstrate that in most instances, $\mathrm{N}$ application did not significantly improve cover crop biomass. Contrary to our hypothesis, $\mathrm{N}$ application had either no effect or a negative effect on N-capture services by the cover crops and no consistent effect on $\mathrm{N}$ leaching. The identity of crop species has a significant effect on productivity and N-capture service of winter cover crops. Vetch, as a legume growing in autumn, has a slow soil cover and low productivity. Whereas black oat and oilseed radish are more productive and have the ability to capture the residual soil mineral $\mathrm{N}$. It was expected that a starting $\mathrm{N}$ application would further improve their growth and subsequently higher amounts of $\mathrm{N}$ would be captured and less would be prone to leaching to ground water. We showed that, in some instances, only the highest amounts of $\mathrm{N}$ application (60 and $90 \mathrm{~kg} \mathrm{~N} \mathrm{ha}^{-1}$ ) can significantly increase $\mathrm{N}$ capture by cover crops as compared to no $\mathrm{N}$ application (Fig. 6.3). These extra captured amounts of $\mathrm{N}$ ranged between 64 to $84 \mathrm{~kg} \mathrm{~N} \mathrm{ha}^{-1}$, which translates into $75 \%$ to $146 \%$ as compared to the amounts captured at no 
$\mathrm{N}$ application. However, the extra captured amounts of $\mathrm{N}$ by plants were either the same or less than the applied amounts, resulting in a linear negative trend in net N-capture for vetch in 2018 and for vetch, black oat and oilseed radish in 2019. Based on these results, we refute the first hypothesis stating that $\mathrm{N}$ application can improve biomass and net $\mathrm{N}$ capture and reduce leaching under black oat and oilseed radish.

Our results support, in part, the second hypothesis that an $\mathrm{N}$ application to vetch neither improves biomass accumulation nor net $\mathrm{N}$ capture. This was as expected since legume cover crops can fix $\mathrm{N}$ from the atmosphere (Moller and Reents, 2009). Possibly, vetch fixed more $\mathrm{N}$ when $0-15 \mathrm{~kg} \mathrm{~N} \mathrm{ha}^{-1}$ was applied which could explain the similar $\mathrm{N}$ yields in vetch at the different fertilizer applications. As expected, leaching was much higher under the leguminous species (vetch) compared to the non-leguminous species (black oat and oilseed radish), which was previously also shown in the literature (Tonitto et al., 2006; Gabriel et al., 2012; Quemada et al., 2013). This highlights that vetch is not a good crop when you try to reduce leaching losses. Surprisingly, higher application of $\mathrm{N}$ fertilizer did not consistently increase $\mathrm{N}$ leaching losses under vetch, rejecting in part hypothesis two. Under black oat and oilseed radish a similar trend existed in 2019, where $\mathrm{N}$ leaching did not increase at a higher $\mathrm{N}$ fertilization rate. For black oat and oilseed radish, applying $90 \mathrm{~kg} \mathrm{~N}$ ha $^{-1}$ resulted in a $\mathrm{N}$ yield increase of $50-70 \mathrm{~kg} \mathrm{~N}$ $\mathrm{ha}^{-1}$ in 2018 and $20-60 \mathrm{~kg} \mathrm{~N} \mathrm{ha}^{-1}$ in 2019 suggesting that 20 to $70 \mathrm{~kg} \mathrm{~N}^{-1}$ was lost. The difference between the years is most likely attributed to the lower amount of mineral $\mathrm{N}$ in the soil in 2018 compared to 2019 and potentially the lower precipitation in 2018 (Table 6.1). Possibly the dynamics of $\mathrm{N}$ leaching were not constant over time and thus more measurements are needed to capture all $\mathrm{N}$ loss via leaching. Or, $\mathrm{N}$ was lost through another pathway, namely $\mathrm{N}_{2} \mathrm{O}$ or $\mathrm{N}_{2}$ emissions. Nitrous oxide emissions are directly related to the soil $\mathrm{N}$ content and fertilizer application (Syakila and Kroeze, 2011; Butterbach-Bahl et al., 2013).

Biomass of the 3-species mixture was either the same (2018), or higher (2019) compared to best performing monoculture. Beneficial interactive effects for biomass production resulting from mixing species of winter cover crops were also reported in earlier studies (e.g., Finney et al., 2016; Murrell et al., 2017; Wendling et al., 2017; Blesh, 2018; Florence et al., 2019). In the current study, in 2018, black oat was the most productive species and it contributed approximately $66 \%$ to the total biomass in the mixture. While in 2019 , oilseed radish was the most productive species and contributed approximately $72 \%$ to the total biomass in the mixture (data not shown). These compensations by the most productive species played a role in 
stabilizing the yield of the mixture as shown earlier in Chapter 3. Unlike the pure stands, the 3species mixture always captured extra amount of $\mathrm{N}$ with $\mathrm{N}$ application, resulting in no extra losses in both experimental years. Considering the high biomass and the low $\mathrm{N}$ losses of the 3species mixture at the different levels of $\mathrm{N}$ applications over the 2 years, we can therefore accept the third hypothesis stating that the mixture outperforms pure stands. It was earlier shown that root systems as well as $\mathrm{N}$ capture patterns differ greatly among cover crops species (Wendling et al., 2016). Subsequently, mixing different species resulted in complementarity for nutrient capture and consequently yield advantage (Wendling et al., 2017). For the 3-species mixture, the net $\mathrm{N}$ capture is not related to $\mathrm{N}$ application rates. $\mathrm{N}$ fertilization can be beneficial for an increased $\mathrm{N}$-content of the biomass produced; yet risking losses and reducing the $\mathrm{N}$ use efficiency of the system.

Based on this study we conclude that application of mineral $\mathrm{N}$ to winter cover crops does not enhance net N-capture from soil and does not reduce leaching losses. Black oat and oilseed radish are suitable species as winter cover crops due to their high productivity and relatively low leaching losses. Vetch growing in pure stands, should not be used because of relatively high leaching losses. Mixing species of black oat, oilseed radish and vetch showed its potential to enhance biomass while it has similarly low $\mathrm{N}$ losses as oilseed radish and black oat. Finally, policies on cover crop fertilization are not based on clear scientific evidence. Our results suggest that the benefits of $\mathrm{N}$ fertilization are not strong enough to promote fertilization of winter cover crops.

\section{Acknowledgements}

This study is a part of the Clever Cover Cropping project which is a collaboration between the Soil Biology Group and the Centre for Crop Systems Analysis (Wageningen University \& Research), the Centre for Soil Ecology (CSE) and the Netherlands Institute of Ecology (NIOOKNAW). This study was supported by a grant from the Netherlands Organization for Scientific Research (NWO green, grant number 870.15.072) with co-financing from seed producers (Agrifirm, Vandinter Semo, P.H. Petersen Saatzucht, and Joordens Zaden). We are grateful to Betty Rutendo Masamba, Shengfang Yang and Péter Garamszegi for help with the experimental work. 
Chapter 6

\section{Appendix D}

Table D1 Modelled downward water flow at $70 \mathrm{~cm}$ depth.

Figure D1 Concentration of $\mathrm{N}$ in total biomass of three species of cover crops.

Figure D2 Concentration of mineral $\mathrm{N}$ in pore water measured in 2018.

Figure D3 Concentration of mineral N in pore water measured in 2019. 
CHAPTER 7

General Discussion 


\section{General discussion}

In this thesis, I analysed the effect of species choice and mixture composition on the performance of cover crops, focusing on biomass, $\mathrm{N}$ yield, radiation interception, radiation use efficiency and yield stability. I investigated the factors that can influence cover crop productivity such as spatial configuration and the application of starter $\mathrm{N}$ fertilizer. I conducted, in collaboration with stakeholders, 14 field experiments between 2015 and 2019 in the Netherlands and Germany. In this general discussion, I summarize the main findings and discuss these in relation to the existing knowledge. I reflect on the strengths and limitations of the applied methodologies and on the implications of the findings for practice.

\subsection{Mixing cover crop species provides the highest attainable yield}

Across this thesis, the yield of 12 species mixtures of cover crops was compared to that of their respective pure stands. Of these mixtures, 11 were tested in three studies at 11 site-years and one mixture was tested in one study at two site-years. Mixtures were created using species that belong to different botanical families and have different phenotypic traits. The combination of traits was expected to result in niche differentiation and therefore reduce competition between species (Vandermeer, 1992). I hypothesized that mixtures would produce a higher yield than pure stands. I found that mixtures produced 25\% higher biomass when compared with the average of all pure stands. However, there was no difference in biomass between mixtures and the most productive species: oats and crucifers.

Provisioning of ecosystem services like $\mathrm{N}$ capture, $\mathrm{C}$ sequestration and weed suppression is positively correlated with cover crop biomass (Finney et al., 2016). Therefore, the biomass of a cover crop mixture should be compared to that of the highest yielding pure stands. A desirable outcome would be that mixture biomass is higher than that of both component species, which is known as transgressive overyielding (Schmid et al., 2008). Transgressive overyielding is only occasionally found in cover crop studies (Sainju et al., 2006; Wang et al., 2012; Hayden et al., 2014; Poffenbarger et al., 2015; Wendling et al., 2017; Wendling et al., 2019). I also found transgressive overyielding in only few instances. Therefore, based on my findings and earlier studies, I conclude that mixing complementary species of cover crops does not guarantee transgressive overyielding, but it does ensure the highest attainable yield in a given site-year. 


\subsection{Biomass accumulation by cover crop mixtures was not related to the number of the component species}

The relation between species diversity and ecosystem functioning is well-studied in the ecological literature (Hooper et al., 2005). Increasing the number of species within a mixture enriches the palette of traits within a plant community and such trait complementarity is thought to be positively related to productivity and resource utilization (Tilman et al., 1996). In Chapter 4, I created mixtures that consisted of either two, three or four species that belong to different families and possess different traits. I expected that productivity would increase with species richness. Contrarily, I found that mixtures with two, three and four species had a similar biomass and $\mathrm{N}$ yield. In the cover crop literature, the relation between species richness and biomass ranges from a weak positive correlation (Finney et al., 2016) to no correlation (Wendling et al., 2019), which is in agreement with the results of Chapter 4. Therefore, I conclude that merely increasing the number of species within a cover crop mixture does not result in a higher biomass or $\mathrm{N}$ yield.

\subsection{Identity of the dominant species defines the performance of species mixtures}

I used replacement designs to create species mixtures, combining all species in the mixture using the same proportion of the full seeding rate. However, in almost all mixtures, more than $90 \%$ the total biomass was produced by either crucifers, oats or a combination of these species, irrespective of the number of component species. The other species contributed little or nothing to the total biomass. Therefore, I referred to oats and crucifers as dominant species. The dominance of grasses and crucifers was repeatedly reported, especially at high availability of soil mineral N (Wendling et al., 2017; Baraibar et al., 2018; Baraibar et al., 2020). Interestingly, dominance of the high yielding species was not shown in a recent study (Blesh et al., 2019). It is unclear why the general trend shown by most studies was not shown in the study of Blesh et al. (2019). Further work may be needed on the causes of balance or imbalance of species contributions to total mixture biomass.

In accordance with the finding that most of the mixture biomass was usually due to a single dominant species, I found that the behaviour of mixtures was similar to that of the dominant species. The dominance of oats and crucifers can explain why increasing the number of the component species did not affect mixtures' biomass. Similarly, earlier grassland and cover crop 
studies reported that the identity of the combined species matters more than species richness (Crawley et al., 1999; Sanderson, 2010; Miyazawa et al., 2014; Wendling et al., 2019). Hence, in Chapter 5, mixtures were grouped into three groups based on the identity of the dominant species: mixtures dominated by crucifers (Mix $\mathrm{M}_{\text {cruc }}$ ), oats $\left(\mathrm{Mix}_{\mathrm{oats}}\right)$, or the combination of both species (Mix cruc-oats).

It is well established that crop growth is positively correlated with the amount of intercepted radiation (Monteith, 1994). Dominant species within mixtures influenced the speed of ground cover and the amount of intercepted radiation. I found that crucifers were the fastest species to establish and covered $50 \%$ of the ground within 15 to 19 days after sowing (Chapters 2 and 5). Accordingly, crucifers and mixtures with crucifers, Mix $x_{c r u c}$ and Mix cruc-oats, intercepted the largest amount of radiation: on average $504 \mathrm{MJ} \mathrm{m}^{-2}$. Oats and Mixoats were the second-fastest treatments to cover the ground, followed by other forbs, while legumes were the slowest. The slower ground cover by legumes as comparted to crucifers and grasses was previously reported by Ramirez-Garcia et al. (2015). Oats, other forbs, and legumes intercepted approximately $10 \%, 26 \%$ and $34 \%$ less radiation than crucifers, respectively. If those species are grown as pure stands, these percentages may be considered as lost radiation that could have been used to produce biomass. Therefore, growing crucifers or mixtures with crucifers as cover crops can ensure a maximum interception of radiation.

The efficiency of converting resources into biomass is an important feature that influences the productivity of a plant species (Sinclair and Muchow, 1999). In Chapter 5, I calculated radiation use efficiency (RUE), which is the efficiency of a plant species to convert radiation into biomass (Kiniry et al., 1989). I found that oats was the most efficient in converting global radiation into biomass. Oats produced the highest amount of biomass despite the lower amount of intercepted radiation as compared to crucifers. The RUE of oats was $1.15 \mathrm{~g} \mathrm{MJ}^{-1}$, which was $27 \%, 30 \%$ and $44 \%$ higher than the RUE of other forbs, crucifers, and legumes, respectively. Mixtures that

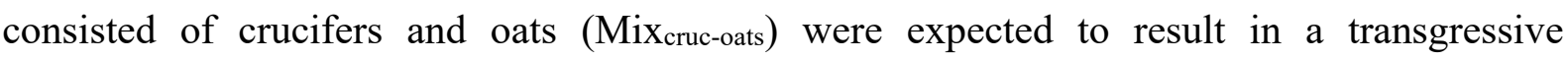
overyielding because they combine species with high radiation interception (crucifers) and species with high RUE (oats). It was, however, found that Mix cruc-oats $_{\text {intercepted similar }}$ amounts of radiation as crucifers but had an RUE intermediate between that of oats and crucifers. Evidently, it was not possible to combine the best of the two worlds, and therefore biomass of Mix cruc-oats did not exceed that of oats. One explanation could be related to the fast ground cover by the crucifer species with its broad and horizontally oriented leaves that shaded 
neighbouring oat plants. Crucifers, the species with the lower RUE, indeed made up two thirds of the biomass of Mix cruc-oats, whereas the relative contribution of oats was only $32 \%$. This indicates that, in a mixture, a species with a greater resource capture efficiency can dominate a species with a greater resource conversion efficiency. Transgressive overyielding might be achieved if the higher radiation capture efficiency of the crucifer is mainly expressed during the early growth stages, thereby minimizing loss of radiation. Once full canopy cover is achieved, dominance of this species should be reduced to allow for the higher radiation conversion efficiency of oats to come to expression. It seems plausible that this might be achieved by modulating the timing of germination of the oats and the crucifer (earlier for oats) or by using a relatively greater seeding density for the oats to increase the fraction of radiation intercepted by oats. Due to the vertical leaf orientation of oats, radiation would be still available to be intercepted by the crucifer species. In this situation, both traits of high radiation interception and high RUE would be utilized and transgressive overyielding could potentially occur. Such a complementarity for resources capture could be the reason for the transgressive overyielding reported in earlier studies on cover crops (Sainju et al., 2006; Wang et al., 2012; Hayden et al., 2014; Poffenbarger et al., 2015; Wendling et al., 2017; Wendling et al., 2019). By synthesizing data from the literature in a meta-analysis, Yu et al. (2016) showed that the balance between the cereal and a legume in a cereal/legume intercrop could be modulated by time of sowing and nitrogen input. It remains to be further explored whether management of cover crops can modulate interactions between oats and crucifers in such a way that complementarity is enhanced and transgressive overyielding achieved. In conclusion, I found that oats and crucifers are the most productive species that define the performance of mixtures. When oats and crucifers are mixed, they are among the cover crops that provide the quickest ground cover, intercept the greatest amount of radiation and produce the highest attainable yield.

\subsection{N yield and $\mathrm{C}: \mathrm{N}$ ratio of winter cover crops}

$\mathrm{N}$ capture is an important ecosystem service provided by winter cover crops (Tonitto et al., 2006). The two most productive species groups, oats and crucifers, showed different abilities to capture mineral $\mathrm{N}$ from the soil. Crucifers, particularly oilseed radish, combined high biomass accumulation with the ability to capture large amounts of mineral N. Previous authors also considered crucifers to be the most effective species to capture soil mineral N (ThorupKristensen et al., 2003; Couedel et al., 2018). As shown in Chapter 4, oilseed radish captured 
on average more than $100 \mathrm{~kg} \mathrm{~N} \mathrm{ha}^{-1}, 7 \mathrm{~kg} \mathrm{~N} \mathrm{ha}^{-1}$ more than the average of all crucifer species. This is a substantial amount of captured mineral $\mathrm{N}$ that could otherwise have leached to groundwater. Oats also accumulated large amounts of biomass but captured approximately $10 \%$ less $\mathrm{N}$ than crucifers. Consequently, both oats and crucifers produced large amounts of biomass but with different $\mathrm{N}$ concentrations and different $\mathrm{C}: \mathrm{N}$ ratios. This difference in $\mathrm{N}$ concentration between oats and crucifers was also shown in earlier studies (Thorup-Kristensen, 2001; Wendling et al., 2016). Oats biomass had a high $C: \mathrm{N}$ ratio (average $\mathrm{C}: \mathrm{N}=26.6$ ) which may have negative effects on the subsequent cash crop, because incorporating plant residues with low quality (high $\mathrm{C}: \mathrm{N}$ ratio) can result in $\mathrm{N}$ immobilisation and reduced availability of mineral N (Abdalla et al., 2019; Li et al., 2020c).

Cover crop species vary in root architecture and strategies for nutrient acquisition (Wendling et al., 2016). Complementarity in rooting patterns is thought to increase the capture of mineral $\mathrm{N}$ from the soil (Blesh et al., 2019). I found that mixtures dominated by crucifers had a higher $\mathrm{N}$ concentration in the biomass and a lower $\mathrm{C}: \mathrm{N}$ ratio (average $\mathrm{C}: \mathrm{N}=17.0$ ) than crucifers in pure stands (average $\mathrm{C}: \mathrm{N}=18.8$ ). Similarly, the $\mathrm{C}: \mathrm{N}$ ratio of mixtures dominated by black oats (average $\mathrm{C}: \mathrm{N}=24.1$ ) was lower than that of black oats in pure stands (average $\mathrm{C}: \mathrm{N}=26.6$ ). The lower $\mathrm{C}: \mathrm{N}$ ratio in mixtures as compared to the respective dominant species in pure stands is related to the higher $\mathrm{N}$ capture by mixtures (Chapter 4). I presented in Chapter 4 that the five most productive mixtures captured $9 \%$ more $\mathrm{N}$ than the five most productive pure stands. Thus, mixing complementary species improved $\mathrm{N}$ capture and the quality of the accumulated biomass.

\subsection{Spatial configuration effect on complementarity and dominance}

In studies on diversity effects in food crops, species are often mixed in alternating rows or in alternating strips of several rows (Rusinamhodzi et al., 2012; Yu et al., 2015; Gou et al., 2016; Li et al., 2020b). Such row or strip designs facilitate the use of machinery to manage each species separately. However, in cover crop mixtures, specific management for each species is not considered necessary because they are not meant to be harvested separately and therefore there is no need to separate species of cover crop in alternate rows or strips. As a common practice, cover crops are sown as seed mixtures, resulting in the species being mixed within the row, which allows for maximum proximity between the complementary mixed species.

I showed earlier that oats and crucifers dominated the biomass of the mixtures (section 7.3). Hence, I tested in Chapter 3 whether separating cover crop species in alternate rows would 
reduce the dominance of the high yielding species during the early growth stage. By separating mixed species in alternate rows rather than combining them within the same row, I expected that the less competitive species (in the experiments: common vetch) would have enough time to come to expression before being overgrown by its companion species (oilseed radish and black oats). I calculated the net biodiversity effect (NE) to investigate whether the biomass of mixtures differed from the expected biomass of pure stands grown in different mixing configurations (Polley et al., 2007). The results suggested that mixtures were more productive than expected, irrespective of the spatial configuration. The configuration effect on the NE was inconsistent. The effects of year and the identity of component species on NE were clearer. This result is in line with an earlier study that reported no effect of spatial arrangement on the biomass of a cover crop mixture (Lowry and Brainard, 2016).

NE consists of two components: the complementarity effect (CE) and the selection effect (SE). The values of $\mathrm{CE}$ and $\mathrm{SE}$ can be used to investigate how spatial arrangement influences complementarity between species and the dominance of the high yielding species (Loreau and Hector, 2001; Li et al., 2020a). The effect of spatial arrangement on CE and SE was inconsistent. Consequently, I conclude that spatial arrangement has no agronomical importance when growing cover crop mixtures. Interestingly, in 2015, the relatively wet soil conditions in autumn were not favourable for the growth of oilseed radish and black oats, while common vetch was the highest yielding species. In this year, oilseed radish and black oats did not overgrow common vetch and therefore SE was not as evident as in the other years. In all years, the high yielding species, oilseed radish and black oats, did not dominate each other. I conclude that complementarity and competition between mixed species are governed by their identity and they are highly influenced by environmental conditions rather than by seeding configuration.

\subsection{Yield stability in winter cover crops}

In ecology, the word stability has multiple meanings (Lehman and Tilman, 2000). In cash crop studies, yield stability is often used to refer to yield variation across site-years (Raseduzzaman and Jensen, 2017), while in cover crop studies, yield stability often refers to plot-to-plot variation in yield (Wortman et al., 2012; Florence et al., 2019). In this thesis, I used mixed effects models and Markov Chain Monte Carlo methods to simultaneously estimate yield variability of pure stands and species mixtures of cover crops at three levels: between site-years, between treatments and between plots. 


\subsubsection{Yield variation between site-years}

I found that growing mixtures does not provide insurance against differences in soil and weather conditions (Chapter 4). Both mixtures and pure stands produced two to three-fold greater biomass at the site "Neer" than at the other sites: "Wageningen", "Scheemda" and "Grundhof". Therefore, yield variability between site-years was large for both mixtures and pure stands. This result shows that site conditions and management have a greater influence on yield of cover crops than species choice or mixture composition. Particularly, a relatively early sowing date was the main factor for the high productivity in site "Neer". It was previously shown that early sowing allows for greater radiation interception, biomass accumulation and $\mathrm{N}$ capture (Vos and van der Putten, 1997). The large site-year effect on yield of mixtures and pure stands was also found by Wendling et al. (2019). To my knowledge, there is no report states that mixing species of cover crops reduces yield variability across site-years. Conversely, in cash crop studies, mixing species (intercropping) was shown to reduce yield variability across site-years (Rao and Willey, 1980; Raseduzzaman and Jensen, 2017). Perhaps, this difference in findings between cash crops and cover crops is related to the large difference in growing conditions between the two systems. Cash crops are grown when growth factors are optimal for maximum productivity. Cash crops receive the optimum fertilization, and protection against pests and diseases and are sown when the weather is favourable. In contrast, the management of cover crops depends on choices made primarily for the main crop. Sowing date of a cover crop is dependent on the harvesting date of the preceding cash crop. That could be as early as July or as late as October. Therefore, it makes sense that for cover crops the variation in yield between site-years is higher than for cash crops.

\subsubsection{The risk of choosing suboptimal species is lower with mixtures}

Understanding growth performance is crucial when selecting a cover crop species. A mismatch between the selected species and the prevailing weather or site conditions may result in a lower yield than the average achievable yield at a given site. In Chapter 3, I showed that, in 2015, oilseed radish and black oats produced a lower yield than common vetch due to the wet soil conditions after sowing. So, it cannot be guaranteed that the species that generally provide the highest yield will always provide the best yield. In Chapter 4, I presented large variation in yield between the pure stands. Variation was substantially smaller between the mixture treatments. The large variation in yield between pure stands is mainly caused by the presence of low yielding species such as legumes and other forb species. Mixture treatments consisted of at least one high yielding species: oats or a crucifer. Due to the strong selection effect, the 
yield of mixtures was similar to that of the best component species (Loreau and Hector, 2001). Consequently, in all site-years, yield variation between the mixture treatments was significantly smaller than that between pure stands. Hence, I conclude that the risk of choosing a suboptimal cover crop species can be lowered by growing a mixture that contains at least one productive species.

\subsubsection{Mixtures increase the uniformity of biomass across the field}

Plot-to-plot yield variability reflects the species response to micro-changes in soil factors across the field. Mixing species with different tolerance to various stresses could reduce variability in production (Huston, 1997). Due to compensation between species in mixtures, I expected that yield variability between plots of a mixture would on average be lower than that between plots of a pure stand (Hector et al., 2010). The results support this hypothesis. This is a novel finding not reported in previous studies, which may be demonstrated here due to the greater plot sizes used in the current study. Smaller plot sizes, used in previously reported work, tend to increase variability of the data and reduce the power to detect patterns (Wortman et al., 2012; Smith et al., 2014; Florence et al., 2019). Unlike for biomass, a lower variation in mixtures as compared to pure stands was not found for $\mathrm{N}$ yield (Chapter 4). This was found to be related to the higher $\mathrm{N}$ concentration in plots with higher mixture yield and lower $\mathrm{N}$ concentration in plots with a lower mixture yield. Therefore, within field, growing mixtures can increase the uniformity of biomass accumulation but not for $\mathrm{N}$ yield.

\subsection{Fertilization of winter cover crops and its effects on yield and $\mathrm{N}$ losses.}

If the purpose of cover cropping is to capture residual $\mathrm{N}$ from soil, then my results provide strong evidence against $\mathrm{N}$ fertilization (Chapter 6). In temperate regions, fertilization of winter cover crops is common to boost the establishment and growth of these crops (van LeeuwenHaagsma et al., 2019). $\mathrm{N}$ is usually applied for grasses and crucifers but not for legumes. However, the recommendation for $\mathrm{N}$ application to cover crops is not based on scientific studies. Therefore, in Chapter 6, I compared the effects of five levels of $\mathrm{N}$ fertilizer $(0-90 \mathrm{~kg}$ $\mathrm{ha}^{-1}$ ) on the net $\mathrm{N}$ capture ( $\mathrm{N}$ capture minus $\mathrm{N}$ input) in four treatments: pure stands of common vetch, oilseed radish, or black oats, and the mixture of the three species. The amount of $\mathrm{N}$ captured by cover crops differed across years and was significantly influenced by the identity of the grown species. The net $\mathrm{N}$ capture was not improved with $\mathrm{N}$ application in any of the treatments. In 2019, the three cover crop species could not capture all the added amounts of $\mathrm{N}$ when grown in soil with sufficient mineral $\mathrm{N}$, resulting in increased $\mathrm{N}$ losses with $\mathrm{N}$ 
fertilization. In 2018, when the initial mineral $\mathrm{N}$ in soil was limited, $\mathrm{N}$ losses were only found in plots with common vetch. Interestingly, $\mathrm{N}$ capture by the 3 -species mixture increased with increasing $\mathrm{N}$ application in both years, resulting in no $\mathrm{N}$ losses. This result could be related to the complementary root traits of the mixed species, e.g. different rooting depths (Kristensen and Thorup-Kristensen, 2004). I found that the 3-species mixture accumulated similar biomass as the best species in 2018 and greater biomass than the best species in 2019. These results suggest that mixing species with complementary traits allows for better capture of resources and subsequently enhances biomass accumulation. In conclusion, to prevent $\mathrm{N}$ losses, fertilization of winter cover crops should be avoided, and mixing complementary species should be promoted.

\subsection{Weed suppression}

Weed suppression is an important reason to grow winter cover crops (Schipanski et al., 2014). Early canopy development was defined as the main factor to suppress weeds in early autumn (Brennan and Smith, 2005; Brust et al., 2011). My findings are in line with this. In Chapter 2 and 5, I showed that species with early establishment and quick soil cover competed for space and intercepted high amounts of radiation. Subsequently, rapidly established species suppressed weeds well. In all experiments, crucifers were the quickest to cover the ground and therefore were the most effective species to suppress weeds. A slower ground cover by the other species, such as legumes, was associated with higher weed biomass. In 2018, I measured weed biomass in plots of mixtures and pure stands at four sites (data not presented). The lowest weed biomass was in plots with crucifers or mixtures, followed by plots with oats or other forbs, while the highest weed biomass was found in the plots with legumes. Similarly, Smith et al. (2020) reported that crucifers and mixtures were the most effective cover crop treatments to suppress weeds in autumn. This high degree of weed suppression was due to rapid canopy development (Lawley et al., 2012; Smith et al., 2020). Therefore, I conclude that crucifers and mixtures that include a crucifer species are the most effective cover crop treatments to suppress weeds in the autumn.

\subsection{Methodology: strengths and limitations}

\subsubsection{Measuring cover crop yield}

An important strength of this thesis is that it comprises the results of 14 field experiments with a large number of treatments and observations. The large number of site-years allowed me to 
compare the performance of cover crop mixtures and pure stands under a range of weather conditions and soil types. Similar studies on cover crop mixtures based on a large number of site-years are limited. Evidently, this research helped fill an important knowledge gap. Still relevant aspects remained underexposed. Due to the limited time and resources, root biomass was only measured in Chapter 6 on starter N-fertilization. Though the results of this study showed that I would have reached similar conclusions if observations would have been restricted to the shoot, there is no guarantee that this is always the case. Obviously, considering root biomass when comparing the total accumulated biomass and $\mathrm{N}$ yield of mixtures and pure stands is desirable.

\subsubsection{Calculation of yield stability}

In cover crop studies, yield variability is often quantified using the coefficient of variation (Khan and McVay, 2019). In some cases, the interpretation of the variance and CV can be challenging (Doring and Reckling, 2018). But, there are now well-established methods for estimating these metrics in meta-analyses, taking into account estimation errors and a possible mean-variance relationship (Nakagawa et al., 2015; Lesur-Dumoulin et al., 2017). Other indicators of stability exist, particularly for analysing extreme values, such as value at risk and expected shortfall. Their estimation generally requires long time series, often available in finance and economics, but more rarely available in agronomy (Cernay et al., 2015). The CV was found to be non-linearly decreasing with the mean and subsequently results of CV can be misleading (Döring et al., 2015). Therefore, I avoided the use of CV though it is commonly used in previous studies on cover crops (Wortman et al., 2012; Smith et al., 2014; Florence et al., 2019). In this study, the use of Bayesian mixed models and MCMC in Chapter 4 allowed me to simultaneously estimate variability of biomass and $\mathrm{N}$ uptake at three levels: between siteyears, between treatments and between plots. The models comprised three variance components, one component for each level of variability. This approach is informative and avoids some of the pitfalls associated with the use of CV. Thus, for studying yield variability at multiple levels of variation, I would recommend the use of Bayesian mixed models to estimate variance components.

\subsubsection{Biological nitrogen fixation (BNF) by legumes}

I measured $\mathrm{N}$ yield of several leguminous species, but I did not investigate the amount of atmospheric $\mathrm{N}$ fixed biologically via symbiosis of legumes with $\mathrm{N}$ fixing bacteria. This can be considered as a limitation. In radish-vetch mixtures, radish dominated vetch and accumulated 
high amounts of biomass and captured large amounts of $\mathrm{N}$. The high yield of radish can be related to the weak competition of vetch for space and nutrients. Another explanation could be that vetch fixed its own $\mathrm{N}$, leaving more resources for radish to use. It was shown earlier that $\mathrm{N}$ fixation by clover and vetch varieties can vary from 50 to $370 \mathrm{~kg} \mathrm{~N} \mathrm{ha}^{-1}$ (Tonitto et al., 2006). In an earlier study on grass-clover mixture, more than $92 \%$ of clover $\mathrm{N}$ was derived from BNF (Thilakarathna et al., 2016). Furthermore, it is sometimes reported that $\mathrm{N}$ can be transferred from the leguminous species to the non-legume companion species via rhizodeposition or root exudates (Fustec et al., 2010; Paynel et al., 2008). However, there are large uncertainties on the quantitative importance of the within-season transfer of biologically fixed $\mathrm{N}$ from a legume to a companion species (Fustec et al., 2010). These uncertainties encourage future research to investigate $\mathrm{N}$ fixation in mixtures of winter cover crops. In my thesis work, I prioritized the measurement of total $\mathrm{N}$ capture in a wide array of treatments and this left insufficient resources to explore the role of biological $\mathrm{N}$ fixation. The relatively small fraction of leguminous biomass (usually below 10\%) present in most mixtures sustained this prioritization. On average, mixtures captured slightly higher amounts of $\mathrm{N}$ than the respective pure stands. It remains interesting to investigate whether and to what extent the extra amounts of $\mathrm{N}$ captured by mixtures was related to the inclusion of legume species. Perhaps, this question can be investigated in further research.

\subsection{Implications for farmers and policymakers}

Selection of cover crop species is a crucial step that requires a priori understanding of species performance under given growing conditions. Selection of species should be objective-oriented (Ramírez-García et al., 2015). In Table 7.1, I summarise the traits and services of the different species groups of cover crops used in this study. Based on the results of Chapter 4 and 5, I identified the best species group to provide each of the listed traits or services. The other groups were compared with the best species group in supplying each of the listed traits or services. This scheme can be used as a guide for selecting species or species mixtures based on the purpose of cover cropping. If the purpose is to achieve the highest $\mathrm{C}$ sequestration to build up

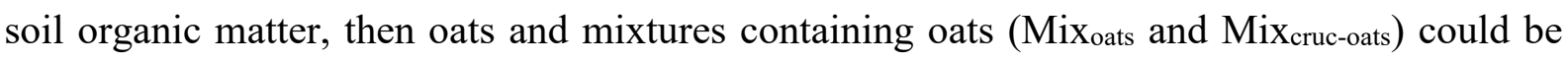
considered. However, C:N ratio could also be taken into account to prevent negative effects on the subsequent crop. I showed that pure stand of oats produced high biomass in most site-years but with a high C:N ratio. Mixing oats with crucifers (Mix cruc-oats) enhanced the quality of the biomass. Oats, crucifers and mixtures containing these species suppressed weeds well. If the 
Table 7.1: Summary of traits and services provided by different groups of species and mixtures of cover crop species, based on data from Chapter 4 and 5. Mix oats $_{\text {are }}$ mixtures with black

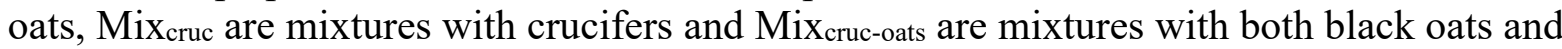
crucifers. For each of the characteristics, the performance of the best group was used as a standard and set to $100 \%$. Values for the other groups are presented as percentage of the best species group. Values with * are significantly lower than $100 \%$. Data on weed suppression are based on four experimental sites in 2018.

\begin{tabular}{|l|c|c|c|c|c|c|c|}
\cline { 2 - 8 } & Oats & Crucifers & Legumes & Other forbs & Mix ${ }_{\text {oats }}$ & Mix cruc & Mix cruc-oats \\
\hline $\begin{array}{l}\text { Biomass } \\
\text { quantity }\end{array}$ & $100 \%$ & $78 \% *$ & $41 \% *$ & $60 \% *$ & $94 \%$ & $81 \% *$ & $92 \%$ \\
\hline $\begin{array}{l}\text { Biomass } \\
\text { quality (C:N) }\end{array}$ & $55 \% *$ & $77 \% *$ & $100 \%$ & $70 \% *$ & $60 \% *$ & $85 \% *$ & $71 \% *$ \\
\hline N capture & $83 \% *$ & $91 \%$ & $49 \% *$ & $54 \% *$ & $81 \% *$ & $100 \%$ & $98 \%$ \\
\hline $\begin{array}{l}\text { Radiation } \\
\text { interception }\end{array}$ & $89 \% *$ & $100 \%$ & $64 \% *$ & $72 \% *$ & $86 \% *$ & $96 \%$ & $97 \%$ \\
\hline $\begin{array}{l}\text { Radiation use } \\
\text { efficiency }\end{array}$ & $100 \%$ & $70 \% *$ & $56 \% *$ & $73 \% *$ & $98 \%$ & $75 \% *$ & $87 \% *$ \\
\hline $\begin{array}{l}\text { Weed } \\
\text { suppression }\end{array}$ & $25 \%$ & $47 \%$ & $10 \% *$ & $15 \% *$ & $41 \%$ & $100 \%$ & $37 \%$ \\
\hline
\end{tabular}

purpose is to capture $\mathrm{N}$ and prevent $\mathrm{N}$ leaching, crucifers and mixtures containing crucifers would be the best choice, while legumes and other low yielding forbs should be avoided. Unlike what was expected, fertilization of cover crops did not enhance net $\mathrm{N}$ capture. Therefore, any addition of $\mathrm{N}$ fertilizer will increase the chance of $\mathrm{N}$ losses. Current policies allow the application of $\mathrm{N}$ to cover crops growing on sandy soils; but my results do not support the notion that this increases the provided services. Results of Chapter 6 can be used to support new policies that limit $\mathrm{N}$ application to cover crops.

When creating a mixture, one should consider the identity of the mixed species. Arbitrarily mixing a greater number of species does not necessarily result in greater benefits. The key species that provide the desired ecosystem service should be protected from being overgrown by other species in the mixture. For instance, if the purpose of cover cropping is to fix atmospheric nitrogen or to suppress pests and diseases, then oats and crucifers should be avoided. Oats and crucifers are very competitive species that will most likely dominate a mixture, yet they can also be complementary with each other. Overall, I demonstrated that yield 
of cover crops is more strongly governed by the environmental conditions and the identity of dominant species than by mixing of species. Spatial configuration, species richness and starter $\mathrm{N}$ application had a negligible influence on mixture performance. 


\section{References}

Abdalla, M., Hastings, A., Cheng, K., Yue, Q., Chadwick, D., Espenberg, M., Truu, J., Rees, R.M., Smith, P., 2019. A critical review of the impacts of cover crops on nitrogen leaching, net greenhouse gas balance and crop productivity. Global Change Biology $25,2530-2543$.

Adekunle, O.K., 2011. Amendment of soil with African marigold and sunn hemp for management of Meloidogyne incognita in selected legumes. Crop Protection 30, $1392-$ 1395.

Alonso-Ayuso, M., Quemada, M., Vanclooster, M., Ruiz-Ramos, M., Rodriguez, A., Gabriel, J.L., 2018. Assessing cover crop management under actual and climate change conditions. Sci Total Environ 621, 1330-1341.

Baraibar, B., Hunter, M.C., Schipanski, M.E., Hamilton, A., Mortensen, D.A., 2018. Weed Suppression in Cover Crop Monocultures and Mixtures. Weed Sci. 66, 121-133.

Baraibar, B., Murrell, E.G., Bradley, B.A., Barbercheck, M.E., Mortensen, D.A., Kaye, J.P., White, C.M., 2020. Cover crop mixture expression is influenced by nitrogen availability and growing degree days. Plos One 15, 15.

Bates, D., Mächler, M., Bolker, B., Walker, S., 2014. Fitting linear mixed-effects models using lme4. arXiv preprint arXiv:1406.5823.

Behnke, G.D., Villamil, M.B., 2019. Cover crop rotations affect greenhouse gas emissions and crop production in Illinois, USA. Field Crop Res 241, 107580.

Blanco-Canqui, H., 2018. Cover crops and water quality. Agronomy Journal 110, 1633-1647.

Blanco-Canqui, H., Shaver, T.M., Lindquist, J.L., Shapiro, C.A., Elmore, R.W., Francis, C.A., Hergert, G.W., 2015. Cover Crops and Ecosystem Services: Insights from Studies in Temperate Soils. Agron J 107, 2449-2474.

Blesh, J., 2018. Functional traits in cover crop mixtures: Biological nitrogen fixation and multifunctionality. J Appl Ecol 55, 38-48.

Blesh, J., VanDusen, B.M., Brainard, D.C., 2019. Managing ecosystem services with cover crop mixtures on organic farms. Agron J 111, 826-840.

Bologna, M., Aquino, G., 2020. Deforestation and world population sustainability: a quantitative analysis. Sci Rep-Uk 10, 1-9.

Bommarco, R., Kleijn, D., Potts, S.G., 2013. Ecological intensification: harnessing ecosystem services for food security. Trends in Ecology \& Evolution 28, 230-238.

Brennan, E.B., Boyd, N.S., Smith, R.F., Foster, P., 2009. Seeding rate and planting arrangement effects on growth and weed suppression of a legume-oat cover crop for organic vegetable systems. Agron J 101, 979-988.

Brennan, E.B., Smith, R.F., 2005. Winter cover crop growth and weed suppression on the central coast of California. Weed Technology 19, 1017-1024.

Brennan, E.B., Smith, R.F., 2018. Mustard Cover Crop Growth and Weed Suppression in Organic, Strawberry Furrows in California. Hortscience 53, 432-440.

Brooker, R.W., Bennett, A.E., Cong, W.F., Daniell, T.J., George, T.S., Hallett, P.D., Hawes, C., Iannetta, P.P.M., Jones, H.G., Karley, A.J., Li, L., McKenzie, B.M., Pakeman, R.J., Paterson, E., Schob, C., Shen, J.B., Squire, G., Watson, C.A., Zhang, C.C., Zhang, F.S., Zhang, J.L., White, P.J., 2015. Improving intercropping: a synthesis of research in agronomy, plant physiology and ecology. New Phytologist 206, 107-117.

Bruno, J.F., Boyer, K.E., Duffy, J.E., Lee, S.C., Kertesz, J.S., 2005. Effects of macroalgal species identity and richness on primary production in benthic marine communities. Ecology Letters 8, 1165-1174. 
Brust, J., Gerhards, R., Karanisa, T., Ruff, L., Kipp, A., 2011. Why Undersown and Cover Crops Become Important Again for weed Suppression in European Cropping Systems. Gesunde Pflanzen 63, 191-198.

Buchanan, A.L., Kolb, L.N., Hooks, C.R.R., 2016. Can winter cover crops influence weed density and diversity in a reduced tillage vegetable system? Crop Protection 90, 9-16.

Buechi, L., Mouly, P., Amosse, C., Bally, C., Wendling, M., Charles, R., 2016. Nondestructive method for estimating cover-crop biomass. Agrarforschung Schweiz 7, 136-143.

Bukovsky-Reyes, S., Isaac, M.E., Blesh, J., 2019. Effects of intercropping and soil properties on root functional traits of cover crops. Agriculture, Ecosystems and Environment 285, 106614.

Burr-Hersey, J.E., Mooney, S.J., Bengough, A.G., Mairhofer, S., Ritz, K., 2017. Developmental morphology of cover crop species exhibit contrasting behaviour to changes in soil bulk density, revealed by X-ray computed tomography. Plos One 12, $\mathrm{e} 0181872$.

Butterbach-Bahl, K., Baggs, E.M., Dannenmann, M., Kiese, R., Zechmeister-Boltenstern, S., 2013. Nitrous oxide emissions from soils: How well do we understand the processes and their controls? Philosophical Transactions of the Royal Society B: Biological Sciences 368(1621), 20130122.

Bybee-Finley, K.A., Mirsky, S.B., Ryan, M.R., 2016. Functional diversity in summer annual grass and legume intercrops in the northeastern United States. Crop Sci 56, 2775-2790.

Callaway, R.M., 1995. Positive interactions among plants. The Botanical Review 61, 306-349.

Callaway, R.M., Walker, L.R., 1997. Competition and facilitation: a synthetic approach to interactions in plant communities. Ecology 78, 1958-1965.

Campiglia, E., Mancinelli, R., Radicetti, E., Baresel, J.P., 2014. Evaluating spatial arrangement for durum wheat (Triticum durum Desf.) and subclover (Trifolium subterraneum L.) intercropping systems. Field Crop Res 169, 49-57.

Cernay, C., Ben-Ari, T., Pelzer, E., Meynard, J.M., Makowski, D., 2015. Estimating variability in grain legume yields across Europe and the Americas. Sci Rep-Uk 5(1), 1-11.

Chu, M.W., Jagadamma, S., Walker, F.R., Eash, N.S., Buschermohle, M.J., Duncan, L.A., 2017. Effect of Multispecies Cover Crop Mixture on Soil Properties and Crop Yield. Agric Env Lett 2(1), 170030.

Cong, W.F., Hoffland, E., Li, L., Six, J., Sun, J.H., Bao, X.G., Zhang, F.S., van der Werf, W., 2015. Intercropping enhances soil carbon and nitrogen. Global Change Biology 21, 1715-1726.

Cong, W.F., van Ruijven, J., Mommer, L., De Deyn, G.B., Berendse, F., Hoffland, E., 2014. Plant species richness promotes soil carbon and nitrogen stocks in grasslands without legumes. Journal of Ecology 102, 1163-1170.

Couedel, A., Alletto, L., Justes, E., 2018a. Crucifer-legume cover crop mixtures provide effective sulphate catch crop and sulphur green manure services. Plant Soil 426, 61-76.

Couedel, A., Alletto, L., Kirkegaard, J., Justes, E., 2018b. Crucifer glucosinolate production in legume-crucifer cover crop mixtures. Eur J Agron 96, 22-33.

Couedel, A., Alletto, L., Tribouillois, H., Justes, E., 2018c. Cover crop crucifer-legume mixtures provide effective nitrate catch crop and nitrogen green manure ecosystem services. Agr Ecosyst Environ 254, 50-59.

Craswell, E., Lefroy, R., 2001. The role and function of organic matter in tropical soils. Managing Organic Matter in Tropical Soils: Scope and Limitations. Springer, pp. 7-18.

Crawley, M.J., Brown, S.L., Heard, M.S., Edwards, G.R., 1999. Invasion-resistance in experimental grassland communities: species richness or species identity? Ecology Letters 2, 140-148. 
Dabney, S.M., Delgado, J.A., Reeves, D.W., 2001. Using winter cover crops to improve soil and water quality. Communications in Soil Science and Plant Analysis 32, 1221-1250.

Dapaah, H., Asafu-Agyei, J., Ennin, S., Yamoah, C., 2003. Yield stability of cassava, maize, soya bean and cowpea intercrops. The Journal of Agricultural Science 140, 73.

De Baets, S., Poesen, J., Meersmans, J., Serlet, L., 2011. Cover crops and their erosionreducing effects during concentrated flow erosion. Catena 85, 237-244.

De Deyn, G.B., Quirk, H., Yi, Z., Oakley, S., Ostle, N.J., Bardgett, R.D., 2009. Vegetation composition promotes carbon and nitrogen storage in model grassland communities of contrasting soil fertility. Journal of Ecology 97, 864-875.

De Wit, C.T., 1959. Potential photosynthesis crop surfaces. Netherlands Journal of Agricultural Science 7: 141-149.

De Wit, C.T., Van den Bergh, J., 1965. Competition between herbage plants. Journal of Agricultural Science 13, 212-221.

Dijksma, S., A., M., 2014. Wijzigingen in invulling van de vergroening GLB. Brief aan de Voorzitter van de Tweede Kamer der Staten-Generaal DGA-ELV / 14119366.

Döring, T.F., Knapp, S., Cohen, J.E., 2015. Taylor's power law and the stability of crop yields. Field Crop Res 183, 294-302.

Doring, T.F., Reckling, M., 2018. Detecting global trends of cereal yield stability by adjusting the coefficient of variation. Eur J Agron 99, 30-36.

European-Commission, 2019. Sustainable land use (greening). Retrieved from https://ec.europa.eu/info/food-farming-fisheries/key-policies/common-agriculturalpolicy/income-support/greening en.

Faris, M.A., Dearaujo, M.R.A., Lira, M.D., Arcovere, A.S.S., 1983. Yield Stability in Intercropping Studies of Sorghum or Maize with Cowpea or Common Bean under Different Fertility Levels in Northeastern Brazil. Can J Plant Sci 63, 789-799.

Feddes, R.A., Kowalik, P.J., Zaradny, H., 1978. Simulation of field water use and crop yield. Pudoc, Wageningen.

Finlay, K., Wilkinson, G., 1963. The analysis of adaptation in a plant-breeding programme. Aust J Agr Res 14, 742-754.

Finney, D.M., Kaye, J.P., 2017. Functional diversity in cover crop polycultures increases multifunctionality of an agricultural system. J Appl Ecol 54, 509-517.

Finney, D.M., White, C.M., Kaye, J.P., 2016. Biomass production and carbon/nitrogen ratio influence ecosystem services from cover crop mixtures. Agron J 108, 39-52.

Florence, A.M., Higley, L.G., Drijber, R.A., Francis, C.A., Lindquist, J.L., 2019. Cover crop mixture diversity, biomass productivity, weed suppression, and stability. Plos One 14(3), e0206195.

Fornara, D.A., Tilman, D., 2008. Plant functional composition influences rates of soil carbon and nitrogen accumulation. Journal of Ecology 96, 314-322.

Francis, T.R., Kannenberg, L.W., 1978. Yield Stability Studies in Short-Season Maize .1. Descriptive Method for Grouping Genotypes. Can J Plant Sci 58, 1029-1034.

Fustec, J., Lesuffleur, F., Mahieu, S., Cliquet, J.-B., 2010. Nitrogen rhizodeposition of legumes. A review. Agron Sustain Dev 30, 57-66.

Gabriel, J.L., Muñoz-Carpena, R., Quemada, M., 2012. The role of cover crops in irrigated systems: Water balance, nitrate leaching and soil mineral nitrogen accumulation. Agriculture, Ecosystems \& Environment 155, 50-61.

Garcia, M., Larcher, F., Hickerson, R.P., Baselga, E., Leachman, S.A., Kaspar, R.L., Del Rio, M., 2011. Development of Skin-Humanized Mouse Models of Pachyonychia Congenita. J Invest Dermatol 131, 1053-1060.

Gfeller, A., Herrera, J.M., Tschuy, F., Wirth, J., 2018. Explanations for Amaranthus retroflexus growth suppression by cover crops. Crop protection 104, 11-20. 
Godfray, H.C.J., Beddington, J.R., Crute, I.R., Haddad, L., Lawrence, D., Muir, J.F., Pretty, J., Robinson, S., Thomas, S.M., Toulmin, C., 2010. Food security: the challenge of feeding 9 billion people. science 327, 812-818.

Gou, F., van Ittersum, M.K., Simon, E., Leffelaar, P.A., van der Putten, P.E.L., Zhang, L.Z., van der Werf, W., 2017. Intercropping wheat and maize increases total radiation interception and wheat RUE but lowers maize RUE. Eur J Agron 84, 125-139.

Gou, F., van Ittersum, M.K., Wang, G., van der Putten, P.E., van der Werf, W., 2016. Yield and yield components of wheat and maize in wheat-maize intercropping in the Netherlands. Eur J Agron 76, 17-27.

Green, R.E., Cornell, S.J., Scharlemann, J.P., Balmford, A., 2005. Farming and the fate of wild nature. science $307,550-555$.

Hadfield, J.D., 2010 MCMC Methods for Multi-Response Generalized Linear Mixed Models: The MCMCglmm R Package. Journal of Statistical Software, 33(2), 1-22.

Haramoto, E.R., Gallandt, E.R., 2005. Brassica cover cropping: I. Effects on weed and crop establishment. Weed Sci. 53, 695-701.

Hartwig, N.L., Ammon, H.U., 2002. 50th Anniversary - Invited article - Cover crops and living mulches. Weed Sci. 50, 688-699.

Hatfield, J.L., Dold, C., 2019. Photosynthesis in the solar corridor system. The Solar Corridor Crop System. Elsevier, pp. 1-33.

Hauggaard-Nielsen, H., Jensen, E.S., 2005. Facilitative root interactions in intercrops. Root physiology: From gene to function. Springer, pp. 237-250.

Hayden, Z.D., Brainard, D.C., Henshaw, B., Ngouajio, M., 2012. Winter Annual Weed Suppression in Rye-Vetch Cover Crop Mixtures. Weed Technology 26, 818-825.

Hayden, Z.D., Ngouajio, M., Brainard, D.C., 2014. Rye-Vetch Mixture Proportion Tradeoffs: Cover Crop Productivity, Nitrogen Accumulation, and Weed Suppression. Agron J 106, 904-914.

Hector, A., Hautier, Y., Saner, P., Wacker, L., Bagchi, R., Joshi, J., Scherer-Lorenzen, M., Spehn, E.M., Bazeley-White, E., Weilenmann, M., 2010. General stabilizing effects of plant diversity on grassland productivity through population asynchrony and overyielding. Ecology 91, 2213-2220.

Heuermann, D., Gentsch, N., Boy, J., Schweneker, D., Feuerstein, U., Gross, J., Bauer, B., Guggenberger, G., von Wiren, N., 2019. Interspecific competition among catch crops modifies vertical root biomass distribution and nitrate scavenging in soils. Sci Rep-Uk $9(1), 1-11$.

Holmes, A.A., Thompson, A.A., Wortman, S.E., 2017. Species-Specific Contributions to Productivity and Weed Suppression in Cover Crop Mixtures. Agron J 109, 2808-2819.

Hooks, C.R.R., Wang, K.H., Ploeg, A., McSorley, R., 2010. Using marigold (Tagetes spp.) as a cover crop to protect crops from plant-parasitic nematodes. Appl Soil Ecol 46, 307320.

Hooper, D.U., Chapin Iii, F., Ewel, J., Hector, A., Inchausti, P., Lavorel, S., Lawton, J.H., Lodge, D., Loreau, M., Naeem, S., 2005. Effects of biodiversity on ecosystem functioning: a consensus of current knowledge. Ecological monographs 75, 3-35.

Hothorn, T., Bretz, F., Westfall, P., 2008. Simultaneous Inference in General Parametric Model. Biometrical Journal 50, 346-363.

Houba, V.J.G., Temminghoff, E.J.M., Gaikhorst, G.A., van Vark, W., 2000. Soil analysis procedures using $0.01 \mathrm{M}$ calcium chloride as extraction reagent. Communications in Soil Science and Plant Analysis 31, 1299-1396.

Huston, M.A., 1997. Hidden treatments in ecological experiments: re-evaluating the ecosystem function of biodiversity. Oecologia 110, 449-460. 
Hwang, H.Y., Kim, G.W., Lee, Y.B., Kim, P.J., Kim, S.Y., 2015. Improvement of the value of green manure via mixed hairy vetch and barley cultivation in temperate paddy soil. Field Crop Res 183, 138-146.

Isbell, F., Craven, D., Connolly, J., Loreau, M., Schmid, B., Beierkuhnlein, C., Bezemer, T.M., Bonin, C., Bruelheide, H., De Luca, E., 2015. Biodiversity increases the resistance of ecosystem productivity to climate extremes. Nature 526, 574-577.

Janzen, H.H., 2006. The soil carbon dilemma: Shall we hoard it or use it? Soil Biology and Biochemistry 38, 419-424.

Johnston, A.E., Poulton, P.R., Coleman, K., 2009. Soil Organic Matter: Its Importance In Sustainable Agriculture And Carbon Dioxide Fluxes. In: Sparks, D.L. (Ed.), Advances in Agronomy, Vol 101. Elsevier Academic Press Inc, San Diego, pp. 1-57.

Kaspar, T. C., Singer, J. W., 2011. The use of cover crops to manage soil. Soil management: Building a stable base for agriculture, 321-337.

Khan, Q.A., McVay, K.A., 2019. Productivity and Stability of Multi-Species Cover Crop Mixtures in the Northern Great Plains. Agron J 111, 1817-1827.

Kiniry, J.R., Jones, C.A., Otoole, J.C., Blanchet, R., Cabelguenne, M., Spanel, D.A., 1989. Radiation-Use Efficiency In Biomass Accumulation Prior To Grain-Filling For 5 Grain-Crop Species. Field Crop Res 20, 51-64.

Knapp, S., van der Heijden, M.G.A., 2018. A global meta-analysis of yield stability in organic and conservation agriculture. Nature communications, 9(1), 1-9.

Knops, J.M., Tilman, D., Haddad, d.N., Naeem, S., Mitchell, C., Haarstad, J., Ritchie, M., Howe, K., Reich, P., Siemann, E., 1999. Effects of plant species richness on invasion dynamics, disease outbreaks, insect abundances and diversity. Ecology Letters 2, 286293.

Kramberger, B., Gselman, A., Podvršnik, M., Kristl, J., Lešnik, M., 2012. Environmental advantages of binary mixtures of Trifolium incarnatum and Lolium multiflorum over individual pure stands. Plant, Soil and Environment 59, 22-28.

Kristensen, H.L., Thorup-Kristensen, K., 2004. Root growth and nitrate uptake of three different catch crops in deep soil layers. Soil Sci Soc Am J 68, 529-537.

Kroes, J., Van Dam, J., Groenendijk, P., Hendriks, R., Jacobs, C., 2009. SWAP version 3.2. Theory description and user manual (No. 1649 (02)). Alterra.

Kroes, J.G., Dam, J.C.v., Bartholomeus, R.P., Groenendijk, P., Heinen, M., Hendriks, R.F.A., Mulder, H.M., Supit, I., Walsum, P.E.V.v., 2017. SWAP version 4 : theory description and user manual. Wageningen Environmental Research, Wageningen.

Kruger, D.H.M., Fourie, J.C., Malan, A.P., 2013. Cover Crops with Biofumigation Properties for the Suppression of Plant-Parasitic Nematodes: A Review. South African Journal of Enology and Viticulture 34, 287-295.

Kruidhof, H.M., Bastiaans, L., Kropff, M.J., 2009. Cover crop residue management for optimizing weed control. Plant Soil 318, 169-184.

Lawley, Y.E., Teasdale, J.R., Weil, R.R., 2012. The mechanism for weed suppression by a forage radish cover crop. Agron J 104, 205-214.

Lehman, C.L., Tilman, D., 2000. Biodiversity, stability, and productivity in competitive communities. The American Naturalist 156, 534-552.

Lenth, R., Singmann, H., Love, J., Buerkner, P., Huerve, M., 2019. emmeans: Estimated Marginal Means, aka Least-Squares Means. R package version, 1(1), 3.

Lesur-Dumoulin, C., Malezieux, E., Ben-Ari, T., Langlais, C., Makowski, D., 2017. Lower average yields but similar yield variability in organic versus conventional horticulture. A meta-analysis. Agron Sustain Dev 37(5), 1-12.

Li, C. J., Hoffland, E., Kuyper, T.W., Yu, Y., Li, H., Zhang, C., Zhang, F., van der Werf, W., 2020a. Yield gain, complementarity and competitive dominance in intercropping in 
China: a meta-analysis of drivers of yield gain using additive partitioning. Eur J Agron $113,125987$.

Li, C.J., Hoffland, E., Kuyper, T.W., Yu, Y., Zhang, C.C., Li, H.G., Zhang, F.S., van der Werf, W., 2020b. Syndromes of production in intercropping impact yield gains. Nat. Plants 6, 653-660.

Li, F.C., Sorensen, P., Li, X.X., Olesen, J.E., 2020c. Carbon and nitrogen mineralization differ between incorporated shoots and roots of legume versus non-legume based cover crops. Plant Soil 446, 243-257.

Li, L., Sun, J.H., Zhang, F.S., Li, X.L., Rengel, Z., Yang, S.C., 2001. Wheat/maize or wheat/soybean strip intercropping II. Recovery or compensation of maize and soybean after wheat harvesting. Field Crop Res 71, 173-181.

Li, R., Zhang, Z.X., Tang, W., Huang, Y.F., Coulter, J.A., Nan, Z.B., 2020d. Common vetch cultivars improve yield of oat row intercropping on the Qinghai-Tibetan plateau by optimizing photosynthetic performance. Eur J Agron 117, 126088.

Li, X.C., Hu, F., Shi, W., 2013. Plant material addition affects soil nitrous oxide production differently between aerobic and oxygen-limited conditions. Appl Soil Ecol 64, 91-98.

Lin, C.S., Binns, M.R., Lefkovitch, L.P., 1986. Stability Analysis - Where Do We Stand. Crop Sci 26, 894-900.

Long, S.R., 1989. Rhizobium-Legume Nodulation - Life Together in the Underground. Cell 56, 203-214.

Loreau, M., Hector, A., 2001. Partitioning selection and complementarity in biodiversity experiments. Nature 412, 72-76.

Lowry, C.J., Brainard, D.C., 2016. Strip-Intercropping of Rye-Vetch Mixtures Affects Biomass, Carbon/Nitrogen Ratio, and Spatial Distribution of Cover Crop Residue. Agron J 108, 2433-2443.

Maltais-Landry, G., 2015. Legumes have a greater effect on rhizosphere properties $(\mathrm{pH}$, organic acids and enzyme activity) but a smaller impact on soil P compared to other cover crops. Plant Soil 394, 139-154.

Mao, L.L., Zhang, L.Z., Li, W.Q., van der Werf, W., Sun, J.H., Spiertz, H., Li, L., 2012. Yield advantage and water saving in maize/pea intercrop. Field Crop Res 138, 11-20.

Marchiori, P.E.R., Ribeiro, R.V., da Silva, L., Machado, R.S., Machado, E.C., Scarpari, M.S., 2010. Plant growth, canopy photosynthesis and light availability in three sugarcane varieties. Sugar Tech 12, 160-166.

Martin-Guay, M.-O., Paquette, A., Dupras, J., Rivest, D., 2018. The new green revolution: sustainable intensification of agriculture by intercropping. Sci Total Environ 615, 767772 .

MathWorks, I., 2013. MATLAB and statistics toolbox release. Author Natick, MA.

Mead, R., Willey, R., 1980. The concept of a 'land equivalent ratio'and advantages in yields from intercropping. Experimental Agriculture 16, 217-228.

Mendonça, E.d.S., Lima, P.C.d., Guimarães, G.P., Moura, W.d.M., Andrade, F.V., 2017. Biological nitrogen fixation by legumes and $\mathrm{N}$ uptake by coffee plants. Revista Brasileira de Ciência do Solo 41.

Mesbah, A., Nilahyane, A., Ghimire, B., Beck, L., Ghimire, R., 2019. Efficacy of Cover Crops on Weed Suppression, Wheat Yield, and Water Conservation in Winter WheatSorghum-Fallow. Crop Sci 59, 1745-1752.

Miyazawa, K., Murakami, T., Takeda, M., Murayama, T., 2010. Intercropping green manure crops - effects on rooting patterns. Plant Soil 331, 231-239.

Miyazawa, K., Takeda, M., Murakami, T., Murayama, T., 2014. Dual and triple intercropping: potential benefits for annual green manure production. Plant Production Science 17, 194-201. 
Mohler, C., Johnson, S., 2009. Crop rotation on organic farms: a planning manual. Ithaca, NY: Natural Resource. Agriculture, and Engineering Service (NRAES).

Moller, K., Reents, H.J., 2009. Effects of various cover crops after peas on nitrate leaching and nitrogen supply to succeeding winter wheat or potato crops. Journal of Plant Nutrition and Soil Science 172, 277-287.

Monfort, W.S., Csinos, A.S., Desaeger, J., Seebold, K., Webster, T.M., Diaz-Perez, J.C., 2007. Evaluating Brassica species as an alternative control measure for root-knot nematode (M-incognita) in Georgia vegetable plasticulture. Crop Protection 26, 1359-1368.

Monteith, J.L., 1977. Climate and the Efficiency of Crop Production in Britain. Philos T Roy Soc B 281, 277-294.

Monteith, J.L., 1994. Validity of the correlation between intercepted radiation and biomass. Agricultural and Forest meteorology 68, 213-220.

Mozumdera, P., Berrens, R.P., 2007. Inorganic fertilizer use and biodiversity risk: An empirical investigation. Ecol Econ 62, 538-543.

Murrell, E.G., Schipanski, M.E., Finney, D.M., Hunter, M.C., Burgess, M., LaChance, J.C., Baraibar, B., White, C.M., Mortensen, D.A., Kaye, J.P., 2017. Achieving Diverse Cover Crop Mixtures: Effects of Planting Date and Seeding Rate. Agron J 109, 259271.

Musa, M., Leitch, M.H., Iqbal, M., Sahi, F.U.H., 2010. Spatial Arrangement Affects Growth Characteristics of Barley-Pea Intercrops. Int. J. Agric. Biol. 12, 685-690.

Nakagawa, S., Poulin, R., Mengersen, K., Reinhold, K., Engqvist, L., Lagisz, M., Senior, A.M., 2015. Meta-analysis of variation: ecological and evolutionary applications and beyond. Methods Ecol Evol 6, 143-152.

Ngala, B.M., Haydock, P.P., Woods, S., Back, M.A., 2015. Biofumigation with Brassica juncea, Raphanus sativus and Eruca sativa for the management of field populations of the potato cyst nematode Globodera pallida. Pest Management Science 71, 759-769.

Norberg, L., Aronsson, H., 2019. Effects of cover crops sown in autumn on N and P leaching. Soil Use and Management 36(2), 200-211.

Ogundele, R.A., Oyedele, D.J., Adekunle, O.K., 2016. Management of Meloidogyne incognita and other phytonematodes infecting Amaranthus cruentus and Telfairia occidentalis with African marigold (Tagetes erecta) and Siam weed (Chromolaena odorata). Australas Plant Path 45, 537-545.

Osipitan, O.A., Dille, A., Assefa, Y., Radicetti, E., Ayeni, A., Knezevic, S.Z., 2019. Impact of Cover Crop Management on Level of Weed Suppression: A Meta-Analysis. Crop Sci 59, 833-842.

Patkowska, E., Blazewicz-Wozniak, M., Konopinski, M., 2015. Antagonistic activity of selected fungi occurring in the soil after root chicory cultivation. Plant Soil Environ 61, 55-59.

Paul, E.A., Paustian, K.H., Elliott, E., Cole, C.V., 1996. Soil Organic Matter in Temperate AgroecosystemsLong Term Experiments in North America. CRC Press.

Paynel, F., Lesuffleur, F., Bigot, J., Diquélou, S., Cliquet, J.-B., 2008. A study of $15 \mathrm{~N}$ transfer between legumes and grasses. Agron Sustain Dev 28, 281-290.

Pinheiro, J., Bates, D., DebRoy, S., Sarkar, D., Team, R.C., 2019. nlme: Linear and Nonlinear Mixed Effects Models. R package version 3.1-140.

Poffenbarger, H.J., Mirsky, S.B., Weil, R.R., Maul, J.E., Kramer, M., Spargo, J.T., Cavigelli, M.A., 2015. Biomass and nitrogen content of hairy vetch-cereal rye cover crop mixtures as influenced by species proportions. Agron J 107, 2069-2082.

Polley, H.W., Wilsey, B.J., Tischler, C.R., 2007. Species abundances influence the net biodiversity effect in mixtures of two plant species. Basic and Applied Ecology 8, 209218. 
Pudasaini, M.P., Viaene, N., Moens, M., 2006. Effect of marigold (Tagetes patula) on population dynamics of Pratylenchus penetrans in a field. Nematology 8, 477-484.

Quemada, M., Baranski, M., Nobel-de Lange, M.N.J., Vallejo, A., Cooper, J.M., 2013. Metaanalysis of strategies to control nitrate leaching in irrigated agricultural systems and their effects on crop yield. Agriculture, Ecosystems \& Environment 174, 1-10.

R Core Team, 2018. R: A language and environment for statistical computing. R Foundation for Statistical Computing.

Ramírez-García, J., Carrillo, J.M., Ruiz, M., Alonso-Ayuso, M., Quemada, M., 2015. Multicriteria decision analysis applied to cover crop species and cultivars selection. Field Crop Res 175, 106-115.

Ramirez-Garcia, J., Gabriel, J., Alonso-Ayuso, M., Quemada, M., 2015. Quantitative characterization of five cover crop species. The Journal of Agricultural Science 153, 1174.

Rao, M.R., Willey, R.W., 1980. Evaluation of Yield Stability in Intercropping - Studies on Sorghum-Pigeonpea. Experimental Agriculture 16, 105-116.

Raseduzzaman, M., Jensen, E.S., 2017. Does intercropping enhance yield stability in arable crop production? A meta-analysis. Eur J Agron 91, 25-33.

Raza, M.A., Feng, L.Y., van der Werf, W., Cai, G.R., Bin Khalid, M.H., Iqbal, N., Hassan, M.J., Meraj, T.A., Naeem, M., Khan, I., Rehman, S.U., Ansar, M., Ahmed, M., Yang, F., Yang, W.Y., 2019a. Narrow-wide-row planting pattern increases the radiation use efficiency and seed yield of intercrop species in relay-intercropping system. Food Energy Secur 8, 12.

Reeves, D., 1997. The role of soil organic matter in maintaining soil quality in continuous cropping systems. Soil and Tillage Research 43, 131-167.

Ren, J.H., Zhang, L.Z., Duan, Y., Zhang, J., Evers, J.B., Zhang, Y., Su, Z.C., van der Werf, W., 2019. Intercropping potato (Solanum tuberosum L.) with hairy vetch (Vicia villosa) increases water use efficiency in dry conditions. Field Crop Res 240, 168-176.

Ritz, C., Baty, F., Streibig, J.C., Gerhard, D., 2015. Dose-response analysis using R. Plos One 10(12), e0146021.

Roscher, C., Temperton, V.M., Scherer-Lorenzen, M., Schmitz, M., Schumacher, J., Schmid, B., Buchmann, N., Weisser, W.W., Schulze, E.D., 2005. Overyielding in experimental grassland communities-irrespective of species pool or spatial scale. Ecology Letters 8, 419-429.

Rusinamhodzi, L., Corbeels, M., Nyamangara, J., Giller, K.E., 2012. Maize-grain legume intercropping is an attractive option for ecological intensification that reduces climatic risk for smallholder farmers in central Mozambique. Field Crop Res 136, 12-22.

Sainju, U.M., Singh, B.P., Whitehead, W.F., 2002. Long-term effects of tillage, cover crops, and nitrogen fertilization on organic carbon and nitrogen concentrations in sandy loam soils in Georgia, USA. Soil Till Res 63, 167-179.

Sainju, U.M., Singh, B.P., Whitehead, W.F., Wang, S., 2006. Carbon supply and storage in tilled and nontilled soils as influenced by cover crops and nitrogen fertilization. Journal of environmental quality $35,1507-1517$.

Sanderson, M.A., 2010. Stability of production and plant species diversity in managed grasslands: A retrospective study. Basic and Applied Ecology 11, 216-224.

Sarlikioti, V., de Visser, P.H.B., Marcelis, L.F.M., 2011. Exploring the spatial distribution of light interception and photosynthesis of canopies by means of a functional-structural plant model. Ann Bot-London 107, 875-883.

Sastre, B., Marques, M.J., García-Díaz, A., Bienes, R., 2018. Three years of management with cover crops protecting sloping olive groves soils, carbon and water effects on gypsiferous soil. Catena 171, 115-124. 
Schipanski, M.E., Barbercheck, M., Douglas, M.R., Finney, D.M., Haider, K., Kaye, J.P., Kemanian, A.R., Mortensen, D.A., Ryan, M.R., Tooker, J., 2014. A framework for evaluating ecosystem services provided by cover crops in agroecosystems. Agricultural Systems 125, 12-22.

Schmid, B., Hector, A., Saha, P., Loreau, M., 2008. Biodiversity effects and transgressive overyielding. Journal of Plant Ecology 1, 95-102.

Sharma, V., Irmak, S., Padhi, J., 2018. Effects of cover crops on soil quality: Part I. Soil chemical properties-organic carbon, total nitrogen, $\mathrm{pH}$, electrical conductivity, organic matter content, nitrate-nitrogen, and phosphorus. Journal of Soil and Water Conservation 73, 637-651.

Sinclair, T.R., Muchow, R.C., 1999. Radiation use efficiency. Advances in agronomy. Elsevier, pp. 215-265.

Singh, R.B., 2000. Environmental consequences of agricultural development: a case study from the Green Revolution state of Haryana, India. Agr Ecosyst Environ 82, 97-103.

Smit, B., Janssens, B., Haagsma, W., Hennen, W., Adrados, J.L., Kathage, J., Dominguez, I.P., 2019. Adoption of cover crops for climate change mitigation in the EU. In: Kathage, J., Perez Dominguez, I. (Eds.), Publications Office of the European Union, Luxembourg, 2019, ISBN 978-92-76-11312-6 (online).

Smith, R.G., Atwood, L.W., Warren, N.D., 2014. Increased Productivity of a Cover Crop Mixture Is Not Associated with Enhanced Agroecosystem Services. PloS one, 9(5), e97351.Plos One 9.

Smith, R.G., Warren, N.D., Cordeau, S., 2020. Are cover crop mixtures better at suppressing weeds than cover crop monocultures? Weed Sci. 68, 186-194.

Steele, M.K., Coale, F.J., Hill, R.L., 2012. Winter Annual Cover Crop Impacts on No-Till Soil Physical Properties and Organic Matter. Soil Sci Soc Am J 76, 2164-2173.

Stirling, G.R., Stirling, A.M., 2003. The potential of Brassica green manure crops for controlling root-knot nematode (Meloidogyne javanica) on horticultural crops in a subtropical environment. Australian Journal of Experimental Agriculture 43, 623-630.

Syakila, A., Kroeze, C., 2011. The global nitrous oxide budget revisited. Greenhouse Gas Measurement and Management 1, 17-26.

Tamburini, G., Bommarco, R., Wanger, T.C., Kremen, C., van der Heijden, M.G.A., Liebman, M., Hallin, S., 2020. Agricultural diversification promotes multiple ecosystem services without compromising yield. Science Advances 6, eaba1715.

Tan, M.X., Fang, G., Stomph, T.J., Jing, W., Wen, Y., Zhang, L.Z., Qiang, C., van der Werf, W., 2020. Dynamic process-based modelling of crop growth and competitive water extraction in relay strip intercropping: Model development and application to wheatmaize intercropping. Field Crop Res 246, 13.

Thapa, R., Mirsky, S.B., Tully, K.L., 2018. Cover crops reduce nitrate leaching in agroecosystems: A global meta-analysis. Journal of Environmental Quality 47, 14001411.

Thilakarathna, M., Papadopoulos, Y., Rodd, A., Grimmett, M., Fillmore, S., Crouse, M., Prithiviraj, B., 2016. Nitrogen fixation and transfer of red clover genotypes under legume-grass forage based production systems. Nutr Cycl Agroecosys 106, 233-247.

Thorup-Kristensen, K., 2001. Are differences in root growth of nitrogen catch crops important for their ability to reduce soil nitrate-N content, and how can this be measured? Plant Soil 230, 185-195.

Thorup-Kristensen, K., Magid, J., Jensen, L.S., 2003. Catch crops and green manures as biological tools in nitrogen management in temperate zones. Advances in agronomy 79, 227-302. 
Tilman, D., Balzer, C., Hill, J., Befort, B.L., 2011. Global food demand and the sustainable intensification of agriculture. Proceedings of the national academy of sciences 108 , 20260-20264.

Tilman, D., Fargione, J., Wolff, B., D'Antonio, C., Dobson, A., Howarth, R., Schindler, D., Schlesinger, W.H., Simberloff, D., Swackhamer, D., 2001. Forecasting agriculturally driven global environmental change. Science 292, 281-284.

Tilman, D., Lehman, C.L., Thomson, K.T., 1997. Plant diversity and ecosystem productivity: theoretical considerations. Proceedings of the national academy of sciences 94, 18571861.

Tilman, D., Reich, P.B., Knops, J.M.H., 2006. Biodiversity and ecosystem stability in a decade-long grassland experiment. Nature 441, 629-632.

Tilman, D., Wedin, D., Knops, J., 1996. Productivity and sustainability influenced by biodiversity in grassland ecosystems. Nature 379, 718-720.

Tonitto, C., David, M., Drinkwater, L., 2006. Replacing bare fallows with cover crops in fertilizer-intensive cropping systems: A meta-analysis of crop yield and $\mathrm{N}$ dynamics. Agriculture, Ecosystems \& Environment 112, 58-72.

Toom, M., Talgre, L., Mae, A., Tamm, S., Narits, L., Edesi, L., Haljak, M., Lauringson, E., 2019. Selecting winter cover crop species for northern climatic conditions. Biol Agric Hortic 35, 263-274.

Tosti, G., Benincasa, P., Farneselli, M., Tei, F., Guiducci, M., 2014. Barley-hairy vetch mixture as cover crop for green manuring and the mitigation of $\mathrm{N}$ leaching risk. Eur J Agron 54, 34-39.

Tribouillois, H., Cohan, J.P., Justes, E., 2016a. Cover crop mixtures including legume produce ecosystem services of nitrate capture and green manuring: assessment combining experimentation and modelling. Plant Soil 401, 347-364.

Tribouillois, H., Constantin, J., Justes, E., 2018. Analysis and modeling of cover crop emergence: Accuracy of a static model and the dynamic STICS soil-crop model. Eur J Agron 93, 73-81.

Tribouillois, H., Durr, C., Demilly, D., Wagner, M.H., Justes, E., 2016b. Determination of Germination Response to Temperature and Water Potential for a Wide Range of Cover Crop Species and Related Functional Groups. Plos One 11(8), e0161185.

Tribouillois, H., Fort, F., Cruz, P., Charles, R., Flores, O., Garnier, E., Justes, E., 2015. A Functional Characterisation of a Wide Range of Cover Crop Species: Growth and Nitrogen Acquisition Rates, Leaf Traits and Ecological Strategies. Plos One 10(3), e0122156.

Trinsoutrot, I., Recous, S., Bentz, B., Lineres, M., Cheneby, D., Nicolardot, B., 2000. Biochemical quality of crop residues and carbon and nitrogen mineralization kinetics under nonlimiting nitrogen conditions. Soil Sci Soc Am J 64, 918-926.

Turk, M.A., Tawaha, A.M., 2003. Allelopathic effect of black mustard (Brassica nigra L.) on germination and growth of wild oat (Avena fatua L.). Crop Protection 22, 673-677.

UN, 2019. Selected Results of the 2019 UN World Population Projections. Popul. Dev. Rev. 45, 689-694.

van Dam, J.C., Groenendijk, P., Hendriks, R.F.A., Kroes, J.G., 2008. Advances of modeling water flow in variably saturated soils with SWAP. Vadose Zone Journal 7, 640-653.

van Delden, A., Kropff, M., Haverkort, A., 2001. Modeling temperature-and radiation-driven leaf area expansion in the contrasting crops potato and wheat. Field Crop Res 72, 119 141.

van Leeuwen-Haagsma, W., Hoek, H., Molendijk, L., Mommer, L., Ulen, J., KroonenBackbier, B., de Groot, G., 2019. Handboek Groenbemesters 2019. Wageningen University \& Research. 
van Oort, P.A.J., Gou, F., Stomph, T.J., van der Werf, W., 2020. Effects of strip width on yields in relay-strip intercropping: A simulation study. Eur J Agron 112, 125936.

Vandermeer, J.H., 1992. The ecology of intercropping. Cambridge University Press, New York.

Vos, J., van der Putten, P., 1997. Field observations on nitrogen catch crops. I. Potential and actual growth and nitrogen accumulation in relation to sowing date and crop species. Plant Soil 195, 299-309.

Walmsley, D.C., Siemens, J., Kindler, R., Kaiser, K., Saunders, M., Fichtner, A., Kaupenjohann, M., Osborne, B.A., 2018. Reduced nitrate leaching from an Irish cropland soil under non-inversion tillage with cover cropping greatly outweighs increased dissolved organic nitrogen leaching. Agr Ecosyst Environ 265, 340-349.

Wang, Q., Li, Y., Alva, A., 2012. Cover crops in mono-and biculture for accumulation of biomass and soil organic carbon. Journal of Sustainable Agriculture 36, 423-439.

Wang, Z.K., Zhao, X.N., Wu, P.T., He, J.Q., Chen, X.L., Gao, Y., Cao, X.C., 2015. Radiation interception and utilization by wheat/maize strip intercropping systems. Agricultural and Forest Meteorology 204, 58-66.

Wendling, M., Buchi, L., Amosse, C., Jeangros, B., Walter, A., Charles, R., 2017. Specific interactions leading to transgressive overyielding in cover crop mixtures. Agr Ecosyst Environ 241, 88-99.

Wendling, M., Büchi, L., Amosse, C., Sinaj, S., Walter, A., Charles, R., 2015. Nutrient accumulation by cover crops with different root systems. Aspects of Applied Biology 129, 91-96.

Wendling, M., Büchi, L., Amossé, C., Sinaj, S., Walter, A., Charles, R., 2016. Influence of root and leaf traits on the uptake of nutrients in cover crops. Plant Soil 409, 419-434.

Wendling, M., Charles, R., Herrera, J., Amosse, C., Jeangros, B., Walter, A., Buchi, L., 2019. Effect of species identity and diversity on biomass production and its stability in cover crop mixtures. Agr Ecosyst Environ 281, 81-91.

Wickham, H., 2011. The split-apply-combine strategy for data analysis. Journal of Statistical Software 40, 1-29.

Wickham, H., 2016. Elegant Graphics for Data Analysis. Springer-Verlag New York.

Wilke, C.O., 2019. cowplot: Streamlined Plot Theme and Plot Annotations for 'ggplot2'.

Wittwer, R.A., Dorn, B., Jossi, W., van der Heijden, M.G.A., 2017. Cover crops support ecological intensification of arable cropping systems. Sci Rep-Uk 7(1), 1-12.

Wittwer, R.A., van der Heijden, M.G.A., 2020. Cover crops as a tool to reduce reliance on intensive tillage and nitrogen fertilization in conventional arable cropping systems. Field Crop Res 249, 107736.

Wortman, S.E., Francis, C.A., Lindquist, J.L., 2012. Cover Crop Mixtures for the Western Corn Belt: Opportunities for Increased Productivity and Stability. Agron J 104, 699705.

Xu, Z., Li, C., Zhang, C., Yu, Y., van der Werf, W., Zhang, F., 2020. Intercropping maize and soybean increases efficiency of land and fertilizer nitrogen use; A meta-analysis. Field Crop Res 246, 107661.

Yu, Y., Stomph, T.-J., Makowski, D., Zhang, L., van der Werf, W., 2016. A meta-analysis of relative crop yields in cereal/legume mixtures suggests options for management. Field Crop Res 198, 269-279.

Yu, Y., Stomph, T.J., Makowski, D., van der Werf, W., 2015. Temporal niche differentiation increases the land equivalent ratio of annual intercrops: A meta-analysis. Field Crop Res 184, 133-144. 
Zahran, H.H., 1999. Rhizobium-legume symbiosis and nitrogen fixation under severe conditions and in an arid climate. Microbiology and molecular biology reviews 63, 968989.

Zhang, C.C., Postma, J.A., York, L.M., Lynch, J.P., 2014. Root foraging elicits niche complementarity-dependent yield advantage in the ancient 'three sisters' (maize/bean/squash) polyculture. Ann Bot-London 114, 1719-1733.

Zhang, L., Van der Werf, W., Bastiaans, L., Zhang, S., Li, B., Spiertz, J., 2008. Light interception and utilization in relay intercrops of wheat and cotton. Field Crop Res 107, 29-42.

Zhang, W.P., Liu, G.C., Sun, J.H., Fornara, D., Zhang, L.Z., Zhang, F.F., Li, L., 2017. Temporal dynamics of nutrient uptake by neighbouring plant species: Evidence from intercropping. Functional Ecology 31, 469-479.

Zhu, G.L., Ren, Z., Liu, Y.Q., Lu, F.G., Gu, L.F., Shi, Y., Liu, J.W., Zhou, G.S., Nimir, N.E.A., Mohapatra, P.K., 2020. Optimization of leaf properties and plant phenotype through yield-based genetic improvement of rice over a period of seventy years in the Yangtze River Basin of China. Food Energy Secur. 9(3), e223.

Zuur, A., Ieno, E.N., Walker, N., Saveliev, A.A., Smith, G.M., 2009. Mixed effects models and extensions in ecology with R. Springer Science \& Business Media. 


\section{Appendix A}

Cover crop mixtures result in a positive net biodiversity effect irrespective of seeding configuration

Table A1 Analysis of variance for biomass and nitrogen uptake grouped by years and harvesting dates.

Table A2 Analysis of variance for biomass and nitrogen uptake grouped by cropping system.

Table A3 Analysis of variance of net biodiversity effect $(N E)$ and its components for biomass.

Table A4 Analysis of variance of net biodiversity effect $(N E)$ and its components for $\mathrm{N}$ uptake. 
Table A1. Analysis of variance for biomass and nitrogen uptake of three cover crops in pure stand: oil seed radish (Raphanus sativus L.), common vetch (Vicia sativa L.), and bristle oat (Avena strigosa), in three years (2015-2017) at 3, 6, 9 and 12 weeks after sowing (WAS). Differences in nitrogen uptake between species was analysed at 12 WAS. $* * *=P \leq 0.001$; ** $=P \leq 0.01 ; *=P \leq 0.05 ;()=.P \leq 0.1$.

\begin{tabular}{|c|c|c|c|c|c|c|}
\hline \multirow{2}{*}{ year } & \multirow{2}{*}{ Harvesting time } & \multicolumn{3}{|c|}{ Biomass yield } & \multicolumn{2}{|c|}{ Nitrogen uptake } \\
\hline & & Df & F. value & $P$ & F. value & $P$ \\
\hline \multirow{4}{*}{2015} & $3 \mathrm{WAS}$ & 2 & 8.34 & * & 1 & 1 \\
\hline & $6 \mathrm{WAS}$ & 2 & 0.34 & & 1 & 1 \\
\hline & 9 WAS & 2 & 4.58 & (.) & 1 & 1 \\
\hline & 12 WAS & 2 & 19.6 & $* *$ & 425 & $* * *$ \\
\hline \multirow{4}{*}{2016} & 3 WAS & 2 & 42.0 & $* * *$ & 1 & 1 \\
\hline & $6 \mathrm{WAS}$ & 2 & 22.3 & $* *$ & 1 & 1 \\
\hline & 9 WAS & 2 & 21.9 & $* *$ & 1 & 1 \\
\hline & 12 WAS & 2 & 15.3 & $* *$ & 5.66 & $*$ \\
\hline \multirow{4}{*}{2017} & $3 \mathrm{WAS}$ & 2 & 25.7 & $* *$ & 1 & 1 \\
\hline & $6 \mathrm{WAS}$ & 2 & 28.4 & $* * *$ & 1 & 1 \\
\hline & 9 WAS & 2 & 34.7 & $* * *$ & 1 & 1 \\
\hline & 12 WAS & 2 & 12.8 & $* *$ & 5.62 & * \\
\hline
\end{tabular}


Table A2. Analysis of variance for biomass and nitrogen uptake of cover crops in three consecutive years (Y; 2015-2017). Treatments were grouped by cropping system (CS; mixtures or pure stands) or spatial configuration (SC; mixed within row, mixed in alternate rows and pure stands). $* * *=P \leq 0.001 ; * *=P \leq 0.01 ; *=P \leq 0.05 ;()=.P \leq 0.1$.

\begin{tabular}{lllllcc}
\hline \multirow{2}{*}{ Source of variation } & & \multicolumn{4}{c}{ Biomass yield } & \multicolumn{2}{c}{ Nitrogen uptake } \\
\cline { 2 - 7 } & & Df & F. value & $P$ & F. value & $P$ \\
\cline { 2 - 7 } & 2015 & 1 & 0.05 & & 0.16 & \\
Cropping system (CS) & 2016 & 1 & 8.22 & $* *$ & 5.2 & $*$ \\
& 2017 & 1 & 3.91 & $()$. & 0.17 & \\
\cline { 2 - 7 } & Year & 2 & 59.8 & $* * *$ & 26.4 & $* * *$ \\
& CS & 1 & 11.1 & $* *$ & 4.38 & $*$ \\
& Year $\times$ CS & 2 & 3.56 & $*$ & 2.02 & \\
\hline \multirow{5}{*}{ Spatial configuration (SC) } & 2015 & 2 & 0.18 & & 0.39 & \\
& 2016 & 2 & 4.78 & $*$ & 2.64 & $()$. \\
& 2017 & 2 & 2.47 & $()$. & 0.39 & \\
\cline { 2 - 7 } & Year & 2 & 59.9 & $* * *$ & 25.9 & $* * *$ \\
& SC & 2 & 5.80 & $* *$ & 2.71 & $()$. \\
& Year $\times$ SC & 4 & 2.44 & $()$. & 1.01 & \\
\hline
\end{tabular}




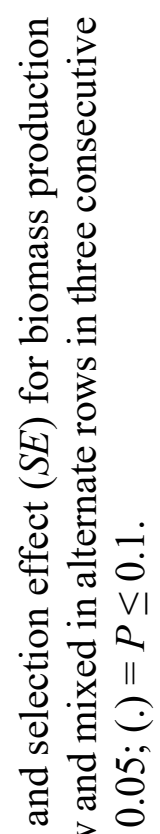

II 3

U

过 $*$

过宁

르ㄹㅣㅣㅇ

吾当 V

ฮี

융 总

Iิ

I. 00

¿记

异

를

क्ते 0

ऐ

吾.尹

귱

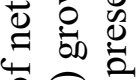

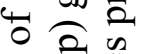

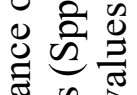

胥

灵

宁

क 응

천 인

安宁

घं $0 \cong$

$<\ddot{\nu}$

常壳

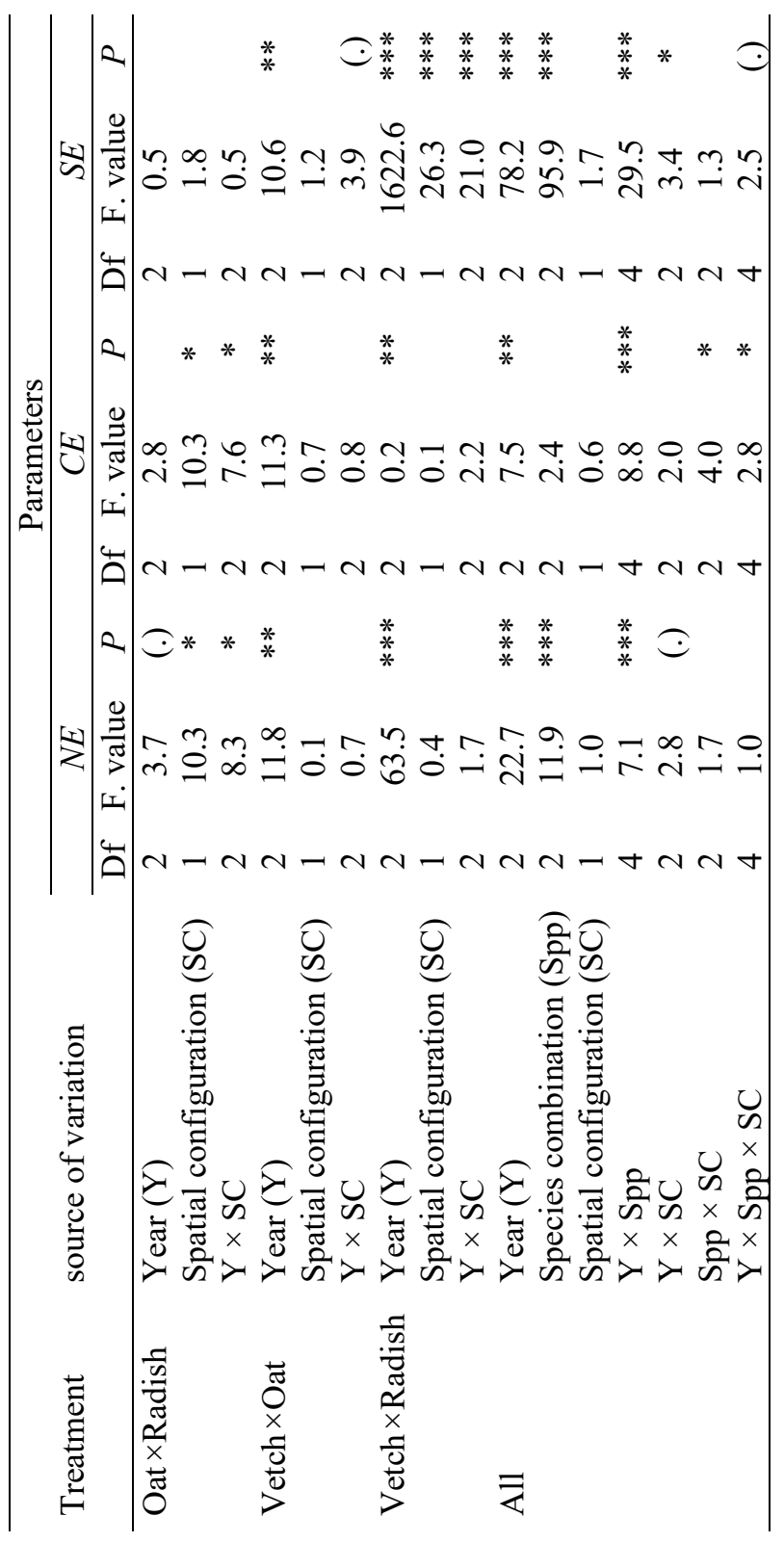




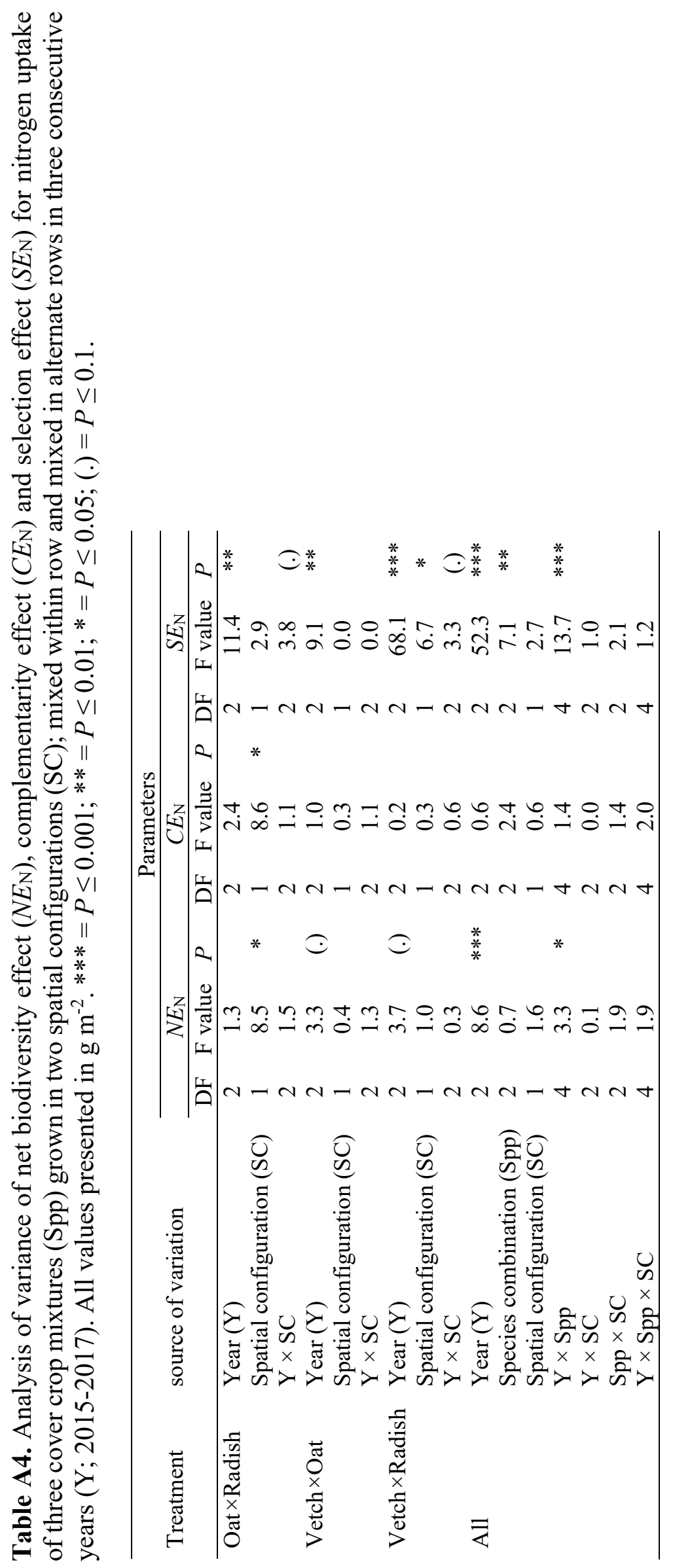





\section{Appendix B}

Do cover crop mixtures give higher and more stable yields than pure stands?

Table B1 mean estimates for biomass and variance of mixtures and pure stands.

Table B2 mean estimates for $\mathrm{N}$ yield and variance of mixtures and pure stands.

Figure B1 Average biomass per treatment in 2017 at four sites.

Figure B2 Average biomass per treatment in 2018 at four sites.

Figure B3 Average N yield per treatment in 2017 at four sites.

Figure B4 Average N yield per treatment in 2018 at four sites.

Figure B5 Average N content (\%) per treatment in 2017 at four sites.

Figure B6 Average N content (\%) per treatment in 2018 at four sites. 
Table B1. mean estimates for biomass and variance of mixtures and pure stands. values were extracted from a Bayesian linear mixed model (Equation 4.1).

\begin{tabular}{|c|c|c|c|}
\hline All species & mean & $2.5 \%$ credible limit & $97.5 \%$ credible limit \\
\hline $\begin{array}{l}\text { Pure stands } \\
\text { Biomass } \\
\text { Between site-year variance* } \\
\text { Between treatment variance } \\
\text { Between plot variance }\end{array}$ & $\begin{array}{l}\text { t ha-1 } \\
3.58 \\
2.47 \\
1.54 \\
1.04 \\
\end{array}$ & $\begin{array}{l}\text { t ha-1 } \\
1.38 \\
1.11 \\
0.89 \\
0.94 \\
\end{array}$ & $\begin{array}{l}\text { t ha-1 } \\
5.38 \\
3.77 \\
2.22 \\
1.13 \\
\end{array}$ \\
\hline $\begin{array}{l}\text { Mixtures } \\
\text { Biomass } \\
\text { Between site-year variance } \\
\text { Between treatment variance } \\
\text { Between plot variance }\end{array}$ & $\begin{array}{l}\text { t ha-1 } \\
4.87 \\
2.79 \\
0.34 \\
0.88 \\
\end{array}$ & $\begin{array}{l}\text { t ha-1 } \\
2.82 \\
1.35 \\
0.13 \\
0.80 \\
\end{array}$ & $\begin{array}{l}\text { t ha-1 } \\
6.73 \\
4.32 \\
0.55 \\
0.95 \\
\end{array}$ \\
\hline $\begin{array}{l}\text { Ratios } \\
\text { Biomass } \\
\text { Between site-year variance } \\
\text { Between treatment variance } \\
\text { Between plot variance }\end{array}$ & $\begin{array}{l}\text { ratio } \\
1.50 \\
1.32 \\
0.26 \\
0.85\end{array}$ & $\begin{array}{l}\text { ratio } \\
0.70 \\
0.50 \\
0.10 \\
0.75\end{array}$ & $\begin{array}{l}\text { ratio } \\
3.11 \\
2.53 \\
0.48 \\
0.95\end{array}$ \\
\hline Top 5 producing treatments & mean & $2.5 \%$ credible limit & $97.5 \%$ credible limit \\
\hline $\begin{array}{l}\text { Pure stands } \\
\text { Biomass } \\
\text { Between site-year variance } \\
\text { Between treatment variance } \\
\text { Between plot variance }\end{array}$ & $\begin{array}{l}\text { t ha-1 } \\
5.04 \\
2.88 \\
0.69 \\
0.99 \\
\end{array}$ & $\begin{array}{l}\text { t ha-1 } \\
2.92 \\
1.37 \\
0.14 \\
0.86 \\
\end{array}$ & $\begin{array}{l}\text { t ha-1 } \\
7.06 \\
4.46 \\
1.19 \\
1.11 \\
\end{array}$ \\
\hline $\begin{array}{l}\text { Mixtures } \\
\text { Biomass } \\
\text { Between site-year variance } \\
\text { Between treatment variance } \\
\text { Between plot variance }\end{array}$ & $\begin{array}{l}\text { t ha-1 } \\
5.09 \\
2.97 \\
0.32 \\
0.92 \\
\end{array}$ & $\begin{array}{l}\text { t ha-1 } \\
2.96 \\
1.37 \\
0.05 \\
0.80\end{array}$ & $\begin{array}{l}\text { t ha-1 } \\
7.13 \\
4.51 \\
0.59 \\
1.03\end{array}$ \\
\hline $\begin{array}{l}\text { Ratios } \\
\text { Biomass } \\
\text { Between site-year variance } \\
\text { Between treatment variance } \\
\text { Between plot variance }\end{array}$ & $\begin{array}{l}\text { Ratio } \\
1.06 \\
1.23 \\
0.74 \\
0.93\end{array}$ & $\begin{array}{l}\text { ratio } \\
0.54 \\
0.46 \\
0.11 \\
0.77\end{array}$ & $\begin{array}{l}\text { ratio } \\
1.86 \\
2.33 \\
1.82 \\
1.12\end{array}$ \\
\hline
\end{tabular}

${ }^{*}$ All variances are given on the scale of standard deviation 
Table B2. mean estimates for $\mathrm{N}$ yield and variance of mixtures and pure stands. values were extracted from a Bayesian linear mixed model (Equation 4.1).

\begin{tabular}{|c|c|c|c|}
\hline All species & mean & $2.5 \%$ credible limit & $97.5 \%$ credible limit \\
\hline $\begin{array}{l}\text { Pure stands } \\
\mathrm{N} \text { yield } \\
\text { Between site-year variance* } \\
\text { Between treatment variance } \\
\text { Between plot variance } \\
\end{array}$ & $\begin{array}{l}\mathrm{kg} \mathrm{N} \mathrm{ha} \mathrm{ha}^{-1} \\
72.3 \\
43.9 \\
24.0 \\
25.6 \\
\end{array}$ & $\begin{array}{l}\mathrm{kg} \mathrm{N} \mathrm{ha}{ }^{-1} \\
39.8 \\
19.7 \\
12.7 \\
23.4 \\
\end{array}$ & $\begin{array}{l}\mathrm{kg} \mathrm{N} \mathrm{ha}{ }^{-1} \\
105 \\
67.2 \\
34.4 \\
27.8 \\
\end{array}$ \\
\hline $\begin{array}{l}\text { Mixtures } \\
\mathrm{N} \text { yield } \\
\text { Between site-year variance } \\
\text { Between treatment variance } \\
\text { Between plot variance }\end{array}$ & $\begin{array}{l}\mathrm{t} \mathrm{ha}-1 \\
99.3 \\
45.3 \\
2.55 \\
28.4\end{array}$ & $\begin{array}{l}\mathrm{t} \mathrm{ha}^{-1} \\
67.4 \\
21.0 \\
0.05 \\
26.0\end{array}$ & $\begin{array}{l}\text { t ha-1 } \\
132 \\
69.8 \\
5.61 \\
30.9 \\
\end{array}$ \\
\hline $\begin{array}{l}\text { Ratios } \\
\mathrm{N} \text { yield } \\
\text { Between site-year variance } \\
\text { Between treatment variance } \\
\text { Between plot variance }\end{array}$ & $\begin{array}{l}\text { ratio } \\
1.50 \\
1.22 \\
0.12 \\
1.11\end{array}$ & $\begin{array}{l}\text { ratio } \\
0.21 \\
0.49 \\
0.00 \\
0.98\end{array}$ & $\begin{array}{l}\text { ratio } \\
5.33 \\
2.31 \\
0.32 \\
1.25\end{array}$ \\
\hline Top 5 producing treatments & mean & $2.5 \%$ credible limit & $97.5 \%$ credible limit \\
\hline $\begin{array}{l}\text { Pure stands } \\
\mathrm{N} \text { yield } \\
\text { Between site-year variance } \\
\text { Between treatment variance } \\
\text { Between plot variance }\end{array}$ & $\begin{array}{l}\text { t ha-1 } \\
91.1 \\
43.1 \\
15.8 \\
27.3 \\
\end{array}$ & $\begin{array}{l}\mathrm{t} \mathrm{ha}^{-1} \\
57.0 \\
19.7 \\
0.07 \\
23.8 \\
\end{array}$ & $\begin{array}{l}\text { t ha-1 } \\
124 \\
67.2 \\
26.6 \\
31.0 \\
\end{array}$ \\
\hline $\begin{array}{l}\text { Mixtures } \\
\mathrm{N} \text { yield } \\
\text { Between site-year variance } \\
\text { Between treatment variance } \\
\text { Between plot variance }\end{array}$ & $\begin{array}{l}\text { t ha-1 } \\
101 \\
46.9 \\
4.11 \\
29.2 \\
\end{array}$ & $\begin{array}{l}\mathrm{t} \mathrm{ha}^{-1} \\
65.2 \\
20.5 \\
0.04 \\
25.1\end{array}$ & $\begin{array}{l}\text { t ha-1 } \\
134 \\
71.8 \\
8.38 \\
32.7 \\
\end{array}$ \\
\hline $\begin{array}{l}\text { Ratios } \\
\mathrm{N} \text { yield } \\
\text { Between site-year variance } \\
\text { Between treatment variance } \\
\text { Between plot variance }\end{array}$ & $\begin{array}{l}\text { ratio } \\
1.13 \\
1.30 \\
0.93 \\
1.08\end{array}$ & $\begin{array}{l}\text { ratio } \\
0.655 \\
0.47 \\
0.01 \\
0.89 \\
\end{array}$ & $\begin{array}{l}\text { ratio } \\
1.90 \\
2.52 \\
1.38 \\
1.29\end{array}$ \\
\hline
\end{tabular}

* All variances are given on the scale of standard deviation 

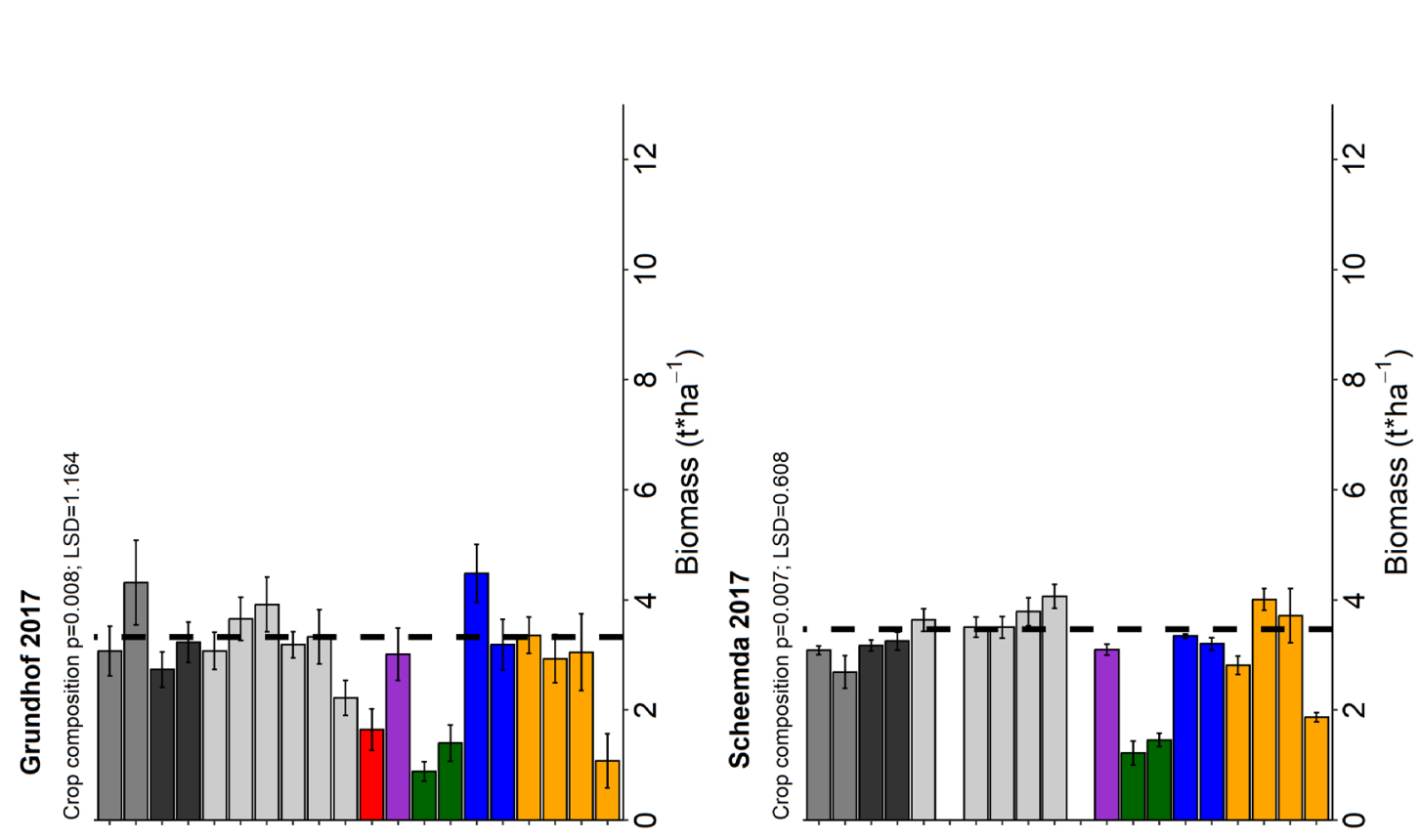

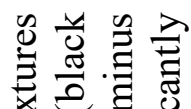
齐 足

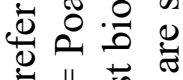
壳苛 ๘ \% $\dot{1} \tilde{0}$

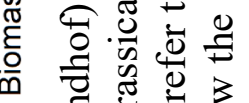

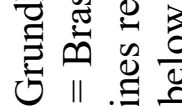
च 淽

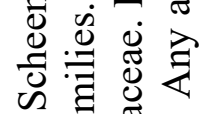

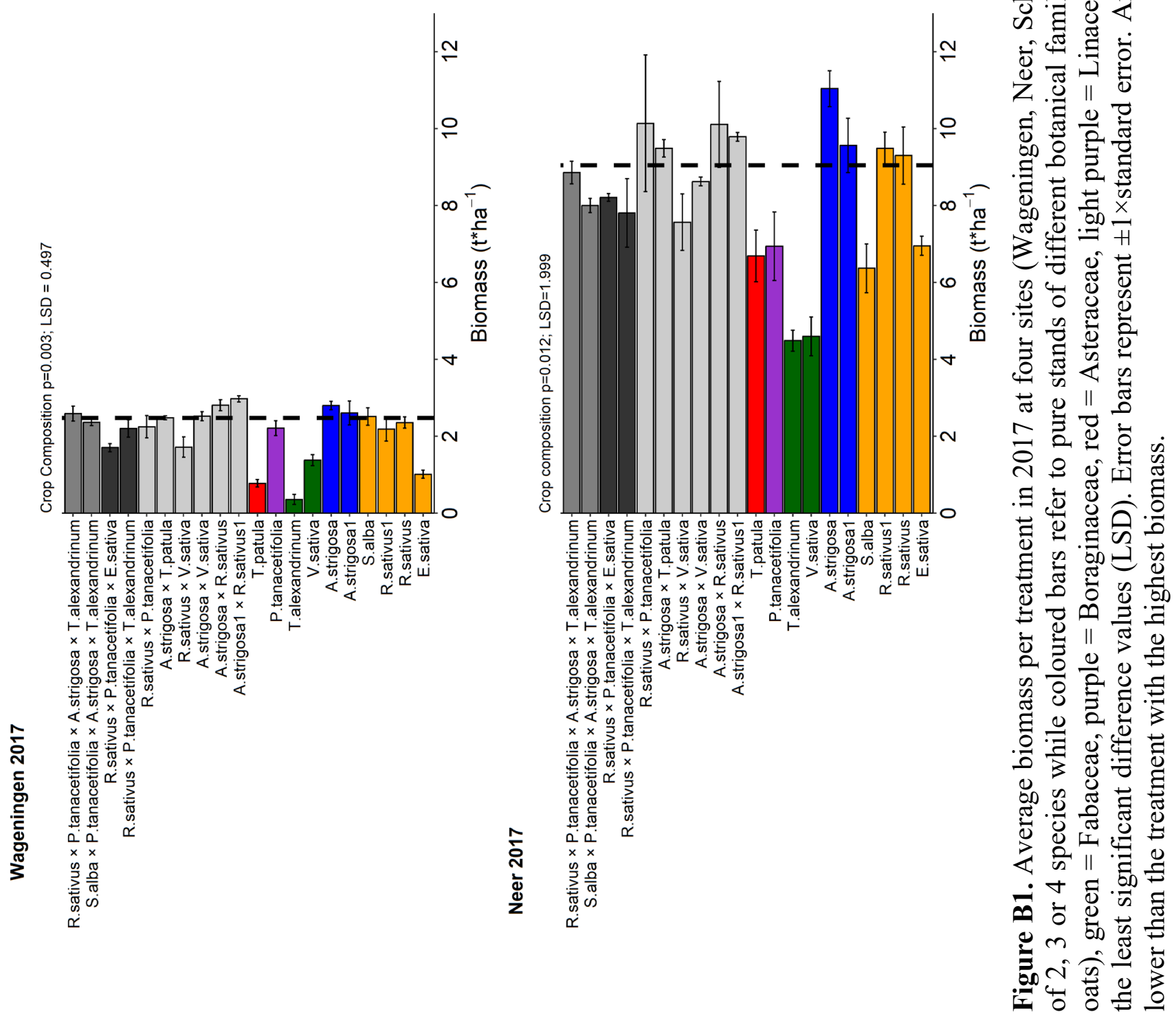



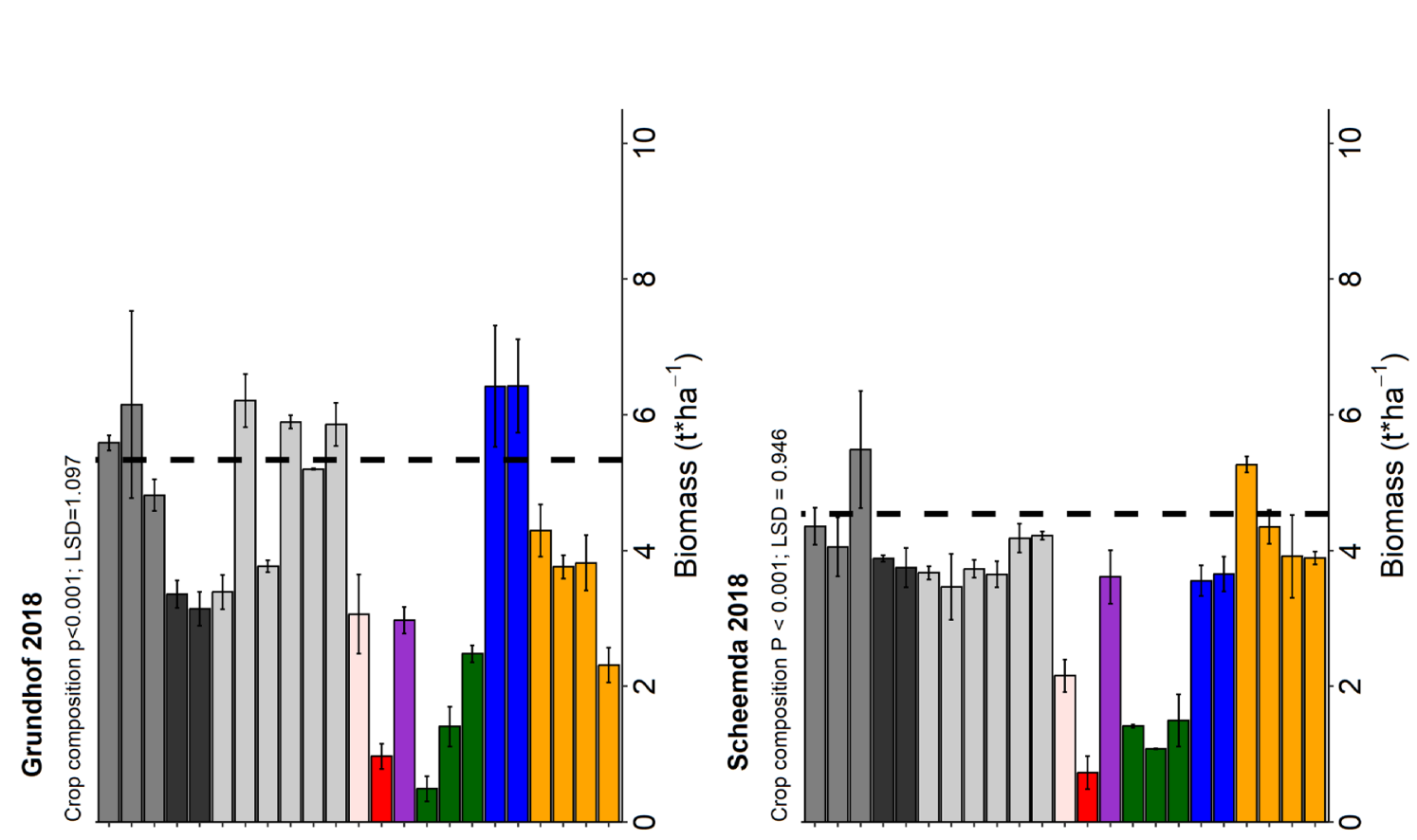

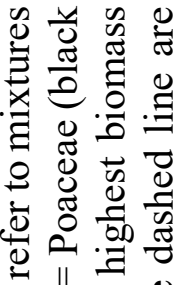
苛五 궁응

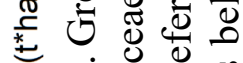
o 0 . 范 司完 苟 䒕过宁 ฮृ 过
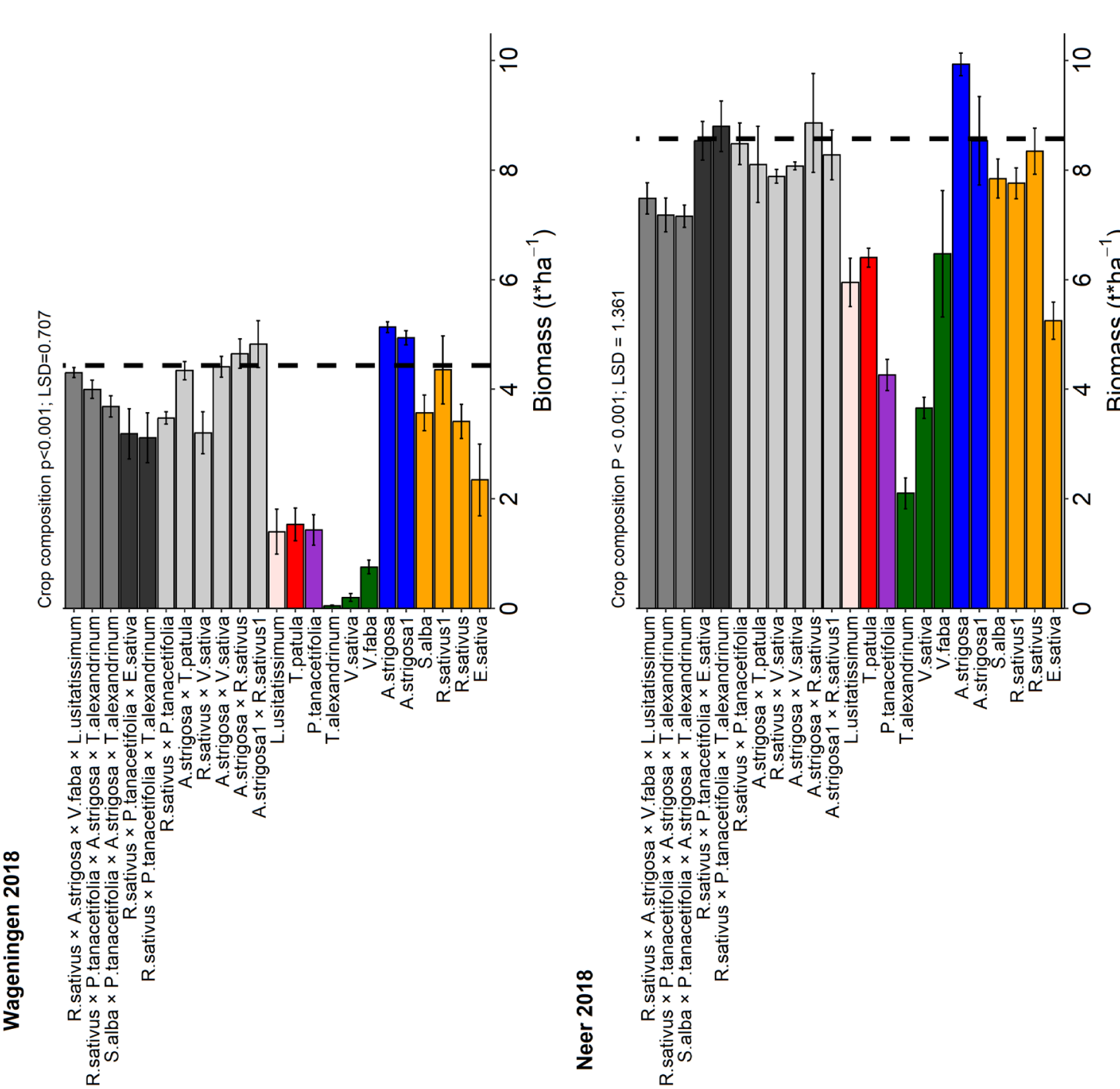

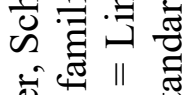

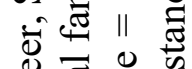
艺. 흘

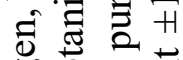
.000 눙

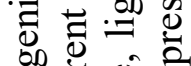

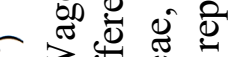
T这鸟

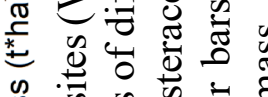

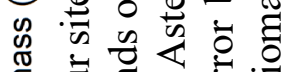

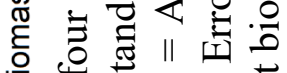

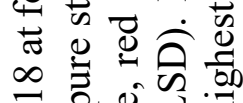
하월 용 $\exists$.

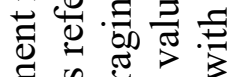

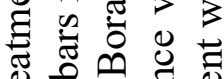

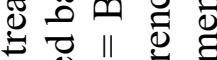
它氙离 西

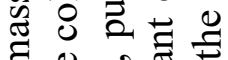

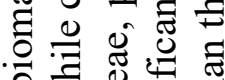

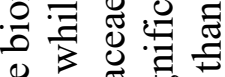

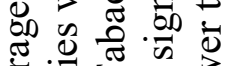

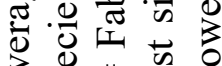

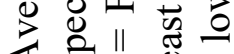
요의

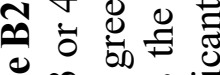
等 


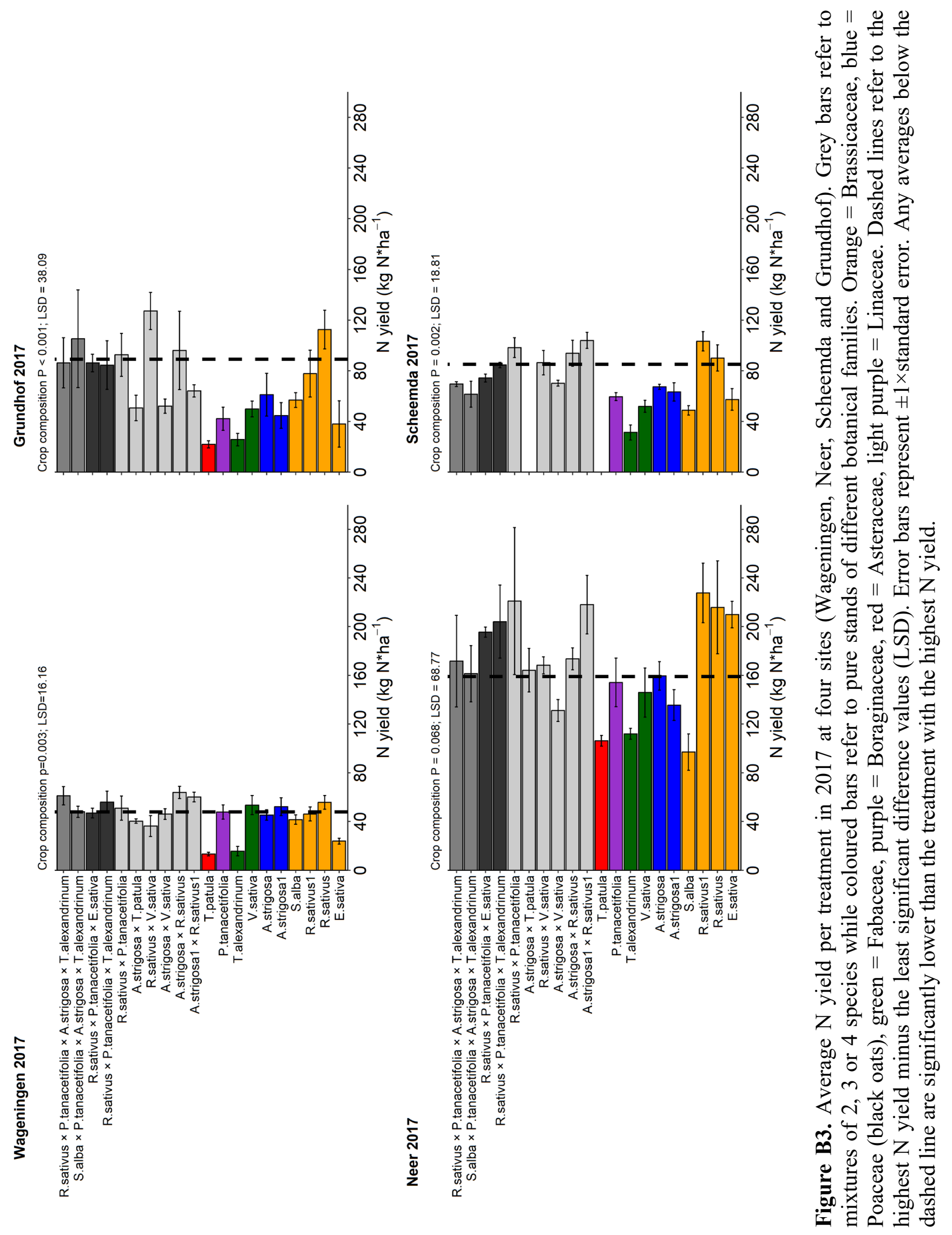



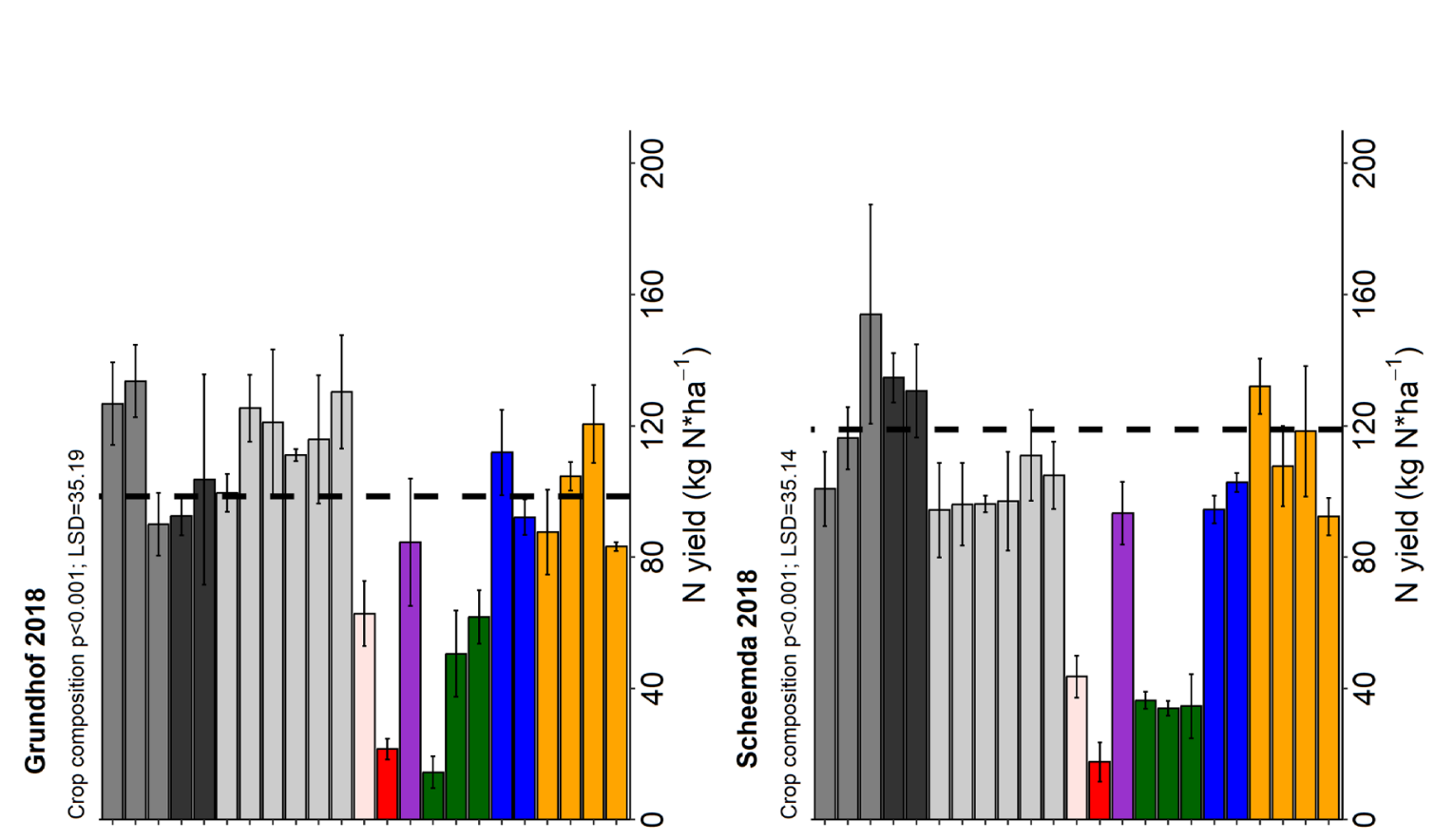

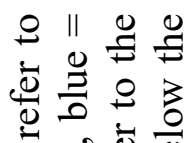
कैष

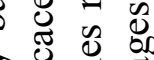
仓ัँ 记 बำ $\infty_{\infty}$ उ芯导

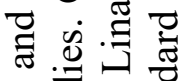
즐 馬葡 过矛言草

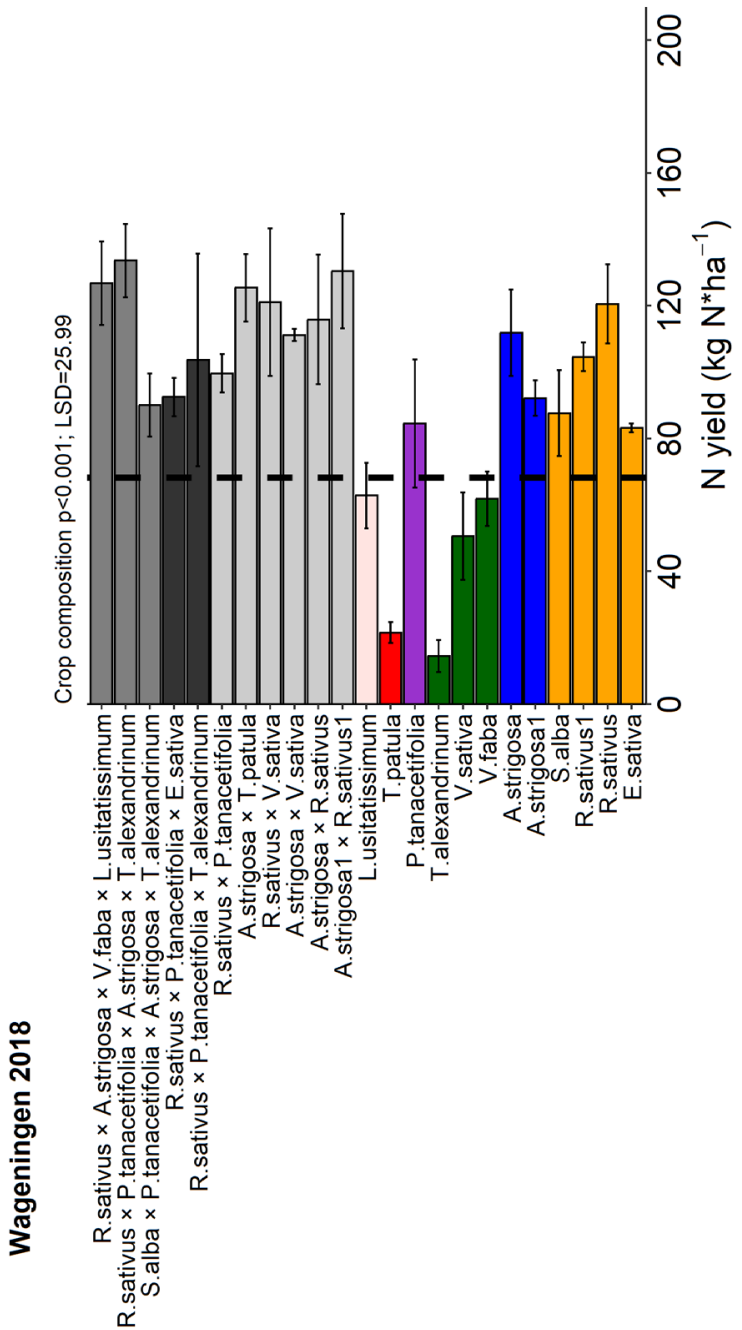

夌

鴊 远: 乙

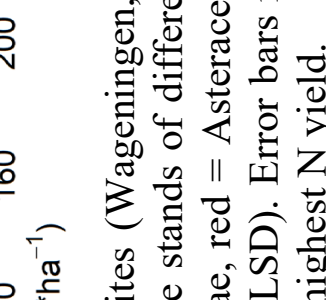

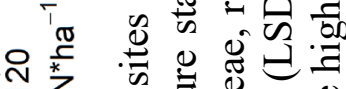
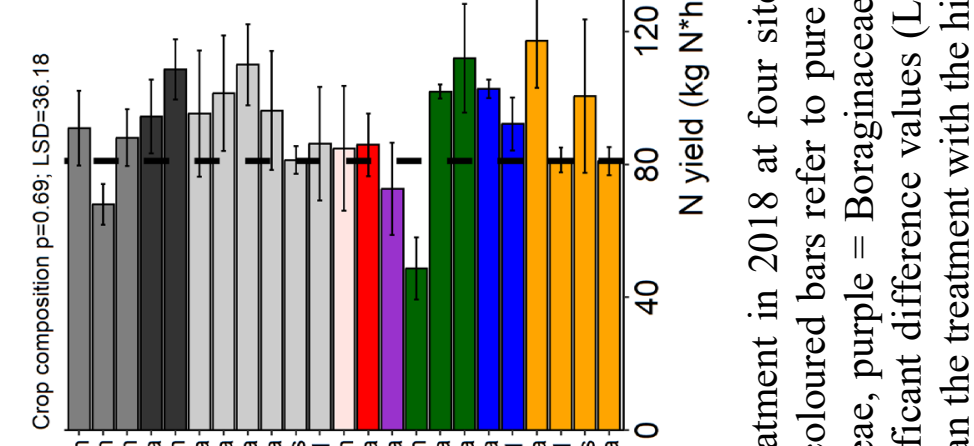
$\infty \underset{0}{0}$

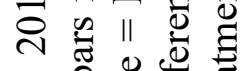
$\exists$ 글

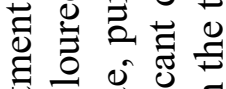

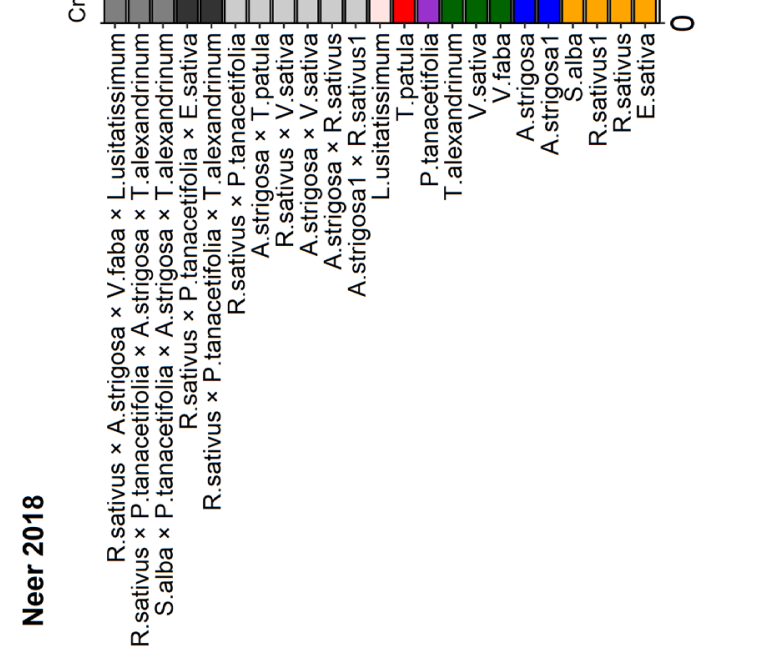

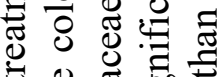
政

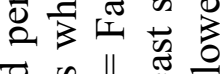

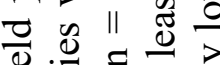
乙

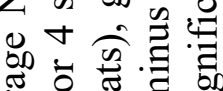
竞

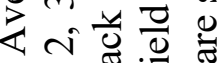

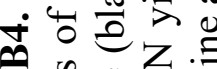

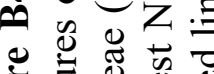
言. 


\section{Wageningen 2017}

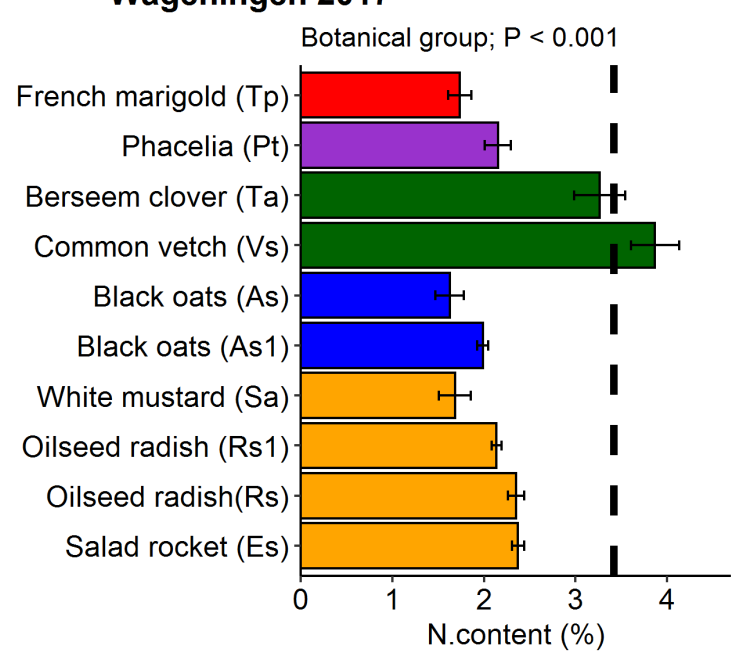

\section{Neer 2017}

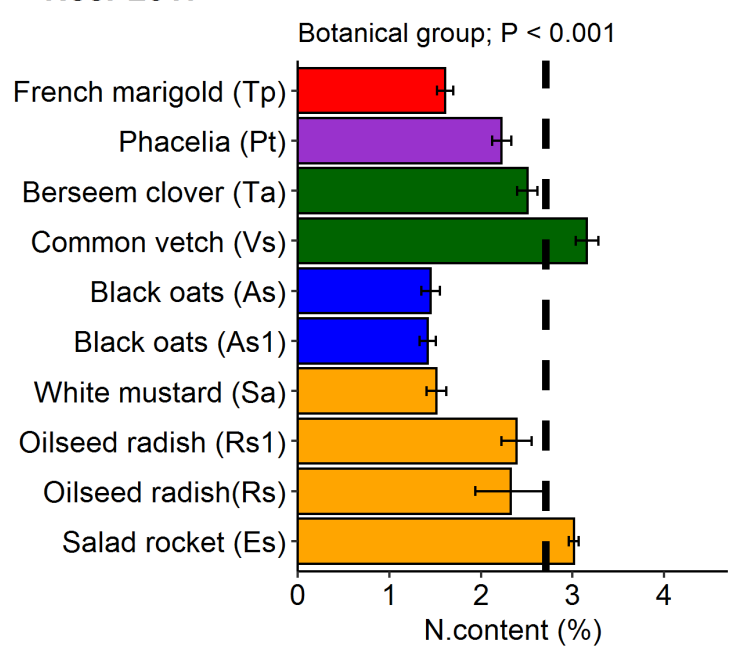

Grundhof 2017

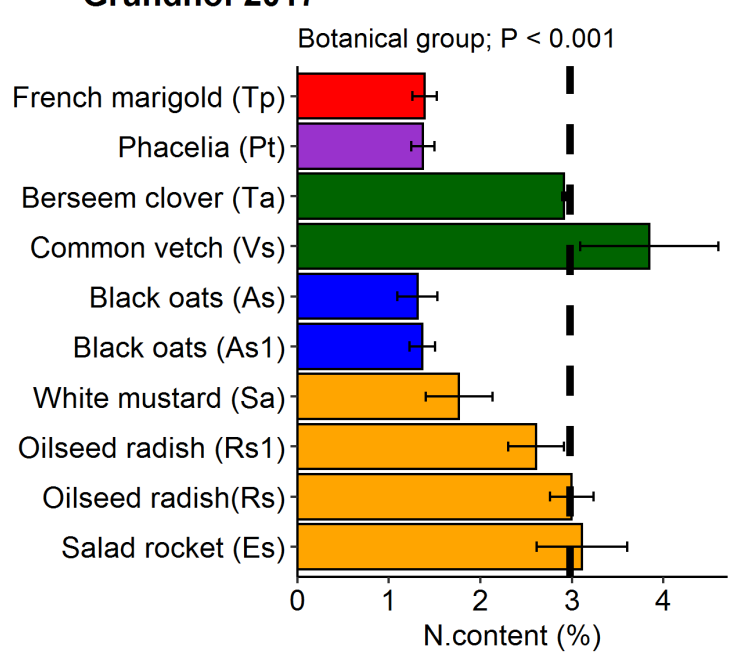

Scheemda 2017

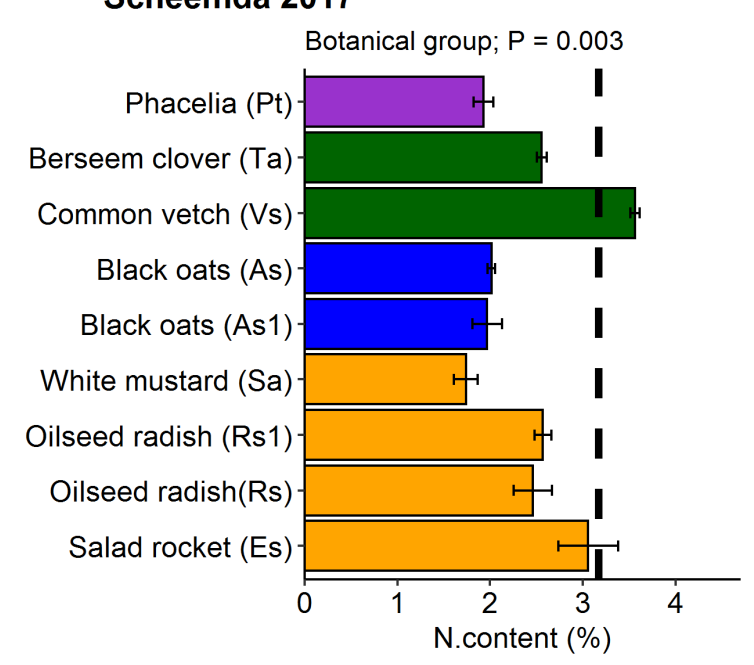

Figure B5. Average N content (\%) per treatment in 2017 at four sites (Wageningen, Neer, Scheemda and Grundhof). Colour of bars refer to different botanical families. Orange $=$ Brassicaceae, blue $=$ Poaceae (black oats), green $=$ Fabaceae, purple $=$ Boraginaceae, red $=$ Asteraceae. Dashed lines refer to the highest $\mathrm{N}$ content (\%) minus the least significant difference values (LSD). Error bars represent $\pm 1 \times$ standard error. Any averages below the dashed line are significantly lower than the treatment with the highest $\mathrm{N}$ content $(\%)$. 


\section{Wageningen 2018}

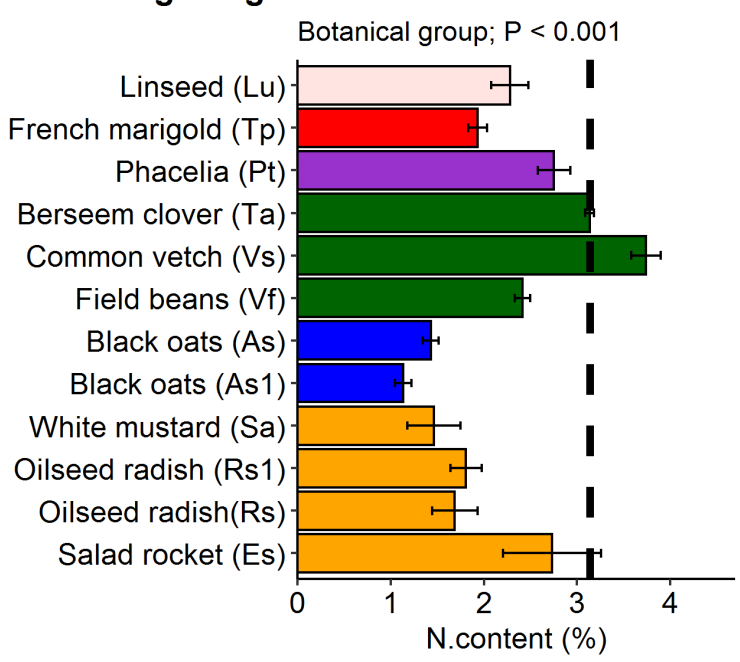

\section{Neer 2018}

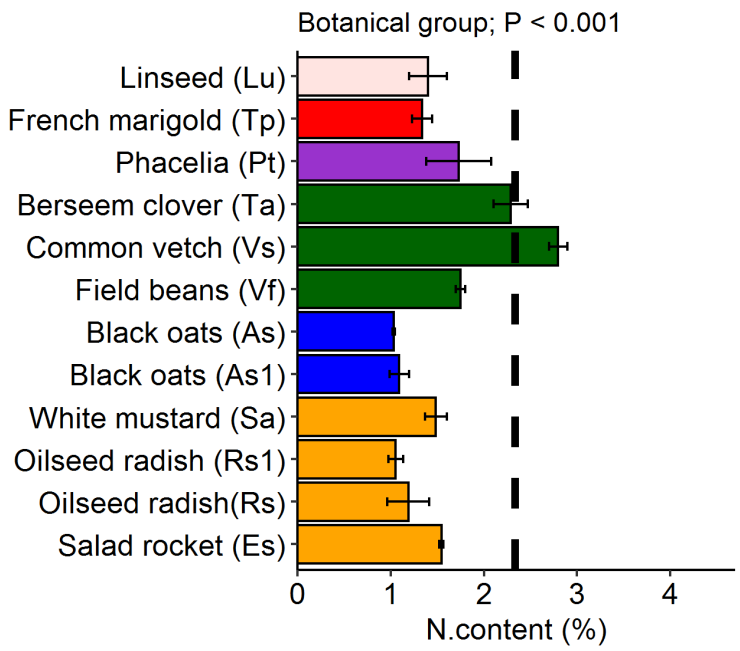

\section{Grundhof 2018}

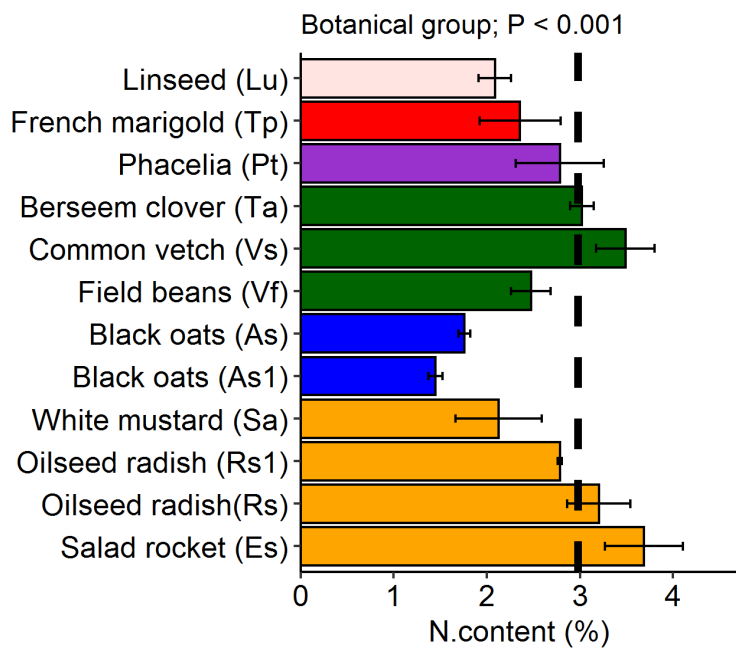

Scheemda 2018

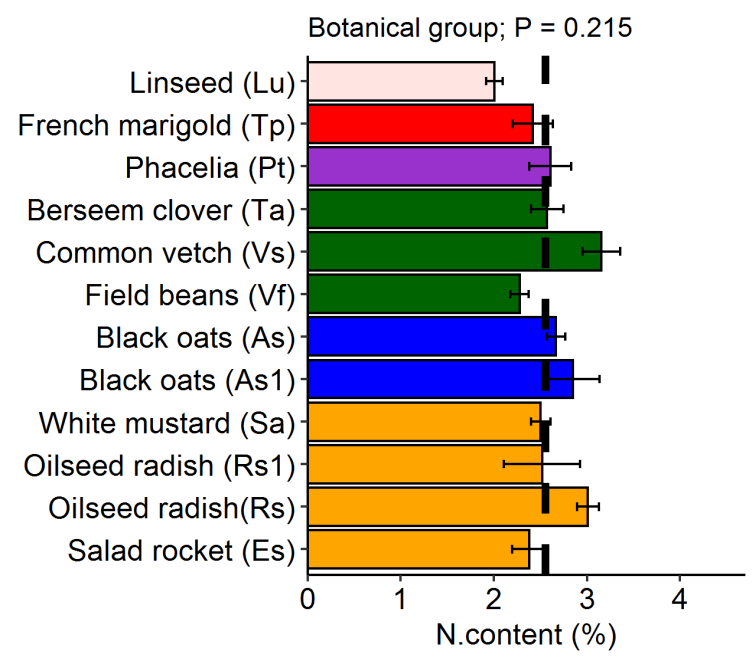

Figure B6. Average N content (\%) per treatment in 2018 at four sites (Wageningen, Neer, Scheemda and Grundhof). Colour of bars refer to different botanical families. Orange $=$ Brassicaceae, blue $=$ Poaceae (black oats), green $=$ Fabaceae, purple $=$ Boraginaceae, red $=$ Asteraceae, light purple $=$ Linaceae. Dashed lines refer to the highest $\mathrm{N}$ content $(\%)$ minus the least significant difference values (LSD). Error bars represent $\pm 1 \times$ standard error. Any averages below the dashed line are significantly lower than the treatment with the highest $\mathrm{N}$ content (\%). 



\section{Appendix C}

Radiation interception and radiation use efficiency in mixtures of winter cover crops

Figure C1 Fraction of ground cover over time of pure stands and mixtures of cover crops.

Figure C2 Scatter plot showing radiation capture and radiation use efficiency of cover crops. 


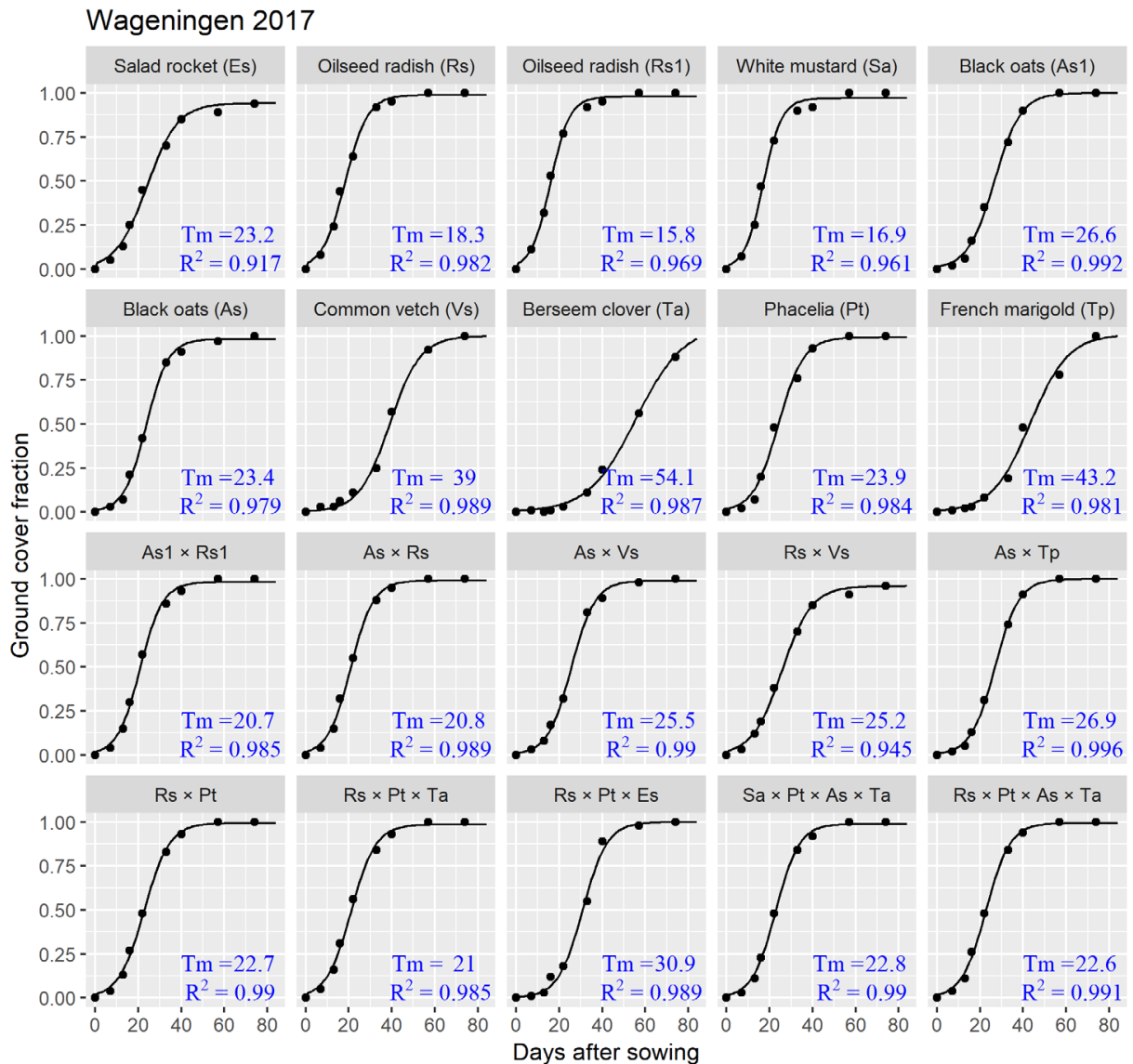

\section{Scheemda 2017}

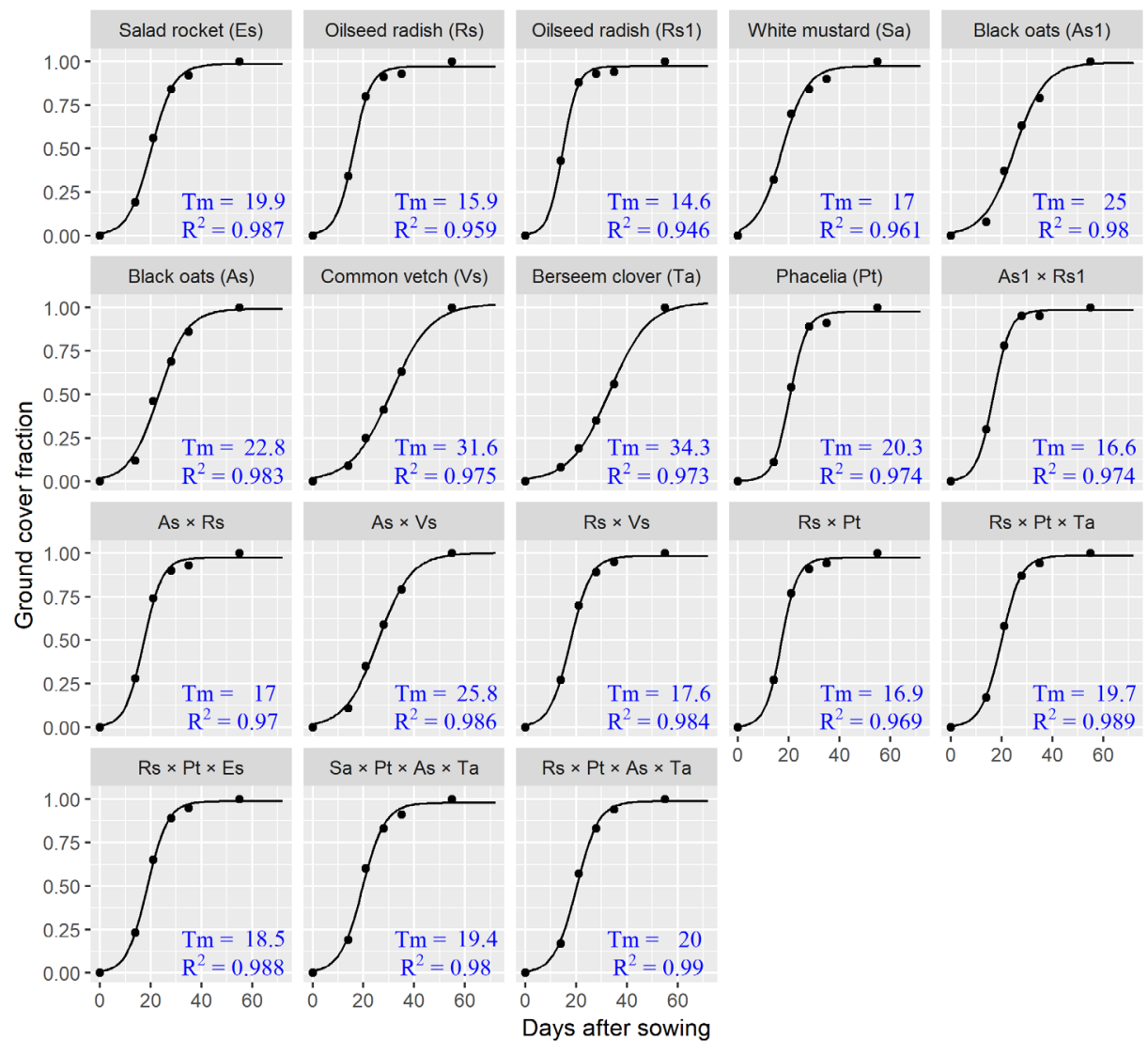



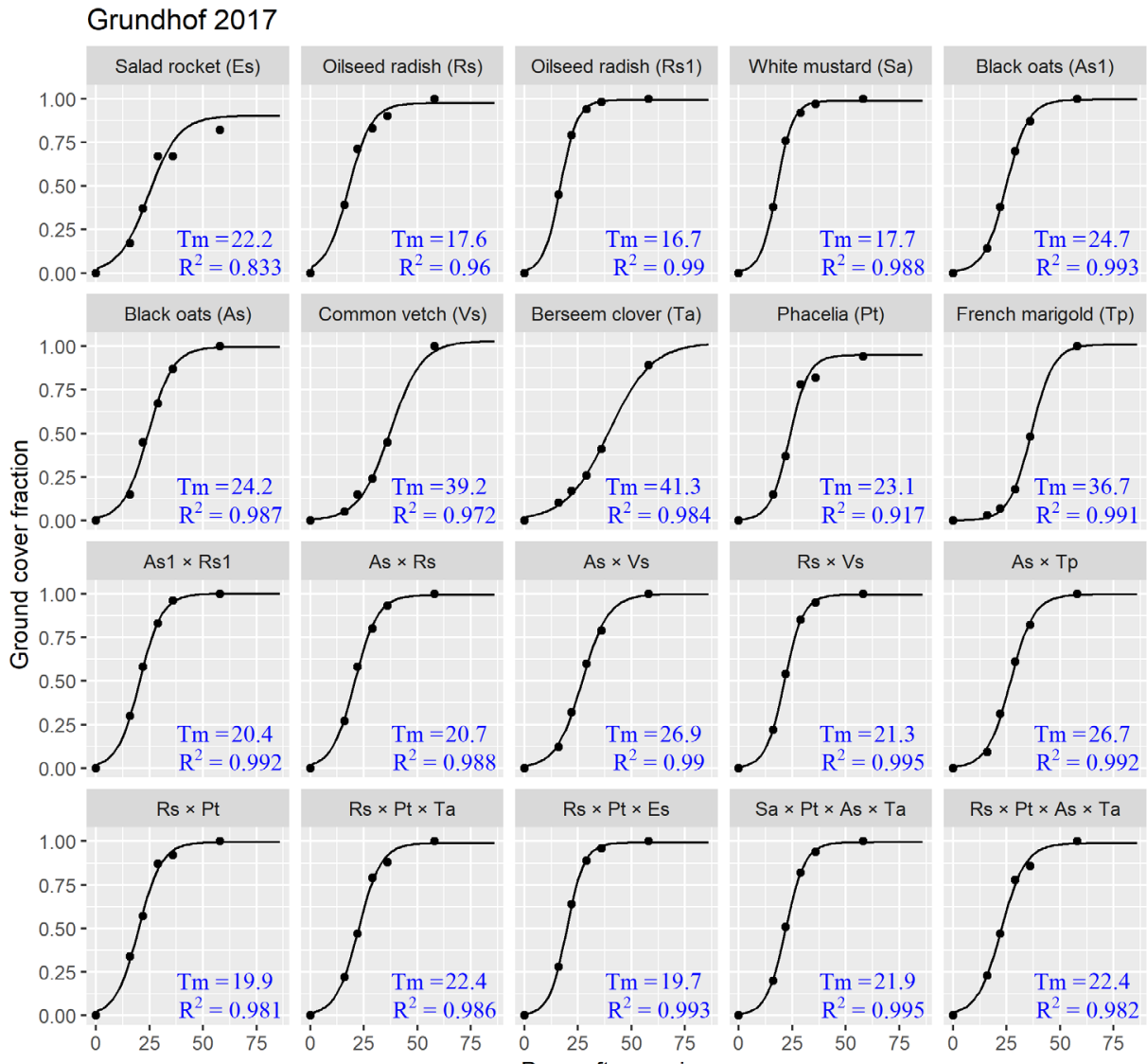

Common vetch (Vs)

Berseem clover (Ta)

Phacelia (Pt)

French marigold $(T p)$
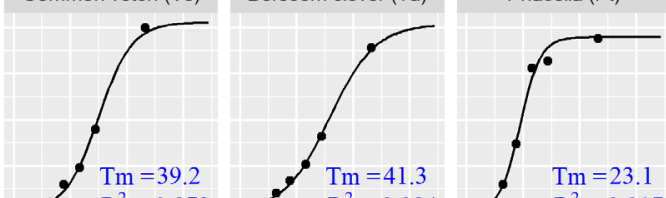
$\mathrm{R}^{2}=0.972$

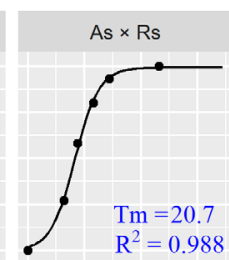

$\mathrm{R}^{2}=0.984$
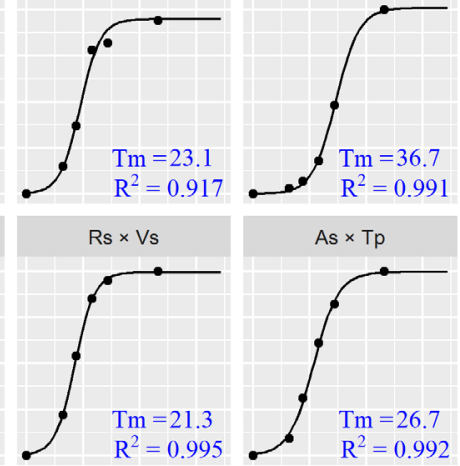

As $\times V s$
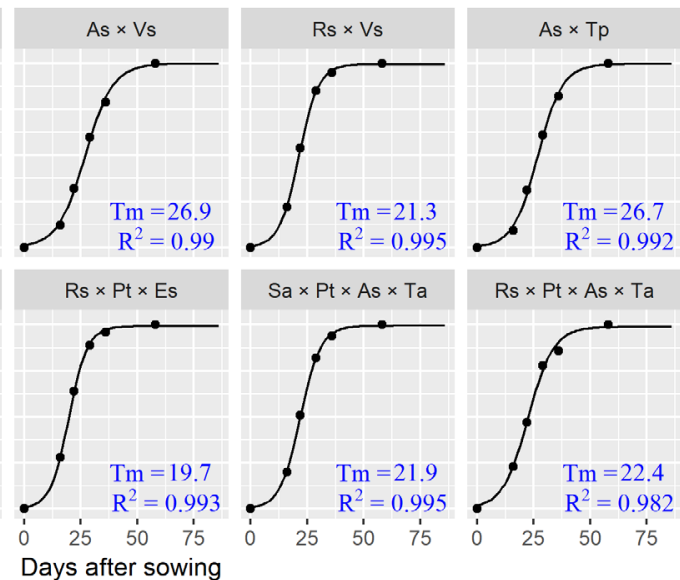

$\mathrm{Sa} \times \mathrm{Pt} \times \mathrm{As} \times \mathrm{Ta}$
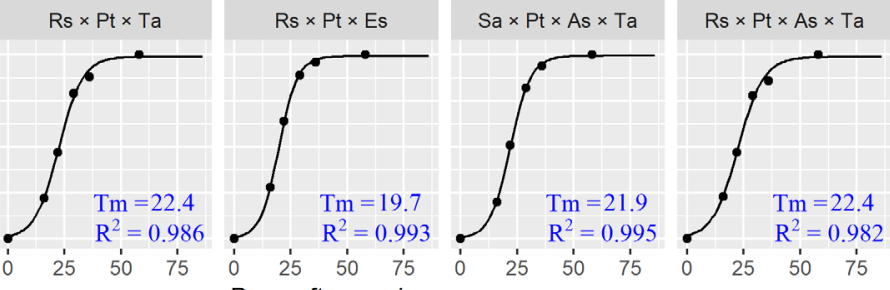

\section{Neer 2017}

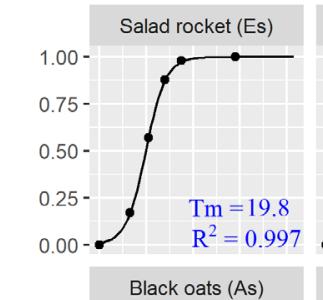

Oilseed radish (Rs)

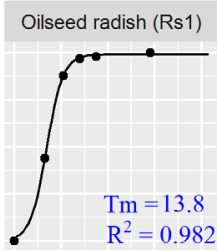

White mustard (Sa)

Black oats (As1)
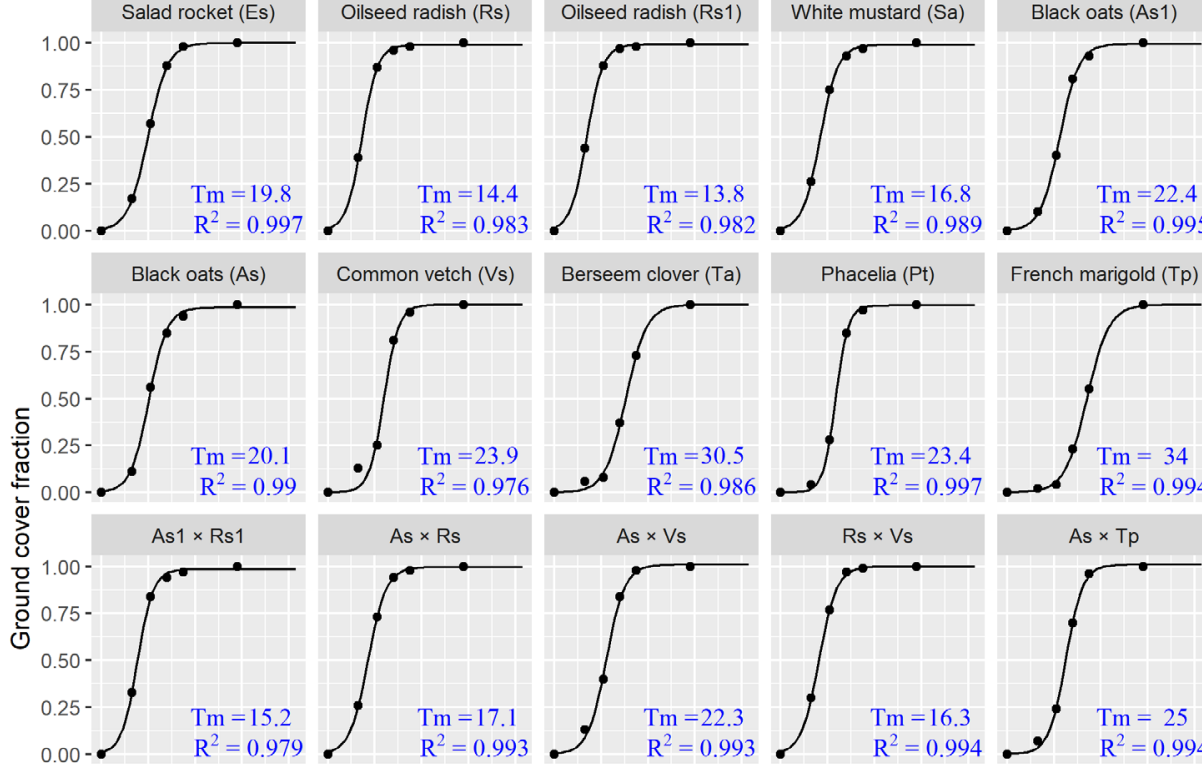

Common vetch (Vs)

Berseem clover (Ta)

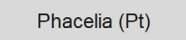

French marigold (Tp)
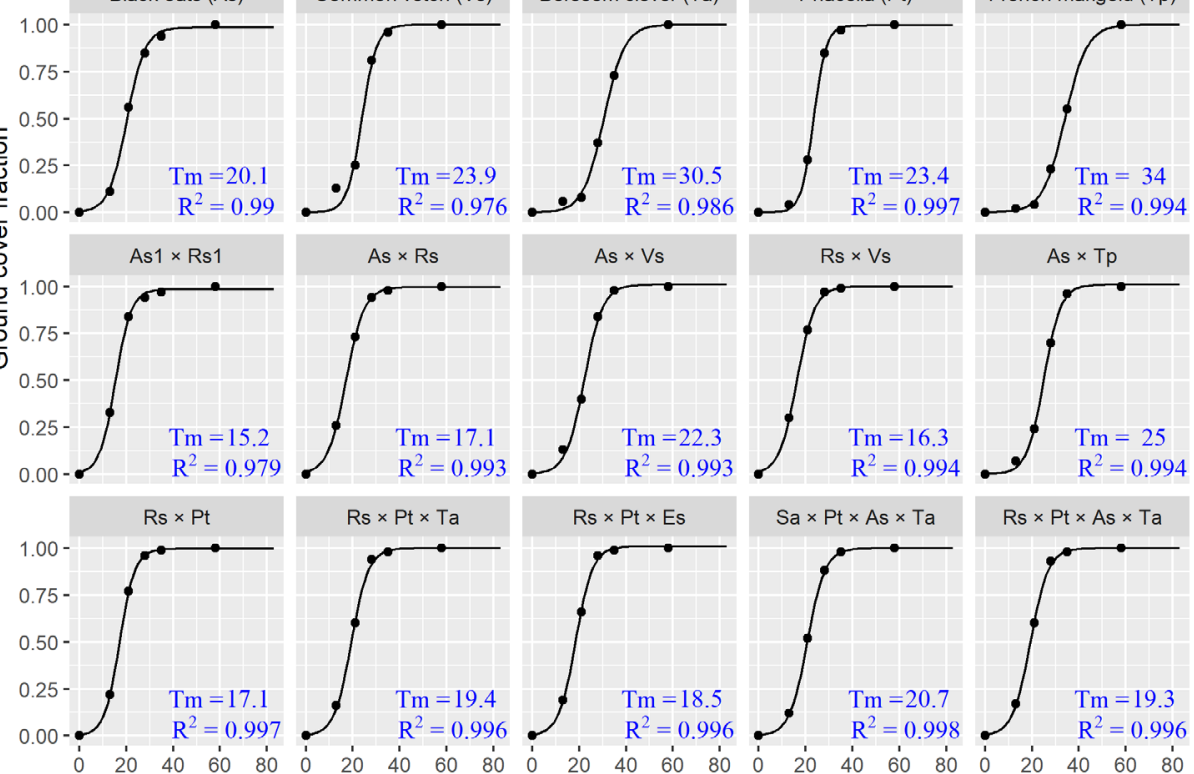

Days after sowing 

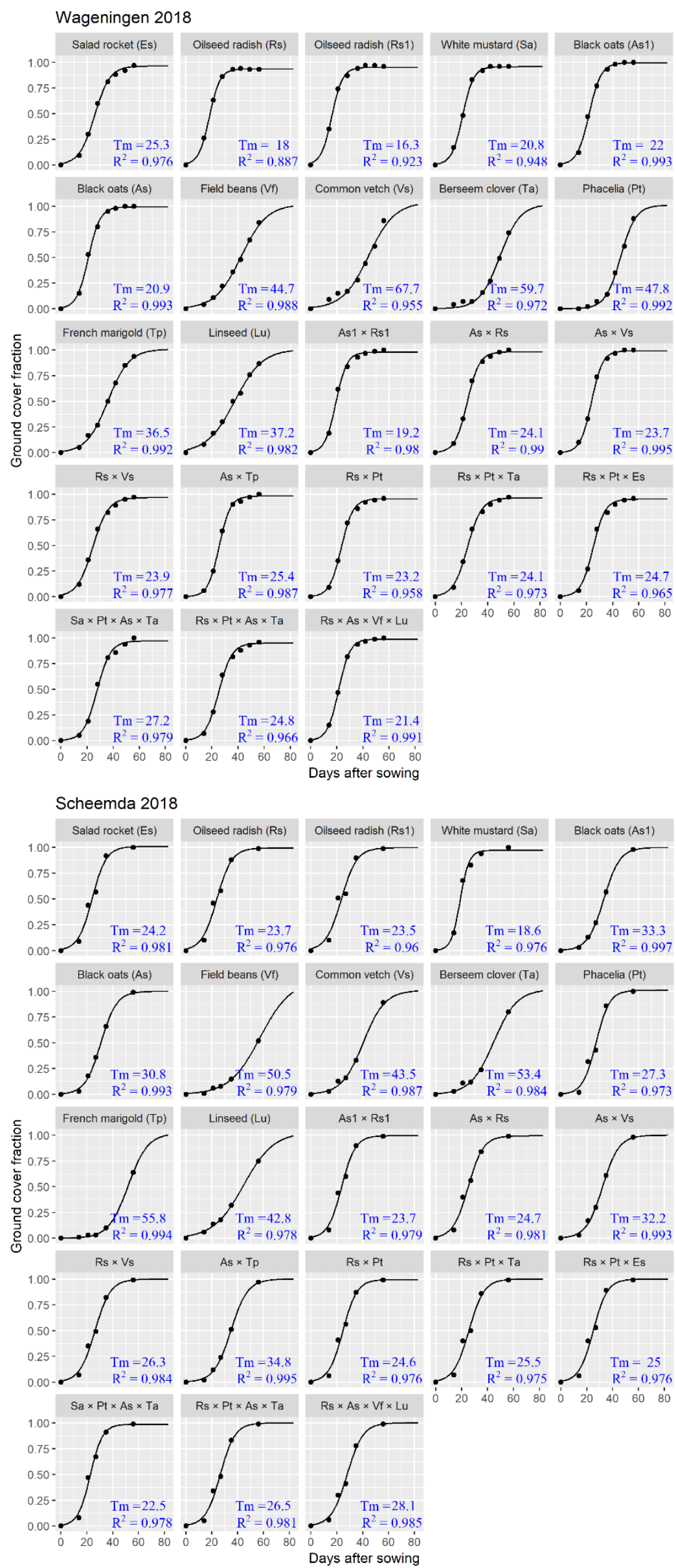


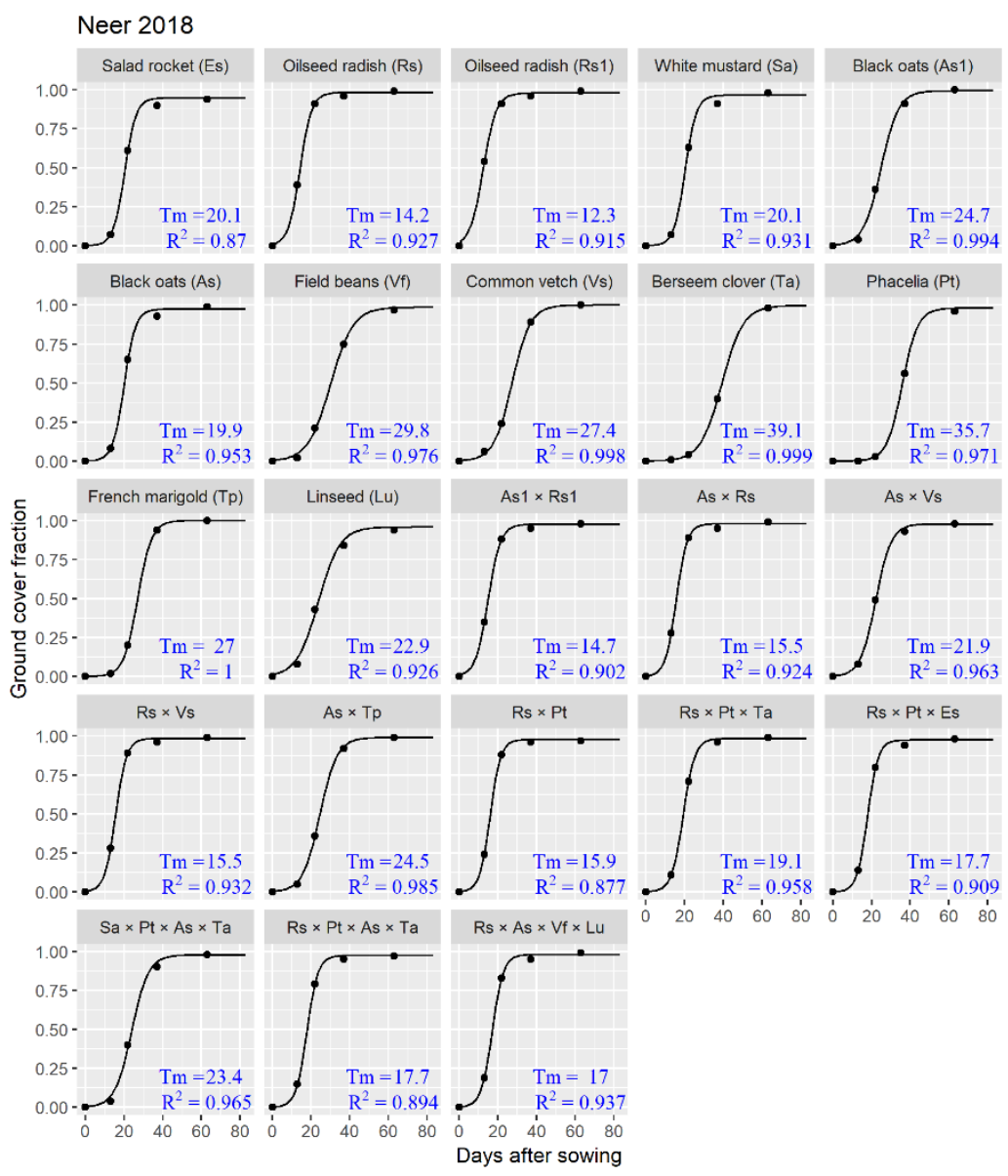

Figure C1. Fraction of ground cover over time of pure stands and mixtures of cover crops. All crops were grown between August and November. Data presented for each species at eight site-years (four sites; Wageningen, Neer, Scheemda and Grundhof and two years: 2017 and 2018). T50\% represents time to reach $50 \%$ of maximum soil cover. Lines are the fitted logistic function.

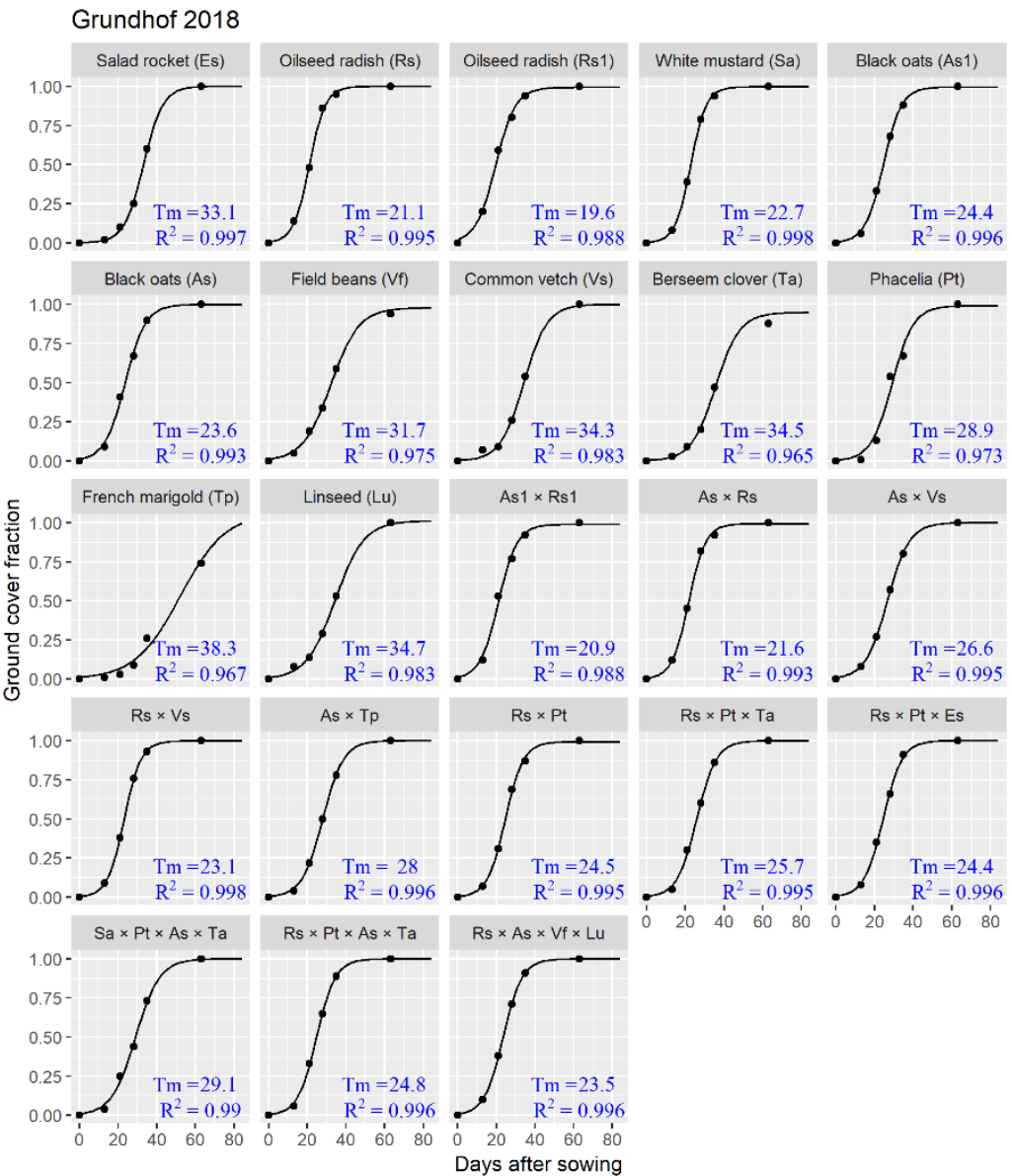



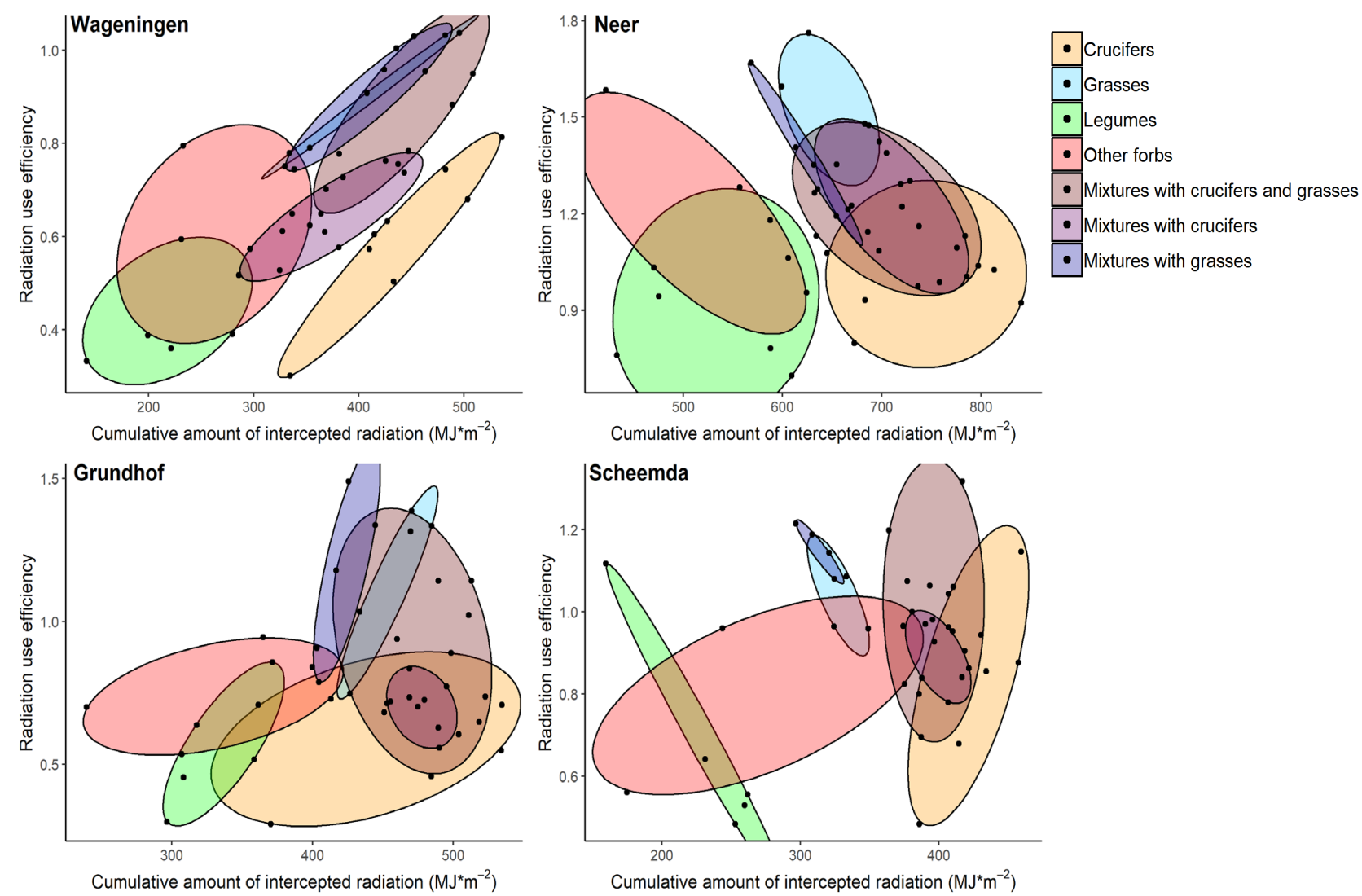

Figure C2. Scatter plot showing radiation capture and radiation use efficiency of 12 pure stands and 11 mixtures of cover crops grown at eight site-years. Data is averaged over two years (20172018) and presented per site. Species were grouped into seven groups: four pure stand groups (crucifers, grasses 'oats', legumes and other forbs) and three mixture groups with either one dominant component species (crucifer or oats) or with two dominant species (crucifers and oats). 


\section{Appendix D}

Can nitrogen fertilization of winter cover crops promote nitrogen uptake and reduce nitrogen-leaching from soil?

Table D1 Modelled downward water flow at $70 \mathrm{~cm}$ depth.

Figure D1 Concentration of $\mathrm{N}$ in total biomass of three species of cover crops.

Figure D2 Concentration of mineral N in pore water measured in 2018

Figure D3 Concentration of mineral N in pore water measured in 2019 
Table D1. Modelled downward water flow at $70 \mathrm{~cm}$ depth calculated with SWAP in $\mathrm{m}^{3} \mathrm{ha}^{-1}$ day $^{-1}$. Only results for days at which we also measured concentration of $\mathrm{N}$ in the groundwater are presented.

\begin{tabular}{llccccc}
\hline \multicolumn{5}{c}{} & & \multicolumn{5}{c}{ Groundwater flow $\left(\mathrm{m}^{3} \mathrm{ha}^{-1} \mathrm{day}^{-1}\right)$} \\
& & $12-09-2018$ & $01-11-2018$ & $11-09-2019$ & $01-10-2019$ & $07-11-2019$ \\
\hline \multirow{5}{*}{ Oilseed radish } & $\mathrm{N} 0$ & 13.05 & 0.00 & 0.70 & 6.91 & 22.46 \\
& $\mathrm{~N} 15$ & 13.07 & 0.00 & 0.74 & 6.91 & 22.46 \\
& $\mathrm{~N} 30$ & 13.02 & 0.00 & 0.72 & 6.91 & 22.46 \\
& $\mathrm{~N} 60$ & 12.97 & 0.00 & 0.72 & 6.91 & 22.46 \\
& $\mathrm{~N} 90$ & 12.96 & 0.00 & 0.72 & 6.91 & 22.46 \\
\hline \multirow{5}{*}{ Vetch } & $\mathrm{N} 0$ & 13.73 & 0.00 & 1.36 & 9.00 & 22.39 \\
& $\mathrm{~N} 15$ & 13.63 & 0.00 & 1.39 & 9.32 & 22.39 \\
& $\mathrm{~N} 30$ & 13.75 & 0.00 & 1.37 & 9.33 & 22.39 \\
& $\mathrm{~N} 60$ & 13.69 & 0.00 & 1.37 & 9.14 & 22.39 \\
& $\mathrm{~N} 90$ & 13.66 & 0.00 & 1.37 & 9.38 & 22.39 \\
\hline \multirow{5}{*}{ Black oat } & $\mathrm{N} 0$ & 13.10 & 0.00 & 1.04 & 7.10 & 22.38 \\
& $\mathrm{~N} 15$ & 13.14 & 0.00 & 1.06 & 7.16 & 22.38 \\
& $\mathrm{~N} 30$ & 13.05 & 0.00 & 1.06 & 7.16 & 22.38 \\
& $\mathrm{~N} 60$ & 13.12 & 0.00 & 1.04 & 7.10 & 22.40 \\
& $\mathrm{~N} 90$ & 13.26 & 0.00 & 1.01 & 6.98 & 22.38 \\
\hline \multirow{5}{*}{ Mixture } & $\mathrm{N} 0$ & 12.96 & 0.00 & 0.72 & 6.91 & 22.46 \\
& $\mathrm{~N} 15$ & 13.09 & 0.00 & 0.93 & 6.84 & 22.38 \\
& $\mathrm{~N} 30$ & 13.14 & 0.00 & 0.91 & 6.83 & 22.38 \\
& $\mathrm{~N} 60$ & 13.26 & 0.00 & 0.93 & 6.83 & 22.38 \\
& $\mathrm{~N} 90$ & 13.09 & 0.00 & 0.97 & 6.89 & 22.38 \\
\hline
\end{tabular}



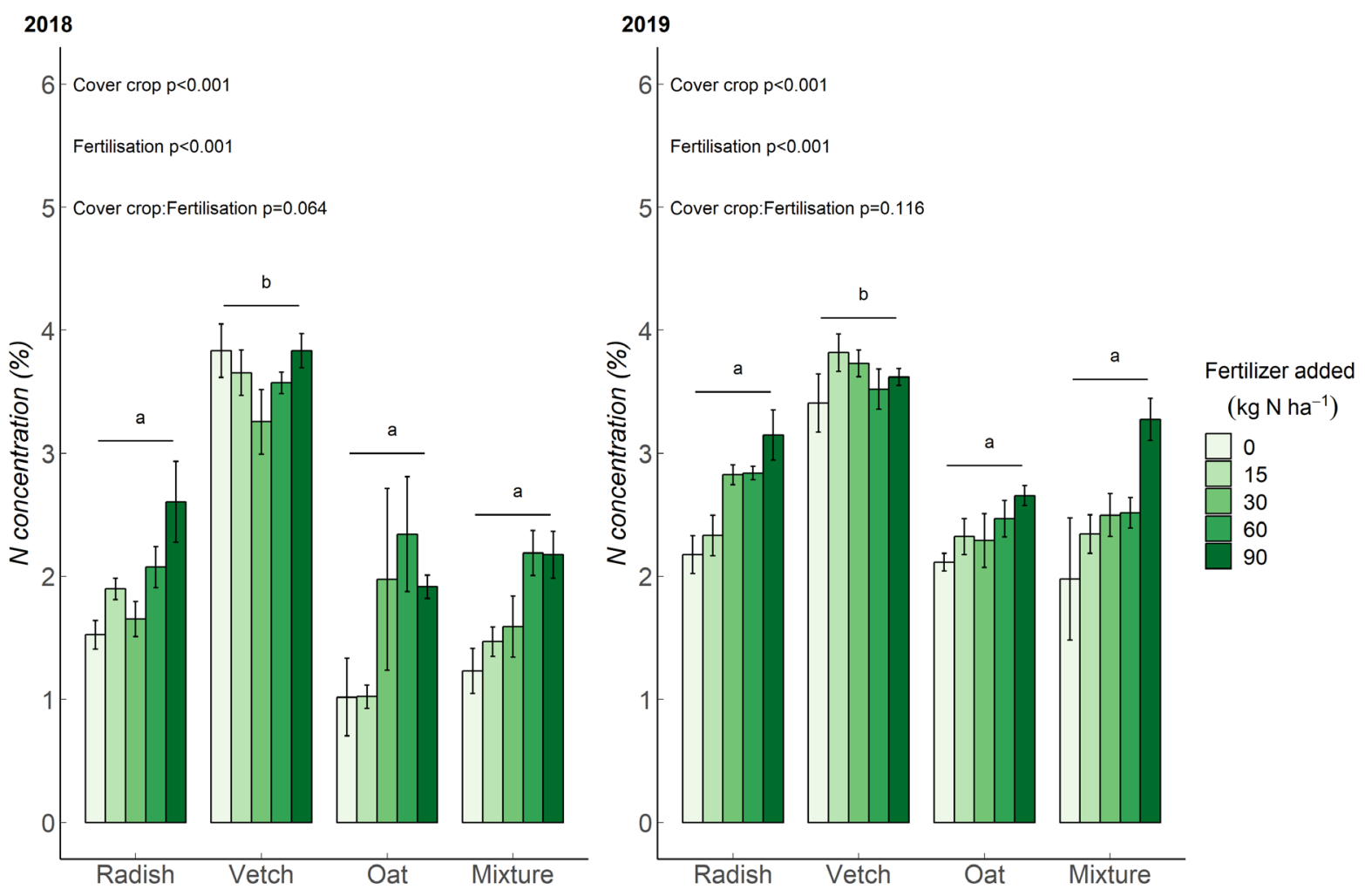

Figure D1. Concentration of $\mathrm{N}$ in total biomass (aboveground and belowground) of three species of cover crops: oilseed radish, vetch and black oat and their mixture in 2018 and 2019. Error bars denote the standard error $(\mathrm{n}=3)$, different letters indicate significant differences between the cover crops in total $\mathrm{N}$ yield $(p<0.05)$. 

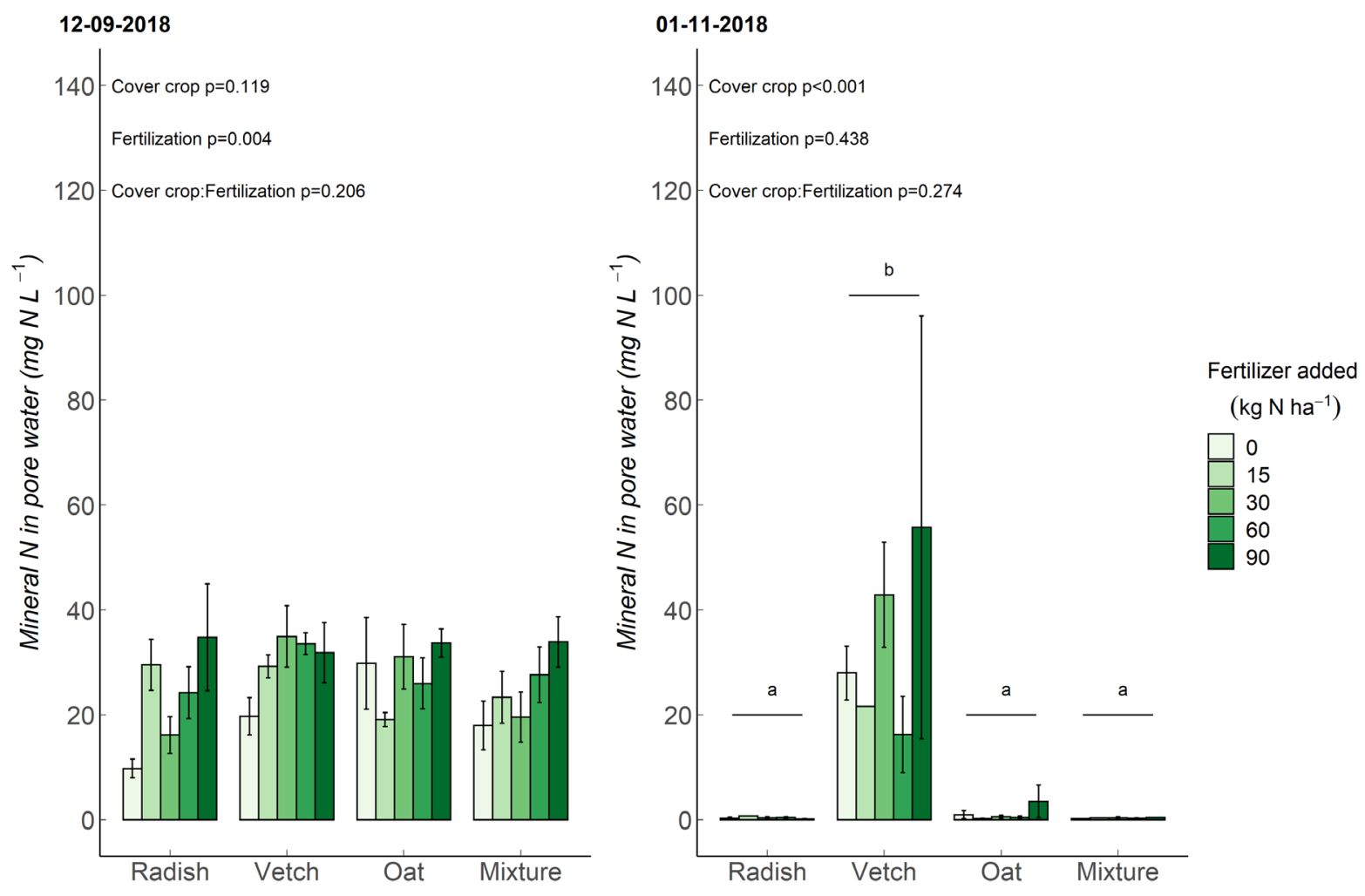

Figure D2. Concentration of mineral $\mathrm{N}$ in pore water measured on the 12th of September and the 1st November during cover crop growth of 2018. Error bars denote the standard error ( $\mathrm{n}=$ $3)$, different letters indicate significant differences between the cover crops $(p<0.05)$. 

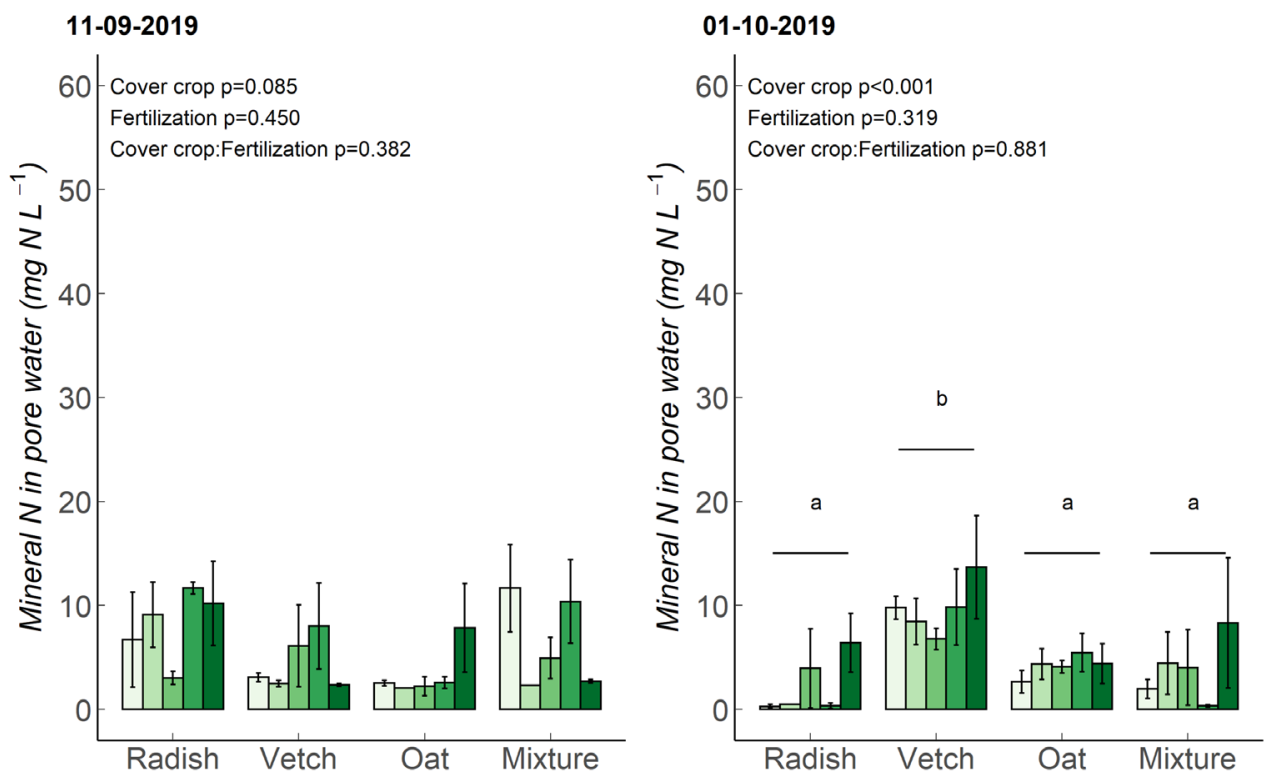

Fertilizer added

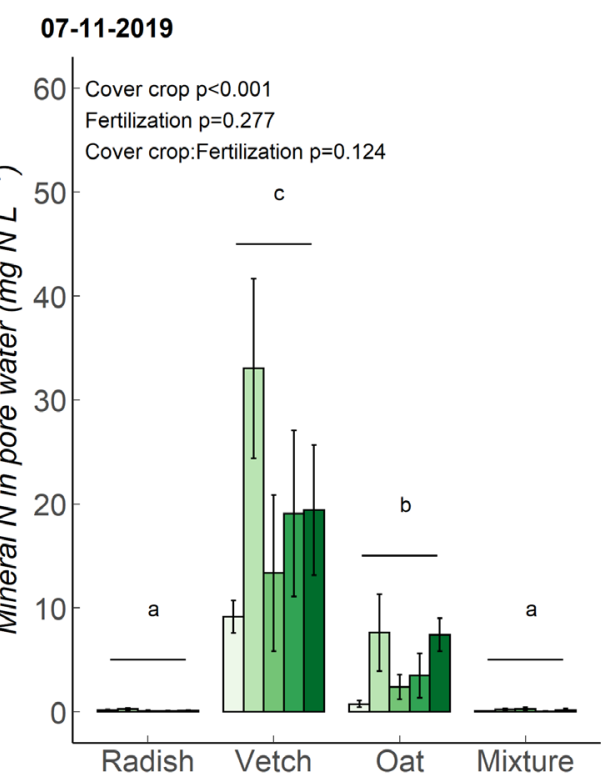

Figure D3. Concentration of mineral $\mathrm{N}$ in pore water measured on the $11^{\text {th }}$ of September, the $1^{\text {st }}$ of October and the $7^{\text {th }}$ of November during cover crop growth of 2019. Error bars denote the standard error $(\mathrm{n}=3)$, different letters indicate significant differences between the cover crops $(p<0.05)$. 



\section{Summary}

In temperate regions, winter cover crops are grown in the fallow period during autumn and winter to produce biomass, capture residual mineral $\mathrm{N}$ and combat weeds. The uptake of $\mathrm{N}$ prevents leaching and the accumulated biomass will be incorporated into the soil to build up soil organic matter, boosting soil productivity. The ecosystem services provided by cover crops are usually positively correlated with the amount of biomass accumulated.

Cover crops are often grown as pure stands. However, plenty of studies have shown that mixing plant species with complementary traits can increase resource capture and improve biomass accumulation. Therefore, the objective of this thesis is to identify whether growing species mixtures instead of pure stands strengthens the ecosystem services provided by cover crops. Particular focus is given to biomass, $\mathrm{N}$ yield, radiation interception, radiation use efficiency and yield stability. Furthermore, this thesis investigates how spatial configuration, species richness and $\mathrm{N}$ fertilization influence cover crop productivity. Fourteen field experiments were conducted in collaboration with stakeholders between 2015 and 2019 in the Netherlands and Germany. In these experiments, performance of species mixtures was compared to that of pure stands.

In Chapter 2, I describe a one-year field experiment characterizing the performance of 25 species of cover crops when grown as pure stands. The objective was to investigate how ground cover development, biomass accumulation, nitrogen capture and weed suppression differed among the species. Most of the species were crucifers (Brassicaceae), grasses (Poaceae) or legumes (Fabaceae), which are common plant families used for cover cropping. Establishment and productivity varied significantly among species. Early ground cover was positively correlated with cover crop biomass and negatively correlated with weed biomass. Crucifers, black oat, sorghum, corn spurrey and phacelia realized early ground cover with a high biomass and good weed suppression. However, biomass accumulated by black oat and mustard was characterized by high $\mathrm{C}: \mathrm{N}$ ratio, which can have a negative effect on the subsequent cash crop due to immobilization of $\mathrm{N}$. Legumes created late and incomplete ground cover, resulting in a low final biomass and poor weed suppression. Results from this Chapter provided useful background information for making a shortlist of species to study in further trials.

Chapter 3 presents how spatial configuration influences biomass accumulation, $\mathrm{N}$ capture and early competition. Species were mixed in two configurations, within-row and in alternate rows. Yield gain from mixing species was calculated for the different configurations using the net 
biodiversity effect (NE). The two components of NE, the complementarity effect (CE) and the selection effect (SE), were used to investigate how spatial arrangement influences complementarity between species and the dominance of the high yielding species. The results showed that mixtures have a positive NE irrespective of the spatial configuration. The effect of year and the identity of component species on yield were clear, whereas the effect of spatial configuration was minor and inconsistent. In both configurations, SE was positive when highly productive species (oilseed radish and black oat) were mixed with a less productive species (common vetch). CE was more evident than SE when the mixed species were equally productive (combination of oilseed radish and black oats). Overall, spatial configuration showed no agronomical or ecological significance.

In Chapter 4, productivity and yield stability were investigated for a wide range of species mixtures and pure stands grown across eight site-years to create variation in growing conditions. Irrespective of the number of component species, mixtures produced higher biomass and $\mathrm{N}$ yield than the average of pure stands. Biomass of mixtures was dominated by the high yielding species (crucifers and oats) and was not different from the biomass of these species growing in pure stands. However, $\mathrm{N}$ capture was $9 \%$ higher in mixtures than in the most productive pure stands. Therefore, mixing species ensures the highest attainable biomass with good litter quality.

Yield stability was analysed for pure stands and mixtures using variance components estimated using mixed effects models and Markov Chain Monte Carlo estimation. Three levels of yield variability were simultaneously estimated: between site-years, between treatments and between plots. For all treatments, variation in yield between site-years was large. Therefore, growing species mixtures does not provide insurance against differences in soil and weather conditions. Difference in yield between mixture treatments was much smaller than that between pure stands, illustrating the moderating effect of species mixtures on yields. In particular, using mixtures resulted in absence of low yielding treatments, whereas some of the pure stands were low yielding. Moreover, within-field variability in biomass was smaller for mixtures than for pure stands, suggesting that mixtures produce more uniform biomass across the field.

From the same experiment, biomass of mixtures and pure stands was separated in the processes of radiation interception and radiation use efficiency (RUE) (Chapter 5). Ground cover was measured for all treatments throughout the growing period to quantify radiation interception while biomass was determined at final harvest. The ratio of biomass and cumulative radiation 
interception was used to estimate RUE. All mixtures were dominated by the high yielding species (crucifers and oats). These contributed more than $90 \%$ of mixtures biomass. Productive species showed different combination of traits that resulted in their high biomass. Crucifers had early ground cover, high radiation interception and low RUE. Oats had a slower start and intercepted less radiation than crucifers but had a high RUE. Combining species that intercept much radiation with species with high RUE did not provide transgressive overyielding. This was mainly due to the strong competition for light expressed by crucifers over oats. Therefore, it was not possible to combine the best of the two worlds.

Farmers usually apply $\mathrm{N}$ fertilizer to kick-start the growth of cover crops in autumn. Chapter 6 presents the effect of nitrogen fertilizer on the net nitrogen capture and productivity of oilseed radish, black oats, common vetch and a 3-species mixture. In a 2-year field study, five levels of nitrogen fertilizer were applied ranging from 0 to $90 \mathrm{~kg} \mathrm{~N} \mathrm{ha}^{-1}$. Addition of nitrogen fertilizer in most cases did not increase the biomass of cover crops. Only biomass of oilseed radish in one year (2018) increased with $\mathrm{N}$ inputs. $\mathrm{N}$ input did not increase the net nitrogen capture $(\mathrm{N}$ capture - N application) in any of the treatments. In 2019, the year with a higher initial mineral $\mathrm{N}$ in soil, all species captured less additional $\mathrm{N}$ than the amount added as fertilizer. Subsequently, $\mathrm{N}$ losses increased with $\mathrm{N}$ input. No $\mathrm{N}$ losses were found in plots with the 3species mixture. Moreover, biomass of the 3-species mixture was either similar or higher than that of the best performing species. In conclusion, to prevent $\mathrm{N}$ losses, application of $\mathrm{N}$ fertilizer to winter cover crops growing in sandy soils should be avoided. Mixing species can improve N uptake.

In Chapter 7, the main findings of the research Chapters (2-6) are discussed. In most cases, mixtures of cover crops were shown to be dominated by one or two high yielding species. Therefore, the identity of the dominant species had the greatest influence on the overall performance of a mixture. Combining complementary species of cover crops does not necessarily result in transgressive overyielding, which occurred only in few instances. However, mixtures took up more $\mathrm{N}$ and produced biomass with better litter quality (lower $\mathrm{C}: \mathrm{N}$ ratio) than the corresponding dominant species in the mixture. This difference in $\mathrm{C}: \mathrm{N}$ ratio has implications for the rate of $\mathrm{N}$ mineralization and the availability of mineral $\mathrm{N}$ to the subsequent cash crop. Overall, species mixtures did not increase yield stability, as yield of cover crops was mainly governed by environmental conditions and identity of the dominant species. Spatial 
configuration, species richness and starter $\mathrm{N}$ application had a minor and inconsistent influence on mixture productivity. 


\section{Acknowledgments}

I presented how important diversity is to obtain a good cover crop. Likewise, the diversity of people around me was critical to successfully complete my thesis. $\mathrm{A} \mathrm{PhD} \mathrm{thesis} \mathrm{is} \mathrm{never} \mathrm{the}$ achievement of a single person, but rather a result of complementarity, cooperation, and inspiration.

First, I would like to express my sincere gratitude to my supervisors Wopke and Lammert. Thank you for teaching me an important lesson that "good is good enough". At the beginning of my PhD, I was lost and not sure what I am supposed to do. I tried hard to avoid the simplest and the most obvious research questions and rather searched for more complex ones just to prove that I am a smart student and to impress my supervisors. I set an unnecessary high bar to myself and created my own phantom. I remember one of our meetings during my first year when I finally expressed my feelings and doubts about my capabilities as a $\mathrm{PhD}$. Your advice and encouragement that day were life-changing to me, so I am very grateful. Wopke, you are the most direct person I have ever met in my life. Those who do not know you well will think that you are tough, but actually you are softhearted and kind. You always care for your students and you invest a lot of energy in their personal development. I was not so direct person before, but I am now, and I like it. I would like also to thank your wife Saskia for inviting me to your house. Lammert, thank you for being patient and for being available whenever I needed you. You never let me down. I was lucky for having you as my daily supervisor.

I also would like to thank my MSc thesis-supervisors Velemir Ninkovic and Niels Anten. Velemir, you have always encouraged me and made me feel better about myself. You encouraged me to do a $\mathrm{PhD}$, and here I am. I still remember your answer for every challenge I faced "do not worry, be happy". Niels, I remember when I was still in Sweden, applying for different $\mathrm{PhD}$ positions and you advised me to apply to the Clever Cover Cropping project because it fits me more than the other projects. Thank you for your valuable advice and your recommendations.

I would like to thank the whole consortium of the Clever Cover Cropping project for the good time we spent together during the last five years. It was my pleasure to know you all. Wietse, Paul and Gerard, thank you for all your inputs. Ellis, thank you for your constructive comments and your help in the lab and the field. I was impressed to see our project leader harvesting plants under rains and washing roots. Gerlinde, thank you for always being enthusiastic and positive 
and of course for all your help in the field and the lab. I am sure you heard that before, I think you are the kindest person on planet Earth.

I am grateful to the stakeholders of the Clever Cover Cropping project for their useful inputs. In particular, I would like to thank Michaela, Peter-Jan and Marije for providing space, machinery and manpower in their premises to conduct my experiments. Michaela, thank you for being positive all the time and for hosting me and my students in Germany during the harvesting time. I am also grateful to David Makowski for his fruitful discussions and useful models that I used in my thesis.

I would not be able to conduct my experiments without the great help that I received from Unifarm staff. I would like to thank John, Gerard, Gerrit and Wim for organizing and managing my field experiments and providing the necessary help whenever needed. I also would like to thank Evert-Jan, Frans, Wim, Herman, Julia and Dafydd for helping me in the field and the lab. I am also grateful to all my friends/colleagues who helped me in weeding, root washing and harvesting. Special thanks to Jan and Hennie for their help in analyzing my plant and soil samples.

Sytske and Rima, my fellow PhDs and project partners. Thank you for making all our group work fun. After four years of field experiments and root washing, I have to say that this thesis was not possible without you. You were always there whenever I needed your advice. Thank you for being professional and kind at the same time. You helped to make this journey ran smoothly.

This thesis was built from massive data that were mostly collected by my students. Therefore, I would like to thank all my students: Mark, Marinka, Danila, Rodrigo, Sebastien, Saskia, Twan, Betty, Shengfang, Laura and Jan. Saskia, thank you for being a devoted student.

I want to thank all the previous and current members of the research group Crop Systems Analysis (CSA). Sjanie, Nicole and Petra thank you for being the coolest secretaries, you helped me a lot throughout my PhD trajectory. Nicole, thank you for all your feedbacks on my thesis. Peter, thank you for helping me to design and conduct my experiments, and for putting me in contact with the right people. Even though you were not part of the project, you found the time to help me. Alex-Jan, thank you for bringing a lot of positive energy and laughter to our group. Paul, thank you for organizing trips to Keukenhof. And for all CSA staff: Tjeerd-Jan, Jochem, 
Willemien, Danae, Bob, Steven, Xinyou, Cor, Jet, Ans, thanks for your discussions, tips and advice during coffee time, Thursday drinks and group dinners.

I would like to thank all my fellow students at CSA/PPS/FSE: Wenjing, Luuk, Marcelo, Uta, Thomas, Cyprian, Ambra, Israel, Daniel, Bei, Zishen, Chunfeng, Jin, Lucette, Paulina, Robbert, Gou Fang, Gu, Herman, Martin, Kailei, Giovani, Dennis, Jorad, Yu, Ioannis, Franca, Alejandro, Joao, Na, Phuong, Qi, Shenghao, Wim, Wytze, Anne, Lotte, Lieneke, Daniel, Wolter and Eva. Special thanks to Luuk who always found an excuse to celebrate. Thank you for organizing the Thursday drinks and for making my office life much less stressful. Eva Huet, I enjoyed all our discussions a lot, thank you for being a very social and open person. I must acknowledge the members of the PV: Cameron, Antoine, Bert, Durk, Jochem, Eva G., Renske, Roos, Eva T., Luuk and Peter. Thanks for organizing all these social activities, games, pub quizzes, and outings, which made my PhD more fun.

I would like to thank my friends in the Netherlands for their support, friendship and for the great times that we spent together (Alaa, Hesham, Marco, Moheb, Ashraf, Georgia, Jana, Gaelle, Myriam, M. Almansoury, A. Fathy, Mohsen, Sara, Amina, Samir, Anas, Heba, Hady and Faten). A special thanks to all my friends in Egypt for the good times we spent together during my holidays (M. Omar, Omar L., Omar A., M. Abdelmordy, Mohannad, Yehia, Fady, Khalid, Abdoos, Islam, Tarek, Ayman, M. Hamdy, M. Ashor and M. Mabrouk).

To my brother and sisters back in Egypt: Omar, Abobakr, Fatma, Zainab and Sakina, thank you for your endless love and for being supportive all the time. To my father (may his soul rest in peace) and my mother, Thanaa, thank you for being an amazing mother and for all your support. You were, you are and you will always be the best. Last but not least, I would like to thank my second half, Asmaa, my amazing wife. We started this journey together and you took good care of me. Thank you for all your love, support and delicious food. A big part of my body mass is because of you :)

\section{Ȯti EShakeem}

Wageningen

February 2021 



\section{Publication list}

Elhakeem, A., van der Werf, W., Bastiaans, L., 2021. Radiation interception and radiation use efficiency in mixtures of winter cover crops. Field Crops Research 264:108034.

Elhakeem, A., van der Werf, W., Ajal, J., Luca, D., Claus, S., Vico, R.A., Bastiaans, L., 2019. Cover crop mixtures result in a positive net biodiversity effect irrespective of seeding configuration. Agriculture, Ecosystems and Environment 285:106627.

Elhakeem, A., Markovic, D., Broberg, A., Anten, N.P.R., Ninkovic, V., 2018. Aboveground mechanical stimuli affect belowground plant-plant communication. PLoS ONE 13(5): e0195646.

\section{Conference papers}

Elhakeem, A., Bastiaans, L., Houben, S., Couwenberg, T., Makowski, D., van der Werf, W., 2020. Do Mixtures Of Cover Crops Enhance Resilience And Resource Capture? XVIe European Society for Agronomy Congress (ESA), 'Smart agriculture for great human challenges', Sevilla, Spain, September 2020.

Elhakeem, A., Bastiaans, L., Houben, S., Packbier, P., Jongenelen, P., Mader, J., Schlathölter, M., Scholte, M., Bremer, G., Hoffland, E., van der Werf, W., 2018. Clever Cover Cropping: Cover Crop Diversity and Yield Stability. XVe European Society for Agronomy Congress (ESA), 'innovative cropping and farming systems for high quality food production', Geneva, Switzerland, August 2018.

Elhakeem, A., Markovic, D., Anten, N., Ninkovic, V., 2015. Can plants respond to root exudates from touched neighbours? ELLS Annual Conference, 'Challenges to Global Resources Management - Social, Environmental and Economic Dimensions', Czech University of Life Sciences, Prague, November 2015. 



\section{PE\&RC Training and Education Statement}

With the training and education activities listed below the $\mathrm{PhD}$ candidate has complied with the requirements set by the C.T. de Wit Graduate School for Production Ecology and Resource Conservation (PE\&RC) which comprises of a minimum total of 32 ECTS (= 22 weeks of activities)

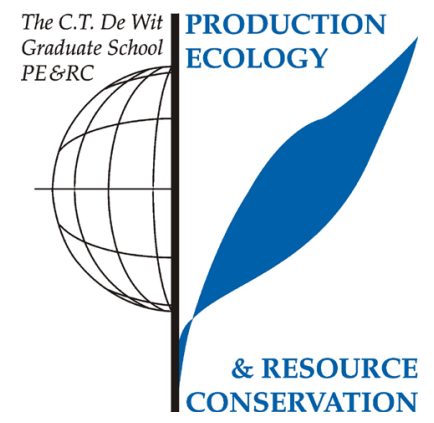

\section{Review of literature (4.5 ECTS)}

- Clever cover cropping: cover crop diversity and productivity

\section{Post-graduate courses (7 ECTS)}

- Root ecology; PE\&RC (2016)

- Introduction to R for statistical analysis; PE\&RC (2016)

- Meta-analysis; PE\&RC, SENSE (2016)

- Dynamic models in R; PE\&RC, SENSE (2019)

- Advances in intercropping; PE\&RC (2021)

\section{Deficiency, refresh, brush-up courses (18 ECTS)}

- Systems analysis, simulation and system management; WUR (2015)

- Functional diversity for sustainable crop production; WUR (2016)

- Advanced statistics; WUR (2017)

\section{Invited review of journal manuscripts (1 ECTS)}

- Renewable Agriculture and Food Systems: cereal-legume intercropping (2018)

\section{Competence strengthening / skills courses (5.4 ECTS)}

- Competence assessment; WGS

- Brain training; WGS

- Time and project management; WGS

- Scientific writing; In'to Languages

- $\quad$ Supervising BSc \& MSc thesis students; Education support centre

- Lecturing; Education support centre

Scientific integrity / ethics in science activity (0.5 ECTS)

- Research ethics; WGS (2017)

PE\&RC Annual meetings, seminars and the PE\&RC weekend (1.8 ECTS)

- PE\&RC First years weekend (2016)

- PE\&RC Day (2017)

- PE\&RC Midterm weekend (2018)

National scientific meetings / local seminars / discussion groups (4.7 ECTS)

Plant Soil Interactions (PSI) (2016)

- $\quad 3^{\text {rd }}$ Wageningen PhD symposium (2016)

- K(C)lever cover cropping; Kleve (2017)

- K(C)lever Cover Cropping (2017)

- Mini-Symposium about intercropping (2017) 
- Sustainable Intensification of Agricultural Systems (SIAS) (2017)

\section{International symposia, workshops and conferences (11.1 ECTS)}

- ELLS Student conference; Prague (2015)

- NAEM; the Netherlands (2016)

- ESA Congress; Edinburgh (2016)

- NAEM; the Netherlands (2018)

- ESA Congress; Geneva (2018)

- ESA Congress; Seville-online (2020)

\section{Lecturing / supervision of practicals / tutorials (13.2 ECTS)}

- Soil plant interactions (2016-2017)

- Functional diversity for sustainable crop production (2017-2018)

- Population and systems ecology (2017-2019)

- Practical weed-crop interactions (2018-2019)

- Agrobiodiversity (2018-2019)

\section{$\mathrm{BSc} / \mathrm{MSc}$ thesis supervision of 10 students (21 ECTS)}

- BSc; The effect of spatial arrangement on rooting patterns of cover crops.

- BSc; Gaining from green manure crops by intercropping: hardly any influence of spatial configuration.

- MSc; Investigating spatial arrangement in cover crops for biomass production.

- MSc; Does spatial configuration influence biomass production and competitive relationship in mixed cover crops?

- MSc; The effect of spatial configuration on light competition dynamics and biomass production in mixed cover crops.

- MSc; Yield and yield variability in mixed cover crops.

- MSc; Effect of cover crop mixtures on yield and yield stability.

- MSc; Impact of N-starter fertilizer on nett N-capture of three cover crop species.

- BSc; Cover crop mixtures and monocultures: Crop biomass, weed biomass, nutrient leakage, nematodes, stability of cover crops.

- MSc; The effect of starter fertilizer on cover crops in terms of net $\mathrm{N}$ capture and $\mathrm{N}$ use efficiency 


\section{About the author}

Ali Elhakeem was born on the $10^{\text {th }}$ of January 1990 in Cairo, Egypt. There he grew up nearby the Nile River, the longest river on Earth and the artery of life for the Egyptian civilization. Ali was very interested in studying biology and agriculture. He obtained his BSc degree in Environmental Agricultural at Cairo University where he gained

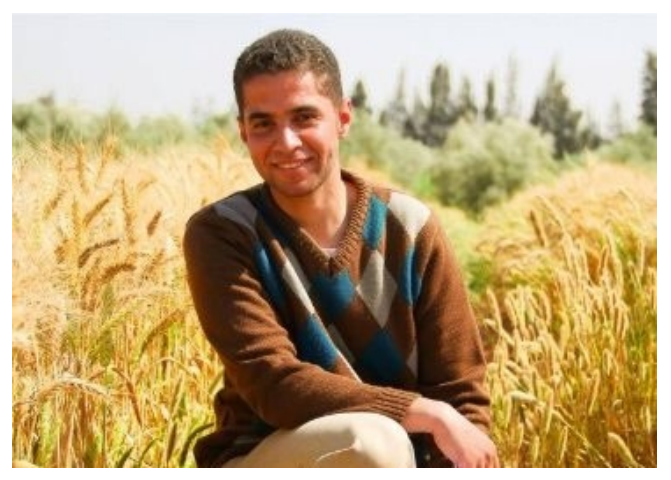
knowledge on a wide range of agricultural disciplines. He was at the top of his class and received his degree with the highest distinction. After his graduation, he worked as a community agronomist in an international organization funded by the United States Agency for International Development (USAID). His task was to link the Egyptian olive producers with local scientists to improve olive production and exportation. During this period, Ali developed an interest in organic farming and decided to travel to the Netherlands to pursue his studies. In 2013, Ali started his MSc studies on organic agriculture at Wageningen University and Research (WUR). Ali performed his MSc thesis at the Swedish University of Agricultural Sciences (SLU) in Sweden. He investigated the communication between neighboring plants through root exudates, which resulted in a scientific publication. In 2015, Ali started his $\mathrm{PhD}$ at the Center for Crop Systems Analysis (CSA) in WUR, where he joined an NWO project entitled Clever Cover cropping. In a large number of field experiments, Ali investigated how different aspects of performance differ between mixtures and pure stands of winter cover crops. During his PhD journey, he discovered his passion for cooking and painting. Finally, after seven years in the Netherlands, Ali decided to spend some time to learn and speak Dutch. 
The research described in this thesis was financially supported by a grant from the Netherlands Organization for Scientific Research (NWO, grant number 870.15.072) with co-financing from seed producers (Agrifirm, Vandinter Semo, P.H. Petersen Saatzucht, and Joordens Zaden)

Financial support from Wageningen University for printing this thesis is gratefully acknowledged.

Cover design Loes Kema

Layout Ali Elhakeem

Printing GVO drukkers \& vormgevers B.V., Ede, the Netherlands 


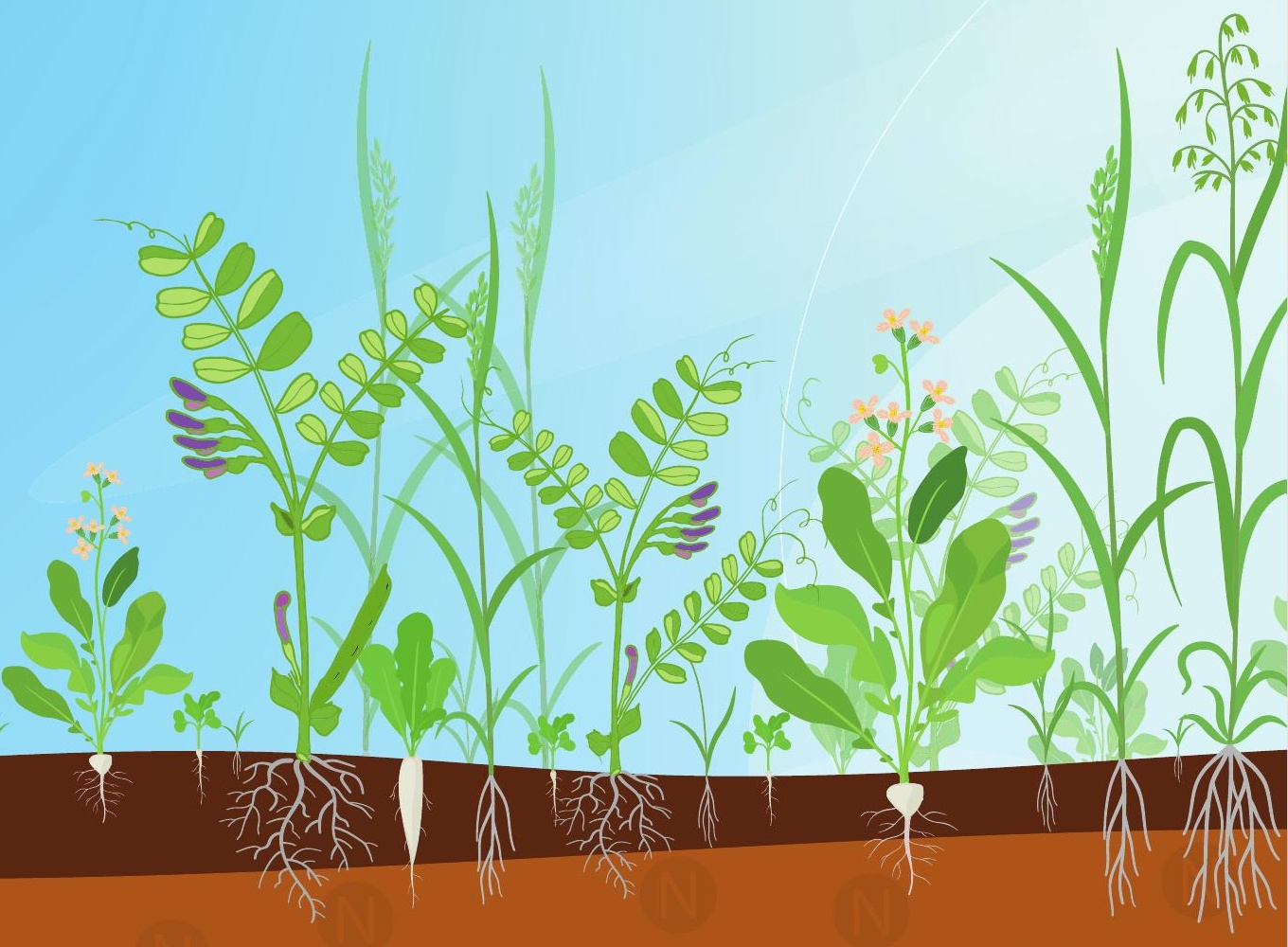

